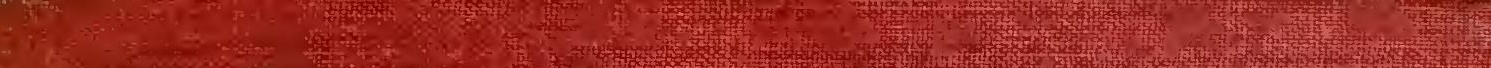
1.

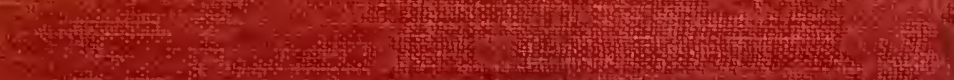
M

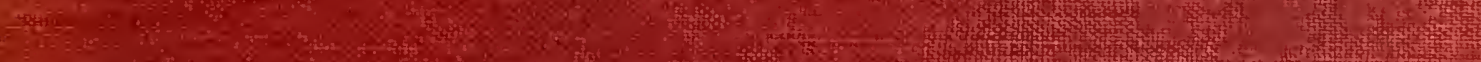

A (3) Q

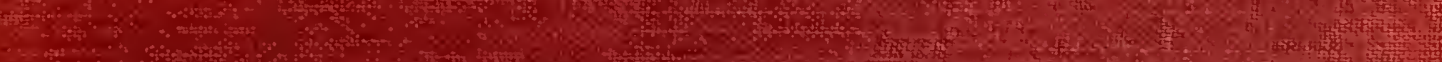
$\therefore$ and +

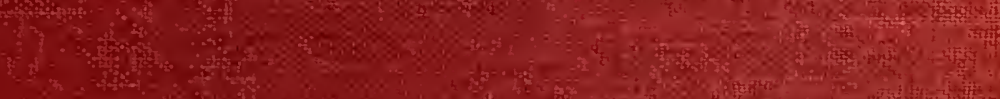

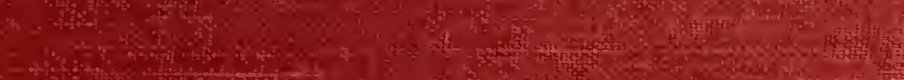

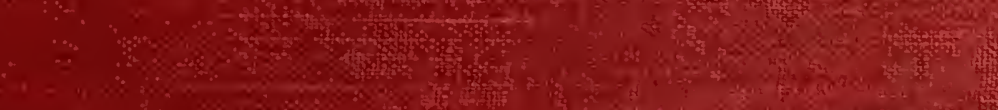
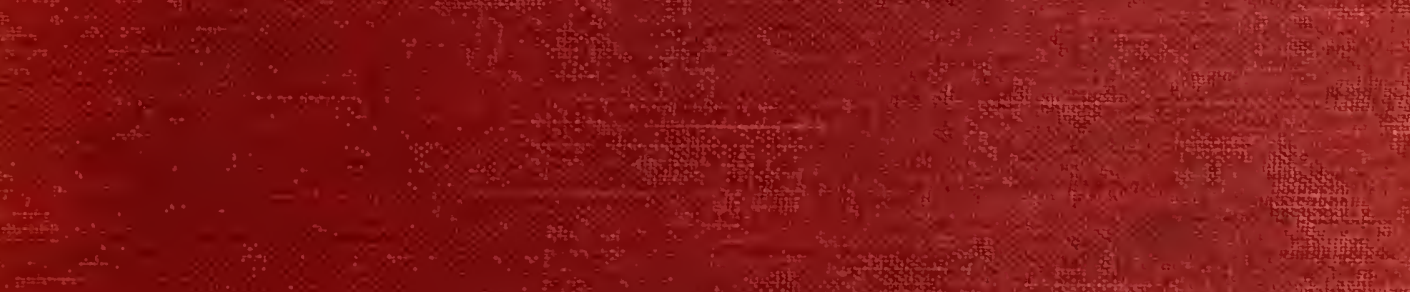

(3)

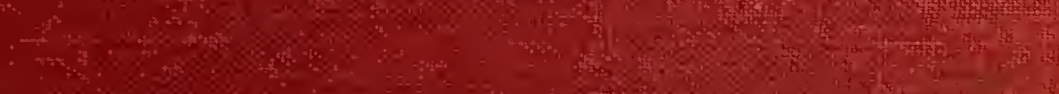

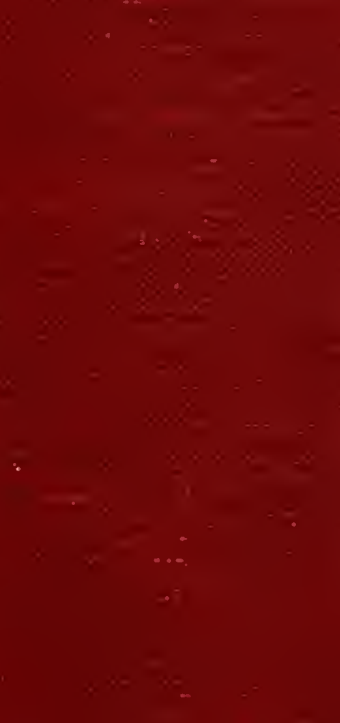




SMITHSONIAN MISCELLANEOUS COLLECTIONS

PART OF VOLUME 54

\section{Landmarks of Botanical History}

A Study of Certain Epochs in the Development of the Science of Botany

Part 1.-Prior to 1562 A.D.

BY

\section{Edward Lee Greene}

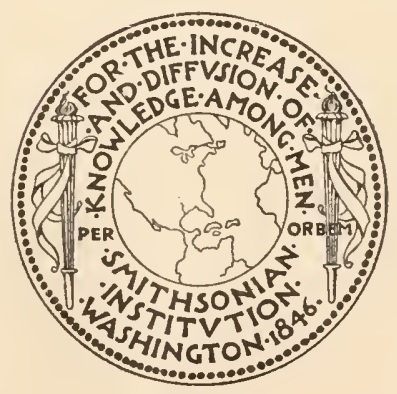

No. 1870

CITY OF WASHINGTON

PUBIISHED BY THE SMITHSONIAN INSTITUTION I 909

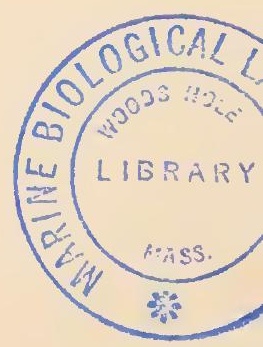




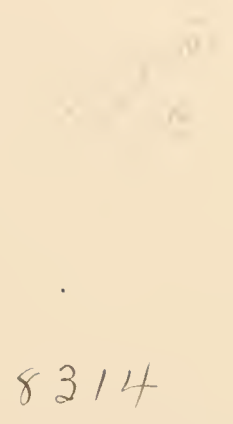




\section{ADVERTISEMENT}

The present paper by Dr. Edward Lee Greene, Associate in Botany in the U. S. National Museum, entitled "Landmarks of Botanical History," discusses certain epochs in the development of the science of botany. The subject is viewed from a philosophical rather than an industrial standpoint. and the author gives prominence to the biography of some of the early botanists, including Theophrastus (B.C. 370-286), and Brunfelsius, Fuchsius, Tragus, and Cordus of the fifteenth and sixteenth centuries. Doctor Greene has in preparation further contributions on this general subject.

Charles D. Walcott, Secretary, Smithsonian Institution.

WASHINGTON,

November, I909. 



\section{CONTENTS}

PAGE

PREFACE

INTRODUCTORY

CHAPTER

I. The RHizotomi . . . . . . . 45

II. Theorhrastus of EResus, B.C. $370-286$ (or 262) 52

III. Greeks and Romans after Theophrastés . I

IV. Introductori to the Sixteenth Centery German

FATHERS . . . . . . . I 65

I. Otho Brunfelsits, I464-153.1. . . . 69

VI. Leonhardes Fuchsites, I 50I-I566 . . I92

VII. Hieronymus Tragus, I 498--i554 . 220

VIII. Euricius Cokdus, I4S6-I535 . 263

IX. Valerius Cordes, I5I5-I $54+4 \quad 270$

INDEX . . 3I5 



\section{PREFACE}

ANY discussion, or any indication even, of landmarks in the history of botany must needs be preceded by a somewhat careful enquiry into the nature and purposes of the science as such. Wherein does botany, as a science, essentially consist? With this question unanswered it were impracticable either to indicate the origin or trace the progress of it.

In the most extended use of the term, all information about the plant world or any part of it is botany. According to this view, all treatises upon agriculture, horticulture, floriculture, forestry, and pharmacy, in so far as they deal with plants and their products, are botanical.

What many will consider a better use of the term is more restricted. In this use of it there will be excluded from the category of the properly botanical whatever has no bearing on the philosophy of plant life and form. For example, that wheat, rice, and maize agree together as to that anatomical structure which is called endogenous would be a fact of purely botanical interest. Quite as clearly such would be the proposition that all three belong to the natural family of the grasses; or this, that each represents a genus; or that the roots in all these plants are fibrous, and of only annual duration. But if it be said that wheat, rice, and maize as food products are of supreme importance to mankind, the affirmation is as completely unbotanical as the several foregoing are perfectly botanical. It is strictly an economical consideration.

If such a distinction between botany and plant industry as I have sought thus to illustrate be received as legitimate, the province of botany is easily circumscribed and its scope clearly definable. In any event, for the purposes of the present work our definition of this science shall be that it occupies itself with the contemplation of plant as related to plant, and with the whole vegetable kingdom as viewed philosophically - not economically or commerciallyin its relation to the mineral on the one hand, and to the animal on the other.

Such a distinguishing between the philosophical study of plants 
and the industrial does not dispute, but rather establishes, the existence of a wide border domain between science and industrial art where botanist and industralist work side by side upon plant subjects; it may be sympathizingly and intercommunicatively, or it may be ignoring each other's presence; a domain within which nevertheless each should be in touch with the other, because each may, and ought to be helpful to the other, as supplying some data useless for his own purposes but of significance in relation to the other's aims. The recognition of this border-land domain illustrates also, if it does not again directly argue, the distinctness of the two realms of botany and plant industry. Here one may observe that the distinction itself would seem less marked if he who is to set himself to the work of an economic or industrial botanist would first of all equip himself with a knowledge of the principles, and cultivate an interest in the aims, of philosophic and scientific botany; so that the industrial botanist as author might always have two reports to make upon any piece of research, one that should be of economic interest, the other one of interest botanical. It may be that this idea will be found to presuppose the conjunction of the philosophic bent of mind with the industrial; a combination of two qualities of mind as rare in the world as genius itself, and less desirable.

In quest, therefore, of a starting point-a first landmark- in the progress of botany, in my understanding of the science, one may pass those authors by who professedly treat of plants from the utilitarian point of view, whether they write of agriculture, horticulture, or of the materia medica. Passing these by, I say, though by no means as not meriting the botanist's attention; for all matters relating to the qualities of plants naturally interest him, unless he be of that school in power a century ago, but now declining in influence, according to whose teachings nothing but dry morphology was of any import. Moreover, to him who, like the farmer, the woodsman, and the primitive pharmacist, has much to do with plants industrially, philosophic ideas may occur about the vegetable kingdom as a whole or in part; and every such idea, though crude, perhaps even erroneous, is a concept essentially botanical. Quite as perfectly so is the distinguishing of different kinds of plants, and the practice of grouping like linds together under one common (generic) name, which is not only universal, but even a necessity, with those who, like the farmer and gardener, have much to do with a considerable number of plants of different sorts. People following these occupations have actually a system- 
atic botany, with a nomenclature, families, genera, and species, all their own. So then if, in the search for a possibly early botanical landmark, the writers upon farming, gardening, and medicine are to be passed by without serious consideration, it is not because no traces of genuine botany occur in them; it is because we are in search of him with whom the leading idea is that of a philosophy of plant life and form. The first botanist is the first man who undertakes research upon plants as plants rather than as things useful or deleterious to man and beast; and the first landmark in the history of botany is the earliest book in which plants and plant organs are discussed each in relation to others. If there is any attempt to distinguish and define plant organs, or any suggestions about the probable functions of any of them, any indications of how plants may be distinguished from minerals on the one hand, and from animals on the other, any attempts to correlate plants as like and unlike, and that upon some recognized principles-in any and all such endeavors, we recognize the activities of a philosophic mind in its attempts to solve problems not economic but scientific. In the author of any such treatise upon plants, however imperfect or even crude his notions may seem to us, we have nevertheless the author to whom belongs the name of botanist, as in the vocabulary of the sciences that name ought to be defined.

What is here undertaken is not a history of botany. There is no purpose of presenting in chronological succession the long line of the contributors to the upbuilding of this science, with an account of the best contributions each has made. That would be the work of a lifetime; indeed, of two lifetimes; for the history of no science can be made out, and presented in its perspective, but by him who first of all has mastered that science itself, in its completeness; and the domain of botany however philosophically restricted remains vast, insomuch that one lifetime seems requisite to the mastery of it in its several departments. A second lifetime should, then, be given to him who should be required to write its history. And still the presentation of a complete and accurate history of botany would reniain impossible. Important data are wanting, and hopelessly so. For one example, more than two millenniums ago a highly philosophic and very extensive treatise upon plants was indited which alone among books of its kind has survived the passing of all the centuries. The author of it cites other authors on the same topic whose books, then extant, are long since lost. This writer had also in early life a very illustrious teacher who instructed 
him orally in botany among other subjects, and who also wrote two volumes of botany both of which passed into oblivion more than two thousand years since. How much, then, of the Theophrastan botany is that author's own? What of its principles are his only as having been imparted to him by his great friend and tutor Aristotle? What passages of the work are but compiled from writings of a more remote antiquity, with which Theophrastus may have been familiar, of which even the authors' names have perished? Questions like these serve but to admonish one of this, that the earliest beginnings of the science do not admit of discovery. The same is in a measure true of comparatively recent periods. The annals of our science, as gathered in hitherto, reveal no more thrilling epoch than that of the sixteenth century. Some of the best known authors of that period, Brunfels, Tragus, Fuchsius, studied, besides the not so very many printed books about plants that were then extant, numbers of old mediæval manuscripts from which they brought forth and quoted many a botanical idea, several of them well advanced beyond the ideas of the ancients as we know them. No annalist of a later age seems to have had time or disposition to ascertain how much of the assumed new and original botany of those German fathers-so they style them-was taken out of old mediæval manuscripts which, although they may still be extant, later historians have neither consulted nor troubled themselves to enquire after.

Contemporarily with those German herbalists there flourished in Italy a learned professor, first at the University of Padua, then at Bologna, afterwards at Pisa, whom people regarded as the one peerless botanist of the time. His university lectures were received as oracular, and students came to him from almost everywhere in Europe; yet Professor Luca Ghini published nothing. His supremacy as botanist of the first half of the sixteenth century is attested by tradition only. In the very next generation after him, several of the chief luminaries of the science were men whom he had trained, and to one of them, Cesalpino, there is now everywhere accorded the praise of having created the epoch of modern botany. To what extent is Cesalpino's great work, De Plantis, a product of the mind of Ghini? The question is one that forces itself upon us and is perhaps the more interesting because hopeless of ever being answered.

Such are a few examples of what the annalist who would be just and truthful will often find himself in need of knowing, yet can never ascertain; and they intimate but too pointedly the impossibility of 
any such thing as a complete and faithful history of any period when once that period is past. It was as realizing this, and also as wishing to avoid presumptuousness, that the present writer declined to undertake a history of botany and chose the title of "Landmarks" as permitting him to evade the responsibilities of the consecutive historian, and leaving him free to bring into clearer light-and especially for study on the part of American botaniststhe lives and teachings of those and those only among botanists of the past whose names are more familiar. This plan bears on its face the appearance of an easier task, and such it really is; though that it is a less responsible undertaking may be doubted; for in this case quite as in the other, one must everywhere investigate individual merit, which is less apt to exist in proportion to a man's great contemporaneous popularity than in the inverse ratio of it. It will indeed be found to have happened now and then that the genius who has discovered principles has also elucidated them, applied them to the construction of a system, and gained for hinself and his principles the credit and the honor that were due; but perhaps rather more commonly the genius discovering principles has but quietly made the simple announcement of them, has died scarcely honored, and has been almost forgotten, when some other, just far enough above mediocrity to see the value of the principles, and possessing industry and ambition to bring them forth and build on them the system which the principles themselves suggest, gets the credit of the whole, is thought to have created the epoch, and enjoys the fame. But the annalist who leaves all these things as he finds them, reiterating popular laudation of the parasitic propagandist, and burying inventive genius yet more deeply in oblivion, deplorably falsifies history. Quite as little does he deserve the name of historian if his mistakes in this regard be those of ignorance; if they come of his having failed to discover merit because of its having lain under the pall of forgetfulness for a century or two.

The historian who is both conscientious and discreet will give small heed to popular opinion about any particular man or epoch. Neither the adulation of the multitude is of any profound import, nor its voiceless indifference. Its outspoken opposition and denunciation may even be the highest praise. Such being any writer's estimate of popular opinion regarding botanical eras past, his readers will be surprised neither by chapters that are iconoclastic, nor by such paragraphs as reveal immortal honors due to men whose names had almost faded from the roll of fame. 
It has seemed to me desirable that, in the tracing of these outlines of botanical history some prominence ought to be given to biography. The reader or the student of a book can never take the deepest possible interest in it so long as its author is unknown to him, or, as it might be said, known by name only; though that is but an empty phrase; for to know a person by name only is not to know him at all. A fair knowledge of the whole career, early and late, of the author of a literary or scientific masterpiece not only intensifies, as I said, one's interest in the work, but is most helpful to the understanding of it, if not indispensable to the full comprehension of it. To this natural and reasonable demand on the part of those who would like to learn something of the history of botany, the historians have not well responded. In most cases they give in a single paragraph, or even in a short foot-note, the year of a man's birth, that of his demise, perhaps the name of the institution whence he had his degree, and of those in which he occupied a professor's chair, and so ends the biography of a man who may have been a genius and the creator of an epoch in science; mere epitaphic statements, which seem only to bury more deeply out of sight the once living and active personality, and to relegate his very name to a still remoter place in the region of myth and shadow. There are probably few botanists of this twentieth century who have the most vague conception of what a single one of the earlier master builders of our science was like in his personality and character. To most of us they are too nearly mythical, and mayhap less livingly pictured in our minds than are some of those really mythological personages that men believed in four thousand years ago. It will be seen that in these studies of the landmarks, I give some prominence to the biographic aspect of botanical history. This has been done at great expenditure of time and thought; but I have felt that the end was an extremely desirable one; and I have little or no doubt that these sketches of the lives of great promoters of our science who lived in other centuries will be received by many as among the most welcome and instructive of my paragraphs.

United States National Museum:

Washington, D.C.

2 July, I907. 


\title{
Landmarks of Botanical History
}

\author{
By EDWARD LEE GREENE
}

\section{INTRODUCTORY}

\section{PHILOSOPHY OF BOTANICAL HISTORY}

Any history, in order that it shall merit well the name and answer the requirements, must have its definite philosophy. History presupposes some end awaiting attainment, and in itself it would seem to be a well connected record of the thoughts, the words, and the deeds that have either furthered or hindered the attainment of that end. It does not, however, assume that the actual makers of history recognize the ultimate end. That is something which not even the wisest can foresee otherwise than dimly and with much uncertainty. The aim of the science of botany, for example, being the fullest and most perfectly systematized knowledge of the plant world philosophically considered, it still is true that not one in a hundred among the rank and file of real contributors toward this ultimate purpose has had it definitely in view. The great bulk of botanical work hitherto accomplished has been done in detached pieces, and by such as had only proximate ends before their mental vision. And for the very best of research work no more is needed. He who carefully investigates and puts on record the whole life history of a dandelion or of a violet; who gives the whole anatomy of a few mosses, reeds, or sedges, or indicates the morphologic distinctions between the pollen grains of hollyhock and those of thistles, or traces the development of either one; who brings out the philosophy of the twining of a morning-glory stem, or indicates the organogeny or the functions of the stipules of vetch and pea; or he who after years of critical field study catalogues, with original notes and observations, the flowering plants-or the 
flowerless ones-of a single county, or of the watershed of any lake or stream, every such laborer contributes to the stock of botanical knowledge, and this without reference to personal conprehensiveness of botanical view, or a looking to far off ultimate ends.

Upon the historian of botany, however, it seems to devolve that he shall have some forecast of what botany in its perfection as a science shall be like; for in practice he sits in judgment on each epoch and decides whether as an epoch its tendency was more to the advancement of the science than to its retardation; from which kind of procedure it becomes certain that some ideal of perfection is in his mind. Every writer on botanical history must have his philosophy of that history, unless he content himself and hope to satisfy his readers with disconnected historic fragments.

It may be useful to survey in this connection, though with the utmost brevity, the methods of several representative historians of botany.

Tournefort (I 700), eminent among even the greatest promoters of botany, was also its historian. The first fifty pages of his Institutiones ${ }^{1}$ are occupied with an abridged history of the science during two thousand years preceding his own date. The history is prefaced by a definition. There are two parts to botany: the knowledge of plants, and the knowledge of the uses (vertus) of them. It is a distinguishing between systematic botany and economic. He says the distinction must be carefully noted. $\mathrm{He}$ denies to the properties or uses of plants any part in, or influence upon, the systematizing of them. A systematized presentation of the known facts constitutes the first beginning of every science. There can be absolutely no botany at all without systematic botany. These are Tournefort's ground principles. From them we shall gather his philosophy of the advancement of botany. The plant world can never come to be well known until sounder principles of classification shall have been established, and the whole aggregate of known plants shall have been grouped over again upon those better principles. The long line of the most noted authors before him had classified plants in all kinds of ways, some according to characters of the roots, some by differences of stems and leaves, onelby fruits alone, another by the qualities and uses of the plants; another grouping them according to their places of growth, or ecologically, as we now say. Seldom were the systems of any two

1 Institutiones Rei Herbaria, Paris, I 700. 
authors at even approximate agreement. Often that of an individual author was a compound of inconsistencies, utterly inharmonious within itself. As to that very first necessity of botany, rational system, confusion seemed to reign. The flower was an organ hitherto little studied, and scarcely yet appealed to in the art or science of plant grouping. Two or three botanists of a century earlier than Tournefort had suggested that, after all, not in roots or stems or leaves, but in the flower there might perchance be found the key to a more satisfactory method of plant classifying. He undertook now a new systematization of the world of plants, everywhere appealing to anthology in so far as by the presence of flowers and fruits the appeal was possible. Ceasing to take as criteria the qualities of plants, or even the characters of their vegetative organs, and by giving special and close study to both flowers and fruits instead, with judicious co-ordination and use of the characters of both, will botanical system henceforward obtain best furtherance.

With neither the strong points nor the weak ones in Tournefort's system, nor with its success or failure, are we here concerned. All that will engage us now is his conception of botany as a science in process of further development and improvement; in other words, what he would have taken to be the leading philosophic threads of botanical history. They would probably be two, at least as chiefly conspicuous; for during his career his mind had been much occupied with (I) the thought that better and more firmly established generic groups had been the most crying need of botany from the earliest times, and (2) that such more acceptable and more securely established genera would result from the defining of them according to morphology of flower and fruit, the consideration of vegetative organs being omitted as far as possible. So then, from his own outlook over the past of botany and from his best forecasting of its future, they have helped it forward most who have most contributed to a better anthology and carpology, and such obtain with him foremost places in his epitome of botanical history. The fullest credit is given to all botanical travellers to distant shores who have contributed to the enrichment of botanical gardens, and to the making of illustrated folios representing flowers and fruits of plants alien and rare. Meanwhile how small consideration Tournefort accorded to plant anatomy and physiology is evinced by this, that in his history he has not a line to spare for the names of Grew and Malpighi, great promoters though they were of the cause of plant organography in general, and well entitled to rank 
among creative botanists. We may chance to find historians of less comprehensiveness of view than Tournefort, and some with greater.

Two generations later a countryman of his, Michel Adanson, sketched less succinctly than Tournefort had done the history of botany. It forms the more important part of a voluminous preface to Adanson's F amilles des Plantes. ${ }^{1}$ Eighty-five years after its first publication this History was reprinted, with many augmentations which the author had left in manuscript at the time his death. ${ }^{2}$

A man whom all nature in her every phase attracted and engaged, but still first and last and always a botanist, Adanson's horizon was a broad one. He was also a botanist with a specialty, that of discovering how genera naturally stand together in larger groups that may be called families. On the whole, and if such distinction be allowed as legitimate, he was a systematic botanist; most pronouncedly such. But the sketch that he gives of the history of botany is neither partial nor one-sided. He reviews the science as having progressed along many lines, not one of them unimportant. But since it is families of plants that he is now to treat of at length, the foremost thought in his mind in the writing of a history of botany as a preface to the book is, that he may demonstrate the early rise and tardy progress of this very idea of plant families. It is not, however, the history of that one aspect of botany merely that he writes. Something a little too near the one-idea history was what Tournefort had presented; even as one may to-day say of the latest of all the historians of our science, that he came rather too near to excluding from very thoughtful consideration almost everything except the history of plant anatomy and physiology, and of the taxonomy of the cryptogams. Adanson appears to have realized that no one part of botany is alienable from. any other part; that the history of a part of it can not be written as disconnected from that of the other parts; and therefore, connectedly with the presentation of whatever had been done before his time towards a natural correlating or grouping of genera, he brings into view not only that line, but others along which botany has made progress; paying due respect to every kind of effort that makes for a fuller knowledge of the plant world.

With the main purpose, then, of finding early traces of the recognition of something like natural families, Adanson analyzes

1 Familles des Plantes, Paris, I 763, Partie I. Preface pp. i-cliv.

${ }_{2}$ Familles Naturelles des Plantes de Michel Adanson, 2 ed. Par MM. Alexandre Adanson et J. Payer, Paris, I 847 . 
briefly and in chronological succession more than sixty leading authors, beginning with Theophrastus and ending with some who have been contemporary with himself in the middle of the eighteenth century. Assuming that these analyses are correct, one may read connectedly, with small sacrifice of time and as it were step by step the progress which, up to Adanson's time, had been made in the grouping of genera into families - or whatever else one may choose to call such groups; and, while it will be regarded an important one among several threads that the philosophical and impartial historian is bound to follow I know not who besides Adanson has ever attempted to trace this one except for a very short distance. ${ }^{1}$

And the next thread of botanical story which Adanson picks up and follows is one that lies close alongside the aforementioned. The earlier endeavors to indicate groups of genera were made anteriorly to the time when structure of flower and fruit had come to be accepted as the guide. By what marks did those pioneers of classification guide themselves in their attempted groupings? By way of answer I give a short selection from Adanson's own more detailed report of the matter. Lobel ( 1570 ), he says was guided by general resemblances, size, qualities, and uses; Porta (I 588), by ecology, forms of roots, of leaves, and vegetative organs generally; J. Bauhin (I650), has 40 classes, by appeal to all organs, as well as to properties of plants and their ecology; Rivinus (I69o), inflorescence, calyx, and corolla; Boerhaave ( 7 Io), general aspects, ecology, leaves, fruits; Haller ( $7_{742}$ ), cotyledons, calyx, corolla, stamens, seeds; Gleditsch (I 749). flowers, insertion of stamens; and so on through a list of some sixty writers, each a celebrity in his day as the author of some new attempt at system in botany. ${ }^{2}$ Of a situation like this, and one so necessary to be brought forward in any history of the science, Sachs knew nothing, neither even Sprengel.

There is another outlook upon the progress of botany that is almost peculiarly Adanson's. At the beginning of the analysis of each author's treatise he notifies us how many different kinds of plants each man knew, or had under discussion in his book-Theophrastus 500, Hermann 5600, Tournefort Io, I46, Ray 18,655, as examples - thus recognizing at every step the important consideration that, other things being equal, the greater the number of plant

1 Linnæus in his Classes Plantarum accomplished this admirably for a very limited period, that is, for the time between ${ }^{5} 8_{3}$ and 1738 ; only a small fraction of the time during which the idea of classes, or families, had been in the minds of botanists and found more or less distinct expression.

2 Adanson, Familles, vol, i, pp. 1xxxix-xciii. 
forms a man knows, the safer his conclusions as to the interrelations of all, or of the members of any group of them.

Of course the specialist in plant anatomy, little interested in the whole chain of plant relationships - he to whom 500 species were enough for his ówn purposes - may chance not to be in sympathy with these searchings of all corners of the earth for new plants. ${ }^{1}$

But to what comprehension of the whole of botany has such a mind attained? It would have something like its parallel in the astronomer, if such astronomer there had been, who had deprecated the labor involved in the discovery of the planets Uranus and Neptune upon the plea that there was already enough to do with the rings of Saturn and the canals of Mars. At least somewhat like that is the attitude of the historian who makes light of the work of plant discovery and plant description. To ascertain, as Adanson was at the pains of doing, what number of species a given systematist had known, was the only possible way of informing himself of the comprehensiveness of the man's view of things. And as to the ideal and ultimate perfection of knowledge of the vegetable kingdom, that is manifestly impossible of attainment, so long as a single type, either living or fossil, remains undiscovered and undescribed. It is a principle which not only justifies, but, in the interests of the science as viewed without partiality or prejudice and comprehensively, imperatively demands the most thorough exploration of every field, the equipment of the best possible botanic gardens and herbaria, and also the highest possible perfection of the art of phytography, that is, plant diagnosis or description.

Of incalculable usefulness to the student of systematization is phytography. Its purpose is that of enabling the botanist to measurably complete his knowledge of this and that group of plants only some proportion of the species of which he has been able to see, inspect, and study in the living state. All that a man may learn about plants in twenty years of field work, supplemented by all that gardens and herbaria have to show, will not amount to the knowledge of any more than a fractional part of the specific membership of as much as one of the many families or considerable genera of higher plants. For the rounding out of his knowledge-general, even superficial knowledge-of whatsoever plant alliance, one is always dependent on descriptions. It is one of the most important conditions of all general botany; one that was fully recognized at the beginning; also one that will forever remain. It has always been and it will always be, that a good plant description, placed before

1 Sachs, Geschichte, pp. 42, 43. English edition, pp. 39, 40. 
one mentally equipped for the exact interpretation of it. is decidedly more satisfactory than the usual herbarium fragment of a plant.

Yet one word as to correct and incorrect phytography. One who has a new plant in hand, and who knows it thoroughly from root to seed, may use the whole of an octavo page and the half of another in what will be supposed to have been an attempt to picture this type in words. This same plant may be much more distinctly pictured to the mind of the trained and habituated phytographer in one-fourth that space or even less, by using the set terminology of descriptive botany. This was invented for the twofold purpose of saving space and increasing perspicuity in plant definition. In its most nearly perfected state it is quite modern; and the history of this terminology is a very significant part of botanical history. The discovery of each term was, in its day, a distinctly botanical discovery and an important one; yet the Sprengels and Sachses have given rarely a hint of the evolution of terminology. To have made out lucidly its history would have been a heavy tax on precious time. Adanson almost alone, it may be said, has not neglected it. It was seen by him that in a well devised scheme of botanical history an account of the development of descriptive terminology and the art of describing should find place. Accordingly in these mere outlines for such history he charges certain authors with having described plants poorly; others he remarks upon as having described them fairly, while to here and there he gives the praise of having described them well.

One must not pursue further the subject of Adanson's topical divisions. Those presented may suffice for what I wished to illustrate, namely his appreciation of what ought to enter into the making of a history of botany. Synoptically placed, those few of his topics of which I make mention are:

I. History of grouping of genera as classes or families.

2. History of accepted criteria of affinity.

3. Progress in discovery of new types.

4. Development of phytography and its terminology.

This mere beginning of Adanson's scheme of history will enable me to indicate the contrast that subsists between his and that of Sprengel, whose not unpretentious work in two volumes was given to the public one year after Adanson's death. ${ }^{1}$ Out of the four Adansonian topics named above, only one, the third, obtains good treatment at the hands of Sprengel. The first and second are blank with him; while under the fourth one may gather little beyond

1 C. Sprengel, Historia Rei Herbariae, Amsterdam, i808, 2 vols., 8vo. 
some salient points in the history of anthology. Anatomy and physiology are so discussed as if not inseparably connected with botany proper. Indeed in his partitioning of the science into the two compartments of the Systematic and Structural he expresses his mind to the effect that while Botany proper is a part of Natural History, the consideration of the inner structure and physiology of plants belongs rather to Physiology. ${ }^{1}$ His treatment of these, as developed in the course of the seventeenth century is nevertheless full and explicit. But it is progress in the discovery of new types, history of botanical exploration at home and abroad, and the enrichment of botanical gardens, which more particularly engage Sprengel; and, as Adanson had been more interested in the development of the idea of plant families, Sprengel, as a devoted Linnæan, gives himself to the investigation of the history of genera and species. All the long way from Theophrastus to Linnæus Sprengel lists new types generic and specific as discovered and published by prominent authors; so that a fair chronological history of at least the European Flora is furnished; and these lists of each man's discoveries form so large a part of the body of his work that its principal index is an idex of genera and species.

There is no need of pursuing beyond this brief initiative our examination into the somewhat diverse philosophies of botanical history that have hitherto found expression. Every one may be permitted to have his own. In the present treatise exception will be taken to one assumption made by all earlier historians, that for the earliest intimations of anything looking in the direction of the science of botany we must have recourse to those oldest pieces of literature in which plants are more or less freely mentioned. Adanson, for example, does not begin botanical history without naming Orpheus, Musa, Solomon, Hesiod, Homer, Metrodorus, and Hippocrates who as poets or as physicians wrote of plants. Sprengel has among his initial chapters one bearing the title "Flora Biblica" another "Flora Homerica," another, "Flora Hippocratica" ; and these chapters of Sprengel are botany, even very interesting botany ${ }^{2}$; but this is not saying that there is botany in the Sacred Scriptures, or in the poems of Homer, or in the medical writings of Hippocrates. They are, however, classic texts upon which a man of Sprengel's rare accomplishments may write botany. And yet I seem to apprehend certain rudiments of a science of botany in those ancient pieces of literature, the real substance of which those

1 Sprengel, Hist. Rei Herb., vol. i, p. 3.

2 Ibid., vol. i, pp. 6-49. 
authors of botanical commentary on the Bible, on Homer, on Vergil, and the classics generally, have completely overlooked. Let me repeat it, that in several pieces of very old literature there are legible traces of a science of botany; traces of which even learned and botanically instructed commentators seem to have failed to take due note.

Here, let any reader who has supposed that certain sciences had their beginnings in the minds of men who wrote books, banish, if possible, that idea. No opinion ever held by a multitude of people was more groundless. If, according to the definitions given by authorities, science is classified knowledge and classification is the process of distinguishing and separating between things like and unlike, then there are certain of our sciences the earliest rudiments of which are almost among the very necessities of human speech. It will not be easy to imagine a tribe of wandering savages on any continent or in any age unused to the distinctions of plain, hill, mountain, or spring, brook, river, lake, and ocean. Their very languages will show that their mind had wrought out these perfectly solid and immovable foundations of the science of Geography. Long subsequently the man of enlightenment, he who knows how to commit thought to writing, takes this old and hitherto unwritten classification of the diversities of the earth's surface, gives it logical statement, dignifies it with the Greek name Geography, and then proceeds to build as on very old yet firm foundations his nobler edifice. He may or may not recognize it that those indispensable group names, plain and mountain, lake and river, are but a heritage to his scientific geography from a very far off antiquity; from an antiquity the history of which neither has been written, nor ever will be. It were well, however, that the geographer should perceive it that the real first beginnings of his science are not with the author of any book, but that they antedate all writing.

Botany, as certainly as geography, had its initiative in primal man's distinguishings and separatings between objects appertaining to the world of plants. The fact that in the rudest and simplest dialects of primitive peoples there exist group names for botanical entities establishes this. It is improbable that there ever was a primitive language, other than that of some arctic tribe, in which there did not occur words equivalent to tree, bush, grass, or to trunk, branch, leaf, fruit, root; and every one of these is the name, not of an individual object, but of a group of like objects. Each is a general-a generic-name, and each testifies most clearly to observation, comparison, reflection, generalization, and also either the invention 
of a new word, or else the more extended application of an old one, which, in as far as science is concerned amounts to the same thing. It is possible to trace to a time that lies well within the period of modern botany the first detection and first naming of that kind of organ which we call a stipule; but no one will have the hardihood to propose that we may trace to its first employment the term leaf. Yet this term, which one may never hope to trace to its origin, is as strictly botanical as the later term stipule, and more important. Furthermore, there was a time when the very term leaf-or at least its equivalent in some lost language of a primal race-first came into use. And still further, the mental processes by which a Malpighi arrives at the distinguishing between the stipule and the other parts of the leaf, and those by which the unknown primal investigator came to distinguish between leaf and the stem or branch that bears it, are the same. Neither was more nor less scientific than the other. Each equally with the other had done a piece of strictly botanical research. This is not affirming equality of intelligence for the two, or questioning that he of the later time was capable of solving many problems of plant life impossible of solution by him of the earlier era. Also the motives leading to examination and distinguishing may have been quite different: he of the more recent period was actuated it may have been by that scientific curiosity, that mere zeal for knowledge, which often fires the cultivated mind; he of the primeval time was impelled perhaps by sheer necessity. He is much dependent on the plant world for life's comforts, even for its necessities. One part of a tree is of great use to him for one purpose, another part for a very different purpose, a third being of no use. Therefore from his utilitarian point of view it becomes manifestly needful that the different parts of plants be distinguished and each different part named. Language demands the introduction of such terms. But the mental processes, I repeat it, are the same in either case, and without respect to the actuating motive. It is all work of examining, comparing, distinguishing, segregating, and naming the segregates. Every step in the procedure of either is scientific. If one is tributary to a science of botany, so is the other. And if these reflections seem to indicate that scientific botany may be, as to its first elements, older than all literature, what of it? There is but one point of view from which it will be disputed, namely that which regards man as having made his first appearance on earth in a condition of advanced intelligence, with a well-developed language, and also bearing a divine commission to assign names to all manner of natural 
objects at first sight. When one notes the perfect silence of the historians as to the possible origin of the most common and universal botanic terms, one seems forced to conclude that they accepted this doctrine of the sudden and inspirational derivation of them; and that then, as if unwilling to say so, they evaded the subject by going about the completely different and really quite irrelevant task of cataloguing the trees, shrubs, and herbs mentioned in the Bible, giving them the appellations due them according to the nomenclature of Linnæus' Species Plantarmm. This was all a mere matter of giving the Linnæan Latin names of certain plants in place of their more ancient Hebrew names. It was not approaching by so much as one step the origin of botany, but rather, as I have said, evading the search.

Assuming that the simplest and most universally employed botanic terms entered into human speech not all at once by sudden and supernatural illumination of one particular mind, but one after another as a part of the natural and gradual evolution of language, it will be conceded that they had been formed and in use during long ages of human existence that preceded the invention of writing. And the chief botanical interest attaching to very early writings will be, not in that they furnish a few score Hebrew or Greek names of plants which the well skilled botanist of a recent period may translate into the terms of modern nomenclature; it will be in this, first of all. that they incidentally record names of some plant organs. Such words as fruit, seed, branch, leaf, and root occur, and these seem to reveal it that plants in numbers have been looked into and studied organologically, and with such success that these names of different parts of trees and herbs are already an indispensable and a firmly settled part of every language. Moreover, the terms tree and herb, grass and grain tell as plainly another story, that of a prehistoric distributing of plants in groups according to resemblances. These two kinds, or at least two phases, of botany are in the writings of Moses and of Homer, and perhaps more valuable because there only incidentally, that is, without botanical thought or purpose in the minds of the writers themselves. They only happen to give us, as through a window accidentally left open, a view in which we see individual plants consisting of named parts or organs, and also assemblages of individual plants, some spoken of as grass, some as herbs, some as thorns, others as thistles, some as bushes, others as trees. Though it be no more than a passing glimpse that one has gained, it is enough to excite curiosity, and to suggest a number of

\footnotetext{
1 Genesis vol. ii, pp. 19, 20.
} 
queries legitimately botanical as to just what, in so primitive a time, may have been the full meaning and acceptation of this or that morphologic or taxonomic term as thus early in general use. Such questionings may not necessarily be idle or useless. There being no room for doubt that as far back as the time of Homer, and even of Moses, there was at least here and there a person somewhat specially skilled in the knowledge of plants, how would such a one have applied, for example, the term root? How many things, in his mind, would have been included under that name? What, in a word, might have been his definition of a root? Possibly we shall never know. Neither is it wholly impossible that we may some day ascertain it, at least approximately; for not so very many centuries after Homer specialists in plant knowledge began to write books upon the subject. Some of those books are still extant, and in print; though they have been made too little use of thus far by our historians, some of whom appear to have been disposed to divide the honors of elementary plant organography between Adam and Linnæus; which was an easy way of evading an important though most difficult part of botanical history. In the writings, I say, of the earliest of professedly botanical authors there would be reasonable expectation of finding a clue to that primitive conception of the root which was theirs who introduced the word into speech; for always the first work of him who is ready to reform and rebuild a science is that of showing wherein the prevailing opinions are at fault. To him nothing is more necessary than this. Our appeal in this instance must be made to Theophrastus of Eresus, whose writings on the philosophy of plant life and form are the oldest that are extant. As a controversialist this philosopher is of the mildest type; more apt to suggest, urbanely, that an old opinion may be wrong than bluntly to pronounce it false. His whole treatment of the subject of the roots of plants reads as if he had gone to work stealthily to undermine an old and everywhere received opinion that roots are simply the underground parts of plants. He names two or three familiar species which, as he reminds his readers, produce roots that are aërial, or at least not subterranean. Then he cites, and very well describes, certain subterranean parts-bulbs and corms, we call them now-which he thinks hardly ought to be considered roots. That Theophrastus openly discredits the doctrine that a root is a root because of its being subterraneously located is proof enough that it was the doctrine commonly received in his time. We are also perfectly warranted in believing that the exceptions he takes 
to it are his own and new; because no writer in ancient times was more careful than he to attribute to their proper authors any new or remarkable opinions which met with his own approval. But, that the primeval understanding of the root was that which I have supposed is again attested by its universal prevalence in our own time among people who have not been initiated into, or influenced by, the botany taught in our schools. Such peoples, dwelling in all parts of the world, if engaged in farming or gardening hold to a certain classification of farm products, and are wont to speak of grain crops, root crops, etc., using the last named expression without ever a suspicion that a potato is a kind of branch, and an onion a kind of bud. Beyond doubt a very great majority of the inhabitants of the earth to-day, if questioned upon the matter, would answer promptly, and fearless of contradiction, that whatever part of a plant grows beneath the soil is its root; and if any remotely domiciled rustic between Nova Scotia and Patagonia should remark that a white potato is a tuber and that onions are not roots but bulbs, we should know without parley that his abandonment of the principles of primeval plant organography had been brought to pass under the influence of modern book or school.

The survival of these primitive notions about the subterranean organs is more interesting than the origin of those notions. The tardiness of their displacement by a more rational organology is to my mind one of the curiosities of botanical history. That most complicated and difficult of organs, the flower, began to be well understood as early as the dawn of the eighteenth century; but at a time when, by the aid of better microscopes, the important function of stamens had been brought to light, and the doctrine of the flower thereby revolutionized and nearly perfected, it still remained that the rhizomes of iris, the bulbs of lilies and tulips, and the corms of crocuses were called roots by all the botanists; this also some two thousand years after Theophrastus of Eresus had suggested that it might not be very good organology. And as for our historians, I have not found with one of them any intimation of who it was who at last solved for us the hard problem of an acceptable definition of a stem; the definition which at once compelled the recognition of subterranean stems as being stems, not roots. In my view this has always appeared to be one of the most signal triumphs of organographic research. Using the term understandingly and comprehensively, organography is more than half of botany. It is the whole foundation and framework of the science, and a good deal more than that. The progress of botany 
all along is largely identifiable with the advancement that has been made in the knowledge of plant organs; yet it is just this which one is able to learn least about from the historians. This statement must be qualified by the admission that, as regards that sudden leap forward which anthology made early in the eighteenth century, Sprengel is quite explicit; though he gives little indeed of its earlier history. It is also acknowledged that the story of the rise of microscopic organology, and its progress down to the middle of the nineteenth century was given by Sachs, and with such fulness as to make it occupy more than half his entire volume of the History of Botany. Still these are but separate and disconnected chapters in the real history of organology.

If I here indicate this incompleteness of the history of botany as hitherto presented, it is not because I dare hope in these landmark chapters to make good the deficiency, though earnest and laborious effort is made to show how I think it may be done.

That prehistorically and primevally there existed not only an organology of plants but also a classification of the familiar kinds has already been suggested; and the proposition may here receive clearer statement. Moreover, certain somewhat stilted and pedantic views rather widely prevalent respecting systematic botany as of recent origin, no less than the interests of a truer philosophy of botanical history, seem to call for a vindication of this thesis.

Owing to the profusion of plant individuals on the face of the earth everywhere, the bewildering diversity of their forms, and the usefulness of them to man, it was never possible for men, at whatever stage of mental development, to intercommunicate concerning plants without having group names for them. Words that should have application to particular assemblages or kinds of plants were among the earlier necessities of language; and to speak of plants under group names is nothing less than to speak of them as already classified. The classification has necessarily preceded the invention, and the adoption into language, of the collective name. By way of illustration I select out of a hundred or two of plant names which in our English speech are as old as the language itself, the word "clover." It tells its own story. It was applied to certain plants which were seen to have this common characteristic, that each leaf was made up of-cloven into-three separate equal and in every way consimilar leaves. I say leaves in order to avoid being anachronistic; because leaflet is a term of really very modern invention; one unknown in English, and without its equivalent in any other language, at least of Europe, 
until the middle of the seventeenth century. Now clover was from the first the name of an assemblage of individuals; if of individual plants of several somewhat different kinds all exhibiting the common leaf character then it was what it now long has beena generic name. It ought to seem superfluous to say that clover is just as much a generic name as Trifolium, and that white clover, red clover, and alsike clover are as perfectly binary specific names as Trifolium repens, $T$. pratense, and T. hybridum; but, as I have intimated already, the curious notion is here and there prevalent that a genus is not a genus, nor a species a species, until it obtain a Latin name. I have thought desirable to indicate thus plainly the incontestable fact that to the most primitive and untaught of herdsmen and cultivators, in their close dependence upon many members of the plant world, generic names and specific are as much a necessity, and as certainly in every-day use, as they are with us their school-taught posterity who call ourselves botanists. The true philosophy of botanical history seems to call for special insistence on this fact; as also that the riewing of a number of related genera, and the speaking of them under a family name, is likewise of a very remote antiquity. The English collective plant name "pulse" is as old as the language itself, as covering under a monosyllable all the sorts of peas, beans, vetches, and lentils. It is nothing less than a family name, invented as a means of briefly designating the whole natural group of those cultivated plants of various genera which, in recent botany, are called Papilionaceæ. Ancient Latin writers, to whom many genera of umbelliferous plants were known familiarly, saw plainly their interrelationship and called the whole assemblage of them the Ferulaceæ, naming it after the well-known genus Ferula which, as a genus, is represented by several species in the Mediterranean flora. And all this the Latins had only borrowed from a still more ancient Greek botany; for the Greeks had known as well the genus Ferula under the name Narthex, and were used to speak of the whole line of related genera as the Narthecodes.

From these two or three lucid examples of the naturalness of plant classifying taken from the records of antiquity, let us proceed to make some enquiry into like usages as they obtain among the most untaught in our own time. It is improbable that there may not be found in every country of the Old World peasant peoples who, entirely uninfluenced by books or schools, have nevertheless each some rudimentary system of botany; some terms expressive of their own classifyings of plants, at least such kinds of 
them as they have much to do with, whether as herdsmen, as cultivators of the soil, or as woodsmen. An American student, however untravelled except in his own broad country, may have gathered even here illustrations enough of the principle now under consideration.

To the colonists and early settlers of a new country no native products of the soil are more important than the trees. Timber, lumber, wood for all kinds of building and fencing purposes, for the construction of bridges, vehicles, and household furniture, not to speak of fuel, bark for tanning purposes, and in autumn mast of nuts and acorns for the fattening of swine for the slaughter-these are among the reasons why early settlers always located their first domiciles along the edges of great forests. And now, if we remind ourselves of certain conditions of the first colonists who came to these shores from western Europe three centuries ago, we shall realize that, while they found themselves in the midst of a land bountifully supplied with timber, the particular kinds were new and strange to them. Nothing was quite the same as anything that they had known in the Old World; and no kind of information would have been more welcome to these colonists than that relating to the enduring and wearing qualities of the woods of these different kinds of strange trees. Every kind was untested, and there was no one to teach them. All had to be learned by trial and experience. Yet not quite all; for, to a band of colonists of three centuries ago, coming to these shores from England, there must be credited such knowledge of English trees and timber as was usual with Englishmen of that period; a knowledge that would be of some service to them as American colonists notwithstanding that American trees were of a much greater number of species, and none quite identical with and European kinds. They had brought with them across the sea a knowledge of oak, walnut, chestnut, beech, elm, linden, and some other trees. As for the chestnut, the beech, and the linden, they found but one kind of each here, and these not very notably unlike their congeneric European species. The settlers would naturally expect to find the American trees of these sorts available for the same economic purposes as their European allies. Neither as to the aspect of the trees nor the qualities of their wood was there so much difference; but with those very important timber trees, the oak and the walnut, the case was different. In place of the one European kind of walnut, the Virginian forests presented them with at least a half-dozen, each strikingly unlike the Old World 
type, both as to characteristics of foliage and fruit, and as to color and qualities of the wood. If one type of these peculiarly American walnuts bears to-day the name of White Walnut, ${ }^{1}$ it is undoubledly because the first settlers of Virginia, taking it for a probable equivalent of the English Walnut for lumbering purposes, found its wood to be by comparison much lighter in color, and named the tree, after the usages of lumbermen, by the color of its wood. The Black Walnut ${ }^{2}$ in like manner obtained its name from the almost blackish hue of its wood compared with that of the tree of Europe. ${ }^{3}$ And both these names bear distinctly the marks of an early colonial origin; for no native American woodsman of however early a period would have known the wood of the European Walnut so as to have made the comparisons.

From this representation of colonists as practical woodsmenbeyond all cavil an essentially faithful representation-it appears that men without the least training in school botany, exploring the woodland resources of a new continent with none other than utilitarian ends in view, find systematic botany an indispensable necessity, create for themselves a serviceable systen of woodland taxonomy, make themselves the pioneers of taxonomic research in the new field; this not, however, as using the terms taxonomy and classification; not even as necessarily knowing so much as the name of the science which they are practising. Let us distinguish mental processes. Nothing more is here needful. He who is occupied with testing wood or timber as to its economic usefulness is doing the part of the industrialist. He who compares one sort of living tree with another, noting by what marks of habit, of bark, of foliage or of fruit the two may be distinguished, and who determines to call one of them by one name and the other by some name that is different, is doing exactly the work of the botanical systematist. This man may never have learned a syllable of the terminology employed in schools of botany. He may not have heard the Latin name for oak, for maple, for poplar, or any other genus of trees, or even the word genus; but he is a botanical systematist none the less; and since his business obliges him to be this he proves the utility of botanical system. It is not possible for the occupations of the farmer, the herdsman, or the lumberman to be carried on without botanical classification and a fixed nomenclature of both genera and species. Therefore those thus engaged have never at any time in

1 Juglans alba, Linn.

2 Juglans nigra, Linn.

3 Juglans regia, Linn. 
history waited for the schools and the school-trained botanists. They have made their own botany, have established both system and nomenclature; and these, in so far as they had proceeded, the professionals when they came upon the scene adopted. The two, that of rustic, of mountaineer, of herdsman, and of woodsman, and that of the schools, are as essentially one botany, as certainly one in kind, as wild pears, wild apples, and wild grapes are respectively one in kind with their cultivated and improved offspring of the orchards and vineyards. If this be true, then the annals of botanical science have another beginning than that which our annalists have assigned it.

When once it is seen that group names for plants are as old as language, and that these very names establish it that men always in all ages classified the many plants with which they had to do, there is another matter which immediately calls for careful investigation, that is, the parts of the plants to which rude primeval botanists looked for the marks by which to range their plants in convenient groups. We have already seen that Adanson alone among historians perceived that attempts had been made down through all the centuries to group plants by other data than those of flower and fruit. In bringing this fact into view, and by citing a long line of early authors in attestation of it, he was fearlessly contradicting, and at the same time successfully controverting what his contemporary, Linnæus, had said when in the warmth of his zeal for the great Cesalpino he had pronounced him first in the order of time among real systematists. ${ }^{1}$ The truth about Cesalpino was simply this, that he had been the first to attempt an orderly arrangement of the plant world by universal appeal to the fruit and seed; and that alone would still have been the superlative of praise, doubtless well merited. But that the Cesalpinian system seemed incomparably superior to every one that had preceded it could never become a warrant for saying that those systems antedating it might be left out of view altogether, as never having been systems at all. I can conceive of nothing which science more inflexibly exacts of every scientific man than truthfulness. She cannot permit an enthusiastic fancy to take the place of fact. But there have been successive generations of botanists since Linnæus who, as if swearing by his authority as if he had been infallible, have seemed to have no idea that any plant classifying ever was attempted upon any other than that anthocarpological basis which now for some three centuries has been

1 Linnæus, Philosophia Botanica, \& 54 . 
steadily in use. As a mere prejudgment it is deeply seated in the botanical mind of to-day, that nothing can be done, or ever could have been done, in the direction of an orderly arranging of the world of plants but by appeal to characters of flower and fruit. And along with this prejudice there dwells another as deeply ingrained, namely, that the flower was the same thing to botanists of four hundred years ago, if not to those of three thousand years since, which it is to us; whereas not yet two centuries have passed since the flower began to be known. Our classifying by flower and fruit was fairly established while as yet the corolla was regarded as the principal part of the flower, and was in fact the synonym for flower, without even its name corolla.

Something may be done towards undermining these prejudices by giving a few examples of primitive systematizing as undertaken while as yet the flower, as to its essentials and its functions, remained an undiscovered organ.

For a good illustration of classifying by leaf characters alone, those of flower and fruit being quite ignored, we need go no farther back than the later years of the sixteenth century and the first quarter of the seventeenth. Let us limit ourselves to the forty years intervening between $\mathrm{I}_{5} 8_{3}$ and $\mathrm{I}_{2} 3$; also inspecting certain pages of two of the widely known and thoroughly approved professional botanists of the time, Rembert Dodonæus and Caspar Bauhin. The genus Clover, in ancient Latin Trifolium, in Greek Triphyllon, already referred to in this chapter, is an ample one with the authors named. Bauhin's book contains names and descriptions of some sixty species; and since both he and Dodonæus are almost as strict adherents of binary nomenclature as was Linnæus himself who came into this field of nomenclature a century later, it will be easy to show what they received into the genus Trifolium by presenting here two opposite columns of binary names. In as far as they admitted to their Clover genus genuine clovers as we now understand them, the reproduction of their names need not be made.

Dodonæus $\left(1_{5} 8_{3}\right)$, and Bathin ( $\left.162_{3}\right)$

Trifolium bituminosun

Trifolium odoratum

Trifolium corniculatum

Trifolium cochleatum

Trifolium palustre

Trifolium acetosum

Trifolium hepaticum
Recent Names

Psoralea bituminosa.

Melilotus officinalis.

Lotus corniculatus.

Medicago orbicularis.

Menyanthes trifoliata.

Oxalis acetosella.

Hepatica triloba. 
It ought here to be noted that for the combining of Melilotus with Trifolium, Dodonæus is reponsible but not Bauhin, who at this point saw fit to abandon the trifoliolate leaves as essentially and without exception conclusive of membership in Trifolium. He does not, however, as others had done before him, accept the melilot species as constituting a genus of their own, but places them all as members of the genus Lotus, where also some species are trifoliolate, others not so.

I observe also that if only the first four of the species of the above list had gained admission to Trifolium along with the clovers proper, one might have thought it probable that some dependence, after all, had been placed upon the floral structure; for in that case the authors would have had a Trifolium composed of papilionaceous plants exclusively. But neither in the defining of the genus nor in the description of a single one of the about sixty species of Bauhin's Trifolium is any mention made of the morphology of the flower. And by the admission of gentianaceous, oxalidaceous, and ranunculaceous types into that genus it is placed beyond question that in his mind the genus was limited by nothing else but the herbaceous nature of the plants, ternate foliage, and dry fruits. I say dry fruits, because in Bauhin's book the strawberries, as typically trifoliolate as the most genuine of clovers and as herbaceous, stand in closest juxtaposition to them, and it is manifest that their, juicy berry-like receptacles, with seeds all on the outside, saved Fragaria from being merged in the Trifolium of that author. And in this giving so much attention to the fruit where flowers were wholly ignored we see the influence of Cesalpino's great treatise; for Bauhin and Cesalpino were contemporaries, in a manner, the former younger by thirty years.

All through such books as have here been cited one reads the resoluteness of purpose and the hard perseverance with which men labored to improve botanical system by studying and comparing texture and duration of stems, and above all else the morphology of leaves; a very crude system at its best; but system of some sort there had to be; the flower was still virtually unknown; the fruit was barely beginning to be appreciated in its usefulness to taxonomy; therefore the vegetative organs, chiefly the leaves, were most commonly allowed to be decisive.

The appeal to leaves was not, however, first thought of in either the seventeenth century or the sixteenth. Even then it had been more or less in vogue for three or four thousand years that we know of. 
As a good example of an antique genus of trees based on leaf characters alone, with no dependence on those of flower or fruit, one recalls the Daphne of the Greeks. The original Daphne with them was the sweet bay, Laurus nobilis Linn., the type-species of the genus Laurus as now received. Its foliage, being lance-shaped, of a somewhat leathery texture, with no marginal indentation, represents a rather common leaf type, and the tree is evergreen. Now there was a period of Greek history within which there was not only some travel to foreign lands, but even some written reports about the natural products of other countries; and there is the most convincing evidence that every new tree or shrub that came to light that was both evergreen and clothed with oblong or lanceolate entire leathery leaves was at once relegated to the genus Daphne; was named as another kind of laurel. Here is a list, possibly not a complete one, of trees with Laurus foliage which ancient Greeks, on that account alone, had referred to that genus: Laurus nobilis, Nerium Oleander, Nerium odorum, Avicennia offuinalis, Rhizophora mucronata, Ruscus Hypophyllum ${ }^{1}$; six species of so-called Daphne or laurel, belonging to five different genera, and representing as many different families, all anciently accepted as of one genus, because the foliage in all was much the same, and for no other reason whatsoever. And this again reminds us that in eastern North America, where there is no laurel, we have a number of kinds of native shrubs that have always been called by that name, just as if they had been members of the genus Laurus to which they are in no wise related. If we ask ourselves how this false naming came to pass, the answer is, that at the time of the early colonization of this new continent the old Greek idea was still dominant, that whatever bush or tree had a laurel foliage was a good enough laurel. The colonists brought that idea hither, and naturally enough applied the name to our Kalmias and Rhododendrons one and all.

This classifying by foliage was never received as anything like a general principle everywhere to be applied. So far from that, the rude primitive groupings were accomplished here and there under the sole guidance of the fruit; though in the main only as to none but its most superficial characteristics. Among fruit-bearing trees the apple tree was perhaps the oldest and most familiar type, unless the pear be excepted; and as new kinds of fruit trees in the course of history became introduced into Europe from other lands, every kind, the fruit of which was of considerable size and of something

1 Bretzl, Botanische Forschungen des Alzxanderzuges, p. 405. 
like the sphericity of the apple, was called a kind of apple tree, a member of the genus Malus, as it was called in Latin speech and writing. Here is a partial list of the kinds of Malus, or apple tree, that find record and description with several early authors; excluding, however, the true apples, which were of many varieties all with binary names.

$\begin{array}{ll}\begin{array}{l}\text { Malus Armeniaca } \\ \text { Malus Persica }\end{array} & \begin{array}{l}\text { Armeniaca vulgaris. } \\ \text { Amygdalus Persica. } \\ \text { Malus arantia } \\ \text { Malus limonia }\end{array} \\ \begin{array}{l}\text { Malus medica } \\ \text { Citrus limonium. } \\ \text { Malus cotonea }\end{array} \\ \left.\begin{array}{l}\text { Citrus medica. } \\ \text { Malus aurea } \\ \text { Malus Punica } \\ \text { Malus granata } \\ \text { Malus Indica }\end{array}\right\} \text { Cydonia vulgaris. } \\ \text { Punica granatum } \\ \text { Zizyphus jujuba. }\end{array}$

In outline, the history of the development of such a genus Malus as the above is this. In primeval southern Europe they had the common apple tree, Malus communis, and, from the beginning of the historic period at least, they had it in many cultivated varieties. The fruit was malum with the Latins, the tree malus. Then, as other kinds of trees were introduced from the East having spherical or ovoid fruits not too small for apples, their fruits were also designated as kinds of apples, and the trees as species of malus. To us who, with also several generations of our botanical ancestry, have become accustomed to a greatly improved classification, such a piece of systematizing as the above list of apple-tree species exemplifies cannot but seem absurd; but the presentation of something of that kind was necessary, partly in order that we might realize from what small and simple beginnings our later and better systems of carpological classifying have been evolved; also partly as demonstrating the groundlessness of the Linnæan hypothesis that classification by fruit characters took its rise with Cesalpino, and as late as the end of the sixteenth century.

I am unwilling to dismiss the subject of early and practically pre-Cesalpinian classifying by fruit without having given one more illustration of it. For this purpose I shall again advert to the taxonomic procedures of the early Virginian colonists. I have cited the case of their having found there, in place of the English Walnut, two allies of that tree, and that they named these new 
kinds Black Walnut and White Walnut respectively; also that this naming of the kinds was made not in reference to any morphological characters of the trees, but to that of the colors of the wood; this having been done quite after the manner of self-taught woodmen, whereas school-taught botanists would have assigned names suggested by organographic marks. But this all relates to nothing else but the making of specific distinctions and the assigning of specific names. When we ask ourselves by what marks they were able to refer these new trees to the genus of the walnuts, we obtain but the answer that it was by those of their fruits; these in such degree resembling that of the one kind of walnut before known to them as to warrant the conclusion that the trees were of the walnut kind, as they would have expressed it, rather than of the oak or chestnut kind.

But our colonists' experiences with the native American oaks, if they had been more fully recorded than they were, would have been still more interesting. As English woodsmen only one kind of oak can have been well known to them. In Virginia they can not have failed to meet at once with about a half-dozen sorts, most of them in aspect exceedingly unlike the English Oak; so much so that they can not reasonab y be supposed to have identified them with that genus of trees at all until after close inspection. One of the sorts displayed to them the foliage of the chestnut tree, another that of the laurel, still another the leaves of a willow. The chestnut-leaved kind had not at all the bark nor the wood of chestnut trees, but of oaks, rather; therefore these first observers of the tree would hardly have needed to appeal to the fruits in order to satisfy themselves that this new tree was but an oak, merely imitating the chestnut as to its foliage. But among the other kinds, such as had neither foliage nor bark nor wood in any way answering their idea of an oak tree, they can not have determined to be oaks by any other note in each but that of its fruit.

That which I have thus far hypothecated concerning early Virginian colonists in relation to native Virginian oaks is demonstrable as something more than even the most rational of hypotheses. There is documentary evidence of the historic truthfulness of all, and more than all, that I have here but intimated as probable. That these men, forced by circumstance to make trial of the timber of trees new to them, did early recognize as oaks certain kinds most unlike what they had known as oaks, in all except their fruits, is attested by a colonial list of names of new American oaks which was published when the colony was but two generations old. I re- 
fer to Banister's Catalogue. ${ }^{1}$ This contains a list of binary names of Virginian oaks, such as Quercus alba, Q. rubra, Q. Hispanica, Q. castanecefolia, $Q$. salicifolia. Now while a casual reader of the catalogue cited would, without a second thought about the matter, attribute those five names to Banister, it is extremely unlikely that any one of them was invented by him. It is next to certain that the whole five are his mere translations into Latin of the oak names that he found in use among the colonists. Perhaps the plainest proof of this is, in that by turning those five binary names back into English you get precisely the names by which five common oaks are known to dwellers in that same region now, two hundred and twenty-seven years after Banister's having written his list. It is really evidence that is incontestable. To dispute it would be to affirm that the names were made by Banister himself, in Latin, then turned into English for the use of the woodsmen settlers; that these had been waiting sixty years or more for the professional botanist to come and tell them by what names to call their several kinds of oak; each part of which proposition, like the whole of it, is absurd. Under pressure of necessity, and from the outset, they must have begun to learn the different qualities of the wood or timber of those strange new kinds of oak. One or two of them were found comparable with the familiar oak of the mother country as being hard, durable, subserving the purposes of the builder, the wheelwright, and the cabinet-maker; another, not subject to decay when set into the ground, useful for posts; still another durable only when used for bars, rails, and like purposes; and there may have been a fourth and fifth kind excellent for winter fuel, but nearly worthless otherwise. No man will pretend to believe that colonial woodmen and handicraftsmen, learning by degrees the different qualities and uses of our various American oaks, did not immediately assign a particular name to each particular kind. The important industries of house-building, boat-building, cabinetmaking, the constructing of vehicles, the building of fences, and the providing of the winter's fuel, all demanded quite imperatively that there be a well ordered and generally accepted system of woodmen's nomenclature of oaks as well as of othe: genera of timber trees. So it came to pass that all important trees everywhere, in America quite as elsewhere, had their established names before the arrival of the writers of floras and silvas; and there is many a kind of tree the Latin name of which bears the

1 Banister, Cat. Plant. Virg., transmitted from Virginia to John Ray in 1680 ; published by Ray, in Hist., vol. ii, in 1688. 
mark of its having been originally the woodmen's vernacular name for it.

Hitherto this fact of the universal existence of a crude primitive system of plant classification-one that antedates all botanical writing, a system that is in vogue to-day all over the world in outof-the-way places, in complete isolation from the influence of colleges and universities-appears to have remained unnoticed by botanical writers. At least, I have met with no allusion to the fact. I therefore doubt that it has entered into the minds of botanical thinkers in recent times that such untutored yet effective and useful plant taxonomy exists, and must have existed primevally.

There will be readers enough to whom this thought will be new and somewhat startling. The fond conceit has long prevailed, that there was never anything in the world that could be called science until some three centuries ago, or four, at the farthest. Among several ideas about the botany of the past-ideas very widely, almost universally, entertained, though without the least warrant from history -I shall here mention but the following: that plant genera did not obtain fair recognition until Tournefort, nor species as distinguished from varieties until Linnæus, nor families before Adanson. Now if, according to the present thesis, the beginning of the receiving and naming of common plants in groups is ancient beyond all possibility of discovery, then no author can be credited with, or any date be assigned for, the beginning of the recognition and naming of either genera or species. What great men like those just named accomplished for the improvement of system in botany was, the better delimitation of several anciently accepted genera, and the laying down of certain rules and principles by which they thought all plants, known and unknown, might be arranged in groups more nearly according to their affinities. Assuming that the rules and principles were philosophic, all this was immensely to the advantage of classification; but when for the twofold purpose of emphasizing the principles and making the new system easy to learn, they caused each genus name to be printed in large type, in the middle of the page, occupying a line by itself, then close under that the formal statement of its characters as a genus, and after that and only less conspicuously the species names, each occupying a separate paragraph, they were by this rigid formalism inaugurating, though they knew it not, an era of didacticism which now after two centuries has degenerated into an almost gross pedantry which rules systematic botany at present well-nigh universally. To illustrate the supremacy of this pedantry let me 
suppose that some accomplished botanist of Italy or France or Germany, having a new genus to propose, ignores all the usual postTournefortian formalities in his naming and defining of it. This will mean only that, declining to follow established typographical usages, he does not place the new generic name in large letters in a conspicuous place above all that he has to say of it, but begins his paragraph with a statement that the type is new, thence proceeding without a break to name the marks by which the genus is distinguishable from all its allies, then directly adding, in the same type and without the formality of an initial capital, even in the middle of a line, if it so happen, the name by which he proposes that the genus shall be known; all this followed, still without breaking the paragraph, by whatever else he may have to say about the plant or plants of this new genus. Between such simple uncapitalized compact taxonomic paragraph as I have supposed, and the familiar stereotyped form of naming and defining a genus, there is at first glance the appearance of great dissimilarity. As to the meaning of the two, and the information that is conveyed, there is no shade of difference between them. The plant type, supposing it to be the same, is as fully described and as certainly named in the more simple paragraph as in the one that is ostentatious. All that the botanical scholar can learn from the one he may learn just as perfectly and just as promptly from the other. Really the differences between the two are hardly more than typographical; yet notwithstanding this, it is probable that forty-nine out of every fifty botanists of to-day, if not even a much larger proporton of them, would in part fail utterly to perceive that the simple unostentatious paragraph which I have supposed, with generic name in small type set in the midst, had been intended as the publication of a new genus; and it is as probable that those of the forty-nine who did perceive the author's intention would deliberately ignore the paragraph, under the plea that the name and characters of a genus printed in a style so very unconventional must not be admitted to answer the requirements of publication. The genus must be treated as unpublished. This, be it noted, will be the same as to order that a new scientific fact be, in as far as possible, suppressed for the reason that certain familiar usages as to type and paragraphing were not followed in the publication of that fact. It will be regarding form of expression as superior to the facts expressed; will be allowing individual whim or fancy to ignore important matter; will make for the establishment of shallow pedantry in place of solid information and the use of plain good sense. I have 
stated this case hypothetically; but there are provinces where the situation is to-day actual.

But the greater number of my hypothetic forty-nine, as I have said, will even fail to discover that a plant group has been named and defined on any page where the modern typographical conventionalities are not in evidence. I think that among such as are quite proficient in systematic botany there are many whose impression of the printed pages of Ruellius, of Dorsten, and of several other classics of sixteenth-century botany would be that they give no account of families, genera, or species; and this only because great authors had not then learned to make a separate paragraph for every group, and to print the names of genera and of species in type different from and more conspicuous than that used for the descriptive passages. There is no question of the superior convenience of our modern style of printing taxonomic matter; still, for the mistaking of mere incidentals for essentials by people professedly scientific, it is not easy to frame excuse. But the psychologic fact is well established that men do in this wise err, and that there are multitudes of biologic taxonomists whom familiar usage has completely deceived into thinking that no name is generic unless printed in large letters; multitudes of botanists who will have been startled by the proposition incontestable that clover, parsley, hazel, and birch, all as here printed, are names as perfectly generic as TRIFOLIUM, APIUM, CORYLUS, and BETULA. Moreover, there have been learned historians of botany in postTournefortian times whose minds appear to have been under the same delusion, and who thereby missed one of the fundamentals of the philosophy of botanical history.

It is impossible that men, even the most primeval and unlettered, manage their affairs with various denizens of the plant world without classifying them. Names of plants, generic and specific, and also other names more comprehensive, are a part of the vernacular of every tribe of the uncivilized, as well as of that of every rural province within the bounds of civilization to-day. The very names attest the fact of classification; for no name is that of an individual plant. It is that of a group of plants, always; a group specific, generic, or more comprehensive than either.

It may occur to some that the named groups recognized by the untaught do not in their delimitation correspond to those that obtain with the professional plant taxonomist; as if that, if it were true, would in the least alter the situation or affect the argument. It will be difficult to understand how the vernacular genera of the 
ruralists can possibly correspond to the Latin-named genera of the scientific botanists when the latter themselves are seldom at agreement among themselves as to the exact limits of any considerable genus, or of any polymorphous species. When we ourselves may have learned to agree as to where one of our Latinnamed groups is to end and the next is to begin, may we with some propriety criticise the same kind of doing as accomplished by the unindoctrinated.

And now let me demonstrate it, that in the history of classification the unlettered vulgus now and again has been first to arrive at the satisfactory delimitation of a natural group, the learned doctors having arrived at this same judgment later by one or more generations, and so as to seem to have adopted it from the untutored laity. This point may perhaps be most easily made plain by returning to the contemplation of North American colonial botany and the colonial dendrologists. It was shown above, that all the several American trees of the walnut alliance with which they became acquainted, although all, in certain particulars, different enough from that one Old World walnut which they had known, they called walnuts; precisely the same as if they had denominated them species of JUGLANS, which would have been the case assuredly, had they but known and used the Latin terminology in place of the English. We, of three centuries later, dispose of these American trees differently, referring nearly all of them to another genus; but what is remarkably to the credit of that colonial and primitive taxonomy is, that so exalted an authority as Linnæus found no fault with it, but simply adopted it. With him all the different kinds figure as good enough species of JUGLANs, and bear with him even the same specific names which the colonists had assigned, but of course Latinized.

When, in a preceding paragraph, I gave early American colonists the credit of having recognized and named as oaks a considerable list of native acorn-bearing trees; even as having determined them to be oaks by their acorns alone, I felt that there might be demurrers to the opinion that these had not learned this mark of the genus Quercus from the schools in some more or less indirect way. I may well, therefore, here place it beyond dispute that in this case also the unlettered men of field and forest did arrive at the proper delimitation of a genus of trees quite in advance of the professional taxonomists, and these last virtually adopted the genus, as we now have it, from the ruralists. In the first decade of the seventeenth century, when the Virginian colonists were beginning to learn the 
industrial uses, and at the same time the characteristic superficial -as we should now say morphological-marks, of many new trees, there was yet no book of botany extant, in as far as I can learn, in which it was taught that any and every tree that has an acorn for a fruit is hereby known to be a Quercus. Neither Pliny nor Tournefort, nor any author of the fifteen centuries that intervene between those two, has fewer than three distinct genera of acorn-bearing trees. With each and all of them a tree bearing acorns, in order that it may be of the genus Quercus, must be deciduous, and its foliage sinuately lobed. In other words, none but deciduous white oaks are properly called oaks by these old authorities. Trees bearing acorns, but evergreen as to foliage, the leaf margins prickly, are of a separate genus, Ilex; while those oaks of southern Europe with peculiar foliage, along with a thick spongy bark,--cork oaks, we call them,-are of a third genus. Suber. At the time, therefore, when Banister was turning into Latin those English binary names which colonists had given to Virginian trees bearing acorns, there was not yet a book of botany extant in which it was taught that its yielding acorns was a sufficient warrant for naming a tree an oak. It was only the country people, the woodmen, who held that view as to the extent of the genus Oak. The learned John Ray, the same who received from Banister the manuscript catalogue of Virginian plants and caused it to be published, himself never swerved from the doctrine then time-honored and classic, that we have here three genera, Quercus, Ilex, and Suber, yet expressly states that "the common people so extend the name Quercus as to include under it all kinds of trees that bear acorns." 1 In as far as I have been able to trace the history of oak classifying on the part of professional botanists, Linnæus appears to have been the very first to repudiate what had been the opinion of all his predecessors, and to adopt as more true to nature the more comprehensive genus Quercus which the vulgus had invented. And so, if we of the present, following Linnæus as to the limits of Quercus, are in the right, then let us concede freely the fact, from which there is no escape, that during long centuries the unlettered vulgus was taxonomically correct, while all the learned botanists were wrong.

By means of the popular nomenclature of common ornamental plants, one is able to see how those uninstructed in botany readily classify things according to floral structure. Everywhere lovers of flowers have a group of plants which they call by the collective name of lily. This happens to be many times more comprehensive L. 'Ray, Historia Plantarum, vol.'ii, I 385 ( 1683 ). 
than the lily genus of the modern professionals; though not so widely different from that of the books of botany of some centuries ago. It embraces Lilium, Fritillaria (Checkered Lily), Hemerocallis (Day Lily), Amaryllis (Belladonna Lily), Vallota (Scarlet $\mathrm{Lly}$ ), and many another genus of liliaceous and amaryllidaceous plants, besides Convallaria and the members of several iridaceous genera. All of these have showy flowers of the same morphological type as that of the true lily. And to this floral type even the white funnel-form spathes of certain araceous plants have been associated, as the name Calla Lily plainly betrays; though it is not to be doubted that the entire, narrow, veinless foliage of all these plants has helped in the making of this popular generic synthesis. And then, on the part of the botanists, the analyzing, assorting, and systematically arranging of these diverse elements of the primitive genus lily-the genus as even now, I say, accepted by a great multitude of mere flower lovers-has occupied a great number of taxonomic specialists during later centuries. The carefully gathered records of the gradual evolution of our present taxonomy of the lily-flowered plants would fill a thick volume; would most perfectly establish the fact that those botanically untaught sometimes classify by the flowers; would illustrate how different generations of professed taxonomists have made their various appeals to different organs, some to the flowers chiefly, others giving much weight to considerations of roots, bulbs, and corms, while others were more influenced by consideration; of the pericarp and seed. And such a book, in its completeness, would form an instructive epitome of the whole history of botany.

It would be as easy to produce instances of a primitive classifying by characters of the root; or, at least, of those subterranean parts of plants which, until within a very recent period, were universally confused as roots. But it may be unnecessary to multiply proofs of the existence of an almost more than fragmentary, and really rather extensive system of what one may paradoxically denominate pre-botanical botany. Enough may have been said already for the accentuating of the opinion that there are beginnings of our science which the historians should not have overlooked. It has been out of those crude beginnings that learning and philosophy have developed what we now call the real systematic botany. They are even the prothallium from which at length there has arisen the frond of whatever strength and symmetry and grace there may be in the now accepted taxonomy of plants.

This condition of things being once seen and admitted, we shall 
for the first begin to be able to understand, to appreciate, and to interpret the earliest botanical authors; not those only of ancient Greece and Italy, but of the fathers of botany in England, in France, in Germany, and Switzerland; a worthy company whose true position seems to me never to have been half understood, and whose works have therefore more or less completely baffled the attempts of profound scholars and eminent botanists who in the capacity of historians, have sought to elucidate the texts of these forefathers and to show what they severally accomplished. Botany did not begin with the first books of botany, nor with the men who indited them; though every historian of the science whom I have read has assumed that it did. The most remote and primitive of botanical writers, of whatever country or language, found a more or less extensive vocabulary of elementary botany in the colloquial speech of all. The chief organs of plants-stem, trunk, branch, leaf, flower, fruit, pod, seed, root, tendril, thorn, and a multitude of others-had been discriminated and named; the organs even known by all who had acquaintance with plants and trees, and the names were everywhere in use. Even the functions of several of the organs had been correctly ascertained before ever a line of botany had been written; most probably even before letters had been invented. The improvement of wild things by cultivation, the propagating of the newly acquired sorts by cuttings, by division of perennial roots, and, in the case of trees, by grafting, are likewise arts that seem to antedate history; as do also the designating of different varieties or species that are evidently nearly akin, by twofold names, one generic, the other specific or varietal.

All these conditions being recognized, a new and peculiar difficulty will confront the critical student of a protobotanical author. It will in exceptional cases seem doubtful as to whether a given fact or generalization is the fruit of that author's own investigations, and therefore new with him, or whether it be something already long understood and accepted, which he is but placing upon written record. It is, however, a kind of difficulty that gives zest to the study of classic texts; and many such doubts may give place to certainty, or something near it, after persevering examinat:on, and comparison with other passages that are not of doubtful import.

I am unwilling to conclude this introduction without repeating it, that the essence and substance of botany proper are organography and the logical deductions that we draw from organography. They may not be said to be the whole of the science; yet duly and comprehensively considered they will be found to come near it. 
The line of the development of organography-organography as necessarily including terminology-is that along which a truly coherent and philosophic history of botany must needs be written. The condition is one that will entail the expenditure of incalculable time and unremitting toil; but the cost of time and energy must not be counted if anything beyond disconnected and fragmentary paragraphs of history are to be the outcome. 


\section{CHAPTER I}

\section{THE RHIZOTOMI}

IT is characteristic of all very early phytography that the root, that least obvious and most hardly accessible of plant organs, is as carefully described as are the stems, the leaves, and the fruits. This fact that the first of all describers of plants should have taken the root into account, and that so uniformly and so particularly, must seem strange enough to every thoughtful botanist of later centuries; it is in such marked contrast to the descriptive usages with which we of the present are better acquainted.

In the voluminous and carefully technical phytographic works of the eighteenth century and the nineteenth, one may chance upon successive pages filled with descriptions of scores of species, about the roots of which not a word is said. Nothing like this occurs in any book or chapter of Theophrastus, Dioscorides, or any other classic botanical writer. In the case of every species of herbaceous plant, and of many that are woody, they do not conclude a description without telling us what the subterranean parts are like, whether fibrous or fleshy or tuberous or bulbous, usually informing us as to the colors of these organs, as well as the properties of them when they are known to have any. And so carefully did the fathers who wrought a revival of botany in the sixteenth century follow those classic models that, in their illustrated folios, never a plant is figured the root of which is not as faithfuly delineated as the foliage or the flower. Even in the letterpress accompanying the plates of Brunfels, Fuchs, Tragus, and others, the root is as well described as the foliage, and much better than the flower. All this for the simple reason that the great masters of remote antiquity had set them the example. But how did it come to pass that the ancient Greek botanists were so almost singularly familiar with the underground parts of plants, and that they so accentuated the importance of them to phytography? One would not have expected this, and it seems almost anomalous. No one who ever went forth to make philosophic conquest of the vegetable kingdom 
was confronted at the outset by the roots of plants. These parts are recondite. He who for any purpose would inspect a root must undergo the labor and inconvenience of digging about the plant, wresting that root from its hiding-place, and then cleansing it, so that its characteristics may become visible and tangible. When all is done, there is a great sameness about roots. They do not promise much aid to him who would find marks by which to distinguish between like and unlike. Stems present a much greater diversity, and either leaves or flowers or fruits a hundred times more differences by which to distinguish plants, than do these underground parts. It being granted that the function of the root as a vital organ was thoroughly understood, as it appears to have been from the earliest historic period, still, as regards early descriptive botany, there would have been less reason to be surprised if the early fathers had commonly ignored it; or at best had made as little account of it in their descriptions of species as most of the modern systematists have done. And there must be a philosophy of this very ancient and once universal appreciation of the root as a subject of phytographic notice equally with stem and leaf. The cause must, if possible, be ascertained.

If the ancestors, even somewhat remote, of the first botanical philosophers had been savages such as, in dearth of animal food, had found the subterranean parts of many a wild plant available in its stead, then would there have been some show of reason for that singular prestige which roots had obtained so almost primevally. In the transition from savagery to civilization such rootfood plants would have come into cultivation, where they would have held their place and been well known to enlightened posterity. But at the time when writing about plants began, at least with the Greeks and Latins, roots and bulbs constituted but an inconsiderable part of their table fare. The bulk of their farm and garden products were the cereals, orchard fruits, pot-herbs, and salads. The ancestry of the philosophers for centuries, possibiy for millenniums, had been highly civilized, perhaps to the degree of having lost the traditions of nomadic life and the feeding upon wild products of the plains and woodlands.

In this civilization, however, the art of medicine held an important place; and in this circumstance we have a clew to that predilection for describing so faithfully the roots of everything which is so almost peculiar to the phytography of the ancients and their sixteenth-century imitators.

Throughout the whole period of Greek antiquity there was a 
class of men who followed as a regular business the gathering, preparing, and selling of roots and herbs that were of repute in medicine. It was of course naturally inferred and easily ascertained that whatever properties perennial herbs possess are concentrated in their subterranean parts during the season of the plants' rest in autumn and winter; so that what were called the roots of plants formed the bulk of the materia medica. All this the very name of rhizotomi, root-gatherers, sufficiently declares.

The botanists of antiquity, that is to say, they who investigated the plant world as philosophers rather than as economists, inform us that the rhizotomi were mostly unlettered men, usually more superstitious than scientific, observing an extensive ritual in the digging as well as in the after preparation of their simples; evidently mixing medicine and magic after a manner almost universal in the early history of the healing art; as often attributing to their preparations magic virtues as medicinal. Concerning some of the ceremonies of the rhizotomi we have information. ${ }^{1}$ There were various prayers and incantations to be said or sung. Some kinds of roots were to be dug in the daytime, some others by night only; the powerful plant hellebore, only after the observance of various precautions. The point of a sharp sword must be drawn three times around certain roots to make them more efficacious. The gatherer of some sorts must be careful to face the east while digging. In the case of others he must stand on the windward side of the plant. Some require to be collected by one newly anointed with oil. As preparatory to the culling of other kinds, the rhizotomos must eat garlic and drink wine. As modern and as learned an author as Kurt Sprengel relegates all those observances without discrimination to the category of foolish superstitions ${ }^{2}$; this, as it seems to me, inconsiderately. There are plants enough the exhalations of which are so deleterious that persons of delicate organism may be uncomfortably affected by the mere passing close to them on the leeward side, of a breezy day. Any discreet American botanist not immune against Toxicodendron vulgare, if tempted to gather specimens of it, would use among other precautions that of holding himself to the windward of the plant if there happened to be a breath of air stirring. His act would be adjudged sane and reasonable. Another such precaution might be that of using gloves while handling any parts of the plant; whereas an old-time oriental,

1 Theophrastus, Hist., Book ix, ch. 9.

2 Sprengel, Hist. Rei Herb., vol. i, p. 63. 
with whom the anointing of the body with scented oil was a common practice, might successfully use oil instead of gloves while gathering particularly acrid herbs and roots. Also when one is informed that the ancient drug gatherer never proceeded to dig certain roots but with breath laden with an odor as intolerable as that engendered by garlic and alcoholic drink, there is still no reason to charge that to superstition; any more than the surveyor or handicraftsman, whose work for the day is in the midst of a steaming and unwholesome marsh or fen, makes free use of tobacco smoke as, by the physician's counsel, tending in some degree toward immunity from malarial influence. With us who believe so much in the efficacy of malodorous disinfectants as bringing immunity from infectious and malarial disease it should seem natural to attribute similar precautions to Greeks of 4000 years ago, especially when assured, as we may assure ourselves, that even at that remote period one of the rhizotomi propounded the theory, now in our day revived, that myriads of germs, minute, invisible, permeate every atmosphere.

Such partial apology for some of the so-called ritual observances of the rhizotomi is no digression. The historians have usually referred to them as in large part a body of superstitious fakers. Such, to a degree, many of them may have become in the long course of centuries during which their profession flourished. Superstitious observance is often enough the end of that which in the beginning was a reasonable and sensible measure of precaution; and it is not a legitimate office of history to exaggerate the differences subsisting between an earlier and a later age or race. The age of superstition even as regards medicine and pharmacy, though passing it may be, is not yet quite past. If the scholarly Sprengel cites the ceremonies of the rhizotomi with impatience, it is because he is influenced-as many another passage in his work makes it evident - by an almost morbid abhorrence of everything that to him has the appearance of a superstition. If anything appeared to be an empty ceremony, he could not tolerate the thought of it long enough to examine into the possibility of its having had an origin that was scientific and utilitarian.

If the rhizotomi were mostly illiterate men and quacks, still there were exceptions. Here and there among them there seems to have been a man of letters; and a few investigated plants more or less scientifically, and wrote books. The names of several such have been handed down through history, together with some of the more original and remarkable of their sayings. THRASYas MANTIN- 
Exsis is mentioned by Theophrastus as one of the worthiest among them, because as if ignoring the common beliefs about magical effects he gave himself to the investigation of the properties of plants. He seems to have been the original proponent of the doctrine that the good or bad effects of a medicine may depend upon the temperament of the individual patient; a proposition which has met with some acceptance, at least outside the profession, if one may judge by its having been long since crystallized into a proverb, that what is medicine to one, may be poison to another. The idea is revolutionary, though without yet having brought about much of a revolution. To this same Thrasyas is ascribed the compounding of that vegetable poison, so frequently in use with the ancients, which never failed to bring a speedy and absolutely painless death. ${ }^{1}$ Theophrastus devotes two chapters to an account of the pharmacological researches of this Thrasyas, and those o his eminently successful disciple Alexius, and of those of a third of the same school of intelligent and really scientific rhizotomi, Eudemus of Chios. One and another of these men, living at periods so remote as barely to fall short of being prehistoric, tested in their own persons the adaptability of the human system to the harmless use of drastic and poisonous vegetable substances. Beginning with small doses and increasing them gradually, it was ascertained that one might after a time consume without bad results such a quantity of hellebore, for example, as under ordinary conditions might have proven fatal. Using at first earthen pots and pans in the probing of questions about possible or probable antidotes to certain poisons, they would proceed, under the light gained by such experiments, to the using of their own stomachs as the crucibles. ${ }^{2}$ And the reports of these instructive and daring experiments, together with the names of the men who made them, were either written and subscribed to at the time or else handed down by tradition to the time of Theophrastus who gave them permanent record.

Among the earlier rhizotomi there was a famous one named Cleidemus, who wrote upon the subject of electrical storms so as to have been quoted by Aristotle in his Meteorology. ${ }^{3} \mathrm{He}$ also investigated diseases of plants, especially of the fig-tree, olive-tree, and vine. Cleidemus is therefore the earliest of vegetable pathologists. And what may be more interestingly significant is this, that Theo-

: Theophrastus, Hist. Plant., Book ix, ch. I 7 .

2 Ibid., ch. I 8 .

3 Aristotle, Meteor., Book i, ch. 2. 
phrastus credits him with having maintained that there is the closest analogy between the organs of plants and those of animals. Information like this can not fail to awaken regret that the writings of Cleidemus have not survived; it would now be so very interesting to know whether this genius o a forgotten time went so far beyond those of later periods as to have apprehended the existence of breathing organs and those of sex in plants.

Hippon was among the rhizotomi who philosophized about plants in general, and wrote books. His writings are quoted by both Aristotle ${ }^{1}$ and Theophrastus, ${ }^{2}$ and he appears to have been the earliest among students of plant life and form to venture the opinion that all cultivated trees, shrubs, and herbs have been derived from wild ones, and are susceptible of reversion to their pristine condition. It is the earliest hint-and a very early one, apparently unknown to the annalists of evolution-of what cultivation may accomplish in the way of 1ransformation. But the doctrine must have had the sound of a heresy verging toward atheism in the ears of a populace that had never questioned the proposition that every cultivated plant and tree had been coeval with the human race, and had been so created at the first.

But it is not that small, better-educated, more reflective, and philosophizing contingent of the rhizotomi, or the possible influence of these few upon early botanical theory, that we are just now chiefly concerned with. It is rather that in this whole body of those who, for so many pre-Theophrastan centuries, followed the root-gatherers' calling, we have the men who securely established that precedent, from which the earliest philosophic students of and writers about plants did not break away, of taking full cognizance of those among plant organs which nature had most deeply concealed, as if they were perhaps the last and the least to be considered. It was the example of the rhizotomists, in their books of plant description extant in the times of Aristotle and Theophrastus, that impelled Theophrastus and others after him to give the form, texture, color, odor, flavor, as well as the active properties, when these were known, of the roots or underground parts of almost every plant. And when, as already noted, it is seen that from Dioscorides and Pliny down through the middle ages, and out to near the end of the seventeenth century, authors in general described and figured the roots of every weed and grass and bush and tree, it will be conceded to have been the lot of the half-illiterate

1 Aristotle, De Anim., Book i, ch. 2.

2 Theophrastus, Hist Plant., Book i, ch. 6. 
rhizotomi to make their peculiar impress upon the character of descriptive botany, an impress that should last for well nigh two thousand years 1

The occupation of the root gatherers is by no means peculiar to Greek antiquity. In every part of the world it may be as old as, or older than, he beginnings of civilization. Nor is it probable that in Europe there was any interruption or cessation of the occupation during the two thousand years intervening between the time of Homer and Hesiod and that of the Renaissance. The botanical writers of the sixteen h century, particularly those of middle Europe, refer to the practices, and even to the opinions, of such as ransack the woods to gather roots and herbs, sell them to the druggists and to the peasantry whom they serve in the capacity of physicians, and from whom the educated and philosophic students of plants themselves sometimes gain valuable information. Nor would it be safe to say that the rhizotomi are even now everywhere obsolete. Their traces are very plainly legible in the popular nomenclature of North American plants. Every common name into which root enters as a component is one that had its origin with the "herb doctor," or "root doctor," as he was called; perhaps not a few of the names were borrowed, along with some information about the plant's virtues, from the aborigines. ${ }^{2}$

${ }^{1}$ It was Valerius Cordus, the greatest if not the only botanical genius of the first half of the sixteenth century, who first gave expression to the opinion that, from the morphologic and phytographic point of view, the importance of the root had always been overestimated. He set the example for a reform of descriptive botany in this particular; but, as usual with men of genius, he was a century in advance of the ideas of the multitude.

${ }^{2}$ The following are illustrative examples: Alum-root, Blood-root, Bowman's-root, Culver's-root, Cancer-root, Canker-root, Black Snakeroot, Button Snakeroot, Seneca Snakeroot, Indian-root, Musquash-root, Colicroot, Pappoose-root, Pepper-root, Pink-root, Red-root, Yellow-root, Sheeproot. It were easy to double the number of such names of American plants, not one of which was assigned either by a learned physician or a professional botanist. 
THEOPHRASTUS OF $;$ ERESUS. B. C. 370-286 (or 262).

LINNEUS, in the practice of his favorite art of systematizing. classified not only plants but the writers about them. The writers he distinguishes primarily as Botanists, and Plant Lovers; recognizing as Botanists only such as treat of plants from some philosophic or scientific point of view. Choosing his illustrations from the annals of remote antiquity, he names among the earliest of the Greeks who wrote of plants Hippocrates ${ }^{1}$; but because he wrote of plants only in the interests of medicine Linnæus styles him Father of Medicine; a title that had been conceded to that worthy ages before Linnæus, and will be accorded him until the end of time, no doubt. Similarly Aristotle, who is also known to have written upon plants, but whose volumes on that subject have been lost, is down in the Linnæan list of ancient celebrities as Prince of Philosophers. To Theophrastus, however, he accords the title Father of Botany. From this opinion, far from having been newly promulgated in Linnæus' time, there has been no dissenting voice. On the contrary, Albert Haller, one of the most learned men in Europe in his day, and a botanist $o^{\circ}$ such renown that Linnæus held him in reverence, and also in some fear, denominates Theophrastus "the first o" real botanists in point of time." 2 Curtius Sprengel in the nineteenth century, having rehearsed the names of a long line of ancient authors who had written more or less concerning plants, says: "But the most illustrious of them all, and the true father of botany, was Theophrastus Eresius." 3 If the author of the latest of nineteenth-century volumes of botanical history, Julius von Sachs, makes but passing mention of Theophrastus, along with the names of Galen, Dioscorides, and Pliny - as if he had not been otherwise a botanist than they-he may be more or less excusable upon the

1. Linnæus, Philosophia Botanica, §9.

2"Primus verorum botanicorum." Haller, Bibliotheca Botanica, vol. i, p. 3 r.

3 "Celeberrimus autem omnium, verus rei herbariæ parens, THEOPHRASTus fuit Eresius." Sprengel, Historia Rei Herbariae, vol. i, p. 66. 
ground that he was not engaged upon a general history of botany, but only dealing with the short period intervening between the years I 530 and 1860 of our era. However, that Sachs had no acquaintance with Theophrastus, or even of Dioscorides, is proven by this, that he credits his sixteenth-century German compatriots with having gone straight to nature and described plants originally, whereas the truth is that nearly all the plant descriptions occurring in Brunfels and Fuchs, are almost word for word translations of the ancient paragraphs of Theophrastus, Dioscorides, and others; sometimes with a few words of their own added, as often with none. And as regards that exact and intimate knowledge of plants which comes of the careful study of them alive and growing, it is safe to say that all which Sachs' sixteenth-century German fathers knew combined, would have amounted to but a fractional part of Theophrastus' knowledge, and that much of their own observing had been suggested to them in their reading of his books. An abstract of Theophrastus' work should enable the unbiased and impartial to judge for themselves whether scientific botany had its beginning with those good German herbalists of the sixteenth century, or with an immortal Athenian or two who had lived, studied plants long and carefully, lectured to thousands of students, and written down the substance of their botanical lectures seventeen centuries earlier than they.

Life. Mitylene, a large and rich island in the Egean Sea close by the coast of Asia Minor, was famous millenniums ago as having given birth to many an illustrious personage. Arion and Terpander, ancient masters of the art of music, Alcæus and Sappho, unrivalled among lyric poets, as learned critics gather from the fragments of their masterpieces that remain-these names but head the list of celebrities that had been born on that island in the earlier half of the thousand years next preceding the beginning of the Christian era. How very famous this island was for the excellent quality of its products, material, artistic, and intellectual, is shown in the fact that Greeks and Romans of a somewhat later period, wishing to bestow the highest praise on anything, whether it were a piece of music, a verse of poetry, or a cask of wine, were accustomed to pronounce it Lesbian-that is, fit to have come from Lesbos, the name by which the modern Mitylene was known anciently. Such are a few of the available hints of the envi.onment in which the protobotanist was born in the year B.c. 370 . His birthplace was Eresos, the most important town of the island, whence he has been styled Eresius-the Eresian, perhaps to dis- 
tinguish him from others of his time who bore the not uncommon name Theophrastus. His father's name, Melanthus, and that of his boyhood's teacher at Eresos, one Leucippus, have found a place in history only as associated with that of this child and youth whom they called Tyrtamus. We shall be warranted in inferring that the child was 0 : unusual gifts and marked by nature for the intellectual life; also that Melanthus, the fuller, was in comfortable circumstances financially, for the educational advantages that were given the boy were then somewhat rare and costly. How well the child had improved his opportunities is attested by this, that while as yet but a'youth, he was away beyond the farther shore of the Egean Sea, at Athens, and there numbered among the disciples of Plato. All historians of the period credit him with having been under that philosopher's instruction before coming to Aristotle; and as Tyrtamus was only twenty-two years old when Plato died, it is plain that the enrolment among Plato's pupils must have been made when the subject of our sketch was but a youth-possibly a precocious, eager, ambitious boy only.

The histories all read as if Aristotle's marked friendship and efficient patronage had had very much to do with establishing the fame and directing the luminous career of Theophrastus. There must be a large measure of truthfulness in this representation, though it is more than possible that it is somewhat exaggerated in Aristotle's favor; and history should take cognizance of the universal and even necessary fact, that in great friendships the influences are mutual, just as when, in the heavens, two planets move to their conjunction each influences irresistibly the orbit of the other, draws it somewhat aside from what should have been its path. The story, as always rather too briefly told, leaves an impression, not intended to be made, of great disparity between the two both as to years and some other controlling influences; seeming to represent Tyrtamus as the brilliant young favorite, and Aristotle the elderly admiring teacher and foster-fatherly patron. That the youth, as if irresistibly obedient to an old and revered master's mandate, should have renounced the name Tyrtamus that he brought with him from the paternal home in Eresos, so that henceforward he should be Theophrastus, is something to create almost a conviction that the one was old and masterful, the other young and submissive, and not to be thought of as an influence upon the thought and action of the elder. Such impressions are wrong, and must vanish by a comparison of certain well authenticated dates, which show that Aristotle was Theophrastus' senior by only 
fifteen years; also that the two were fellow students under Plato. Aristotle from the age of seventeen to thirty-seven had been Plato's pupil. Tyrtamus, it may reasonably be assumed, entered Plato's discipleship at seventeen if not earlier. If so, he may have been Aristotle's student companion there for from five to seven years before the day when Aristotle left Plato and opened a Lyceum of his own. Shortly after this Plato died; and then, unless he had done so even earlier, Theophrastus became Aristotle's student. And as for this new name, it is not necessary to suppose that it was bestowed merely as the flattering compliment paid a highly promising young student by an old preceptor. The two were in truth much upon an equality. They were companions and much attached friends, with no signal disparity between them as to years; so that the change of name may well be thought to have been brought about by mutual agreement.

I can not but wonder at the boldness with which Meyer pronounces this change of name from Tyrtamus to Theophrastus to be a fable. ${ }^{1}$ No one else has questioned the authenticity of this part of the biography; and he has not been able to adduce so much as one valid reason for his pronouncement against its truthfulness. One of his supposed reasons is, that Aristotle was no flatterer. To have rendered this an argument, Meyer should first have disputed the sincerity of Aristotle's friendship for Theophrastus; for between genuine and devoted friends flattery is impossible. But he says the name Theophrastus was not uncommon among Greeks of the period, which is equivalent to saying that, if the philosopher had been going to give his disciple a new name he would have selected some uncommon name, or else that the Eresian had always been Theophrastus and never Tyrtamus. That "such a changing of names was unknown" is quite as inane as the rest of this historian's argument upon the subject. Not one in ten thousand of the ancient Greeks has been known to us by any name at all. Even of that comparatively very small number whose names we have heard, who shall say that none besides Theophrastus ever underwent a change of name because the event if it happened was not recorded? There is not the least reason for thinking that with Greeks, in passing from one age or condition of life to another, the taking of a new name was uncommon. There were distinguished examples of it among some of their neighbors, the Hebrews, for example. Meyer concedes that this "fable" about Theophrastus was universally received as a fact by all the ancients. and we add that it ' E. H. F. Meyer, Geschichte der Botanik, i, p. 147. 
is as perfectly authenticated as any other fact or incident in Theophrastus' life. He who can make fiction of this part of it may upon similar grounds invalidate, piece by piece, the whole biography. No reason having been given for doubting about this incident, every one to whom the appellation is not meaningless will see that Tyrtamus was a grotesque name, if not a ridiculous one, to be borne by a scholar and orator of commanding presence and predestined great renown. The young man himself, as well as his master and friend, must have realized this; and it is hardly to be doubted that the displacement and rejection of the unsuitable name was the first object which the change had in view; and that what the new name should be was but a secondary consideration - a matter of less importance. Indeed, the biographer Laërtius relates that at first the Eresian began to be called Euphrastus, and then later Theophrastus. Posterity should be grateful that the change was made; and also grateful for that devoted attachment between the two philosophers by which it came to pass that the elder of them, dying in middle age, had his own work taken up, and carried forward with success during almost another half-century. ${ }^{1}$ It was such a friendship as led Aristotle to give to Theophrastus his own library, said to have been the richest one then in existence, and to have included the manuscripts of his own works, a treasure which by means of Theophrastus' jealous care was almost singularly preserved, and handed down to posterity well-nigh complete. Also the botanic garden which Aristotle had established at Athens was made a gift to Theophrastus; by whom also it was newly equipped, variously improved and adapted to greater usefulness; this, too, on a scale so extensive, that a wealthy friend of Theophrastus and benefactor of science is named in history as having borne the expense of those improvements. ${ }^{2}$ The fact of the existence of this Athenian botanic garden will explain how Theophrastus, occupied as he was with the management of, and also engaged in teaching in, a school of two thousand students, with no time or opportunity for travel, gained so intimate a knowledge of the life histories of many plants as he surprises us with in certain chapters of his books. He had studied in that garden at morning, noon, and

1 Aristotle died at the age of sixty-three years. Theophrastus was then forty-eight; and, according to his own statement in his preface to that book entitled Characteres, he had finished it in his ninety-ninth year. St. Jerome says that Theophrastus died at the age of 107 .

2 The name of this first wealthy patron of botanical science was Demetrius Phalereus, according to Laertius, vol. i, p. 350 . 
evening for perhaps sixty years or more when, almost a centenarian, he wrote such clauses as the following in his will. They should help us to a realization of the scientific zeal and activity of a :orgotten time.

"I bequeath to my friends, who are specially named in this my Will, ${ }^{1}$ and to those that will spend their time with them in learning and philosophy, my garden, walk, and houses adjoining; upon condition however that none of them shall claim any particular property therein, or alienate them from their proper use; but that they shall be enjoyed in common by them all, as a sacred place where they may familiarly visit one another and discourse together like good friends." 2 And further: "I desire to be buried in any part of the garden that they shall think most suitable; charging them not to be at any superfluous expense either upon my funeral or upon my tomb. Which being done, my will is that Pomphylus who lives in the house take care of everything, as he did before." 3

That Pomphylus was an overseer, directing the labors of bondsmen gardeners owned by Theophrastus, comes out incidentally in another clause. "As for my boys, it is my will that Molo, Cymo, and Parmeno be forthwith set at liberty. As for Manes and Callias, I will not have them given their freedom until they shall have labored four years longer in the garden, so that there be no fault found with their labor and diligence; but after that, let them have their freedom." Besides these five, two others are mentioned. "I give Cano to Demotimus, and Donax to Neleus." 4

By means of this testamentary document, the transcript of which has been fortunately preserved, one is able to realize something of the extent, and even of the perpetuation during perhaps three generations, of this pristine garden for biologic research. And this realization will be exceedingly helpful toward a comprehension of the magnitude of Theophrastus' work along these lines. The philosopher was never, like many of his class and in his time, a traveller. He did not devote any more than a fraction of his time to botany. His writings on this subject amount to perhaps not more than a twentieth part of all that he did in the line of written authorship. And there are chapters in the Historia Plantarum that

1 Hipparchus, Neleus, Strato, Callio, Demotimus, Callisthenes, and Cresarchus are their names, according to Laërtius, vol. i, $36 \mathrm{r}$.

2 Laertius, vol. i, $35^{8}$. 3 Ibid., 359.

4 Laèrtius, vol. i, 360 . Note also the botanical names of the two young slaves Cymo and Donax. 
are so crowded with facts about seeds, seeds in process of germination, young seedling plants and older ones, observations upon this plant and that shrub as they appear in spring. summer, autumn, and winter, that, all being considered, we should have wondered greatly how this most untravelled and sedentary of the great philosophers had gained all this minuteness of knowledge about the little things of plant life had we not been informed concerning this great garden in the midst of which he dwelt, taking his daily recreation along its paths, and among its seed beds, and within the bounds of which, obedient to his last request, they buried him.

Theophrastus was a voluminous author, having written upon a great diversity of topics. The biographer Laërtius gives the titles of 227 treatises. Not many of these have reached us; but among those preserved are the Historia Plantarum, in nine books, with the fragment of a tenth, and the De Causis Plantarum, originally in eight books according to ancient records, of which the last two have long been lost. The following paragraphs are the result of a prolonged and laborious study of the principal work, the Historia, the edition quoted being that of Stapelius, published at Amsterdam in 1644 .

As we have already seen, ${ }^{1}$ there existed in the old Greek literature that was before Theophrastus, many a trace of properly botanical observation and reflection, so that he is not in such wise the father of botanical science as that no one before him had recorded a philo ophic thought or suggestion about the plant world separately considered. Yet he is, in most cases which he cites, the sole perpetuator o the name and fame of such as Menestor, Hippon, and Leophanes whose passages he quotes and in quoting has saved from oblivion. There is, then, no reason to suppose that in his philosophizings about plant life he had been helped by any predecessors beyond that for which he has given them full credit. It has been observed by historians and critics that a few passages in Theophrastus are also in Aristotle, unaltered, and uncredited to their real author. This hardly merits notice. It is undoubted that the enlistment of Theophrastus' great talents in the service of botany was secured by Aristotle; and it is as certain that the alliance between these two celebrities of antiquity was that of the most devoted friendship; that at Aristotle's demise all his manuscripts, published and unpublished, complete and fragmentary, were gladly bestowed on Theophrastus. They became his property.

1 See pp. $4^{8-50}$ preceding. 
He was free to dispose of them, to publish any parts of them, according to his own judgment. Modern science and erudition have no example to show us of like community of even intellectual property between two illustrious friends. Moreover, from the fact of Theophrastus' having lived and studied and written during half a century after Aristotle's demise, we are warranted in thinking of him as of one who had acquired a great store of knowledge about plants beyond all that to which Aristotle in his briefer day had attained.

As having been the author of the oldest distinctively botanical treatise that is extant, the place of Theophrastus is unique, and invites to special and careful consideration. He writes from the midst of an advanced civilization; a state of society in which there is much farming, extensive cultivation of the vine and olive, fruit growing, market gardening, and cultivating of medicinal, aromatic, and ornamentally flowering herbs, shrubs, and trees; a time when many improved varieties of all sorts of things have been derived through cultivation, and when it is already perfectly well known that such improved varieties can not be depended on to come true to seed, but may be preserved, and the stock of each increased by division of roots, by cuttings, and by grafting. It is also a time when the very masterpieces of literature-some of them even in Theophrastus' time ancient and classic-abound in facts and fancies and myths and fables about flowers and fruits, shrubs and trees. Of course all obvious and familiar parts of plants - their organs - have their names. These are a part of the common vocabulary of things. Also group names for growths that are alike are in as universal requisition. If a genus evidently consists of several different kinds, be they what the botanist of the present would denominate species, or be they notable varieties only, each such kind is designated in speech or writing by a cognomen; so that a binary nomenclature, precisely that which all farmers, gardeners, and foresters find needful and have always created and employed, is perfectly established.

Such, in brief outline, is what Greek civilization had attained to in the way of experimental knowledge of plants, independently of all philosophy, and without help from the philosophers. And if Theophrastus had been less than a botanical philosopher, and if as a mere annalist he had but recorded the untaught industrial and experimental botany of his period, together with that very considerable vocabulary of botanical terms which then formed a part of the Greek language, he would still have done us an ines- 
timable service; though masters of the science in the seventeenth, eighteenth, and nineteenth centuries of our era would not have styled him Father of Botany.

In our study of this maker of the first Landmark in the History of Botany the main object must be that of discovering in what ways, under what limitations, and yet how well, he accomplished the placing of knowledge of plant life and form upon the list of the sciences.

Method. That a treatise be recognizable as scientific it must be methodical. It is even a necessary characteristic of it. There must be a principle, or a set of principles according to which the facts or propositions find an orderly arrangement. This does not, however, imply that the method or system be of some particular kind, as, for example, that in botany one should be required to arrange the matter of one's treatise according to what are conceived to be the natural affinities between plant and plant. The author who writes botany from the industrial point of view, if he so elect, may discuss his plants in the order of their relationship in families, genera, and species; or, ignoring taxonomy of that sort, he may arrange them according to the nature of their serviceability in household economy and what are called the useful arts; may discuss in successive chapters food plants, drug plants, textile plants, vegetable dye-stuffs; trees, as supplying timber, fuel, oils, gums, sugars, resins, nuts, etc. That botanical matter so arranged may be scientific can not successfully be controverted.

Theophrastus of Eresus might have adopted such a method as this last. He was abundantly capable of discussing the plant world from the economic and utilitarian standpoint; indeed, had he so arranged the substance of his work he would but have been following established precedent. Every treatise on plants which was extant in his day was of the natur of agricultural, horticultural, or medical botany. There was not yet any other method of arrangement for botanical writing but the economical. Furthermore, his own chapters everywhere abound in references to the qualities of plants, and their uses in the economy of human life; though such references are commonly supplementary to the statement of other and different considerations. The very title of his work, History of Plants -in more idiomatic English, The Story of the Plants-seems to look toward an investigation of this realm of nature for its own sake, the vegetable kingdom thought of philosophically rather than industrially. No work was yet in existence, unless one by Aris- 
totle which has been lost, in which plant organ was discussed in relation to plant organ, and the kinds of plants in relation to other kinds. The prevailing attitude of mind respecting the plant world was not such as would tend to the encouragement of other than utilitarian views of it. That these objects were brought into existence only with reference to man, and for his use and benefit, was even a part of the religious belief. And so deeply seated and generally prevailing was this sentiment that it is said the students of Aristotle and of Theophrastus became objects of ridicule with some of the literaries, poets, satirists of the time, because of their going about the country picking up and curiously peering into the least little things of nature, such as were of no possible use. And one may not attribute to antiquity alone these prejudices against philosophic nature study; for they rule the mind of untold millions even now. Antiquity, in this phase of it, is with us still, in the ideas of the uncivilized races, and also in rural districts of the lands of the enlightened. Not many a botanical traveller and explorer along the frontiers and in the remoter country sides has failed to be accosted with friendly queries respecting plants of which he has been seen to be making specimens: What use has this plant? What is that kind good for? And what betrays in these good-naturedly inquisitive rustics their complete subjection to the pre-Theophrastan utilitarian botany is, that when the man of science answers frankly that he knows no use whatever for the plants in question, he is not believed, but is silently credited with wishing, for his own pecuniary advantage, to keep their use a secret. The adherents of this archaic philosophy of the vegetable kingdom are, I say, doubtless numbered by thousands on all the continents; people who have not heard of any other; and we have no proof that another had been any more than merely suggested before Theophrastus.

In the Second Chapter of the philosopher's First Book there is presented the following list of the external and obvious organs of a highly organized plant, i.e., a tree: root, stem, branch, bud, leaf, flower, fruit. ${ }^{1}$ I recall that upon first reading these initial chapters of Theophrastan botany I was quite startled to find here this complete and faultless statement of the external organs of a tree or shrub; to be confronted with it even here, and be made to realize that it is so very, very old; that our own masters and tutors of a few years ago did not invent it, neither their own immediate

1 Hist., Book i, ch. 2 . 
botanical ancestry, but that all so-called modern botany has this fundamental of plant-morphology from old Theophrastus, and all unawares. But the surprise passes. The sentence is so simple, so natural, so logical, the connection between term and term so perfect, that one doubts that it could have been done otherwise; and may be disposed to say to himself that any botanist of whatever epoch might have gone out on a morning walk, looked at a number of different kinds of growths, come in and written down that methodical proposition offhand. It is extremely improbable that it was so done. It is next to certain that it cost its author a great deal of careful observation and prolonged study and reflection. The sentence is studiedly methodical, and no less a dictum of science than a work of art. It is easy to forget that, as in art, the production from which all evidence of the artist's anxious care and hard work has been eliminated is the masterpiece, so in science and philosophy the axiom or the aphorism which when finished reads as easily, smoothly, and convincingly as if every one always must have seen its transparent truthfulness, and as if almost any novice in that same science might have written it down in just those words-that this is the little sentence which may have cost its author the expenditure of time and mental energy with which he might have written a whole volume upon some topic that was not difficult.

If the origin of the simplest elements of universal botany is to be shown, this Theophrastan list of plant organs will have to be looked into rather particularly; will need to be studied with great care and caution. Those six or seven important terms, as our philosopher links them together, constitute the most classic piece of elementary botany in existence. The sentence has also much to reveal about the author's botanical method in general.

First of all, the terms of the sentence, root, stem, leaf, bud, etc., have not been created or invented by Theophrastus. As the names of those things they are part of the common vocabulary; botanical terms, assuredly, yet in their framing and use doubtless far antedating all written botany. That our first philosopher of plant life, he who first brought the terms together and placed them in line, altered the meaning of certain of them by giving them a more comprehensive or else a more restricted application, is easily possible; though that does not here concern us. We have but to note that this fine equipment of most fundamental botanic terms, the first botanist-as we must denominate him despite the suggestion of the paradoxical-found ready made. They and other 
such terms had been the legacy to human speech made by a primeval race of nature-ponderers, almost infinitely remote and prehistoric even in Theophrastus' time.

Observe now, that while root, stem, bud, leaves, flowers, etc., are familiar and obvious parts of a tree, they are far enough from being a complete list of such obvious parts. Viewed at close range the bark is very conspicuous; more so than either the buds or flowers in the majority of arboreal and arborescent growths; and since he has here left it out, one is obliged to think that this point was well inquired into by him; that the omission was deliberate, and the result of sound reasoning. We shall find proof by and by that he investigated the inner structure of trees; and there, among the anatomical parts of the tree as they disclose themselves in the cross-section of its trunk or stem, we shall find him cataloguing the bark. To separate organography into the two divisions, morphological and anatomical, is, then, also classic. It is another part of universally approved botanical method which originated with and was established by Theophrastus.

With that Theophrastan list of organs under consideration, modern botany at the very outset divides it into two parts, labeling one division of them the vegetative organs, the other the reproductive. The Greek has incidentally given us to know that he, too, pondered very seriously indeed the question of a natural division of his series, and that he effected one. It is as far as possible from corresponding to our modern classification of the same organs, and must needs have been so; because the only reproductive organs of plants known to Theophrastus were seeds and buds. Of the sexual organism of the flower he had no information. He was without a microscope. His dividing line between the two classes of organs is drawn, not as with us toward the upper end of the series, but near the middle of it. Root, stem, branch, bud, form the first division; and the perfect naturalness of it may be realized by observing that precisely those organs, and no more, are what one enumerates as constituting deciduous woody plants in their winter condition. No leaf, no flower, no fruit is there; yet the organism as it stands betrays no imperfection. From its deepest rootlets to its remotest twigs and scaly buds it is alive, in health, perfectly normal in every particular. What is more, every such tree and shrub on the face of the earth passes half the period of its life in just that condition, no difference whether that life period be fifteen years or fifteen hundred. It is a classifying of the external organs of a plant as permanent and 
transient; a very remarkable division of the series, as true to nature as any classification of organs that ever has been proposed anywhere by any man, and yet, as I suppose, entirely peculiar to Theophrastus' method. How thoroughly natural and scientific this proposition is, may be further shown; as also how studiously the learned Greek nature student reached his conclusion about it. It is not the deciduous tree only whose different organs fall into the two classes of the permanent and the transient. He has discovered that the evergreen trees, like the rest, acquire one set of new leaves each year, and as unvaryingly lose an old set ${ }^{1}$; so that their perpetual verdure is due to this only, that each set of leaves remains on the tree during two or more seasons. It is clear to his mind that if leaves, flowers, and fruits are to be catalogued as plant organs at all, the division of the whole series into constant organs and inconstant must be maintained. But he is even perplexed with a question of whether those inconstant and scarcely more than occasional parts are to be listed as plant organs at all ${ }^{2}$; a position which most twentieth-century readers will think very singular and strange. But must there not also have been with him a time of doubt as to the placement of certain other very common and external parts of plants? Such things as prickles, spines, thorns, tendrils, excrescences of several kinds which imitate fruits but are not-it was by no accidental oversight that these were omitted from his catalogue of plant organs. Since in the phytographic and taxonomic parts of his writing he evinces his perfect familiarity with them, it becomes certain that he surveyed with his wonted carefulness the ground of their possible right to enumeration among these other organs, and that he deliberately ruled them out. The ground of his doubt concerning leaf, flower, and fruit as admissible into the line he states fully. Being himself first a zoologist, then a botanist, and always interested in making comparisons between these two kingdoms of nature, he is aware that the fœtus of a gravid animal is no part or organ of that animal. The fruit of plants, being analogous to the animal fœetus, should be denied any place in the list of plant organs. To make this part of the Theophrastan argument quite clear to the reader, it will be needful to anticipate our study of his anthology in so far as to say that the conception of ovary and ovules as being parts of the flower is one that never entered into the mind of Theophrastus. With him those first small rudiments, as they appear still encircled by

\footnotetext{
I Hist., Book i, ch. I 5 .

2 Hist., Book i, ch. I.
} 
or concealed within their colored floral leaves, are the fruit. From this incipient stage, in which, as I say, we call them parts of the flower, the Greek held them to be the fruit, and so forward to their fuller development and final maturity, always the fruit. Whether, by the way, his doctrine of the fruit or ours is the more natural, the more logical, and the less forced and arbitrary, he may determine who may divest his mind of its every prejudgment about the case. In the light of this explanation it will be easy to see that, if the fruit be denied by Theophrastus its place in the list of plant organs, the flower, that is what we call corolla, is equally disqualified, partly on account of its intimate connection with the fruit, and partly on the score of its exceeding transiency in all cases. Furthermore, because in the thought of the Greek the flower itself was but a circle of leaves, different from the ordinary foliage only as to form and coloring, if the floral leaves must fall short of mention in the list of important organs, the green leaves must remain with them. So the catalogue would begin and end thus: root, stem, branch, bud. Indeed, his first presentation of it is in this abbreviated form. Now against his own argument for the exclusion of such parts from the list, he presents such reflections as the following. It is only when trees stand vested in their full foliage, flowers, and fruits, that they seem to have reached their fullness of beauty and perfection. That which makes for the perfection of an organism should apparently be accounted a part of that organism. And as for permanency, there are exceptional cases among animals in which certain parts are transitory. Fowls periodically shed their feathers, and stags their horns; and his last observation here is that animals and plants are in many ways so very different in their constitution that arguments from analogy must not be pressed too far. And so, after much observation and astute reasoning upon the subject, he convinces himself that leaf, flower, and fruit are entitled to places in the list of plant organs, where nevertheless they by their nature form themselves into a separate division. One can not but admire this piece of Theophrastan method, wrought out originally and laboriously by himself, and so unique; in its deepest meaning fairly amounting to a division of the organs as vegetative and reproductive, and drawing the line between bud and leaf-mistakenly, of course-instead of between leaf and flower.

There is another mark of deep study in the making of this list. It lies there, rather well concealed from our first glance, in that elegant sequence according to which the names of the organs are 
placed: root, stem, leaf, flower, fruit. Its mere orderliness pleases one, even captivates the mind to that degree that one readily believes that it is of both natural and logical necessity, and that any single modification of that arrangement would make the whole unmethodical and altogether bad. To begin at one pole of the plant axis and proceed thence without a break to the opposite pole is artistic, and therefore satisfies our æsthetic fancies. It may also be that such procession of names of plant organs is called for by scientific principle; and since our protobotanist was keenly in quest of principles and a little indifferent to matters of phraseology, we must inquire into his scientific reason for writing the root first on the list of plant organs, rather than the stem.

We have already seen that primevally the root received more attention morphologically than any other organ of the series ${ }^{1}$; that early descriptive botany is rather anomalous in this particular, and that all this came to pass through the influence of root-gatherers and their patrons the physicians and the pharmacists. Such a merely economic and commercial consideration as that which influenced men of the time in their descriptions of roots can not be supposed to have the least effect upon the mind of Theophrastus at this particular juncture, where he is engaged upon a study that is in nature purely scientific, biologic. No botanist has lived in any age of the world more capable of distinguishing between the economic and the biologic in nature study. Now in those parts of his work which are descriptive, written for the purpose of enabling the reader to identify the plant, his sequence of the organs is different. It is now stem, leaf, flower, fruit, root; another not unnoteworthy item of Theophrastan method; one sequence for the treatment of organs phytographically, and another sequence for the discussion of them biologically. The former is well suited to its purpose; for, to the great majority of observers, nothing is seen of any plant or tree but its stem, foliage, flower, and fruit; and any reader would be discouraged if not repelled by a description beginning with a full account of the root, about which part he neither knows nor particularly cares to know anything. As to the other and biological sequence, it is evident that the philosopher arrived at it only after careful and prolonged investigation. "In all plants the growth of the root precedes that of the superior parts." 2 The allusion is to young plants, whether growing from seeds or from cuttings; which latter means of propagation was

${ }_{1}^{1}$ Page 45 preceding.

2 Hist., Book i, ch. Ir. 
only less extensively resorted to by the ancient Greeks than it is by ourselves; and they knew as well as we that when a cutting set into the ground has remained for weeks and maybe months without having been increased by so much as one leaf, that only means that it is slow in forming its roots, and that until these are somewhat grown, other growth will not begin. It is improbable that this kind of fact was not of common knowledge with gardeners and orchardmen ages before Theophrastus; so that all he had to do was to verify it by experiment. But when he states that even within the seed it is the radicle which first begins to swell and grow, and that this is invariably the first part of the growing seed to appear outside the shell, ${ }^{1}$ we feel assured that these are fruits of observation on the part of no gardener, but of a biologist.

In the year 1672 of our era Nehemiah Grew, aided by a microscope (!), had repeated those investigations of the seed as germinating, and published what was but a confirmation of the view that Theophrastus had presented some nineteen hundred years before, namely, that biologically considered the root is first among plant organs, then the stem, and after them, leaf, flower, and fruit.

One must now leave the Theophrastan method in merely elementary organography, and survey briefly the outlines of his dealing with plant as compared with plant.

The philosopher has several different viewpoints from each of which he perceives the vegetable kingdom as a whole to be divisible into two parts. The first of these divisions is according to texture and duration of stem and root; a chapter in botany which he wrote for all time; the distinction between woody plants and herbaceous. Trees and shrubs, alike as to their woodiness, are distinguished by him precisely as in the most recent botany, not neglecting the word of caution that no hard and fast line separates the two; that many, like the filbert and the pomegranate, are naturally shrubs, the stems growing in clumps, and are seen in the form and dimensions of trees only when under the cultivator's care and art. Even the pear tree, olive, and fig when left to themselves become many-stemmed and shrub-like. He also apprizes the reader that certain pot-herbs of the gardens have always the one-stemmed and arboreal mode of growth, even approaching trees in their dimensions, and all within the time of a few months; but that these have not the duration of trees or even of shrubs, and therefore prove that they are neither. He mentions certain mallow and cabbage 
kinds as of this category. ${ }^{1}$ He denominates them $\delta \varepsilon v \delta \rho \circ \lambda \alpha \chi \alpha v \alpha$, which his Latin translators have rendered olerarbores, and would appear in English as tree-potherbs. All herbaceous plants he classifies as perennial, biennial, and annual; also carefully stating that the annual and biennial are hardly distinguishable, inasmuch as both die, root and branch, within the space of a year, and as soon as they have once perfected seeds.

While this important example of botanical method is in hand, it will be pertinent to take note of those two mental processes, analysis and synthesis, of which every piece of method is the outcome; this for the purpose of clearing our own mental vision for an inquiry into the question of how much of this classifying according to texture and duration was found by Theophrastus ready-made and in common use, and to what extent, if at all, he revised, augmented, and improved it. Problems of this kind are most difficult; even impossible of exact solution by the mere botanist. The erudition of the specialist in philology and the history of language is here called for, without the aid of which the early history of botany never can be written. Happily, however, great linguistic learning is not requisite to a few reasonable inferences respecting Theophrastus' part in this classic piece of method. The distinguishing between woody growths and herbaceous is doubtless older than history. It is also evident that with remote enlightened antiquity tree and shrub were distinguished. The words representing these ideas are very ancient; but the halfshrub, or suffrutescent growth as we of to-day speak of it, appears to have been set apart as a group, and assigned a distinctive name by Theophrastus himself. There are many old and classic names for plants distinctively herbaceous. There is weed, grass, herb, vegetable, even the word "plant" itself as originally used, every one implying the herbaceous as to texture and short-life period; and so much for very primitive analysis and synthesis; but the putting of all these things together, the synthesis of them under one comprehensive term, was, if I mistake not, a Theophrastan contribution to botanical method. Moreover, and what is of even more profound interest, it appears as if the synthesis of everything that vegetates - tree, shrub, half-shrub, and herbaceous plants, including even sea-weeds and fungi-into one vast comprehensive assemblage of living entities called plants, is also to be attributed, if I mistake not, to Theophrastus. Primeval and prehistoric observations 
and reasonings, I say, doubtless established and named such lesser groups as tree, perhaps bush, certainly garden vegetable and field and garden weed, and grass and reed, rush and mushroom; but the synthesis of all as in some way alike and interrelated, and as spoken of comprehensively under one word-that would seem to have awaited the advent of a master mind like that of Aristotle. The written record of so significant a piece of method in nature study I find for the first time in Aristotle's greatest botanical disciple. The fuller investigation of this topic may be deferred until we come to Theophrastus as the founder of Botanical Terminology.

From another viewpoint Theophrastus beheld the world of plants as divisible into the cultivated and the wild ${ }^{1}$; and he formally approves this line of separation, though almost as compelled by circumstances; for he admits that it is not natural, and that the differences are in the main such as result from cultivation. It presents, nevertheless, a forcible example of rude primitive plant classifying. Untaught peoples of all countries, and many all around us, hold to such a division, - and that even superstitiously; firmly believing that the wild parsnip or wild carrot--differing from its parent plant only as growing spontaneously by the wayside, rather than within the garden wall under cultivation-is a poisonous thing, perilous to the life of him who would dare to eat it. Our present nomenclature of plants, the vernacular as well as the Latin, presents countless clear vestiges of the former popularity of this antique parting of all the plant world into these two divisions. Such specific adjectives as agrestis, silvestris, trivialis, arvensis, pratensis, hortensis, sativus, urbanus, and many more tell of a time past when about the first question concerning any plant was, whether it was wild or cultivated. There is no need of citing examples of those hundreds of vernacular plant names the first term of which is "wild"; but all of them, as relics of pristine botanical ages. attest the once universal prevalence of this partitioning of all things that grow out of the ground, into the two groups of the cultivated and the wild.

As for Theophrastus, out of the some 500 species and varieties of plants of which he treats, only an insignificant proportion are other than domesticated; and he says that the uncultivated things of wildwood and mountain are mostly still unknown and have no names. To have assigned space in his book for the consideration of many wild plants must have appeared like a marked innovation;

1 Hist., Book i, ch. 6. 
one that indeed looked in the direction of a widening of the field of botanical investigation, and was therefore of promise for the future of the science; but it must have given occasion for carping critics to ask how wild plants, such as have neither names nor history, are entitled to a place in the History of Plants. But while this newly suggested distinction had within itself one element that would eventually accomplish its obliteration, Theophrastus did not perceive this. Among wild trees and other growths which it had been sought to introduce into gardens, there were some which had baffled every effort to transfer them, whether by root or seed. From this he reasoned that there existed a line of natural demarcation, at least between plants that were susceptible of domestication and such as were not. But some trees which he named as apparently impossible of domestication are now successfully cultivated.

Having held the status of an acceptable part of botanical method for a millennium and a half, at the revival of botany in the first part of the sixteenth century this distinction began to decline in popular favor, and within two centuries more it became so nearly obsolete that, in books descriptive of the plants of particular regions or districts, those of field and garden were wholly omitted. Only wild plants were now taken note of; and so an extreme squarely opposite to that of Theophrastan times had been reached. And what lends deeper interest to these observations now, is the circumstance that of late years there has been awakened the keenest passion for the study of cultivated plants that history has known. I speak, of course, of that purely philosophic and scientific investigation of them which; either together with or apart from the industrial in motive, engages the attention of many botanists. And here, realizing that the very father of written botany was chiefly attentive to domesticated growths, and upon these as principal subjects wrought out his scientific system, one wonders whether or not in botany the first cycle of its history is being completed.

From yet another outlook over the vegetable kingdom as a whole, all the subjects thereof range themselves under the two assemblages of the "flowering" and the "flowerless". Theophrastus records this; but assuredly the invention of such a division cannot be ascribed to him. It must have formed a part of the universal prehistoric botany. Never since human intelligence came into the world, and lived in converse with nature, can people have failed to remark the presence here, and the absence there, of those differ- 
ently shaped, differently colored, and singularly congested foliar parts that they call the flower. It must have been observed immemorially, and accepted as a nature-taught fact, that such and such trees, weeds, and other plants never display flowers. They are flowerless. What I have been careful to state, namely, that the primitive notion of a flower is that it consists of leaves, must be insisted on. The reader must not permit himself to think of the pristine idea of flowerless plants as embracing anything less than the cryptogams plus the whole body of the apetalous phanerogams. With this fixed in our minds, we are then ready to inquire whether or not Theophrastus made any improvements of his own upon this part of pristine botanic method; whether perchance he looked into the matter far enough to have discovered that there exist such things as flowers destitute of flower leaves, and thereupon enlarged the boundaries of the flowering plants and correspondingly restricted those of the flowerless group. The answer must await our study of Theophrastan anthology.

In close connection with his separating between the flowering and the flowerless, the Greek divides the whole plant world again into the two categories of the "fruit-bearing" and the "sterile". I Judged by certain criteria that are of comparatively recent adoption there would be no call for this last distinction; for the flowering and the fructiferous would exactly correspond to each other, as would also the flowerless and the sterile; so that this last seeming distinction would be but a different naming of two primary groups before indicated. But this is not true; for when we have learned his doctrine of the flower we shall perceive that he had in mind fructiferous plants, and trees even, the flowers of which he had been unable to detect and which therefore of logical necessity he must classify as flowerless. Also, since he knew nothing of such sexual distinctions as have their ground in floral structure, there presented themselves to him what we of to-day know as the males of certain diceious plants, which flowered freely, and yet were sterile invariably. There was, then, no correspondence at all between those two items of his method as he saw and indicated them.

As regards the scientific merits of these two groupings our estimate must be formed according to their correspondence with the facts known at the time the groups were proposed, and not by bringing, for example, Theophrastus' groups of "flowering" and "flowerless" abruptly into contrast with those groups as they stand

1 I have inverted Theophrastus' order here.

He places fruit-bearing and sterile before flowering and flowerless. 
in recent botany under those same names. Such a mistake as this the historian Meyer ${ }^{1}$ must have made when he pronounced the Theophrastan distinguishing between "flowering" and "flowerless" to be "of little value." Its worth or worthlessness should have been determined-in the judgment of a historian, at all events - by the measure of its answerability to the state of knowledge actual at the time of its promulgation, and also with reference to its usefulness as an incentive to further inquiry into the nature of plants as flowering and flowerless. Or, even as the historic starting point in the designation of two groups, in name at least equivalent to Phanerogams and Cryptogams, this Theophrastan and very suggestive expression is of deep interest, and of no small value.

These mere outlines of his general method must be concluded with the bare mention of some other aspects of the vegetable kingdom as it presented itself to the comprehensive and deeply thoughtful mind of the protobotanist. He discusses, and in much more than mere outline, meteorology and climatology in relation to plant life; has chapter after chapter upon ecology and geographic distribution, and even touches more than lightly the topics of plant pathology and the transmutation of species.

Vegetative Organography. Theophrastus begins his botany at the beginning. The remark is pertinent; for with recent writers it is no uncommon practice to begin somewhere toward the middle of the subject, leaving the foundations of the science out of sight. It is an easy way, avoiding as it does the difficulty and the responsibility of laying down first principles. To recognize three separate realms of nature seems necessary; yet to indicate clearly the boundary lines between them is confessedly anything but easy. Theophrastus at the outset acknowledged the difficulty of distinguishing universally between the vegetable and animal kingdoms, but he faced it. There was no evasion. He addresses himself at once to the task of defining the plant as differing from the animal. And first he presents what must have been the popularly accepted method of indicating the distinction, though only to show its insufficiency for the purposes of science. Animals of whatever description have at least a mouth and a stomach. But it can not be said that all plants have roots, stems, branches, buds, leaves, or fruits. To circumscribe the plant world by listing the common organs of plants may enforce the exclusion of many things which are neither of the animal kingdom nor of the mineral, and are there-

1 Meyer, Geschichte der Botanik, vol. i, I6z. 
fore plants. Here it should be remarked that well toward the beginning of the seventeenth century there were people-among these at least one very eminent botanical author-who did not allow the fungi to be classed as plants at all. Theophrastus knew all these lower forms of vegetable life, fungi both terrestrial and hypogeous, lichens and algæ in abundance, and proclaimed it unhesitatingly that they are plants; plants indeed without stem or leaf or root or seed. "The phases of plant life are so exceedingly diverse in nature and constitution that, to give a general (i. e., morphological) definition of a plant, and that in few words, is not possible," 1 he savs. He ventures. however. one distinctive peculiarity of plants. "They are not, like animals, endowed with ethical susceptibilities and the power of voluntary action." 2 This is metaphysical, indeed, yet no whit more so than that which Linnæus gave in the middle of the eighteenth century when, pressed for one single mark of distinction between the genus Homo as separate from those anthropoid mammals next in rank, he was compelled to cite the "Nosce teipsum"; that is, man's consciousness of his own existence. Between animal and vegetab!e kingdoms the man of the eighteenth century could offer no better distinction than this: "Plants grow and live. Animals grow, live, and feel."'3 But he of twenty centuries earlier had been more circumspect and cautious. Such movements as heliotropisn and nyctotropism, and others seemingly akin to nervous irritability, were not unrecognized by Theophrastus, and may well have seemed to indicate something too closely allied to feeling.

In defining the manifest organs of higher plants the philosopher proceeds with like caution, preferring physiological to morphological characteristics; in this, the first precursor of the modern biologist, who, if required to name one distinction between plant and animal, confines himself to a point in physiology.

The root, Theophrastus says, is that by which aliment is taken up ${ }^{4}$; not a satisfactory definition to us moderns who demand morphological distinctions. Yet very safe is Theophrastus in his reserve; for what he names as characteristic of roots, albeit a merely functional characteristic, is one that holds. It is also apparently a new definition, framed by himself, and intended to

1 Hist., Book i, ch. 2.

2 Hist., Brok i, ch. I. I trust I may not be found to have rendered too freely the words $\eta \dot{\eta} \theta$ and $\pi \rho \alpha^{\prime} \xi \epsilon i s$.

syst. Nat., $4^{\text {th }}$ ed., p. 3 .

4 Hist., Book i, ch. 2. 
displace another definition which, though time-honored, was fallacious. That antique fallacious definition of a root has not yet been universally displaced. Without going quite out of sight of some of our colleges one may elicit that same old characterization of the root, and from the voices of people who have a certain familiarity with this particular plant organ. Multitudes in every land under the sun to-day will answer promptly that the root is the underground part of a plant. The Lesbian boy, while yet untaught by either Plato or Aristotle, it is most likely would have given this same answer. In maturer years, after much careful questioning of nature, he has found that that popular definition of a root does not hold good. The shrub or tree which the Greeks call Helix, the common ivy, he has observed minutely and experimented with until he has established it that those threads by which it climbs rocks, walls, and tree-trunks have nothing of the nature of tendrils, but are perfect roots, exercising in some degree even the usual function of roots. ${ }^{1}$ He knows quite as intimately the shrub Ixos, the mistletoe, and that its seeds refuse to so much as sprout elsewhere than on the bark of living trees, into which bark it strikes its roots. ${ }^{2}$ He had not seen the banyan tree of the Indies; but there were Greeks, educated Greeks, who had both seen and described it, with its many lesser subsidiary trunks grouped around the large central and original one. In their descriptions the travellers had stated so definitely the origin of the accessory trunks as starting out from main branches and growing straight downwards, that Theophrastus without hesitating declared that such things, however trunk-like they may at last appear, are roots. ${ }^{3}$ Thus did the first master of organology completely invalidate the ancient world's definition of the root, and at the same time indicate with clearness the two categories of roots, subterranean and aërial. He did not, however, name them. As nomenclator of even his own most brilliant discoveries he was usually delinquent. We seem to read it between his lines that there were in his mind some suggestions of root characteristics which, had he been less cautious than he was, he might have added to that very reserved and merely physiological definition. The downward growth from the branches, in case of the banyan, and also the statement that those pendents at first and while young and tender are of a light color and hairy(!) - both these

:Hist., Book iii, ch. I 8 .

2 De Cansis Plantarum, Book ii, ch. 23.

3 Hist., Book iv, ch. 5 . 
reported facts influenced his decision that these were roots. We shall also see presently that he had noted other morphologic marks, but such as he did not think universal.

The roots of herbaceous growths he in general classifies as ligneous, fibrous, and fleshy; and these include many things recognized in recent botany as subterranean stems, that is bulbs, corms, tubers, and the more thick and fleshy forms of root stock or rhizome. All really fleshy underground parts he distinguishes again as vertically elongated, spherical, depressed-globose, and what he calls nut-like; this last class embracing such incongruities as the small and solitary shell-covered corms of the crocus, and those tuberiform enlargements that appear, as if strung like nuts, on the roots of the asphodel. The rhizomes of arundo, and of what he names as arundinaceous plants in general, and which he remarks are sometimes partly above ground, he denominates jointed roots, but notices that these all have fibrous roots attached to them Others, like the bulbs of squill and onion, are composed of a multiplicity of scales or tunics which can be removed one by one; so that these differ from other fleshy roots in that they exhibit two different kinds. Their nature is so peculiar that one might be excused for doubting that they are roots at all; for if in that they are subterranean they would at first seem to be such, they are in other particulars of quite another nature; because roots properly so-called diminish in size toward their lower extremity and end there acutely, whereas these bulbs and their like are widest at base and grow smaller in the opposite direction; moreover those fibres which descend from the bases of some and from the sides of others are the real roots which take up aliment; but the extuberant part is more like a fœtus, or a fruit. ${ }^{1}$ However, after still further discussion, he seems to rest in the conclusion that, as roots are of various kinds, and even bulbs and other fleshy roots are functionally much alike, all may well enough be continued under the category of roots. If to any botanists of the twentieth century it may seem a strange thing that the Greek, having distinguished between roots as subterranean and aerial, should have failed-and after all his study of them-to classify stems also as aerial and subterranean, let them recall to mind that philosophic conservatism which led Theophrastus to make more of the function of an organ than of its form; that he was sure that corm and rhizome and tunicated bulb attract nutriment and are by that token roots.

Hist., Book i, ch. Io. 
Let them also contemplate the fact that for twenty hundred years and more all botanists accepted the decision of Theophrastus, and that even with Linnæus, those organs which we have somewhat recently been learning to regard as subterranean stems were nothing but roots; and that Linnæus in this particular was even so far back of Theophrastus that he had no doubts about their being roots.

That in the most primitive phytography roots received almost singularly minute attention has been adverted to, and the probable reason assigned. Accordingly we shall find Theophrastus, when done with their morphology, anatomy, and physiology, giving a full account of their differences as to color, odor, flavor, and their qualities as wholesome or deleterious. In color, some are white, others black, not a few yellow, some tinged with red, and some quite intensely red. As to odors and flavors there is again much diversity; and some that are sweet and pleasant to the taste are deadly poisonous, while several kinds that are of disagreeable odor or bitter are harmless, and even of medicinal value.

At the correct definition of a stem as being that part of a plant which bears leaves, Theophrastus did not arrive. His imperfect conception of the leaf, for one thing, stood in the way. Those merely scale-like short leaves, upright and even appressed to the stem, such as those of asparagus and orobanche, were mere scales in his view of them, and the stems of such plants he considered leafless. Again, to his vision there was a horde of stemless plants the leaves of which arise not from any stem at all, but directly from the roots. Here I can not forbear remarking that we of to-day, despite our better characterization of the stem, and our recognition of it as present in all except the very lowest plants, yet contradict our own definition in our practice, and have fallen back upon that of Theophrastus whenever we speak or write, as we freely do, about acaulescent plants and radical leaves. The ancient author defines the stem primarlly as that part which is the main vehicle of aliment to the other parts; adding that it rises up singly from the ground ${ }^{1}$; which is of course to distinguish it from the branches and leaf-stalks, both of which he knew to be also channels for aliment. This definition, equally with that of the root, evinces his distrust of morphological characteristics as definitive, and his feeling that the physiological are safer. But, the stem once defined functionally, he proceeds with care and skill 
to indicate its many morphological diversities; and here not only classifies but also names several of the classes. He acts as if he thought the language of science would be defective if such dissimilar things as an oak log, a mullein stalk, and a rye straw all were to bear the name of stem. In practice, therefore, he called the stem of a tree its trunk, $\sigma \tau \dot{\varepsilon} \lambda \varepsilon \chi 05$, the light hollow or pithy stem of all grassy and reedy things was a culm, «á $\alpha \mu 05$; thus the ordinary word stem or stalk, navidos, was mostly limited to designate those of what we know as herbaceous exogens; and so our modern botany has these three kinds of stems as designated by Theophrastus. Culm is even very manifestly a modification of the Greek kalamos. Embracing as it does almost all endogenous stems, it is more comprehensive than the English words straw, reed, and rush all combined; and in our botany we were obliged to borrow and make over just the Greek term which Theophrastus invented-unless he, too, borrowed it; or, what amounts to the same, extended the use and gave a new and scientific meaning to an old and familiar term. As to their forms and modes of growth he distinguishes many kinds of stem among herbaceous plants. And, as woody growths are classified as trees and shrubs, according as their trunks are one or several from each root, so the herbaceous are distinguished as one-stemmed or many-stemmed. The numerous kinds of bulbous plants both wild and cultivated he understands as being invariably one-stemmed, and therefore does not speak of this in his descriptions of such; but of other herbaceous growths his custom is to mention, in his descriptions of them, whether the root sends up a single stem or many. It is a distinction of importance to phytography; and if the anthological extremists of one and two centuries ago thought it superfluous, and neglected it, its value is now again beginning to be clearly seen and freely admitted. Again, herbaceous stems are upright, or reclining, trailing, climbing, or twining. ${ }^{2}$ He also has observed that one-stemmed herbs are apt to be erect, the many-stemmed otherwise; or at least that the reclining or trailing are always many-stemmed. Among upright stems he perceives how different those of the umbellifers are from most others in that they are fluted, or at least striate, and, giving these and all their like a name that really points to their anatomical structure rather than to their external appearance, he denominates all such plants nervose-stemmed. Through having missed the discovery of the 
good morphologic mark of stems, he is constrained to offer the category of what he calls smooth-stemmed plants. Such "stems" are nothing more or less than the flower-stalks of acaulescent perennials, called smooth stems because devoid of those unevennesses now designated as the nodes and internodes, and received as the most universal mark of real stems. His examples of the smooth stem are those of the onion and leek, 1 good illustrations of the scape, as named and defined in later organography.

The leaf is a thing so almost infinitely diversified that he does not attempt to characterize it morphologically, or even physiologically, for he can not with any degree of certainty name its chief function. So without vouchsafing any definition of it, he goes about the rehearsal of its many aspects. Although as an organ it heads the list of that division of them which he has distinguished as transitory, and therefore in a manner secondary, no part of a plant would seem more deeply to have interested him, or to have been more carefully observed. He is even somewhat diffuse in his writing upon it; more so than in the case of any other organ, unless the fruit and seed are to be excepted; and, since the opinion now prevails almost too widely that little was done in the direction of plant organography until within the last two centuries, the interests of truth can not at just this point be better subserved than by giving the substance of this ancient Greek's morphology of the leaf somewhat in detail.

"Leaves are commonly attached to the stem or branch or to whatever else supports them, by a stalklet; this either firm and holding the leaf steadily in a certain position, or else slender and feeble, allowing the leaf to hang downward and perhaps tremble with the passing breeze, or even to become inverted, turning the usually paler lower face upward. But there are also leaves with no stalklet, these adhering directly to the branch. Some leaves arrange themselves only in opposite pairs, with regular intervals between the pairs, while others are scattered singly and without order up and down the stem." 2

It will be seen that these beginnings of Theophrastan teaching about the leaf are precisely what one finds in every primer of botany to-day. Every beginner has to be taught the importance of the distinctions between a petiolate leaf and one that is sessile, and between the opposite and the alternate in leaf arrangement.

! Hist., Book i, ch. I6; also Book vii, ch. 7 .

2 Excerpts from Hist., Book i, ch. 16. 
We have improved the descriptive phraseology, and are able to say the same things in fewer words; but that is about the only difference. Some general differences in the configuration of leaves are also adduced. There are those of rounded periphery, or even somewhat elongated, all without angles, and there are the angular in outline, some of them like those of the fig deeply cleft, others like those of the oak sinuated all around, still others with saw-like teeth all around; and some are sharply pointed at the apex, the slender leaves of pine and others even ending in a prickle. In certain thistles he notes that spines take the place of foliage. He is convinced that certain leaf-like organs in a number of asparagus allies are not leaves, yet he gives them no name; nor had they obtained a name-that of cladodes-even as late as the time of Linnæus, who, as if he had been of a preTheophrastan age, still called them leaves. The hollow and fistulous foliage of the onion and some of its kindred elicited remark from Theophrastus as being very exceptionally curious. So did that of the sedges, as being conduplicate and keeled. The essential characteristics of the leaf that is pinnately compound he also seems first to have detected; for he is at the trouble to argue the case before those who, as he seems to acknowledge that he himself also once did, regard this as a leafy branch. He has observed the autumnal falling of the foliage in the ash tree, elder, and sorbus, and reports that the whole of that which seems a branch falls away piece by piece, thus establishing it beyond dispute that the whole is one leaf. He even speaks of it, afterwards, as the pinnate leaf. ${ }^{1}$ And, as there are kinds of tree in which leafy branches, by being somewhat lengthened and having their leaves set closely in two opposite ranks, resemble the compound leaf, Theophrastus in one place that I have noted cautions the student against being deceived. The case is that of the elm, the pinnately leafy twigs of which might be mistaken by the unwary for compound leaves. The observer is warned that the elm has but a simple leaf, $q u \dot{\lambda} \lambda \boldsymbol{y}^{\prime}$ $\alpha \sigma \chi^{\prime} \delta \delta^{\prime} s^{2}$ The leaves of the rose bush I do not find described in Theophrastus. These shrubs were so universally familiar that description of their foliage was needless; but that he recognized this as a pinnate foliage is evident by one comparison that he makes. Wishing to convey some notion of the leaves of an interesting tree of the Orient (Tamarindus Indica, Linn.), he says it is "many-leaved, after the manner of the rose bush," 3 meaning that

'Hist., Book iii, chs. II, I2, I3, and 16.

2 Ibid., ch. I4.

${ }^{3}$ Ibid., Book iv, ch. 9 . 
the individual leaf of the tamarind tree is of many leaflets, like that of the rose. The philosopher devised now and then a new botanical term, but did this with reserve; and the discovery of compound leaves does not appear to have called, in his thought, for any such distinction as that of leaf and leaflet. He applies the term leaf, qu$\lambda \lambda \circ v$, to the compound leaf as a whole, and to the individual leaflet indiscriminately. As regards the differences of compound leaves and the classification of them he did nothing; nor, indeed, does anything appear to have been attempted in this direction, after Theophrastus, until the time of Jung, who in the middle of the seventeenth century strongly advanced the morphology of the leaf. But Theophrastus in his environment can not have met with anything like that diversity of compound leaves with which Jung was familiar. He must have known the bipinnate fronds of certain ferns, but did not essay any description of them; and when a certain bipinnate-leaved tree from Egypt (Mimosa polyacantha, Willd.) was in need of a description, he evaded the difficulty of the situation by saying that its leaves were like those of a fern. ${ }^{1}$

We shall be furnished later with some proofs that the venerable Greek could make significant discoveries in connection with such very little things of the plant world as small apetalous flowers, and even the inner structure of small seeds. Without microscope, hand lens, or spectacles, he seems to have been almost microscopiceyed sometimes, as well as always alert for the detection of the exceptional or unusual in the grosser morphology of things. We therefore wonder that, after his having noted so carefully that some leaves, even small ones, are compound and even doubly compound, he should not have taken stipules into account; for he makes no mention of them. During it may have been fifty winters he had seen the branchlets of the plane trees under which lay his daily walks, encircled at intervals by their wheel-shaped stipules still persistent after the body of the leaf had fallen. During as many summers of his centenarian career he had observed the foliage of many garden leguminosæ, in some species of which everywhere in cultivation anciently, more than half the foliar area is stipule; and yet this organ is unmentioned by Theophrastus. As to its presence on the boughs of the most common Athenian wayside shade tree, and its more conspicuous showing amid the herbage of every sort of pea and vetch and lentil, this father of plant organography is as silent as if the organ had not existed. This 
seems anomalous. To the average reader it will seem like a curious hiatus in the Theophrastan leaf-morphology. The situation seems nevertheless readily to explain itself. One has but to recall to mind the ancient botanist's strong inclination to regard function first and form last everywhere in his organography. The excessively enlarged and leaflet-like stipules of Pisum and some other leguminous herbs have not the least appearance of being functionally different from the other leaflets. They are larger and also located a little differently from the others, but that is all; and there is the best of evidence that a thorough training in modern organographic refinements is requisite to the determination of the enlarged basal leaflets of the pea-vine as stipules. The evidence is this: that the most original and logical of great organographers and terminologists, Joachim Jung, as late as the year I $66_{2}$ of our era knew nothing of any such organ as a stipule. Tournefort in the year I $700 \mathrm{knew}$ them not, and Linnæus claims them as among his own organographic discoveries. though unwarrantedly, as we shall see later.

There is, however, one particular kind of stipule which, unless I misunderstand Theophrastus, drew his attention and elicited his comment. It was a case in which there is about the strongest possible contrast in appearance between the leaf proper and the stipular appendage; that of certain umbellifers in which while the decompound blade is deep green and almost capillarily dissected, the large stipular development below it is pale, membranaceous, wholly uncut, sometimes cup-shaped and hollow. Here again it would seem to require our modern refinement in organography to perceive in such a thin bladdery stipule and green capillarily cut blade the different parts of one and the same organ. Theophrastus, at all events, knew some umbellifers of this description, and wrote concerning one species of the genus Ferula that it puts forth at the nodes of its stem leaves and $\beta \lambda \alpha \sigma \tau o \dot{i} .^{1}$ The blastoi, one from each node of the stem, have perplexed some of the botanical commentators upon the text. I think they are the stipules.

If Theophrastus does not anywhere formally define the leaf, that may have been for the reason that, not at all comprehending its function, it was not possible for him to define the organ, as he had defined root and stem, physiologically. Nevertheless he did state, in a most informal way, its very best morphological mark; that by which it is almost always readily distinguishable from a 
stem or any part of it. He observes that most leaves have an upper face and a lower. The upper, exposed to the sun, he notes as being of a deeper green and smoother; the lower face is paler, roughened by the greater prominence of the veins, and apt to be pubescent. ${ }^{1}$ From the fact that the lower face of leaves when pubescent is found to be moist he says it has been inferred that it absorbs nutriment and feeds the rest of the leaf. This he confidently declares to be erroneous, affirming that all parts of a leaf are fed by way of the veins and fibres which are carried to every part, and which he knows to be connected with the bark. This was the thing which he could easily demonstrate and prove. The other proposition was not in his day demonstrable; for he could not know either the structure of a plant hair, or the existence of stomata. Theophrastus, like his class in all ages, is likely to be correct in that which he affirms, and wrong as to that which he denies.

Anthology. Without any understanding of flowers as organs of sex, and quite in the dark as to their significance in the economy of plant life, Theophrastus applied himself assiduously to the study of their morphology, and that with a measure of success compelling the admission that he is the founder of anthology; for several of his distinctions remain fundamental in the anthology of to-day, notwithstanding that the theory of the flower has been completely revolutionized within the modern period. ${ }^{2}$ And his success is the more remarkable because of his having made his researches at a time when, for mere lack of optical equipments, the discovery of the functions of the essential floral organs was impossible.

From ages antedating all history cultivators must have observed that in such trees, garden shrubs, and herbaceous field crops as flower conspicuously, no fruit or seed develops but as an aftergrowth from the flower; that a young tree never fruits until after having for the first time flowered, and that any mischance befalling the flowers of the tree in their season extinguishes, for that year, all hope of fruit. Upon a considerable array of facts of this kind, the first philosophic investigator who came along might naturally propound such a theory as this, that wherever there is now a fruit or seed, at some time there must have been a flower; a proposition which the cultivators at once and with one voice would have disputed; for in the husbandry of antiquity no tree was more esteemed, nor any more familiarly known than the fig

1 Hist. Book i, ch 16.

${ }^{2}$ Namely, by Sebastian Vaillant, De Structura Florum, Paris, I717. 
tree, and this, as all the world understood, produced its fruits two crops a year, without a trace of flower. And Theophrastus, after all his searching for and philosophizing about flowers, seems to have found no way of controverting the universal opinion. $\mathrm{He}$ thought that the fig produces its fruit without flower of any description. ${ }^{1}$ But in his philosophic quest for flowers of some sort as the forerunners of all fruits and seeds, he appears to have discovered true flowers, though sometimes recondite, in other trees that had been supposed to be like the fig, flowerless. The flower, in prehistoric thought and speech, may most reasonably be assumed to have been a thing showy on account of its being made up of leaves colored differently from ordinary foliage, and differently arranged. It must have been essentially that which modern botany knows as a corolla. This inference as to what a flower was before either botany or history began to be written is confirmed by our experience with untaught rustics and mountaineers of to-day, as to their understanding of what trees and plants have flowers and what have none. They are the modern counterpart of those unlettered ruralists of remote antiquity whom Theophrastus cites as denying that oak and walnut trees, hazel bushes and chestnut trees and junipers have any flowers at all. ${ }^{2}$ The philosopher, the man of science who is truly such, has this among other characteristics, that with him negations are apt to go for naught. Of the populace they are largely the mental stock in trade, so to speak, but himself negations do not satisfy. They say that neither oaks nor hazel bushes have flowers. They recognize it that oaks put forth clusters of loose pendulous tassels that they call oak-moss, and also globose bodies denominated galls; but oak-moss is not a flower, any more than oak-galls are acorns. These are specimens of the facts, and of the reasonings upon them, which confronted the protobotanist of so long ago. Stimulated by the thought that almost always where a fruit or seed now is, there was once a flower, from the very heart of which the fruit or seed took its origin, he enters upon his researches. Now this very idea that flower and fruit are related as antecedent and consequent so that where any manner of fruit or seed is found the essentials of a flower must be sought, is the germinal idea out of which the whole of systematic

${ }^{1}$ Hist. Book ii, ch. 6. There is but one record of the discovery of the flower of the fig until after the invention of magnifying lenses, and some eighteen centuries after Theophrastus. Even Linnæus, still later by two centuries, had the genus Ficus under the Cryptogamia.

${ }^{2}$ Hist., Book iii, ch. 6. 
botany as we have it has been engendered; and the originator of that idea would have been the father of botany even if he had accomplished nothing further.

There is one thing which he who would know, even in outline only and superficially, the history of botany, must not do. When in Theophrastus he meets with the word $\ddot{\alpha}^{\prime} \theta_{0}$, or in Pliny with the term "flos," he must use care not to read into that term the meaning which the word flower has in modern botany; for, if he assume that the word stood, with those authors as with us, for a congeries of four circles of different organs, beginning with the calyx and ending with the gynœeium, he will never correctly apprehend a word they say about the flower. That view of the comprehensiveness of the flower which we now take, extremely unlike the ancient idea, was really first presented for acceptance within somewhat less than two hundred years from the date at which I write. The flos of remote antiquity, the pre-Theophrastan anthos, appears to have been simply the corolla, as we have said before; and that without a special name as such. It was but a set of leaves, shaped and colored and arranged differently from ordinary foliage, and having for its function the protecting of the future fruit and seed while in their tender and rudimentary stages.

Now oaks, walnut trees, alders, and hazels have no corollas. They had been considered flowerless because they have none, and correctly enough so long as the flower was defined as a whorl or tuft of specially altered and colored leaves; and it was so defined in the minds of the majority of people in that time, as it is in the minds of untold thousands in every land to-day. And the very possibility of detecting upon oaks and filbert bushes some small thing that should mark the point of origin and presage the coming of each nut and acorn involved the possibility of a revolution in the idea and definition of a flower; an extension of the term, to make it embrace anything, no matter how colorless, shapeless, and obscure, which should be found in the place where a flower ought to be.

This earliest Historia Plantarum, intensely interesting though $t$ be as we have it, would have been still more so had its author given some record of his own processes of research; his successes and his failures in attempting to find flowers on trees and herbs that had the reputation of being flowerless. But the traditions of the lyceum at Athens were against that. Men were taught that knowledge is best communicated in language concise and brief; and Theophrastus' three short chapters of anthology may vie with 
any other three chapters of scientific matter ever written, in respect to the terseness and brevity with which important propositions follow one another in close succession. ${ }^{1}$ His first proposition as to the general morphology of the flower is this: "Some flowers are capillary, like those of the grape, mulberry, and ivy; others are composed of leaves, like those of the almond, apple, pear, and plum trees." 2 These are trees; but he proceeds to say that quite the same is true of the flowers of herbaceous and annual plants, some of which have foliaceous flowers, others capillary. It is evident as can be that by examining the earliest germs of fruit in plants that never show flower-leaves, he has found those fruit-germs at a certain early period encircled by hair-like or filamentose things quite as transient as flower-leaves, and which seem in some way to take the place of them, though they have not always the usual special coloring of flower-leaves. On the strength of what he has studiously observed, he has now virtually given to the term $\alpha v \theta 0 s$, flower, a new definition, a scientific one. The term must embrace whatever is intimately though transiently connected with a fruitgerm, whether laminal and colored or filamentose and greenish. This, in so far as written records show, is the earliest proposition ever laid down concerning the morphology of the flower; and it was a mighty contribution to scientific botany. It is in substance the distinction of petaliferous and apetalous flowers. It will therefore hold its place in the science of plant life and form as long as such a science shall exist.

The investigations of Theophrastus along the line of what we denominate apetalous flowers appear to have opened his eyes to the presence of the capillary organs in a large and showy petaliferous kind; for in this same chapter he states that many flowers are twofold, showing another flower inside the main one. He cites such familiar garden flowers as the rose, violet, and white lily as examples; and, as against any suspicion of ours that his twofold flower of rose and violet and lily might mean a double flower, as composed of multiplied petals within the main outer circle, there occurs the one word $\delta x x \rho \circ \alpha$, two-colored, or differently colored. It is, of course, the stamens within the corolla of red rose, purple violet, and white lily that are colored differently from the corolla. This is the earliest recognition of the flower as other than a simple organ. It is the beginning of the classification of its parts; a small beginning, but highly significant. It is given out for the first

1 Hist., Book i, chs. 20, 2 I, 22.

2 Ibid., ch. $2 \mathrm{r}$. 
time, that many flowers have two circles of organs, a flower within a flower, the one within readily distinguishable from the broad, Ieafy one outside. He does not formally name this inside flower, qut he has found so many flowers that lack the leafy outside circle altogether, displaying nothing but the inner, that he names this kind capillary or woolly flowers. It must here be affirmed that Theophrastus knows nothing of the calyx as being any part of a flower. The color and texture of floral organs were what distinguished them from ordinary foliage; and by their points of agreement with the latter any green leaf-like organ or circle, however near the "flower," would fail to be included as a part of it. Also the ovary and ovules were not indicated or received as organs of the flower. They were simply the fruit or seed, in whatever stage from that of the flowering to that of full maturity; and this neither through dullness nor indifference. The colored leaves, together with the colored threads, set in the midst of them, were all there was to the flower. One may fancy some brilliant Greek pupil asking the master if that protuberance in the middle of many flowers ought not to be regarded as a part of the flower, and called the fruit, ought not to be called by a name of its own while in the flowering stage. He who knows the keenly penetrating and severely logical mind of Theophrastus will infer without chance of a mistake, what the substance of his answer would have been. At what particular point in its development will that protuberance begin to be a fruit? I suppose that such logic might silence the ablest morphologist who has lived hitherto. Our modern term ovary is but an illogical convenience. It suitably abbreviates the following expression: "fruit at the budding or flowering stages and for an indefinite period thereafter." Our neighbors the industrial botanists even of to-day have no need of the term ovary and ignore it. When a hard unseasonable frost has sterilized the ovaries of their trees, whether in bud or in flower, it is the "fruit" that has been killed; and so the Theophrastan anthology still lives and is widely though unwittingly approved.

What are now known as the styles were not segregated from the other flocci, or capillamenta-that is, from the stamens-until ages after Theophrastus. He made no distinction between these two, at least when found together within the same flower; and his capillary flower might consist of stamens alone, or of styles only, or of both. What is more, there are certain arrangements of stamens under which they failed to gain recognition by him as being of the nature of floral parts, as in the aments of hazel, the 
walnut, the oaks, and many more. He gave them a name, iov $\iota^{1}, 1$ Latinized as juli, writing about them so minutely and describing them so well as to attest his perfect familiarity with them; but apparently the more he studied them the more enigmatic did they seem. ${ }^{2}$ The filbert, Corylus avellana, not only grows wild in Greece, but it had been cultivated there doubtless for ages before Theophrastus' time. It would be irrational to question that it was among the shrubs of that botanic garden in the midst of which lay his daily walks for many years. At all events, his perfect familiarity with its tassels is attested by the following account which he gives of them. "In autumn after the nuts have fallen, there appear in bunches of several certain things that look like worms, inserted on a short thick stalk. These are called juli. Each is made up of countless scales arranged somewhat after the manner of those of the nut pine (Pims pinea, Linn.), the whole longer in proportion to its thickness than that, and also of cqual thickness throughout. Before the end of winter it begins to grow. In early spring the scales separate and stand apart, and are then become yellow, the whole then sometimes as much as three inches long. When the leaves begin to put forth, these things shrivel and fall. Then the cups that enclose the nuts develop; one cup for each flower, and one nut in a cup." 3

The concluding sentence places it beyond doubt that the writer knew the crimson pistils of the shrub as well as he did the yellow aments. He does not stop to describe them. They are of his class of capillary flowers, and that is enough. In a later chapter, ${ }^{4}$ in which he brings out the habit and vegetative characters of the filberts, indicating two species (C. avellana, Linn., and $C$. tubulosa, Willd.) by differences of fruit, he has no occasion to mention again the flowers, but can not forego renewed allusion to those perplexing aments. "To these shrubs belong that julus of compacted scales which we have elsewhere described." The sterile aments of the oaks, slender, lax, more tufted than those of the hazel as well as of short duration, must also have been known to Theophrastus; and so were the colorless and very inconspicuous pistillate flowers; for, while he quotes the popular opinion of his time that

1 Hist., Book iii, ch. 7 .

2 Pliny, some three centuries after Theophrastus, refers to the juli of the filbert in terms that prove them still incomprehensible to nature students of the time. He says they are ad nihil utiles; which we remark is a negation, and therefore unscientific.

3 Hist., Book iii, ch. 7 .

4 Ibid., ch. I 5 . 
these and other like trees are flowerless, he tersely contradicts it. "Both oaks and alders flower" 1 ; by which he must have meant the axillary and scattered pistils of the oak, and the cone-like clusters into which the alder pistils are congested.

Of the aments of fir and pine I observe no mention in Theophrastus. Even the young cone of pistils with their subtending scales in the conifers, from its form he denominates a julus; but it is not of the enigmatic class. Without hesitation he denominates that the flower. It is also plain that with him this must be received as a petaliferous or leafy flower, for it shows nothing that could be called a capillamentum. The rudiment of each fruit rests in the axil of an ample and highly colored leaf. ${ }^{2}$ Nor does he here cite the opinion of any of his forerunners or contemporaries as having denied or questioned that these are flowering trees, as they had done in the case of oaks and alders and hazels. The flowers of the fig tree he could never discover. To him it was as flowerless as a tern or moss. He was loath to believe that junipers are not equally flowerless. He had investigated them; had observed that in summer their fructiferous branches bear one set of fruits full grown, and another set newly formed and not half grown; a proof that its fruits require a year and somewhat more for their growth and ripening. He can hardly have failed to see the staminate aments, small though they be, and of brief duration. They were nothing, in his view; at least nothing floral, and not worth mentioning after he had once described the like phenomenon as conspicuous and of long duration in other trees and shrubs. What he was looking for, he could never find, that is, what he would have accepted as a flower, a folium, or a capillamentum indicating the seat of the juniper berry that is to be. The pistillate or fertile juniper flower is as far away as it is possible to go from having the appearance of a flower at all. It shows even under a lens no trace of style or stigma or ovary. It is so little different from the minutest first rudiment of a merely vegetative twig, that an experienced botanist, even of these later times, may fail to recognize it, though he search with a lens. It is improbable that there is a man in the world to-day who, in the feeble botanical light of the Theophrastan age, and without the aid of magnifiers, would ever have found the pistillate flower of a juniper.

1 Hist., Book iii, ch. 5 .

2 "The flower of the fir is yellowish red, and otherwise beautiful." - Hist." Book iii, ch. 6 . 
But what is fully as interesting as Theophrastus' failure to find anything upon a juniper tree which he could demonstrate to be a flower, is his recording the opinion of those who think differently. "There are those who say that the juniper tree is of two kinds, one that flowers and bears no fruit, and another that is flowerless but fructiferous." 1 The pronouncement is interesting as being diametrically opposed to the Theophrastan doctrine that nothing not in immediate juxtaposition to a fruit rudiment is to be regarded as a flower. It is a virtual contradiction of the opinion that juli or aments can not be flowers. These people who held that male and fruitless juniper trees have flowers, and that fertile ones have none, were people who evidently regarded those small evanescent yellow, dusty male aments of the juniper as true flowers, even the only flowers that any juniper ever has. If evidence were elsewhere wanting to prove Theophrastus a true philosopher and scientific man, devoted to the truth whatever that may be, rather than to his own theories, it is not wanting here. He publishes this adverse opinion of his neighbors for the very reason that it may possibly turn out to be the right opinion, concluding the whole passage with the recommendation that investigation of the subject be continued. "The matter should be looked into further." 2

Quite as briefly as he had indicated the distinction between leafy flowers and capillary does Theophrastus give the suggestion that the leafy flower in certain plants is made up of but a single leaf. ${ }^{3}$ It is practically classifying corollas as choripetalous and sympetalous. He writes of what he calls the monophyllous flower as if within the field of his observation it had been somewhat exceptional; and he warns the reader that it is not always distinguishable at a glance from the other kind. Viewed as to their periphery they will seem to be made up of separate leaves, but at the center or base they are seen to be monophyllous. In the morning-glory (Convolvulus sepium, Linn.), however, the monophyllous character is readily apparent, only a certain angularity of the periphery remaining in place of the appearance of separate leaves. Even small flowers may be monophyllous. Such are those of the olive tree. Lying on the ground under the trees they are readily seen to be perforate. From his having cited the olive blossom, one is assured that he held a corolla to be monophyllous even if the leaves were united only at base. But one must guard against mentally 
attributing to him any general recognition of all sympetalous corollas as being such as that to which later generations have arrived; for evident ${ }^{\dagger} y$ he had not proceeded far along this line of anthological research, but was only at the beginning of the subject. Having so perfectly settled the monophyllous structure of the small and quite choripetalous-looking olive blossom, we are disappointed that he has not done as much for that of the elder tree. It is a tree in which he has manifested a special interest, and with which he has grown very familiar. The thin wood of its shoots and branches, along with an extraordinary development of pith; then externally the remarkably long internodes, and the foliage, from watching the falling of which in autumn he seems to have learned the very important classification of leaves as simple and compound-all these aspects of Sambucus he has noted fully. Will he not perceive that its flowers, like those of the olive, are of that structure which he designates as monophyllous? They are too small; much smaller than those of the olive tree; even quite minute to one who is without a lens; and Theophrastus may not have examined them very carefully as individual flowers. Either that, or else, in condescension to popular usage, he permits the corymb or umbel of small flowers to pass for a flower. And so he describes the blossoming of the elder thus: "The flower is white, composed of many small ones all white, the whole with the appearance of a honeycomb, and attached to the summit of a shoot by a number of stalks." 1 There is another type of monophyllous flower not as small, which first and last remained to him an enigma. It was the ovate, hollow, and pitcher-shaped corolla of Arbutus unedo, a most common type among ericaceous plants. He says it is not a leafy flower; an expression equivalent to the modern phrase apetalous flower. He describes it as being in the form of an egg-shell with one end cut off, leaving an aperture. ${ }^{2} \mathrm{He}$ can not have detected the five obscure recurved teeth at the orifice; for they would have taught him that this, like the faintly five-angled morning-glory blossom, is of five almost completely united leaves.

One chapter of the Historia opens with a sentence like this: "Flowers differ in respect to their origin and insertion." 3 It is one out of a number of Theophrastus' brief statements of significant fact, any one of which would have rendered famous any herbarist of the sixteenth century or the seventeenth who had been privi-

\footnotetext{
1 Hist., Book iii, ch. 13 .
}

2 Ibid., ch. I 6.

3 Hist., Book i, ch. 22. 
leged to announce it as a discovery of his own. In the most recent and approved taxonomy of flowering plants, this point? in anthology, first indicated by the ancient Greek, holds a most conspicuous place. Let the Greek himself explain what he means by the origin and position, or insertion, of the flower; always keeping it in mind that with him the leaves and the thread-like parts in their midst are all there is to a flower, the ovary be ng the fruit. "Some produce the flower around the [base of the] fruit, as do the grape vine and the olive tree. . . In the greater proportion of plants the fruit thus occupies the center of the flower. But there are not wanting such as support the flower on the summit of the fruit, as do the pomegranate, apple, and rose, all of which have their seeds [ovules] underneath the flower. A few bear the flower on the summit of the seed itself, such as the thistles, and all that have their flowers in that manner crowded together." It is a clear distinguishing between the hypogynous, perigynous, and epigynous in floral structure; clear notwithstanding that the one example brought forward to illustrate the epigynous insertion, that of the flowers of the composites, was not from the modern point of view well chosen; because then what he understood to be the seed we regard as a fruit. If he had been accustomed to assign names to what have proven to be his great discoveries in anthology, he would have called this third mode of insertion the epispermatous. He learned this springing of the "flower" from the top of the "seed" to be characteristic of the whole family of the umbellifers, and of the few rubiaceous plants that he knew, as well as of the thistles and their kindred. It seems to me that what is more to be wondered at in Theophrastan anthology than his distinguishing of the hypogynous, perigynous, and epigynous modes of insertion, is the fact of his having made out so positively, that the head in the composites is not a flower, but that it is a dense cluster of separate and distinct individual flowers, each complete in itself. Less than three generations ago, eminent systematists were still writing up the scales of such involucres as "sepals," the whole involucre as a "calyx," and the circle of ray flowers as the "corolla." At this juncture the sublime old Greek will appear to have lived before his time by more than two thousand years.

In his study of flowers the arrangement of them was not unnoticed. He observes that in most trees they appear as scattered on all the branches, all appearing nearly simultaneously, so that the flowering period of such is but short. In many herbaceous and half-shrubby growths they are clustered together; and in 
describing such plants as to their flowering he makes frequent use of terms equivalent to spike, raceme, and umbel, though not with such definiteness of meaning as they convey in modern botany. In these clusterings it is observed that the flowering of the whole cluster at once seldom takes place; that usually the lowest flowers are first to expand, then those next above them, this succession continuing in some plants so long that the seeds from the basal flowers are ripe before the terminal flowers have opened. The aromatic garden herb ocymum is named as a case in point; ${ }^{1}$ but he mentions this kind of inflorescence repeatedly. He also names one plant whose flowering begins at the top, the succession of later bloom following downwardly. Thus is Theophrastus again a botanical discoverer. He has distinguished between the centripetal and the centrifugal in inflorescences. The historian Meyer was surprised at this, remarking also that he knew of no other botanist's having noted this distinction again until the time of Link and Robert Brown. ${ }^{2}$ It is evident that Meyer pondered the fine picture books of his compatriots of the sixteenth century, Brunfels, Fuchs, and Tragus, to the neglect of the one real botanist that there had been among them all, Valerius Cordus.

Fruit and Seed. Without fully appreciating the significance of truit and seed as furnishing the best clew to plant affinities, Theophrastus nevertheless studied them assiduously. Even flowers in their beauty and fragrance, and by their multitudinous forms, engaged hin chiefly as being heralds of the fruit and seed. The perfecting of fruit he alludes to here and there as being the culmination of the plant's existence. He notes it that even such vigorous and enduring things as trees and shrubs shorten their life period by excessive fruit-bearing; that myriad annuals live but the length of one summer season because they exhaust all their vitality in the yielding of their one crop of seeds. Seeds were of very special interest, in his view; and succeeding generations of botanists have been with him in that opinion.

The scientific examiner of even commonest objects finds more things in nature than there are names for in common language. The investigator of things is therefore obliged to be the inventor of new terms; and every science has therefore its vocabulary of special terms, every one of them necessary to the science and to the man of science, but to the world at large useless. In connection with his study of seeds, Theophrastus was obliged to invent ne

: Hist., Book vii, ch. 3 .

2 Meyer, Geschichte der Botanik, vol. i, p. 166. 
terms, and to give new meanings to old ones. Most seeds were grown and perfected under some special covering formed to shelter, contain, and nourish them until mature. For particular kinds of such coverings particular names were in common use: pod, husk, chaff, shell, and for succulent or fleshy coverings of seeds pome, berry, acine, or more comprehensively, fruits. A general term which should include all these coverings was needed, and the word pericarp was coined. ${ }^{1}$ This done he defines a fruit scientifically. It consists of a pericarp and the seed or seeds which it encloses. Henceforward, while in agriculture, gardening, domestic economy, and the world's commerce a fruit is what it always was, in botany the term has another meaning, a meaning at once more exact and more comprehensive; and it has this new meaning "universally, and from Theophrastus forward; for modern botany reiterates it from him, unaltered by a syllable; and that of the future will do the same. In practice he did not always rightly distinguish between pericarp and seed. Lecturing upon the fruit, and having a mature sprig of sage or other labiate in hand, he would have taught that the four black nutlets are the seeds, and that the green calyx is their pericarp. Or with a handful of spikes of wheat or barley before him, he would have mistaken the grains for mere seeds, and the chaff for the pericarps. Errors like these in the mere application of his terms were inevitable. They could never have been corrected without microscopically aided vision; and it was indeed a long, long time after the invention of the microscope that botanists first learned the structure of sage nutlets and wheat grains to be that of fruits and not that of seeds.

About pericarps he seems to have observed everything that lay before him within his own limited field. He notes the extreme diversity of them, but, as usual with him, and doubtless for want of time to correlate and classify he gives to the most distinctive kinds little more than an informal mention. Only a single deduction does he venture concerning pericarps in general as unlike other organs, a deduction superficial, curious, geometrical: "No pericarp shows a rectilinear or angular circumscription." 2 Yet the cursory reader of the main chapter on fruits-perusing it in the Greek original-might well wonder with what justice or propriety it can be said that the philosopher did not carefully and effectively generalize about seed in relation to pericarp, when he finds him

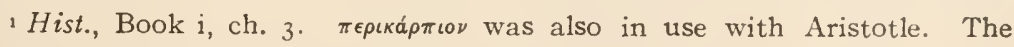
invention of it lies between him and Theophrastus.

2 Ibid., end of ch. I8. 
using over and over again such exceedingly important taxonomic terms as angiosperm and gymnosperm. The fact is, he employed neither in anything like that breadth of meaning which they convey as used in later botany; but both of them very restrictedly. He used angiosperm only to designate one particular circumscription of what are known with us as capsular fruits, namely, the subglobose or urn-shaped or vase-like kinds. The example given is "that of the poppy and those like it." It is corrrelative with

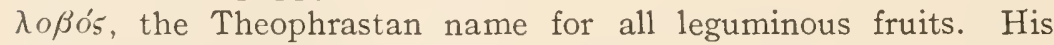
gymnosperms include nothing really gymnospermous in our taxonomic use of that expression. By the examples cited, "coriander, anise, fennel, cyminum, " and several others among kitchengarden plants, the gymnosperms were the umbellifers. They were naked-seeded to him, because, as already noted, he had not recognized any such organ as a calyx; one nowhere in all the plant world more recondite than in the umbellifers. The only real gymnosperms-according to our application of the term-which he knew, were the conifers; but they do not enter, with the umbellifers, into his category of that name. He expresses distinctly though modestly the idea as his own that, as to fruit and seed these stand naturally aloof from all other groups, and thinks the view may be tenable that cones are not fruits at all. "No trees bear capsular fruits, unless you can call a cone a capsule; but it is possible to regard the cone as different from a fruit." Under the head of anthology it was seen that the cone-scale at its flowering stage was a flower-leaf in Theophrastus' understanding of it. Logically, therefore, he would have regarded it in its maturity as a sort of pericarp. But that he left the cones in a place apart, as unclassifiable with other seed vessels - the types of what were to be named gymnosperms twenty centuries afterwards-is yet another evidence of the profound sagacity of the protobotanist. After these things, it is no longer with any surprise that we read his accurate descriptions-descriptions of them from center to circumference-of such fruits as the drupe, the pome, the nut, fig, pomegranate, and other types, and citing as he always does familiar examples of each different kind. But that he should have been as near as he was to a systematizing of the placental attachment of seeds within the pericarp is again almost startling; for when he records it that in many the seeds are as it were promiscuously crowded within the pericarp, while in others they are ranged in regular lines, or at least in separate groups-of which latter he says the squash, cucumber, and apple are examples-we 
know that he has been carrying on research in this direction, and has been able to make this fair beginning at discriminating the different modes of placentation.

The foundations of the whole philosophy of higher plant life and form center in-are concentrated within, if one may so speakthe seed. In botany no less than in zoology is embryology indispensable to a right understanding of the interrelations of things. From the minuteness of his researches into the structure of seeds and the behavior of seedlings, it almost seems as if Theophrastus may have realized this fact. He records many observations on them in all, even their most familiar aspects, not neglecting the diversity of them as to form and coloring. ${ }^{1}$ In a few terse sentences he gives the results of what may have been years of investigation in his botanic garden, upon the subject of the different periods of time required by the seeds of different plants for their germination. "Ocimum, blitum, eruca, and radish are most prompt of all, for they come up on about the third day after the sowing; lettuce on the fourth day; cucumber and squash on the fifth or sixth; anise on the fourth, pepper-grass and mustard on the fifth; beets sown in the spring, on the sixth, in the fall, on the tenth day, orache on the eighth, cabbage on the tenth." Leek and shallot are such close congeners that he evidently expected they would agree as to the time required for their germination, but he finds the seed of shallot coming up at the end of from ten to twelve days while that of the leek takes nineteen or twenty. More than thirty days must be allowed, he says, either satureia or origanum, and forty for celery. After long experience he finds it remarkable that the most favorable conditions as to the season of the year and the state of the atmosphere do not shorten the usual time required for the germination of any kind of seed, though a cold atmosphere, concurring with clouded skies retards it. ${ }^{2}$

These studies in seeds and seedling plants, though by chance interesting and instructive to the gardeners of his time, are essentially those of a great botanical philosopher, with whom not the smallest fact relating to plant life is held unworthy to be placed on record. And as he proceeds, the twentieth-century botanist will be apt to read with amazement a passage like the following as occurring in Theophrastus. "Some seeds in germinating put forth their primary root and leaf from one and the same point; others, the root from one end and the leaf from the other." 3 Pre-

1 Hist Book vii, ch. 3 .

2 Ibid., ch. I.

${ }^{3}$ Hist., Book viii, ch. 2 . 
serving all the terseness and brevity of the original in this very literal rendering, the statement of the fact may seem a trifle exaggerated. The first roots issuing from a grain of wheat or barley appear not quite from the base, but from near it, and the first leaf appears from a point well toward the summit of the grain. The two do not, as in dicotyledonous plants, come forth from the same point. But thus early in the history of botany, even by this first forefather, was given in these words, the first hint of a fundamental distinction between flowering plants as dicotyledonous and monocotyledonous. By way of further elucidation he continues: "Wheat, barley, rye, and all the grains sprout from both ends; that is to say, the basal and thicker end of the grain puts forth the root, the upper and narrower end the green herbage. The two, however, are connccted and continuous as one. But neither the bean nor any other seeds of leguminous plants have this way of sprouting. These put forth root and stem from the same point, namely, that at which the seed was linked to pod, as if under that point [the hilum of later terminology] lay the special seat of the growing principle. In the case of seeds of this kind the root at first appearing begins to show a downward tendency, the stem an upward. The seeds of the frumentaceous and the leguminous kinds are alike in this one particular of sprouting from the point of insertion; but of certain trees, the almond, walnut, the oaks and their allies, the seeds sprout from the opposite end." I have omitted here one of the most important clauses; that in which he indicates his having observed in the bean and lupine allies the two cotyledons, joined to the hypocotyle. ${ }^{1}$ Later in the same chapter he states without simile or comparison the same characteristic. "The seeds of all the latter," that is, of the particular trees he has mentioned, and of the leguminous herbs, "are in a manner two-parted." And again: "Wheat and barley make their first appearance with but a single leaf, peas and beans with several"; from which it is manifest that hc counts the cotyledons as leaves, along with the one or two that appear in the plumule. Still other facts and phenomena observed and recorded by him about germinating seeds, and young seedlings, must enkindle toward Theophrastus the wondering admiration of the most accomplished modern botanist. He says that he finds it uniformly true, whatever the kind or the structure of the seed, that the "root" is first to appear, after that the leaf or leaves; also that the cereals, while

1 In Latin the clause runs thus: "Id quod in quibusdam partis pudendæ refert formam, ceu in faba et cicere, sed maxime in lupino." 
as yet showing but a solitary primal leaf, exhibit quite a tuft of roots, these all simple and equal, whereas the two-parted seeds in their germinating exhibit several leaves and but a solitary "root." Furthermore he notes that the grains with their multiple roots send up culms that never branch, while the merely tap-rooted leguminous herbs exhibit stems that branch freely and widely.

To the beautiful work of a Malpighi one gives somewhat more credit than is fairly due it, until one has read these chapters of the ancient Athenian master. Then it is clearly apprehended that the man of the seventeenth century may have received the suggestions of his own work directly from the Greek philosopher; and is almost ready to add that the beautiful drawings of sprouting grain adorning Malpighi's folio might almost have been done from the Theophrastan descriptions of the same. It must needs be conceded that the botanic garden at Athens, founded by Aristotle, and the earliest of which there is any record, was wonderfully prolific of new botanical facts of profoundest import. What later one has equalled it in supplying first principles to botany as a science? Or who since Theophrastus has used an opportunity of that kind so immensely to the advantage of succeeding generations?

Anatomy. Immediately after having enumerated the principal external organs of plants, and given the first outline of a system based on these, Theophrastus takes up the subject of internal structure. Two short chapters contain the simplest elements of plant anatomy, as he is able to make them out. If these chapters commend themselves to our most careful reading, it is partly because they are the earliest in which such matter was discussed, and partly for the reason that after the writing of them some eighteen centuries elapsed before another botanist resumed the topic.

Apparently having in mind all forms of plant life except the lowest and simplest, he opens. the subject with the statement that "plants are made up of bark, wood, and pith when pith is present." 1 We of the present are accustomed to this as being the structure of stems. Let none be disquieted by the fact that Theophrastus does not limit bark, wood, and pith to stems; for we are learning that he never writes a line carelessly; never indites the simplest and most fundamental proposition without rigid investigation and profound forethought. Possibly we shall find that he thinks the substances of bark, of wood, and of pith all 
occur in other parts besides stem and branches-in leaves, or even in fruits.

Now if the history of plant anatomy is to begin as near its true beginning is possible, those three Greek terms must be consulted which come into our language as bark, wood, and pith. The first two will not detain us. The bark and wood are, each in many different ways, too indispensably necessary to primal man, to have failed to be distinguished and named long before the advent of the most primitive philosophies. Theophrastus took the terms $q$ lorós and Éxhor as he found them, ready to hand and well suited to his use. It was otherwise with the term which he selected by which to indicate the pith of plants. This part was not well known. Primal man, in quest of only the obvious and the useful in nature, may have been unaware of the existence of it. Woody growths, in that mature condition in which they supply the savage and the half-civilized with timber, fuel, bast, and dye-stuffs, show no pith. But that enlightened and philosophic inquiry into nature's obscure things, which Greeks had begun to pursue before Theophrastus' time, had brought to notice this part of plants which was not bark, neither wood. The philosophic must have discussed the substance, perhaps had written about it, for they had attempted to name it. This we have from Theophrastus himself, who says that some called it the heart of plants, others called it the marrow. ${ }^{1}$ In this connection he did what with him is most unusual, almost timorously conservative man that he was; he declined to accept either "heart" or "marrow" as a suitable name for this part of a plant. This can mean nothing else but that he himself had taken the pith under special investigation and thereby had reached a new conclusion; had found that it was in no important point analogous to marrow, and farther still from corresponding to the heart in animals. We know enough about 'Theophrastus' temperament to warrant the assertion that he would have been the last of men to reject two names already in use for a thing, until he was able to prove that both were utterly false to nature. The new name which eventually he offered is one which can not have suggested itself from any study of the substance in that dry, whitened, imponderous, and effete condition in which it is seen in mature stems and branches, in which condition alone we of to-day call it pith. As philosopher, and as one whom we, if he had lived in our time, should have 
known as a "scientific botanist," what he wished to ascertain was the function of this substance in the economy of plant life. This he certainly did discover; but he never could have done so had he confined his investigations to the pith as no longer vitalized and operative; therefore he must have sought it in its young and growing state, when of all parts of the plant this is most tender, replete with sap, and a strong center of vital activity, really the matrix within which are generated both bark and wood. The

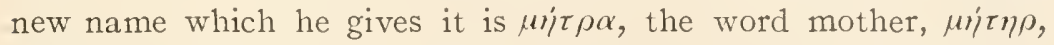
somewhat altered, and in earlier Greek the womb, the mother of life. ${ }^{1}$

Theophrastus never records his processes of investigation; but when he selects the word metra, matrix, to be the appropriate name of the pith of plants, we see at once that it does not really apply to it in its white, imponderous, and devitalized condition, and that he must have named it in reference to its earlier state, that of living parenchyma. We may well divest ourselves of the prejudice that the beginnings of a scientific and sound plant anatomy were not made until after the invention of lenses and microscopes. This man of antiquity, he who had progressed so far in plant embryology as to have made out even the seed distinctions between exogens and endogens, could just as easily discover, in the crosssection of a large and very tender shoot of elder or of maple, the first traces of the several fibro-vascular bundles standing in a circle midway between where the pith was to be and the place of the bark. Successive cross-sections made at intervals would reveal to him the gradual hardening and widening of those bundles, their final apparent meeting and coalescing into the cylinder of hard wood intervening between the central pith and the now formative bark. It is undoubted that Theophrastus had thus seen, in young shoots, the early stage at which bark and pith are all one in form and substance, and that from it, even within it, both wood and bark are gradually generated; and that because of this he called the juicy soft living pith the metra, the matrix. In reality, while searching to find what pith would be like in its living state, and what in that state its function might seem to be, Theophrastus had discovered living parenchyma.

Such a conclusion, when we have been driven to it in order that the man's words may not be meaningless, needs no further support; and yet there is one other circumstance which would confirm it

1 Just as in certain European languages still spoken there is no one word for womb, but the phrase "mother of life" instead. 
were confirmation called for. Hitherto I have conformed to usage, very ancient as well as modern, of writing bark, wood, pith, in just that sequence. It seems natural. It is at least a geometrical succession of the terms, and therewithal not inelegant. Even the translators of Theophrastus from Greek into Latin have made him out as having named first the bark, then the wood, and lastly the pith. Uniwitingly they committed an inaccuracy, and have misrepresented him; for Theophrastus wrote it thus: bark, pith, wood. This sequence is not geometric, but it is biologic. It would be illogical and awkward, were it not more exactly truthful than the other and merely geometric succession of the terms. As he placed them, the story is told again of how in early stages of development bark and pith are substantially identical. Therefore in their most widely differentiated condition they are next of kin, more nearly related each to the other than either one is to the wood.

This biologic investigation of the pith led to the detection and segregation of other elements in stem structure; discoveries that are all his own, for he expressly says of these elements that they have no names. He thinks that he can not do better than apply to each the name of some analogous part of the anatomy of animals. The whole fabric of stems he makes out as consisting of what he calls veins, nerves, and flesh. They are new uses of these terms and he defines the botanical use of each, premising first of all that vein and nerve are substantially one, differing scarcely otherwise than as to dimensions, nerves being smaller than veins; adding also that in plants these are simply elongated and do not branch. The universal mark of the fabric which is composed of them is, that it splits, and is not otherwise readily divisible. Flesh has the very different quality of being divisible with equal readiness in all directions, like a lump of earth. ${ }^{1}$ Here, quite as we had been prepared to expect from his new naming of the pith, and his indicating its consanguinity with bark rather than with wood, we see plainly that Theophrastus discovered and distinguished well what in post-Malpighian times we have learned to know as parenchyma and prosenchyma. He is now able to add a new chapter to plant anatomy, for he can name the elemental constituents of bark, of wood, and of pith. Wood, he says, is composed of nerve and moisture; although some woods, such as of the palms and of ferula, are of flesh; such however in mature and dry condition show that the flesh has been partly converted into wood. When he cites

1 Hist., Book i, ch. 4 . 
the wood of palm and umbellifer, we realize the expression of the popular notion of wood as being that which the bark of any tree encloses, without regard to density or ponderability. His language here nevertheless evinces plainly his having taken full cognizance of the fundamental difference between the wood of palms and that of all exogenous trees. To pith he attributes flesh and sap only. Bark is composed of all three of these elementals in most cases, as in the oak, poplar, and pear tree, though in some, the grape-vine, for example, of nerve and sap only-that is to say, without flesh, or what we call parenchyma.

The structural elements of the leaves of exogens he apprehended as substantially identical with those of the bark. The stalklet, and therewith the fibrous framework of the blade, are of that which he designates as nerve, or sinew. ${ }^{1}$ Next to this he names the epidermis, and after that, what he calls the flesh, known to us as the mesophyll. In the leaves of palms and reedy or grassy plants he finds no flesh at all, and thinks these are composed of fibre and epidermis only. The edible fruits of trees and shrubs are composed mostly of flesh, with little or no fibrous tissue; while, on the other hand, some pericarps consist of a rind or skin only. He has so clearly distinguished these two or three elementals of the plant fabric that he is able to trace and point them out in every plant organ from root to fruit.

Phytography. In descriptive botany there are two different nethods by which it is undertaken to convey by means of language the image, so to speak, of some tree or other growth which the describer has seen, and the reader is supposed not to have seen. That two distinct methods in phytography exist is something of which I have seen no mention either with any botanical author, or with any historian of botany; but a suggestion of them has been made very recently, with also a good account of Theophrastus' phytographic method, in an excellent treatise on some parts of Theophrastan botany by Dr. Hugo Bretzl. Let me for convenience designate the methods as the natural and the artificial. They may, however, quite as fitly be named the comparative and the positive methods of plant description. Of the two, one is very ancient, the other strictly modern; and the artificial or positive is doubtless the more perfectly adapted to its purpose, though only for such writers and such readers as are competent to use it; for it requires the mastery, on the part of both, of a very extensive vocabulary of special terms; in reality, the learning of a new

1 Hist., Book i, ch. I 7 . 
language. What I have designated as the natural method of describing plants vindicates its right to that title by the fact of its primitive universality. If I speak of it otherwise as the method of comparisons, in allusion to what it chiefly exacts of him who would use it: that is, first, familiar acquaintance with certain specific types as standards of comparison, and second, the ability to construct a mental image of the unknown by means of the describer's telling in what several particulars it differs from the given type known to both. By way of illustration, an untaught woodman, familiar with junipers, reports to a botanist that in a new region to which he has wandered there are trees in all respects like red cedar, or juniper, except that instead of yielding berries they bear round cone-like bodies approaching the size and form of smallish walnuts. The botanist at once pictures in his own mind cypress trees, and assures his informant that his new trees are cypresses. Such is the method of comparison in phytography; and it may quite as aptly be called the natural one, for it is that invariably used by the primitive and untaught; not, however, always very well and successfully. Being the primitive method, it is therefore that of Theophrastus; not, however, to the complete exclusion of a number of absolutely definitive terms such as are now in use and always have been. The Greek observed that, taking the plant world as a whole, the leaf is the most endlessly diversified of organs, and also that within the limits of a species its form is constant; from which two conditions it follows that no other organ is so readily available in making distinctions between different plants. Now as to the art of plant-description by the method of comparison, it is very necessary that the types to be used in comparing be chosen considerately. There seem to be indications of his having thought upon this matter, though he has not explained, or even didactically set forth his scheme. It is only by a certain order and fitness in the scheme itself that one infers the author's having studied it out. The most common types of leaf outline are perhaps the lanceolate, ovate, oblong, and suborbicular. He knows nothing of any such terms; but when he wishes to say that which would express what modern botany expresses by the term lanceolate, he says the leaf is that of the laurel, i. e., Laurus nobilis. A leaf that we should describe as oblong, unless it be much too large, is with him that of the olive tree. A leaf that is of rounded contour and nearly as broad as long is compared by him to that of the pear tree. For the ovate in outline his type is the leaf of the ivy, Hedera Helix, in respect to which one must 
not fail to note that it is the leaf peculiar to the mature and fruiting ivy bush, not that of the rooting and climbing young plant; for the leaves of this are too broad to represent the ovate, and are angularly lobed.

Note now certain points of agreement among these four leafoutline types. (I) All are leaves of trees; for few herbaceous plants display such uniformity of foliage as to the individual specimen. There is apt to be one form and size of leaf near the base of such a stem, and another widely different description of leaf at the summit, with intermediate forms up and down between base and summit. With some notable exceptions-of which the Greek takes advantage here and there-leaves of herbs do not answer the purpose. (2) The trees are all selected from among such as are most universally and familiarly known; every one of them common in cultivation. Every civilized Greek of three thousand years since knew the sweet bay, the olive, the pear tree, the ivy. (3) The leaves of them all have a certain firmness of texture, either leathery, or approaching it. By this prevision any soft herbaceous plant having lanceolate entire foliage may be described as to its foliage by merely saying that its leaves are like those of the laurel, but thin. (4) The leaves of all four of the types are entire: whereby the leaf that is of lanceolate cut, coriaceous texture, and entire margin, no matter in what genus it may occur, may be described by simply saying that it is the leaf of the laurel. Supposing, however, that a tree is to be described the leaves of which are lanceolate, coriaceous, but with margin serrated, then its description as to leaf will be, that it is like the laurel leaf, but serrated. And this selecting of types that have entire leaves is manifestly better than it would have been to have selected serrate leaves for types. In such a climate as that of the Mediterranean, evergreen trees and shrubs predominate, all of them with coriaceous foliage, the kinds with entire leaves being very notably in excess of those having toothed or serrated leaf-margins; therefore the choosing of as many entire-leaved types as he could was natural to a man in Theophrastus' place and enrironment, as well as making for economy of time and space in describing things. It was by no means accidental that this descriptive botanist selected the olive, the sweet bay, the myrtle tree, and the box as patterns of leaf outline to be referred to in his phytographic work. ${ }^{1}$

How well such a system of morphologic types is adapted to the - See also Dr. Hugo Bretzl, Botanische Forschungen des Alexanderzuges, pp. 8-22. 
purposes of description may best be shown by quoting a few examples. A wild elm tree that inhabits the mountain districts he says has "leaves like those of the pear tree, but longer in proportion, with serrated margin, and a rough rather than smooth surface." 1 This makes it plain that Theophrastus' first purpose in choosing leaf types was that of imparting ideas of general outline. To begin the account of an elm leaf by affirming it to be like that of a pear tree is awkward and even mischievous, upon any other supposition than that by such phrase he alludes to size and general circumscription only; which also the expressions immediately succeeding prove; for he who had pictured in his mind at first a pear leaf for an elm leaf must now proceed, under direction of the describer, to alter it by giving it a very distinctly sawtoothed margin, and after that a roughness of surface, of which there is no trace upon the pear leaf. What he now sees mentally as a leaf of the little known wild elm is like a pear leaf in nothing save its general contour. The elder tree, Sambucus nigra, Theophrastus seems to have taken pleasure in describing rather minutely, although the tree was no rarity, but rather familiarly known. But it seems to have been this which taught him the existence of such a thing as a compound leaf; and he gives a particular account of the species from root to fruit. When he comes to the lanceolate individual leaflet he says it is like the leaf of the sweet bay but larger, relatively wider in the middle and at base, more pointed at summit, serrated all around, and the whole more soft and pliable in texture. ${ }^{2}$ To one acquainted with the sweet bay and the elder, I do not know where, in even the most recent botany, he will find a more complete description of the elder leaflet. The leaves of maples, mostly wildwood trees and less familiarly known, are compared with those of the omnipresent plane. The maple leaves are also ample, cleft somewhat after the same manner, but not to the middle as in the plane, Platamus orientalis, longer in proportion to their breadth, of a more delicate texture, and not rough to the touch. ${ }^{3}$

This system of leaf describing by comparison with types is both natural and not ill adapted to the purposes of phytography. Had it not been so it would not have remained in vogue for two thousand years after Theophrastus. Greek authors after him, as well as Pliny and other Latin writers, knew no other method of leaf

I Hist., Book iii, ch. I3.

2 Ibid., Book i, ch. I3.

3 Ibid., Book iii, ch. II. 
diagnosis. The number of the indicative types was gradually augmented, and the use of them was universal even with the fathers of sixteenth- and seventeenth-century botany; nor has any later generation wholly ceased from the usage; though it is perhaps chiefly conspicuous nowhere but in nomenclature, where such specific appellations as salicifoliu, alnifolia, betulifolia, delphinifolia, and a hundred more, though ostensibly figuring but as names, may chance to be the best part of the diagnosis, at least in the estimation of any not well versed in the post-Linnæan descriptive terminology.

It is not to be inferred from anything here said, that the Greek knew nothing of any geometric terminology of leaf forms. In that chapter in which he treats of leaf forms in general he names the orbicular, the oblong, the angular, and some others ${ }^{1}$; but they lack definiteness of meaning, at least such definiteness as the exigencies of plant diagnosis call for; though terms that bear upon differences of apex, margin, and base as well as the superficies of the leaf are of more fixed and certain meaning.

It will be observed that even flowers are described by Theophrastus comparatively, the less known being brought into contrast with the well known; and the same rule applies, of course, in his diagnoses of fruits and seeds. He was not particularly given to describing plants. A great proportion of those which he discourses upon were well known to all who would become his readers. The common things of the gardens, of the cultivated fields, of orchard and vineyard and of academic grove, were so familiar that the mention of the name was sufficient. But when he undertakes the description of any herb or bush or tree, he is apt to give more than a rude outline of it; very often a good word picture of it; and he who does this is a master of phytography, without question about the age in which he has lived, or the method he has employed. In the case of a number of Asiatic and African trees unknown to Theophrastus except by report of travellers, he so carefully gleans all that others have said about them, and with such consummate art sums up the whole, and draws up his own description, that in reading it one finds it not easy to realize that the author of it never saw the tree. The books of botany that were composed by Greeks and by Latins within three or four centuries after Theophrastus show that the authors of them copied his descriptions whenever such were available, and in other cases made his the model of their own diagnoses. When we come to the

1 Hist., Book i, ch. I6. 
era of strongly renewed scientific activity in the sixteenth century, we shall find botanical authors of the time employing many of 'Theophrastus' descriptions of plant species without alteration of any kind; some, like Brunfels, Tragus, and Cesalpino and their class, formally crediting each such diagnosis to its ancient author, others without making such acknowledgment. But they of this period who rentured upon new descriptions of plants which Theophrastus had described of old seem to have exposed themselves to public censure, as needlessly, perhaps irreverently, supplanting or amending the excellent work of the father of phytography.

Taxonomy. To teach, as it has been taught and is still taught, that Tournefort (1694) first ranged the members of the plant world under genera, that Linnæus ( 753 ) first clearly distinguished species and varieties, and that Adanson ( $176_{3}$ ) first proposed the grouping of genera into families - all this is to inculcate fable. It has been already suggested, and forcibly enough, that plant taxonomy was not invented in any school, or by any philosopher; that it is everywhere as old as language; that no plant name is the name of an individual plant, but is always the name of some group of individuals, and that all grouping is classifying. Botanical taxonomy began at whatever time far off and prehistoric men began to give names to plants; and it increased with the recognition and the naming of new groups-always groups, never single plants. Had some earlier Theophrastus appeared upon the scene some thousands of years earlier than this one did, in this particular at least he would have found himself in the midst of a like environment. He would have found some hundreds of kinds of cultivated plants familiarly known, spoken of always under group names. In other phrase, he would have found a certain taxonomy ready to hand, such as answered the needs of those who had to do with plants industrially.

The real Theophrastus, entering the field, not in the far-off age of Homer, whose poems are full of tree and plant lore, but many hundred years later, had much to do in the first place in acquainting himself with the vast sum of knowledge, of theory, of poetic fancy, and of superstitious fable that was then extant concerning plants. All this he accomplished, as his pages plainly show, and that with the occasional expression of something like the scientific man's impatience of the superstitious and the fabulous. As distinctively a nature student, however, exploiting the realms of nature from the philosopher's viewpoint rather than from that 
of the economist, it would not have been strange had he invented some new taxonomic scheme of his own, and then, thrusting aside all the commonly accepted plant groupings, had sought to install an entirely new system of taxonomy in place of the old. ${ }^{1}$ He did nothing of the kind; and if he did not, it may have been for the excellent reason that that already in vogue, when duly examined, to a great degree commended itself to the philosophic judgment as having been deduced from nature, and that in as far as it had progressed, was often well enough done. Parts of it could not be amended, and, we may now say confidently, were destined to acceptance as sound taxonomy as long as the world of plants should endure, or a botanist remain to study it; at many points it might be amended or added to, and the whole must be extended and variously improved.

We may assure ourselves by a study of Theophrastus, that something very like this was the task to which he addressed himself as regards the classification of plant organs and the systematization of $p$ ants themselves; and the careful reader of his chapters will note often his great conservatism-his manifest aversion to startling the good public by pronouncements that are new, and that will openly antagonize them as assailing their old doctrines and their deeply ingrained prejudices.

All these things being true, one ascertains with difficulty, if at all, what the historian is most in need of knowing, namely where this writer of the first book of botany is recording points of taxonomy that are of prehistoric discovery and universal traditional acceptance, and where he is introducing some amendment or improvement of his own. For example, in a very early chapter of his work Theophrastus ranged all the plants that he had ever seen, or heard, or read about, under the four primary groups of tree, shrub, half-shrub, and herb-ír $\delta \rho o v, \theta \alpha \dot{\alpha} \mu 0_{5}^{-}, \phi \rho v^{\prime} y \alpha v o v, \pi o^{\prime} \alpha{ }^{2}$ It is one of the most classic pieces of plant taxonomy; one that stood the test of all the ages and is immortal. Nothing that by any means could be elicited from out the hazy past would be of deeper botanical interest than information as to whether this fine piece of taxonomic work had been handed down in its completeness to Theophrastus, or whether as he gives it it represents much augmentation, or condensation, or finishing and perfecting accomplished for it by himself. We have met with like pro-

1 This is almost precisely what Tournefort undertook to do in the seventeenth century, and Linnæus again in the eighteenth.

${ }^{2}$ Hist., Book i, ch. 5 . 
blems before ${ }^{1}$; to the full solution of this I am incompetent. For this, the botanist's best skill would need to be supplemented by the erudition of the specialist in Greek philology. Nevertheless the following hints may make it plain that $\delta \varepsilon^{\prime} v \delta \rho o v, \theta \alpha^{\prime} \mu \nu \sigma_{\xi}, \phi \rho \dot{y} \gamma \alpha-$ $v o v, \pi o \alpha$, is a piece of classification that was studiously wrought out by Theophrastus himself. In the Greek of his time there were at least two words for tree, $\delta \dot{\varepsilon} \nu \delta \rho o v$, and $v^{\prime} \lambda \eta$, the former more particularly designating such as were cultivated; the fruitbearing, nut-bearing, and such as were planted for shade or ornament; the latter applying more specifically to wild trees used as timber; almost the equivalent of our English terms woodland, forest, timber-tree, etc. We have elsewhere remarked upon the Theophrastan classifying of all growths as tame and wild. The idea was deeply seated in the Greek mind; and for trees in general, wild as well as domesticated, he could not well have chosen any other term than $\delta \varepsilon^{\prime} \delta \rho o v$, though it was more properly the appellation of the civilized contingent of arboreal growths. Similarly $\theta \alpha \mu v 0$, at least etymologically, signified a densely compacted woody growth,- and not necessarily of low stature. The full-grown olive tree was sometimes called a $\theta \dot{\alpha} \mu v_{0}$; , on account of the bushy density of its head. Also as looking to the distinction between bushes of cultivation and a wildwood thicket, the latter was also $v^{\prime \prime} \lambda \eta$ sometimes, if not even usually. Thus again as with $\delta \varepsilon \dot{\varepsilon} \gamma \rho \rho v$ the botanist selects for extended use that which signifies the cultivated and better known.

Coming now to the class of suffrutescent plants-the halfshrubby, half-herbaceous kinds-it appears to me no less than certain that Theophrastus was first to discover, indicate, and name this particular category. There seems to have been no word for this kind of thing in the older Greek; for $q \rho \dot{y} y \alpha v 0 v$ meant nothing more than a bundle of faggots, dead and dry branchlets and twigs of trees which, either as windfalls or as left behind by the woodchopper, were laid lengthwise and tied into bundles for fuel. There was, however, the old word $\theta \alpha \mu v i o v$, which one almost wonders he did not adopt for his category of the half-shrubby. It is but a diminutive of $\theta \dot{\alpha} \mu r_{0}$ and means a little bush or small shrub. At second thought one perceives that it would not well answer the purpose. It gives no intimation of the true characteristic of the suffrutescent growths, which is this, that the lower and woody part represents a shrub, while the upper portion, that which bears more scattered foliage together with the flowers and fruits, is

1 See page 66 preceding. 
herbaceous-that is, dies back every autumn after the fruiting and is renewed again in the summer. In late autumn and early winter, while the dead or half-dead upright and parallel summer branches are still present, surmounting the shorter tuft of truly woody lower branches, the bush would vividly enough recall a faggot bundle. Even where abounding, as such growths do on open plain or stony mountain slope throughout all half-arid regions of the world, they must have been used as faggots always. He who knows familiarly such ancient garden plants as the lavender and sage and rue, and the wild half-shrubby artemisias and other like composites of all dry climates, will perceive readily that $\phi \rho \dot{v} \gamma \alpha \nu \nu \nu$, the faggot bundle, lent itself to Theophrastus' scientific purpose in this instance. He might have created a new term; but the conservative prefers to make new use and application of some old and familiar term. The public never takes kindly to new names.

In distinguishing the category of the suffrutescent, the Greek had proceeded analytically. In establishing upon all herbaceous plants one comprehensive group under one name, his procedure was synthetic. It was not indicating a single new group hitherto unrecognized and naming it. It was the synthesis of a number of groups long recognized and separately named; the putting together of such, to constitute a single more comprehensive assemblage, and under one name.

A glance at the actual situation in which we English-speaking people find ourselves as to our terminology of the herbaceous will help us to apprehend clearly the Theophrastan standpoint. We have no single word by which we venture commonly to designate the aggregate of things herbaceous. If in our fundamentals of botany we still follow Theophrastus in writing or speaking of tree, shrub, and herb, that is at once the beginning and the end of our using the term "herb" thus comprehensively. Thenceforward we ignore it and write or speak about "herbaceous plants"; this for the manifest reason that "herb" used by itself has almost universally a special meaning of which it seems impossible to divest it. An herb is something, neither tree nor shrub, which is either medicinal, aromatic, or culinary. The other terms in common use for subordinate groups of herbaceous plants are vegetable, weed, grass, and worst of all the word "plant" itself; for this, as first introduced into our English speech, and as almost universally employed down to our day, signifies only things herbaceous, yet not all; for neither weeds nor grasses are commonly called plants, in our tongue, except technically. Thus our category of the herbaceous includes the 
segregates herb, vegetable, weed, grass, plant. And the endeavors of our English scientific forefathers to make any one of those terms serve as the name for herbaceous growths in general have been unsuccessful. Theophrastus had been in the same predicament as that which became theirs. In his mother tongue

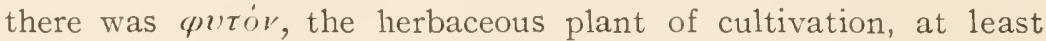
as to its most primitive signification; there were $\lambda \alpha \chi \alpha v o v$, the kitchen-garden vegetable, $\beta \circ \tau \alpha v \eta$, the weed, and $\pi \dot{o} \alpha$, the grass, the forage herb. The first of these terms quto $v$, the herbaceous thing that men plant and transplant and cultivate, was a term that he himself appears to have rendered unavailable. He had made it to include the whole vegetable kingdom from oak and pine to seaweed and fungus. The name that to him seemed most reasonably available for designating the sum of all things green-herbaceous-was the common name of the grasses and fodder plants, $\pi o^{\alpha} \alpha$. When I say reasonably available, my thought is that the selecting of the term grass rather than the term herb for expressing the aggregate was most natural to any one who, like Theophrastus, had thought the matter over. The grasses form by far the greater proportion of that low-growing verdure which, outside of the forests and thickets, covers the whole earth in all temperate latitudes during half the year. It was therefore more true to nature - more scientific-to take up that term which came so near being synonymous with verdure. The term herb is comparatively unfit, as suggesting a much smaller aggregate, and that also of plants marked by odors, flavors, and other qualities which the eye can not detect. There are even modern languages in which the word for all green herbage is the correlative of our word "grass": languages in the botanical vernacular of which, what we call herbaceous plants are known only as "grass." This was strictly true of our English of only a few centuries ago. ${ }^{1}$ Thus again how plain it is that the forefather of all botany produced this primal outline taxonomic only after the most careful weighing and considering of every point involved. Nor must our attention be called away from this first chapter of Theophrastus' classification without our having observed the sequence of the groups. Why does he begin with the Grand Division of the trees and proceed downward to that which

1 There is a familiar sacred verse that attests this: "All flesh is grass, and all the glory of man is as the flower of grass. The grass withereth, and the flower thereof falleth away." - - Pet. i, 24. At the date of this translation gramineous plants were regarded as flowerless. Therefore in the minds of the learned translators even showily flowering herbaceous plants were a part of "grass." 
will include such phytologic ambiguities-for such they were in his day and for ages afterward-as lichens and fungi? There is no room for doubt that one consideration was the very rational one, that botany may not safely begin at any point where doubt may arise as to what realm of nature the subjects of study belong to. The title of trees in general to be regarded a part of the plant world is secure; that of no other growths more so; while judged by his own criteria of phytologic rank, the very highest place must be accorded to trees. In his view they were the most perfectly organized of all.

Inasmuch as the fourth and last Grand Division $\pi \alpha^{\alpha}$, the Grass Plants, i. e., the Herbaceous, is the largest of all as to numbers both of individuals and of species and as regards their almost universal prevalence, it will naturally be here that we shall look for further expression of taxonomic idea; suggestions of grouping subordinate to that of $\pi \dot{s} \alpha$, the herb.

The most comprehensive of his subordinate groups is that which he denominates $\varkappa \alpha \lambda \alpha \mu c \delta \delta \eta, 1$ which comes into Latin as Arundinaceæ; its type being that superb grass Arundo Donax. In an author so primitive one does not look for any rigidly formal diagnosis of a group. Calamodes in itself is diagnostic. It will include all plants that recall calamus, that is, Arundo Donax. In one place he has written that the leaves of this, and other things which he cites, seem to be made up of nerves only, comparing them with those of the grape and fig, which he says have not only nerves but also flesh and epidermis in their make-up. ${ }^{2}$ The interpretation of this is that he has become aware of the differences of anatomical structure subsisting between the leaves of endogens and exogens. His group Calamodes-better written, after the usage of his Latin translators, Arundinaceæ-embraces Arundo and the cereals Triticum, Secale, Hordeum, Oryza, and others; that is, he names these as types. By their leaf characters all other gramineous plants cultivated and wild, known or unknown, fall within the lines circumscribing his Arundinaceæ. And what else besides the true grasses? In one place he names as among the arundinaceous certain plants the leaves of which in so far depart from the typical as to present an angular cross-section, and these seem to him as if made up of two leaves joined by their edges to something like a keel. It is the conduplicate and keeled leaves of such things as Cyperus and Sparganium, as any botanist would know from the

2 Hist., Book i, ch. Io.

${ }^{2}$ Ibid., ch. I 7 . 
description of them, even without 'Theophrastus' having named those particular genera, adding that other denizens of marshy grounds have such foliage. Even the palms - of which he knew only Phonix, pinnate-fronded-he cites by name as being arundinaceous. ${ }^{1}$ Such reeds and rushes as to him seemed quite leafless would still vindicate to themselves places within the group by virtue of their altogether pithy or else hollow stems or culms. We are sure, then, that this assemblage of the Calamodes embraced all true grasses, all sedges, besides the juncaceous, typhaceous, sparganiacous, plants, and palms. It will be observed that all are monocotyledonous; that the group embraces by far the greater proportion of such; only the showily spathaceous and the really petaliferous genera being left out. Recalling here the circumstance that in all early taxonomy roots figure very conspicuously, it becomes interestingly significant that into this great class of the Calamodes,a group which, as regards the number of species, comes near being the equivalent of our endogens-not a genus is admitted that has either bulb or corm. Every member of the vast assemblage has copious fibrous roots; these in moiety of the species supplemented, as Theophrastus might have worded it, by that which he had chosen to name the jointed root, i.e., the slender rhizome; a single sedge, Cyperus esculentus, bearing nut-like protuberances as if at the ends of some few of the root fibres. There is not the shadow of a doubt that this pristine plant anatomist and systematist recognized the structure of leaf-stalk and flower-stalk of Arum and Colocasia as at full agreement with that of half his Calamodes; and the same must have been familiar to him in the case of the grassy-leaved crocus and its allies; and the "roots" of these must have excluded them from taxonomic consociation with the rest, in all probability, even had their flowers been leafless and less in contrast to those of grass and reed and sedge. The aggregate of bulbous and cormose plants, the araceous I think excepted, were known and spoken of by him as $\beta 0 \lambda \beta \omega \delta 175$ - the Bulbaceæ. As a group it contained, first of all and typically, the onion and its several congeners, even the leek, a plant that though alliaceous is not bulbous; after these the bulbous Liliaceæ, Amaryllidaceæ, and the cormose iris allies. With the types and several of the species of all these he was familiarly acquainted.

There are other natural families not a few of which Theophrastus apprehended with precision, even assigning names to several of them. Such are the Umbelliferæ, for an example, to which as a 1 Hist., Book i, ch. r 6 . 
family he gives the name vapAnucions, which in the Latin versions had to be written Ferulaceæ, from ferula-in Greek $\vee \alpha p H \eta \xi$, a stalk of fennel or of ferula-commonest umbellifers of the Mediterranean region. Plainly the thistles and their natural allies were accepted by him as constituting another such family group; for he often refers to them under the collective name of $\alpha \varkappa \alpha \nu \theta$ co $\delta \eta 5$, and twice mentions that all of them are prickly-leaved herbs whose flower consists of a head of florets, each floret sitting on the summit of a seed. ${ }^{1}$ In Latin versions these are the Acanaceæ, from Cnicus Acarna, Linn., one of the most common thistles of Greece and Italy. Into this family Theophrastus admitted Dipsacus, the leaves of which are not prickly, as he concedes, but on account of its answering to the thistles in this, that its florets crown each its seed. And Eryngium also, and not unnaturally, with its spinescent foliage and capitate inflorescence, finds place among the thistles rather than with the umbellifers. The numerous cichoriaceous genera, with their peculiar habit, milky juice, and sameness of character as to flower and fruit, formed also a family with our Greek, who called it myapıos $n s,{ }^{2}$ which the Latins wrote Cichoraceæ. These for examples of his having given to groups of genera class names and family names. Others need not be cited; but it should be mentioned that the family relationship of small groups of genera is in many an instance clearly seen by him when no group name is used. The pines, fir, spruce, and larch are discussed in a place by themselves; the various poplars, together with alder and birch, occupy successively another place, and the same is true elsewhere in the dendrological chapters of the book. The intimate relationship between the poppies and the pond lilies was so clearly perceived by Theophrastus that, while in general he seems to like to group things ecologically, the aquatics in chapters apart from mesophytes, he nevertheless proceeds without a halt from the papaveraceous plants of the grain fields to their kindred of the lakes and rivers. ${ }^{3}$ He perceived upon them all, th: marks of one and the same family.

It is again very interesting to note here and there a question raised as to the extent of some family; whether such or such a genus is or is not of the same family with such another, for example: "Some affirm that cucumbers and squashes are as closely interrelated as radishes and turnips are; others deny it." 4 The

1 Hist., Book i, ch. 22.

'Ibid., vii, ch. II.

${ }^{3}$ Ibid., ix, ch. I3.

- Ibid., vii, ch. 4 . 
passage reveals gardeners and botanists of remote antiquity in debate about the affinities of genera; and the man whose word of authority might or might not have ended the debate, diplomat that he is, as well as philosopher, expresses no opinion; though none who have studied him well can doubt that he had one, and the correct one.

This outlining of families of plants and giving them family names entails one extremely important logical sequence, which one must not fail to indicate. His Arundinaceæ, Bulbaceæ, Ferulaceæ, Acanaceæ, Cichoriaceæ, and all the rest, as established on certain organologic characters, are each and all logically and completely subversive of that distinction which he formally keeps up, between things cultivated and things wild; for each such family necessarily includes both. The few historians who have not shrunk away from the time-consuming task of studying the Theophrastan volumes, have been perplexed by his seeming approval of ancient Hippon's theory about the origin of cultivated plants, which seeming approval is at once followed by a feeble argument or two against the theory. Here is what Meyer says, referring to the primary divisions of tree, shrub, half-shrub, and herb: "Each of these four is subdivided into the groups of the Cultivated and the Wild. Hippon's pronouncement, that every plant is at first wild, and then by cultivation made tame, is thus in a general way approved, though Theophrastus immediately adds that certain wild plants are not at all amenable to cultivation, while others take to it readily, whence it will follow that such a.distinction is not altogether untrue to nature." 1 This historian's difficulty arises through his having missed two items important to the understanding of the man Theophrastus. First, that the illustrious Greek was as successfully a student of human nature ${ }^{2}$ as he was an investigator of the plant world; and that he studied to avoid opposing with needless directness the prejudices of the multitude. If he should pay no respect to those time-honored categories of the tame and the wild, but should jumble them all together, and openly, forty-nine out of fifty among his readers would adjudge him not only a bold innovator, but perhaps also a godless heretic; for, as elsewhere intimated, the staple plants of agriculture, even in ancient paganism, were viewed as special creations of the gods-their immediate gifts to men. Old Hippon

1 Meyer, Seschichte der Botanik, vol. i, p. I62.

? See his Characters of Men, a work completed, as he tells us, in his ninetyninth year. 
the rhizotomos had been an outspoken heretic of this stamp. Theophrastus quotes his bold theory. In his secret soul he believes it sound; yet for the sake of avoiding scandal to the forty and nine or the ninety and nine, he veils his belief by admitting that some wild plants refuse to be tamed; a fact which may innocently be construed as against Hippon's idea. The other fact which the historian failed to apprehend is that the Greek outlines, and gives names to, a half-dozen or more of large natural groups, every one of them embracing without discrimination plants domesticated and wild. He thus completely nullifies that distinction, yet it is all so quietly, and as regards the superficial reading so covertly, done as to escape the notice of the forty-nine out of fifty of his readers; even also of our latter-day botanical historians, learned men and able, yet with mental vision impaired by the strong light of those typographic pedantries-convenient and helpful, certainly-which the botany of the nineteenth century had as a legacy from that of the eighteenth; affected by a sort of botanico-literary dysopsia which is slow to perceive that such a name as ferulaceæ is as perfectly the name of a natural family of plants as when printed FERULACE E.

The recognition of genera-using the term in a modern senseis as informal with Theophrastus as that of families. However, when we come to the word itself, $\gamma^{\prime}$ vos, genus, it is employed variously-that is, with several different degrees of comprehensiveness. Indeed every natural group is with him a "genus," whether it be of the whole assemblage of herbaceous growths, or a family group, or a genus in our sense, or a species, or a variety merely. It seems to be the exact equivalent of our English expression "a kind"; and because such use of the word "kind" is not yet obsolete. at least surviving in rural districts, it will not be difficult to make plain its meaning. If a gardener or farmer of the present day mention to a botanist that he has in cultivation a strange plant of the squash, cucumber, and gourd kind, the latter understands perfectly that this is something belonging to the family of the Cucurbitaceæ, though he can go no further. But if it now be said in rustic phrase that the plant is something in between the squash kind and the gourd kind, he has used the word in a different and much more limited sense; for now the skilled botanist at once puts out of mind seven out of the eight primary divisions-subfamilies -of the cucurbits, or, in other words, dismisses from his thought. we will say, sixty or more of the seventy genera of this family; for he clearly understands the farmer to have that in view which must 
lie close to the two nearly related genera Cucurbita and Lagenaria. Now for a third manner of using the word "kind," with a most distinct third meaning, the farmer shall say that he has a new kind of squash. The botanist now has not the least doubt that the genus Cucurbita is meant; whether a species or a variety he can not tell; but the expression "kind of squash" at once translates itself into the school-taught expression, "species or variety of Cucurbita."

These three distinct old-fashioned uses of the word "kind" illustrate well the different ways in which ancient Greeks and Latins employed their word "genus." It is not a usage that makes for that perspicuity which a science calls for. For three meanings, three words are better than one. Nevertheless there is seldom room for doubt in Theophrastus' writings as to whether by "genus" he means such a group of species as we receive under that name, or a more comprehensive, or a less comprehensive group; any more than one well read in English fails to get the meaning of each of the uses I have brought forward of the equivalent word "kind." But the modern botanist who innocently should read into the term genus of an ancient author always the meaning which it has in modern botany would soon reduce his own mind to a state of utter bewilderment as to the ancient author's meaning. I have therefore been at the pains of making this attempt at an explanation. Upon this and many another important matter of terminology the historians have been silent.

Employing now the word "genus" quite as used in modern botany the genera of Theophrastus are numerous; most of them obtaining acceptance and holding their places in the systematic botany of the present, most of them also bearing the same names under which they were written about by him. This will be best shown by a few examples, which I select from under the letters $\mathrm{A}$ and $\mathrm{C}$ of any Latin index to his work:

$\begin{array}{ll}\text { Abrotonum } & \text { Calamagrostis } \\ \text { Acanthus } & \text { Calamintha } \\ \text { Aconitum } & \text { Cedrus } \\ \text { Agilops } & \text { Celastrus } \\ \text { Agrostis } & \text { Cenchrus } \\ \text { Aira } & \text { Cerasus } \\ \text { Alopecurus } & \text { Ceratonia } \\ \text { Althæa } & \text { Cercis } \\ \text { Anchusa } & \text { Chelidonium } \\ \text { Anemone } & \text { Cissus }\end{array}$


Anethum

Anthericum

Antirrhinum

Aparine

Aristolochia

Arum

Asparagus
Colutea

Coriandrum

Coronopus

Cratægus

Cycas

Cydonia

Cyperus

There must be more than a hundred Theophrastan genera the names of which are as familiar as these. A very considerable proportion of them were then known only as consisting of a single species, and are therefore of the kind which we speak of as monotypical; others were made up of from two to several, and the species are mentioned by name at least, when not described. If he establishes no new genus, and all of them which he enumerates or describes were of common recognition, and under those same names, even before he had penned a line on botany, this fact of itself will demonstrate anew the truthfulness of the proposition that the perception of genera and the naming of them are older than history, and that plant names, generic and specific, are a part of human language always and everywhere.

As to the grouping of his genera, almost the whole story has been told, at least by implication. There were the genera of trees, the genera of shrubs, etc., in places apart; and there were ecological groupings of wild plants and particular assemblages of genera of things cultivated in field and garden; as to these last, the mere retention of antiquated popular groupings which, in deference to the cultivators, he was unwilling to ignore or displace.

There occur in Theophrastus a number of passages which seem like forecastings of a system based more particularly upon flowers and fruits; a system the development of which was of course impossible then, or even at any later period preceding the invention of the microscope. But the very impossibility of his having been able to develop such a system is something which makes his few and faint adumbrations of it interesting and remarkable. I shall cite but two or three.

Commenting on the cylindric spicate inflorescences of certain cereals and grasses, he recalls that those of the plantains are so like them and even the flowers so similar, and thinks it might not be presumptuous to regard them as being interrelated. ${ }^{1}$ To the average botanist of to-day the idea of any consanguinity as sub-

1 Hist., Book vii, ch. Io. 
sisting between Plantago major and an Alopecurus or a Phleum will seem crude enough; and this partly because parallel-veined leaves do not indicate to a certainty that a plant is an endogen and therefore more or less allied to grasses, and partly because we with our hand lenses and microscopes perceive between the small apetalous flowers of Plantago and Alopecurus marked differences that were impossible of discovery by Theophrastus. But the one thing noteworthy is that the Greek thus makes flower and inflorescence the criterion of natural relationship. He does not positively affirm it. It was but a pointed suggestion; and the suggestion passed unheeded during seventeen centuries.

The true hellebore and the veratrum are not more closely allied than are alopecurus and plantago, but as to their flowers and more particularly as to their follicular fruits, there is a strong likeness between them. It may have been this circumstance which, along with their powerful medicinal qualities, led to their being named as of the same genus, Helleborus. ${ }^{1}$

More signally indicative of his regard for fruit characters as sometimes taxonomically outweighing the vegetative, is the fact of his having associated the yellow water lily with the poppies, rather than with nelumbo. Having given account of the wild poppies of the grain fields and stony uncultivated lands, he who is so apt to treat of plants in ecologic groups proceeds now to speak of the poppy "that is called nymphæa." 2 Evidently its milky juice, the generalities of its floral structure, and above all the external form and the inner structure of the capsule, as well as the seeds themselves, constrained him to think of this and the poppies as congeneric. Also when this same chapter ends with an account of Aristolochia, the capsules of which are so much like those of poppies, one can assign no other reason for it than that by their fruits he guessed that Papaver and Aristolochia were interrelated. Other like instances need not be cited; though it should not here be lost sight of that his families, the Umbelliferæ and the Carduaceæ, were in his mind characterized each by marks of flower and fruit. And so, when the antho-carpologic doctrine of affinities is traced to its beginning, one no longer may think of it as having originated with Cesalpino. The idea had been suggested to his mind, and most impressively, by Theophrastus.

Nomenclature. No such thought as that of botanical nomenclature finds expression with the Greek. When he wrote of any

1 Hist., Book ix, ch. I I.

${ }^{2}$ Ibid., ch. I3. 
tree or shrub or herb he used that name by which it was known in the everyday speech of Greeks. It does not appear that it ever occurred to him that a living thing, or any group of living things, required to be named otherwise than as commonly designated in his mother tongue. When in reading his books one encounters batrachium, erigeron, lithospermum, leucoium, myriophyllum, myrrhis, narcissus, and a hundred more as familiar, it is because he knew no other names for them. Nevertheless Theophrastus has great part in what is now come to be received as the scientific nomenclature of the genera and species of plants; and if this has come to pass without forethought or purpose on his own part, it is still natural and was inevitable. During some two centuries next succeeding the writing of it, this was almost the only treatise on botany that was extant, and the names of plants therein written about obtained by that very fact great prestige. When at length the Latins began to study plants, and would write about them, they had to learn Greek in order to be able to read the works of Theophrastus, for that was the one supreme treatise on plants. All well-known plants were therefore known to Latins by their Theophrastan and Greek names, as well as by their Latin names when they had such. Pliny, the supreme Latin writer about plants, in translating Theophrastan texts by the hundred into Latin for Roman readers, made use of familiar Latin names in place of the Greek names when there were such, e. g., instead of the Greek itea he wrote salix; in place of drys, quercus; Latin ulmus, sambucus, and ranunculus in place of Theophrastan ptelea, acte, and batrachium. There were still many scores of plant types which were known to Latins by no other names than those that had been assigned them in Greek; another evidence that Theophrastus by his books had been the one teacher and authority upon botany to Latins as well as Greeks. Platanus, cerasus, rhamnus, anemone, thalictrum, delphinium, helleborus, pæonia, and a host of other such remained the only names of the genera, whether one spoke or wrote botany in Latin or in Greek; and so during some seventeen centuries most of the plant names in use were quoted from Theophrastus. The popular fable about Linnæus as first nomenclator of botany is not yet a hundred years old, and will need to be perpetuated for sixteen centuries yet to come if the years of his nomenclatorial fame are to equal those Juring which Theophrastus held the prestige.

Early in the sixteenth century, when new impulses moved men everywhere to scientific research, Latin had now long been the 
universal language of the educated. Theophrastus had been translated into Latin for the convenience of those who had not learned Greek; but still, as to botanical nomenclature Greek held its prestige fully. When in the course of their herborizings the botanists found plants in no wise answering to any descriptions in the ancient books, and therefore adjudged new and nameless, under the conditions then prevailing it would have been the most natural thing in the world if all new plant names of the period had been made in Latin; and this indeed often happened, e. g., Pulicaria and Fragaria, Brunfels (I53I); Digitalis, Fuchs (I 542), Sanicula, Tragus (I 552), Bidens, Cesalpino (I 593): yet Latin names for new genera are somewhat exceptional even for that period, Greekmade names being commonly preferred. The reason was simply this. The greater proportion of plant names then in use, even in Latin botany, was Greek, and that by unbroken tradition from the Greek father of all botany; and Greek-made names for new types were more in harmony with the general tone of botanical nomenclature than Latin names. Thus has it come to pass that even down to our twentieth century the favorite etymology for new generic names is Greek. Such very modern names as Calliandra, Cinimonanthus, Chionanthus, Chionophila, Chionogenes, Epigaa, and hundreds like them, all very modern, attest the perpetual influence of Theophrastus upon botanical nomenclature.

In botany as elsewhere the genus presupposes species. A genus may consist of many species, of few, or of one only. Theophrastus had very many monotypic genera, at least as they were then known. The specific representative of a monotypic genus has with him but one name, commonly a one-worded name; that is, the one species constituting such genus lacks a specific name. It really has no need of any. Where there is but one thing of a kind, there is never in ordinary speech a second and qualifying name. If neither men nor things existed but in monotypes, language would not need adjectives, and there would be none. Had there been but one race of men on the earth, the name of that race would have been man simply, and the adjectives Caucasian, Mongolian, African, etc., would not have existed. The Theophrastan nomenclature of plants is as simply natural as can be imagined. Not only are monotypic genera called by a single name; where the species are known to be several, the type species of the genus-that is, that which is most historic-is without a specific name, at least very commonly, and only the others have each its specific adjective superadded to the generic appellation. The situation may best 
be shown by examples. In giving these it seems advisable to present the Theophrastan Greek names in Roman type.

Theophrastan

Clethra

Melampyron

Dolichos

Ostrya

Peuce

Peuce Idaia

Peuce conophoros

Peuce paralios

Mespilos

Mespilos anthedon

Oxyacantha.

Syce Idaia

Aria

Cydonion

Coccymeles

Spodias

Cerasos

Pados

Oié
Modern

Alnus oblongata.

Melampyrum arvense.

Phaseolus vulgaris.

Ostrya vulgaris.

Pinus picea.

Pinus maritima.

Pinus pinea.

Pinus Halepensis.

Mespilus Cotoneaster.

Cratægus tominalis.

Mespilus Pyracantha.

Mespilus Amelanchier

Cratægus Aria.

Pyrus Cydonia.

Prunus domestica.

Prunus institia.

Prunus Cerasus.

Prunus Padus.

Sorbus domestica.

The first four names above are those of genera known to Theophrastus as consisting each of a single species. It is evident he saw no occasion for any second and qualifying name in any case of that kind. To have given such second names would very certainly have exposed him to the criticism of having abandoned the attitude of the philosopher, the man of literary taste and scientific brevity, and having assumed the rôle of the pedant. Why do botanists of a recent time invariably append the needless second name to every monotype? I ask the question but to emphasize this point in the history of biologic nomenclature. I recall no instances of the assigning of the useless specific adjective to a generic monotype until well toward the time of Linnæus; and despite the weight of his authority in favor of it, the nineteenth century was on the dawn when there were no longer eminent botanists standing out against the practice. The assigning a species name in these instances is, of course, previsional. The monotypic genus may cease to be such; but even then, according to Theophrastan usage, the generic name alone might stand as that of the original and typical specific member; but that is too pro- 
vincial. Theophrastus' work, in as far as relates to taxonomy and nomenclature, is provincial; not a universal flora, but a somewhat local one. It was not a perfect pattern for the universal. There is also a certain lack of uniformity in a system of nomenclature which fails to provide every species with a distinctively specific name; and it was nothing more than the desirability of uniformity which brought about the modern usage. But, as we shall see, this question was long in controversy, and was settled late.

Matters of nomenclature and taxonomy are almost inseparably connected. The name itself is but the expression of a taxonomic idea. Excepting those rare instances in which an individual historic tree has received a proper name, every plant name that ever was, in any language, is the name of a group. Naming is classifying. The Theophrastan names for pomaceous and drupaceous genera have been above placed in close succession, and opposite them Linnæus' disposal of the same type. By comparing those several names it is readily seen that the eleven species are distributed to five genera by Linnæus, whereas by Theophrastus they had represented nine. In what may be called the average twentieth-century classification of them, - as far as the century has proceeded, - the same eleven species are ranged under about eight genera, namely Amelanchier, Cotoneaster, Cratægus, Cydonia, Sorbus, Cerasus, Padus, Prunus. If we of the present are correct, the mean between Theophrastus and Linnæus is the happy one; and this in any case must be admitted, that every revulsion against the Linnæan taxonomy of these fruit trees is a step in return toward the Theophrastan. The same sort of departing and then returning finds illustration in the naming of water lilies as that was done formerly, and has been done over again of late.

Theophrastan

Nymphaia

Sida ${ }^{1}$

Lotos

Cyamos $^{2}$
Linnæan

Nymphæa lutea

Nymphæa alba

Nymphæa Lotus

Nymphæa Nelumbo
Recent

Nymphæa lutea.

Castalia alba.

Castalia Lotus.

Nelumbo speciosa.

The Greek, it is thus seen, received the four species as representing each a genus. With Linnæus the genus of them all was one; while recent systematists have well-nigh completely returned to the Theophrastan view, in all save the names of the genera; and the

${ }^{1}$ Linnæus, suppressing the white water lily genus, daringly transferred its name to that of a genus of insignificant malvaceous weeds.

${ }^{2}$ Sir J. E. Smith, most ardent Linnæan though he was, restored Cyamus instead of Nelumbo, insisting on its right of priority. 
restoration of even these will follow, under the law of priority.

The shortcomings of Theophrastan nomenclature as to uniformity have not all been indicated. There is one other. While something like half his plant species have but a single one-worded name and that the generic, there are not a few of his genera that are invested with a double-that is, a two-worded name. It is highly important that this be fully understood. This kind of name is frequent with every botanical author that I am acquainted with, between Theophrastus and Linnæus; and with this fact overlooked there is no understanding any single pre-Linnæan author's plant names either generic or specific. Nor have I found any writer of botanical history making so much as a passing reference to this. I subjoin a very few such Theophrastan genus names as samples; giving, as usual, their equivalents, with also the specific names as now in use.

Theophrastan

Calamos Euosmos

Dios Anthos

Dios Balanos

Carya Persica

Syce Idaia

Ampelos Idaia
Modern.

Acorus Calamus.

Agrostemma Flos Jovis.

Castanea vesca.

Juglans regia.

Amelanchier vulgaris.

Tamus communis.

Most of the names in the left-hand column have exactly the form and structure of ordinary generico-specific binaries, one term being a noun, the other a qualifying adjective. Their respective equivalents placed over against them demonstrate beyond cavil that these particular binaries are not of the usual meaning of such two-fold names, but are purely generic. To take up the first on the list: Theophrastus has a genus Calamos, the great reed-grass arundo its type, phragmites also being included in the genus. It is not imaginable that a botanist of Theophrastus' ripe experience and great attainments should think those large grass-plants and the sweet-flag to be of the same genus. Beyond doubt, however, that name Calamos euosmos did originate in the notion that arundo and acorus are next of kin; for, however unlike they are as to size, foliage, and other particulars, there is a remarkably close similarity in their rootstocks, these being of almost the same size, form, and color in the two. The gatherers of roots and herbs, as we know, looked first of all to the "roots" of things, and these were their first criteria of plant relationships. To these it would be perfectly natural to place the sweet-flag alongside arundo, the true $\varkappa \alpha$ al $\alpha \mu \mu_{5}$, 
by its closely imitative "root," and then on account of the aro-

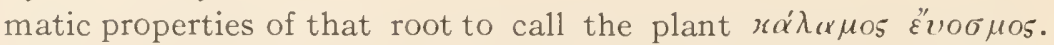
It is equally incredible that Theophrastus should have adjudged the service tree which grew on Mount Ida to be a kind of fig tree. The country people who found the sweet fruits in some way suggestive of figs must have been the creators of that name $\sigma v и \dot{\eta}$ 'Iீir $\alpha$. But the author who desires to conciliate the public will use great reserve in the matter of suppressing, altering, or even amending established and familiar names; and Theophrastus left plant nomenclature as he found it. And what reasonable objection could have been raised against such binary generic names? It can hardly have entered his mind that it made any difference whether such name were one-worded or two-worded. Outside the domain of our Latin-worded technicalities it makes not the least difference to any of us to-day how many words go to the making of a generic name. Ivy is a generic name, and as certainly such are Ground Ivy and Poison Ivy. Pine, Ground Pine, and Princes' Pine are names of three genera in no wise interrelated. The same may be said of the five following, Pink, Moss Pink, Squaw Pink, Mullein Pink, and Pink Root. We having no fault to find with such generic names as Star of Bethlehem, Lily of the Valley, Grape Hyacinth, Jerusalem Artichoke, Indian Turnip, American Cowslip, and some scores of others like them. We are a living illustration of Theophrastus in this regard, except that we have two languages for our botany, whereas he had but one. We have two languages in which we use botanical names, with a separate set of rules for each. Into our Latin nomenclature we do not admit any of these two-worded generic names which we use so freely and so readily in our vernacular. In this we differ from a very long and illustrious line of our own botanical ancestry. It is less than two hundred years since what we know in English as Dogtooth Violet and in Latin as Erythronium was in all Latin botany the genus Dens Canis, Taraxacum was Dens Leonis, Convallaria was Lilium Convallium, Glechoma was Hedera Terrestris, Helianthus Flos Solis, Drosera Ros Solis, Centaurea was Centaurium Majus, and the little gentianceous genus Erythræa was Centaurium Minus. By the same token, Chelidonium was the genus Chelidonium Majus and Ficaria was the genus Chelidonium Minus. In a word, Latin botany for more than seventeen centuries admitted two-worded generic names as freely as the simpler kind; and all after the example of Theophrastus and the prehistoric nomenclators.

This is not the place in which to give the history of the elimina- 
tion of binary generic names from Latin-written botany. But it was imperative to show that such names are common with Theophrastus, Dioscorides, Pliny, and thenceforward for well-nigh two thousand years. Without knowledge of this fact the ancient names can not be understood. Without understanding of names as applied during such period, its taxonomy is an enigma, and the setting forth of the history of taxonomy is impossible. To read into that ancient Greek name Aster Atticus, as has been done lately, the character of an ordinary binary plant name of the nineteenth century, ${ }^{1}$ - to fail to recognize in that a mere two-worded generic name-seems to evince a condition of bewilderment as to the whole subject of botanical nomenclature with ancient Greek and later Latin authors. That the term Aster is generic and Atticus specific can not well be believed to have been in the mind of Dioscorides; for the genus was monotypic, and they did not then give specific names to monotypes. ${ }^{2}$ Nevertheless, in genera of several species generico-specific binaries quite like Aster Atticus as to form were very frequent with Theophrastus; though he applied them to species and to varieties indiscriminately, ${ }^{3}$ as the subjoined Latin versions of some of his binary names will show:

Salix alba

Salix helix

Salix nigra

Papaver rhœas

Papaver nigrum

Papaver corniculatum

Origanum album

Origanum nigrum

Origanum creticum

Origanum heracleoticum
Triticum agrigentinum

Triticum africum

Triticum assyricum

Triticum egyptium

Triticum siculum.

Triticum thracium.

Olea domestica.

Olea silvestris.

Phlomis alba.

Phlomis nigra.

Ecology. Among forecastings of method with Theophrastus, that of the natural associations of plants in particular places is very definitely presented. That which we have learned to designate as the ecologic he accepts as being a very natural kind of grouping. "All are distinguishable as either terrestrial or aquatic, just as we also primarily distinguish animals; for there are some

' E. S. Burgess, Memoirs of Torrey Club, vol. x, (Ig02), pp. 57 et seq.

${ }^{2}$ Sixteenth-century botanical scholars knew this well. Cesalpino wrote the name always as one word, Asteratticus, or else Asteracticus.

${ }^{3}$ It was the usage of nearly all authors down to and including Tournefort in the year 1700 . A binary name meant either a genus, a species or a variety. 
plants which grow nowhere but in the sea; small ones in our sea (i. e., the Mediterranean), larger ones in the Red Sea. Others affect only marshes or other very wet places. Some can not live in very wet ground, but restrict themselves to dry ground. Certain others are littoral only. A few trees thrive in either moist land or dry; such are the myrtle, alder, and willow." 1 In another place, having wild trees and the diversity of them under consideration, he affirms that they differ according to the different nature of the localities in which they grow. "There are lands that are overflowed by water, there are marshes, and there is dry ground; there are rocky places and smooth pasture lands and harder soils, besides other diversities. There are depressions in the landscape where all is tranquil, and there are elevated and wind-swept exposures; which varied conditions tend to the production of many different things." 2 Hereupon follows a considerable catalogue of trees which in Macedonia he says occur nowhere but in the mountain districts: fir, wild pine, spruce, holly, linden, hornbeam, beech, box, arbutus, juniper, yew, wild fig, alaternus, phillyrea, walnut, chestnut and holly-leaved oak. Then there is given a list of such as are common to mountains and lowlands: tamarix, elm, poplar, willow, cornel, alder, oak ( $Q$. robur $)$, wild pear, wild apple, privet, hop-hornbeam, ash, hawthorn. As to these denizens of both highland and plain he says that "in general they are of larger dimensions and more comely form on the plains, but of better timber and better fruit in the mountains. To this rule the wild pear and wild apple are exceptions, both being of better timber and better quality of fruit on the lowlands; for in the mountains the trees are gnarled and thorny. Even as to the peculiarly montane sorts of trees, those inhabiting the lower valleys are both the largest and the most copious; and on the highest summits everything is in its most stunted condition, excepting such as by nature require the cold." 3

Reminding ourselves of this, that Theophrastus treats mainly of field and garden plants, giving much less space to the uncultivated, it becomes particularly noteworthy that in one place eight successive chapters are given up to locating and describing aquatic and other hydrophilous growths; 4 all of them, of course, wild plants. Without any formality of naming the distinctions, yet in practice

1 Hist., Book i, ch. 7 .

2 Ibid., iii, ch. 3 .

3 Ibid., iii, ch. 4.

4 Ibid., iv, chs. 7-r 4 . 
he distinguishes (I) marine aquatics, (2) marine littoral plants, (3) plants that grow in deep fresh waters, (4) plants of shallow lake shores, (5) those affecting the wet banks of streams and rivers, (6) and those of marshes. His marine herbaceous plants are mostly algæ. The submerged trees, resembling in mode of growth and branching oaks, fig-trees, the palm, and the vine, and attributed to the Red Sea, are mostly corals; organisms that were still considered to be plants, denominated lithophytes, until within the last two hundred years. The author, in describing the marine oak, marine fig-tree, etc., is careful to inform his readers that their resemblances to the trees of the land are only those of mode branching; that they are smaller than their terrene analogues and have no leaves. In stagnant fresh waters several cubits deep thrive nelumbo, nymphæa and trapa. Along the shores, in shallow water are reeds, rushes, the papyrus, sparganium, and typha. The banks of running streams suit the poplar, alder, and willow, the roots of which only are laved by the flowing waters. In wet sandy soil not far from streams thrives the cyperus with nut-like edible roots.

That ecology should have formed a sort of taxonomic basis for Theophrastus in his treating of wild plants was most natural. Such pronouncedly hydrophilous growths as reeds and rushes, coarse sedges and the largest grasses, phragmites and arundo, besides typha and sparganium-all are at agreement not only ecologically but in many respects also morphologically. They all have upright, smooth, and simple stems, filled with pith when young, some of them hollow when mature, but none ever woodysolidified; their foliage long, narrow, entire, never with any trace of the network of veins. Moreover, every one of the group was what would have been called flowerless, by all save Theophrastus and his students; because they had no flower-leaves. Other aquatics, such as nelumbo and the water-lilies, colocasia and sagittaria, were like the rest structurally except as to foliage, the leaves being large and ample, rounded rather than narrow-elongated, with radiating veins if any, and some of them with large flowers made up of showy leaves. The Greek, I say, might have written such a diagnosis of his aquatics as a group viewed morphologically. That he saw these marks none will doubt who reads his descriptions of the species.

In the vegetation of the mountains he again lists the trees that grow on the exposed and sunward slopes, and those that flourish nowhere but upon cold northward declivities, and such as inhabit only the frigid summits. 
Dendrology. Almost an undue proportion of Theophrastus' space is given to the consideration of trees. He appears to have been a great lover of them; and his knowledge of them is presented with so much system that at least a considerable dendrological paragraph becomes a necessity if one is to convey any adequate notion of his botanical work as a whole. He classifies them (I) as cultivated and wild. This is one of his general divisions of all kinds of plants; one that has already been sufficiently discussed in another place. Trees are (2) deciduous or evergreen. Their diversity as to tenure of foliage is so thoroughly discussed, and withal so judiciously, that the more than two millenniums that have passed seem to have recorded but few and unimportant additions or amendments to the principles of this chapter as he left it. ${ }^{1} \mathrm{Ad}-$ hering to his classification of all things as cultivated and wild, he gives two lists of trees that are evergreen; the olive, palm, sweet bay, myrtle, the cypress, and our pine among the domesticated; for the wild, the fir and spruce, wild pine, certain kinds of oak, holly, box, and the arbutus tree. The last, he says, sheds the foliage from its lowest branches, while the head of the tree remains evergreen. This distinction of evergreen and deciduous he regards upon the whole as quite natural and valid, despite reports he has heard, and readily accepts as probably true, that in the warmest climates grape vines and fig trees shed their leaves so tardily as to seem almost evergreen. He has observed that, among perfectly familiar species, some regularly divest themselves of all foliage in earliest autumn, others later, while a few habitually retain it until winter has begun. He can therefore credit those who assert the existence, in other lands, of kinds that do not cast their old leaves until near the time of the development of the new in spring. He has even found out that the most strictly evergreen develop one new set of leaves, and as invariably lose one old set, every year. Upon deciduous trees and shrubs he seems to have kept phenologic records. He relates that certain kinds come into leaf early, others late; also that such as are first in leaf in the spring are not the first to shed their foliage in autumn, and it is equally established, that those latest in leaf do not retain them longer than others. He has likewise learned that trees in a moist climate and soil retain their foliage for the longest period, while deciduous things of a dry soil and poor shed their leaves earliest of all; and finally, that a young tree keeps its foliage until a later date than does an old one. The foliage of evergreens is usually narrower

1 Hist., Book i, ch. I 5 . 
than that of deciduous trees, is of a firmer texture, and in a much greater proportion of species is fragrant or aromatic.

In respect to their modes of branching, trees are (3) regular or irregular. If at any time before having studied Theophrastus I had been asked who first taught the distinction between the excurrent and deliquescent in the forms of trees, I should have attributed it by guess to some dendrologist of about the middle of the nineteenth century whom I could not name. Therefore nothing that I have come upon in this author of antiquity has more surprised me than his lucid setting forth of these two modes of tree development. The differences seem to have forced themselves upon his notice while studying the fir tree. At least, he gives fir as the best type of what we call the excrescent; and the oak is his example of the other mode as to branching. The distinction (4) of flowering and flowerless in trees did not imply the recognition of such as in modern botany are called cryptogamous. It was but a matter of the author's success or failure to find what he would have allowed to pass for flowers. And the classifying them as (5) fructiferous and sterile is not at all the equivalent of the flowering and flowerless division. There is one kind of sterility that is manifestly accidental only; a consequence of something unfavorable in the environment. The palm is sterile in Greece; yet if transplanted to Babylon from Greece, it becomes as fruitful as the Babylonian. ${ }^{1}$ Peach trees are sterile in Egypt. The wild sorbus of Greece, transplanted from its mountain habitat to the fervid low country, though flowering copiously in the new situation, never fruits there. The reason is plain to him. Its nature requires the cold climate of the mountains. But when he alludes to the black poplar of the island of Crete as sterile when introduced on the mainland, one may suspect that to have been owing to the possible circumstance of only male trees having been brought over. I do not think Theophrastus ever suspected the fact of diœcism in any plant or tree, however often we may find him speaking of them as male and female. Of this I have more to say in another place. Again individual trees according to their species have (6) certain of their branches fructiferous, certain others always sterile. ${ }^{2}$ He has observed that some, like the vine and the fig tree yield fruit on no branches but the newest, those of the season; that almond, apple, pear trees, and many more fructify upon no other branches than those that are one year old;

1 Hist., Book ii, ch. 3 .

2 ibsd., j, ch. 23 . 
some like the carob (Ceratonia Siliqua, Linn.) produce their fruits both upon those of this season and the season before, with also a few at the same time upon old and thick branches. Some kinds are fruitful on none but their topmost branches; others are fruitless at summit, and only fruitful on lateral branches. Another distinction is that of (7) the location of fruits in respect to foliage. Some trees bear their fruits beneath the leaves; on others it is borne above them; while in some, like the sycamore fig tree (Ficus Sycomorus, Linn.), it grows down on the naked trunk. ${ }^{1}$ From our point of view this is a useless distinction; but not so with Theophrastus, who seems to have been unable to attribute to the foliage of trees any more important function than that of a protection to the young and growing fruit or seed.

Trees are extensively treated of (8) as to their ecology and geographic distribution. There are trees peculiar to mountain districts, and others confined to lowlands and plains. As of the former habitat he names the fir, wild pine, spruce, holly, box, walnut, chestnut, and many more. A still greater number of different kinds are of the plains only; among them are one of the elms, the ash, maple, alder, willow, poplar. A few kinds are common to mountain and plain. ${ }^{2}$ Among the montane some, like the wild pine, luxuriate on slopes that look southward, and will hardly grow at all in any other places, while the fir, on the contrary, attains perfection on the cool and shady sides, and if ever seen elsewhere, has an inferior growth and is unlike itself. The tallest and largest firs known occur in a deep valley in Arcadia where they say the sun never shines. He notes it as a general rule that the kinds of tree affecting shady and cool places are tall and straight, their trunks not forking or parting into subsidiary trunk-like branches; but that arboreal growths of this latter description are those of open and sunny places. Certain trees are wont to grow nowhere but along watercourses; and certain others belong exclusively to the highest elevations of the mountains near perpetual snow.

It is evident that in those coniferous and hardwood trees belonging to cold northward slopes of southern mointains Theophrastus sees a sort of fringe, so to speak, of the great almost unknown regions of Europe northward; for what reports have been brought from that direction indicate that there, even the lower lands are clad with forests of fir, pine, oak, chestnut, and others known at the South only on the mountains; and he thinks it may be reasonable

1 Hist., Book i, ch. I.

2Ibid., iii, ch. 4 ; also iv, ch. I. 
to infer that the whole North has no other silva than that thus indicated. He has not been able to learn that it has kinds of trees peculiarly its own. ${ }^{1}$ Southward, however, across the Mediterranean, and away up the Nile, are very different kinds of trees; many that can not be successfully transplanted from that dry and heated climate into regions where the $\bullet$ are rains and cold weather at the winter season. There, in some localities where it never rains, the palms attain their greatest dimensions and their best quality of fruit; not, however as indicating that they have no need of moisture. On the contrary, wherever a grove of wild palms occurs water is sure to be found at no great distance below the surface of the ground, though it is usually subsaline, a circumstance which, he says, has taught the cultivators to use a little salt with advantage in growing dates in other than their native soil. ${ }^{2}$ In Phœnicia and in Syria there are various kinds of palm; because these like other trees differ according to differences of region and climate as well as according to the culture given them. The palms as a group interest him deeply; they are in many ways so very unlike other trees, in their best known type bearing every thing-leaves, flowers, fruits - in a single terminal tuft, the caudex being without a branch. Now, with Aristotle, father of biologic investigation, and with those of his school, there was much and serious inquiry into the question of a soul, and some particular seat of life in plants. The latter was hard to locate; so many are the trees which, as susceptible of propagation by mere cuttings, thereby proclaim it that their seat of life is everywhere, so to speak. But these palms were different. Cut off the leafy and fructiferous summit of the tree and the whole is killed, just as one kills an animal by decapitation. ${ }^{3}$ He was near thinking that in this kind of tree that one terminal part is the seat of life; but he knows of a smaller palm, native to the islands of Sicily and Crete (Chamcrops humilis), which, if the top be removed, or if even the whole tree be cut down to the ground, renews itself by shoots from the root. He has grown from seed the few kinds of palms available at Athens, knows all about their germination and early stages of development; finds no distinction of bark, wood, and pith in the structure of their trunks $;^{4}$ recognizes in them the only

sist., Book i, ch. 6 .

2 Ibid., ii, ch. 8.

${ }^{3}$ Theophrastus had heard that at Babylon there were palms of some sort the top of which could be made to root and grow again. Hist., Book ii, ch. 2 .

4 Ibid., i, ch. 9 . 
plants of which he dares to say that they exist in the two sexes, a male that flowers and is fruitless, and a female that is Jowerless but bears fruit ${ }^{1}$; but a special seat of the vegetal soul, or life, evades him even here. That he admits trees into the alliance of the palms on vegetative characters alone, when the fruits are not in the least date-like, is seen in two instances. One such is so described as to have convinced some authorities that what he had in view must have been the cocoa-nut palm of the farther Indies; but it is now no longer doubted that it is the Hyphane coriacea, and not Cocos nucifera. He also knew, and well described the type of the Cycadaceæ, Cycas circinalis, as a kind of palm.

Theophrastus, like an ancient Humboldt, or Grisebach, takes pleasure in making comparisons between certain of those trees of arid northern Africa and certain others of southern Europe with which all his readers are well acquainted. There is the persea, as he calls it (Cordia Myxa, Linn.), which in some ways suggests to him the pear tree, a large and very handsome tree, in its mode of branching, its foliage, flower, and fruit externally resembling the pear; but it is evergreen and ripens fruit at all seasons, the fruit however possessing a nut at its core like that of a prune, etc. ${ }^{2}$ There are other Egyptian trees so unlike any known to his untravelled countrymen that he can not contrast them with any familiar kinds; but the competent botanist of to-day will recognize the genera and species of some of them by his descriptions. About Memphis are trees frightfully armed with thorns in every part except the trunk. It is the arid subtropic region of several gumbearing acacias and their allies. He attributes to all of them the leguminous fruit, $\varkappa \alpha \rho \pi \dot{\delta}_{5} \varepsilon^{\prime} \lambda \lambda \cap \beta 0_{5}$, says the pods are gathered and employed as a substitute for galls in tanning leather, and also used medicinally. One kind he calls white thorn (Acacia Senegal, Willd.). To this he attributes flowers beautiful and fragrant, so that they make garlands of them. Another he denominates black thorn (Acacia Arabica, Linn.). Quantities of gum are gathered from this kind. It exudes from the trunk where incisions have been made, or even spontaneously without incision of the bark. In the vicinity of Thebes there are extensive forests of these trees, and that far away from the river, where they are never irrigated. Such pen pictures of foreign dendrologic scenes are not rare in Theophrastus; and they are always so vividly drawn that the reader inevitably thinks of him as writing from the very midst

1 Hist., Book i, ch. 22 ; also Book ii, ch. 8.

2 Ibid., iv, ch. 2. 
of the things he is describing, whereas it is quite certain he is only compiling from travellers and historians. To this picture of Egyptian dendrology he will add yet another member of this same alliance of trees, and this the most remarkable one. Forbiddingly spinescent or thorny like the others, it has a more delicate foliage, like that of a fern. Whenever a branch of this tree is disturbed by a touch, all the leaves upon it seem very suddenly to wither away and collapse; then after a little time they revive and return to their former condition. This quaint description of what has been called sensitive foliage is probably the oldest extant. The species that was described by Theophrastus is doubtless Mimosa polyacantha. These and as many more kinds of tree and shrub he mentions by name and short description as "peculiar to that region."

In succeeding chapters he dwells at some length upon the ligneous growths of the Arabian deserts, where it rains no oftener than once in four or five years, and trees are scarce and all of them spinescent ${ }^{1}$; and describes the varied and often luxuriant silva of the more distant Indies. ${ }^{2}$ It is to be remembered here that Theophrastus was contemporary with Alexander the Great, whose expedition to the farther Orient was the first of its kind in all history to include among its officials learned men whose duty it was to write up the geography, climatology, and even the zoology and botany of the regions traversed; an enlightened thought of Alexander's, beyond doubt suggested by his boyhood's illustrious tutor, Aristotle, father of all nature study. ${ }^{3}$ To the manuscripts brought back by this scientific staff of Alexander, Theophrastus was indebted for all that he knew of the farther Oriental plant ecology and geography; and all that remains of those reports is what the philosopher quoted from them. The originals were long since lost. In these chapters of Theophrastus we have the earliest, and very interesting and faithful accounts of the banyan tree (Ficus Bengalensis, Linn.), citron (Citrus medica, Risso), the cactus-like euphorbia ( $E$. antiquorum, Linn.), the oleander (Nerium Oleander, Linn.), the tamarind (Tamarindus Indica, Linn.), a tree which they reported to possess the singular faculty of folding up closely its pinnated leaflets at nightfall and going to sleep for the night;

$1^{*}$ Hist., Book iv, ch. 8.

${ }^{2}$ Ibid., ch. 5 .

- See Bretz1, Botanische Forschung des Alexanderzuges; also an excellent abstract of the same by Dr. F. Fedde in Abhandl. des Bot. Verein Brandenburg for 1903, pp. 97-109. 
the earliest record in botany of the phenomenon now known as nyctotropism.

The Historia Plantarum is not without its chapters on the diseases of trees, and the influences of the seasons upon them ${ }^{1}$; the proper seasons of the year for felling timber of different kinds ${ }^{2}$; qualities and special uses of wood of different trees ${ }^{3}$; but space must not here be given to comment on these economic aspects of the subject. A more philosophic interest attaches to questions of longevity in trees.

Under the caption of duration (9) he records a number of curious facts, and discusses briefly a question that may arise in reckoning the age of certain trees. He certifies that it is common with orchardists and vine growers of his time to renew, as it were, an old and moribund tree by cutting it down near the ground, and then training up in its place one of the new shoots that are thrown up from the base of the stump. How, he asks, is the duration of the tree upon this spot to be estimated? Do the old and new tree constitute two individuals or only one? If the main trunk be essentially the tree, then the new trunk is that of a new individual; and he adds that the very roots of the original tree perish, eventually, and that the new one now has none other than its own. ${ }^{4}$ Yet individual grape vines the continual growing and fruiting of which during two centuries is perfectly authenticated have in this way been renewed by the cultivator's art, several times over within the two centuries. He finds it a prevalent opinion in the rural districts that all wildwood trees are long-lived and all the domesticated of short duration. This the philosopher does not think well grounded. It is true only in a very general way, and with many exceptions. Some kinds of forest trees live very long, others do not; and the same may be said of the domesticated, though these, upon the whole, have a shorter period. And, universally, those that fruit copiously have a shorter time of life than the unprolific; also the kinds of wild trees that affect low and wet land are shorter-lived than those occupying dry and barren ground. Even sweet-fruited and aromatic trees live longer than the sourfruited kinds, he has observed. On the reputed great ages of certain individual trees still living in his day as well as carefully preserved and religiously venerated-such as the olive tree at

1 Hist., Book iv, chs. I6, I7.

2 Ibid., Book v, ch. I.

${ }^{3}$ Ibid., chs. 2, 3, 4, 5 .

4Ibid., Book iv, ch. I4; De Causis, Book ii, ch. 15 . 
Athens said to have been planted by Hercules, and the Caphian and the Delphic planes, both believed to have been planted by Agamemnon-he is somewhat incredulous. The traditions as to their origin have come down by some who also wrote fables. It might be well to investigate. He thinks it quite certain that olive trees and planes, as well as many other kinds, live a very long time. Beyond this platitude he will not go; but it is manifest that he is not in sympathy with the mind of the credulous multitude as to the extreme age of this or that individual and historic tree. $\mathrm{He}$ was rather skeptical on the subject, and probably would not have believed it possible that northward in Europe far beyond the Mediterranean oaks sometimes lived through ten or a dozen centuries; nor that on another and unknown side of the world there were conifers ${ }^{1}$ of considerable dimensions then living which would be flourishing still, after the passing of twenty-two or three hundred years.

Transmutation. In this twentieth century of our era there are farmers in the world, and not unintelligent, who believe that to some seed of wheat or barley after it has been sown in the field something may happen by which it comes to sprout and grow up into a plant of what they call chess, or cheat; a plant known to botanists as Bromus secalinus; this name itself now apparently destined to perpetuate forever that old opinion-older than history, no doubt-that a grain of barley, secale, may become the parent of a plant of chess.

The seemingly indicative facts upon which this transmutation theory appears as if it might have established itself in the minds of prehistoric grain growers were several. Neither chess nor darnel grew commonly elsewhere than in the low wet parts of grain fields. In these spots only very few, depauperate, and almost infertile were the stalks of wheat or barley, though the seed of one or the other had been sown there copiously. The explanation which a very primeval and elementary philosophy could offer was, that the grains of wheat, debilitated to the verge of decay by unusual cold and dampness, became unable to generate a better plant than the small-grained and worthless chess, or cheat, as the farmers still call it. Even Nature herself had taught them with what ease she can, and how every year she actually does effect more marvellous transformations, at least in the animal kingdom. The fish-like creatures that swim about in pond and pool in the spring

1. The conifers were favorite subjects of study with Theophrastus; and if some of our Sequoias are rightly estimated to be twenty-five centuries old, they were not small trees in our philosopher's time. 
months, they had seen come forth in summer, changed to such things as frog and toad. In their simple life, lived very much out of doors, the observing and intelligent had taken note of how underground grub and tree caterpillar by and by assume a larval state, rest in that for months together, and then suddenly are born again, the one as beetle, the other as butterfly. In his environment, the primeval nature student would not doubt the easy possibility, or the apparently strong probability, of some kind of sudden transformation in the world of plants; and the well-known frequent appearing of chess in wet ground instead of wheat where only wheat had been planted might be evidence enough of such transmutation.

That the supreme philosopher of antiquity, the father of animal biology, who knew so nearly everything about metamorphosis in lower animals, also must have investigated the case of the supposed transmutations of plants, appears most probable. For this department of botanical history it may be thought particularly unfortunate that Aristotle's botanical writings have not survived.

Theophrastus does not formally and didactically discuss this question, though he makes a number of references to this changing of one plant into another as something universally believed in his day. I shall reproduce a number of them.

Recording in one place the usages of his time as to the different seasons of the year and the several methods of sowing cereals, as well as giving a long list of leguminous plants that he names, he concludes the chapter with a remark like this: "None of the above are liable, on account of a bad condition of the seeds, to change into other plants except wheat and barley, which people say may change into darnel (lolium); more particularly wheat, and this being said to occur as the result of wet weather, and in muddy places of the fields." 1 In the same connection he records it that "Some think flax also changes into darnel." 2 Quotations like these read much as if the author had been unwilling to take the responsibility of either affirming or denying the proposition. "People say" that such metamorphoses occur. But in another paragraph, one relating to different kinds of wheat as imported into Greece from other parts, he affirms that from Pontus, from Egypt, and from the island of Sicily grain-growers of his time obtain seed wheat which matures crops free from lolium; though that from Sicily comes up infested by a different weed called melampyrum,

1 Hist., Book viii, ch. 6.

${ }^{2}$ Ibial., ch. 7 . 
i. $e$., black wheat. ${ }^{1}$ In this report about certain of the imported seed wheat as immune from changeability into lolium, one almost reads between Theophrastus' lines that he regarded the absence from or presence of darnel in wheat fields to be due to the absence or presence of darnel seed in the seed wheat at its sowing. There is another passage in which the philosopher by implication seems to question the wheat-darnel metamorphosis. With the ancient husbandmen as with the modern it was usual to sow wheat either in autumn or in spring. Theophrastus records this, and also says that lolium always germinates in the autumn. He has investigated the case, and gives some points of diagnosis by which young plants of lolium may be distinguished from young plants of wheat. ${ }^{2}$ This autumnal germination and winter growing of the lolium almost forces upon the thoughtful reader the inference that if lolium occur in a field of wheat that was sown in spring, it was already up and growing at the time the wheat was sown. But there is one phase of this popularly credited metamorphosis doctrine of which Theophrastus is so impatient that he openly denies it. "Some say that barley changes to wheat sometimes, and wheat to barley, and that in the same field. Such statements are to be received as fables. Changes of that kind would be without a cause. It is diversity of condition that induces change." 3

However skeptical Theophrastus may have been about all such pretended metamorphoses, he had doubtless the usual prudential reason for declining to assail them openly at every mention of them. The belief in them was universal; and the time for the elimination of such belief from even thoughtful minds was yet far distant. We find it persisting with men of intellectual attainments as late as the seventeenth century; at which time Scaliger, a most learned commentator on Theophrastus, avers that he himself has witnessed the transformation of wheat into barley and intimates that the Greek might have done better than to discredit the phenomenon.4

If it was the metamorphosis attending the devalopment of the individual reptile, and the insect, which helped to elevate to the dignity of a quasi-rational belief the superstition about the changeability of wheat into lolium, it must be allowed that the reasoning was not very cogent. The cases are not parallel. One is that of the changes in an individual between youth and maturity. In

1 Melampyrum arvense, acc. to Sprengel, Hist. Rei Herb., vol. i, p. 96.

2 Hist., Book i, ch. 7.

4 See Stapel's edition of Theophrastus (1644), p. 78 . 
the other it is the seed of one species which, "between the sowing of it and the germination, mysteriously changes to that of another species.

There is, however, a phase of transformation in plant life that runs parallel to the metamorphoses of lower animals. This has become generally known only recently, and by means of the compound microscope as applied to the making out of the life histories of ferns, liverworts, and other flowerless plants of lower organization. As illustrated in these plants, this kind of individual metamorphosis could never have become known to the nature students of antiquity, or even to those of the earlier modern epoch, owing to their lack of the necessary optical aids. But somewhat analogous metamorphoses take place in the individual life histories of certain higher plants, even of trees; and this fact is not so commonly known as it ought to be. In the family of the Mimosaceæ there is a considerable list of trees which only in the state of seedlings of a few years old exhibit the usual delicate fern-like doubly pinnated foliage of their family. Before the trees are old enough to flower they have divested themselves of every trace of that kind of leaf and are clothed instead with very narrow, simple, entire, firm and almost leathery organs, in cut somewhat recalling willow leaves, or perhaps better compared to those of mistletoe. Now it will not be in the least to the discredit of a circle of experienced and quite skilful botanical amateurs of the Northern Hemisphere if, placing before them two branches of such an acacia, one from the ferny-leaved young tree, the other from the mature tree with its stiff phyllodes like mistletoe leaves, and stating that these two branches represent one and the same species of Australian acacia, the whole circle of them suspect at first that I may be jesting. Some of the Australian eucalyptus species undergo as complete a metamorphosis in the individual, with this difference that the adult tree, at least in the earlier stage of maturity, exhibits both phases of branch and foliage; the lower and flowerless portion of the head of the tree seeming to represent one genus, the middle and upper branches-those that have the flowers and fruits-seeming as if they must be those of another genus, or even of another family. It is quite as if the tree at a point just below midway of its axis, had become by grafting from that point upwards a tree of another genus.

Of these changeable acacias and eucalypts the ancient Greeks of course knew nothing; but they were familiar with a similar case, that of what is known in very modern botany as Hedera Helix, 
the English ivy. This, as they well understood, is most commonly seen as a trailing or climbing shrub, the stems rooting everywhere, all the foliage leathery, of angular outline and dark green. In this phase the plant may pass the whole of its existence and remain flowerless. Occasionally, when very old and having climbed by wall or tree trunk to sunlight and upper air, a new thing happens. Out of the summit of this dark-green creeping ivy mass an upright bush appears; its branches not rooting, firm, independent, bearing leaves not leathery in texture, not in the least degree angled, and even of a decidedly light green; and this bush up at the top of the ivy will in course of time bear flowers and fruits. The ancients before Theophrastus had no difficulty in explaining this phenomenon. Their firm belief in all sorts of transmutations as taking place in nature saved them any perplexity. They held these two phases of the ivy to be generically distinct, and had their fully established names for the two genera: Helix for the rooting and climbing plant of dark angular foliage, Cissus for the upright bush of the pale thin ovate leaves, that into which the Helix sometimes in old age transformed itself.

Again Theophrastus fails to be satisfied with the popular philosophy, and suggests one that he thinks more rational. If every plant of Helix under the right conditions and with fair opportunity would develop a Cissus bush at summit in maturity or old age, which he says some agree to as being probable, then he would be of the opinion that the distinction between the two is not a generic one, but only a matter of the age of the individual. ${ }^{1}$ He who has taken note of this philosopher's way of advancing his most revolutionary propositions with urbane reserve will understand him as here pronouncing against the time-honored doctrine of a generic change from Helix to Cissus, and as averring that these are but the young and the old phases of one species. It was the inductive philosopher, the scientific botanist, undermining as it were by stealth an ancient botanical superstition, because he had a truly scientific proposition to put in place of it. In this instance Theophrastus was, as usual, far in advance of his own time. For centuries after him men still held to the bigeneric ivy. I should confidently expect to find this pre-Theophrastan view surviving still among the peasantry of some parts of Europe where Hedera Helix is common and well known.

Living in the midst of a time when a thousand superstitions prevailed everywhere concerning plants, their origin, magic powers,

1 Hist., Book iii, ch. 18. 
and their often grotesque metamorphoses, it is greatly to the credit of Theophrastus that he should have risked something of his own popularity as a teacher and author by expressing, even covertly, some of his own doubts and disbeliefs; even as to some, the truth of which seemed so probable that the belief in them is not yet in our time obsolete.

Recapitulation. Certain opinions that are completely groundless respecting Theophrastus' merits as a botanist, opinions quite opposite to any that had ever before been expressed, and such as no man who had read three chapters of that author could have entertained, have been widely disseminated during the last thirty years. One such statement of opinion is before me and reads thus: "Greek authors built their views of the philosophy of botany on very weak foundations; scarcely a plant was known to them exactly in all its parts; they derived much of their knowledge from the accounts of others, often from dealers in herbs. From this scanty material, and from various popular superstitions had Aristotle formed his views on the nature of plants; and if Theophrastus possessed more experimental knowledge, he still saw facts in the light of his master's philosophical doctrines." 1 Such reckless writing as that, betraying innocency not only of Theophrastus' work, but also of that high opinion of it which had been expressed by most accomplished botanists of the eighteenth century and the nineteenth, has been widely read by botanists of the present generation. In view of this, it seems more than desirable that there be presented briefly and synoptically something like an enumeration of those items, or elements, of universal botany of which Theophrastus appears to have been the discoverer and first promulgator.

In this recapitulation I shall employ a few modern terms, such as petal, corolla, and andrœcium, unknown to ancient Greek botany, that I may thereby both more clearly and more briefly express the fact of the Greek's having recognized, though under other names, the things themselves.

I. He distinguished the external organs of plants, naming and discussing them in regular sequence from root to fruit; the naturalness of which sequence was afterwards pointedly denied; but in modern botany it stands everywhere approved.

2. He classified such organs as (a) permanent, and (b) transient; a division of them which may yet be shown more scientific than the modern distinguishing of them as $(a)$ vegetative, and $(b)$ reproductive. \& 1 Julius von Sachs, History of Botany, English edition, p. 16 . 
3. The existence of aerial roots, as being of the nature of roots, and thus different from tendrils and other prehensile organs, was discovered by him and has never since been disputed.

4. He remarked upon the inconsistency of retaining in the category of roots certain enlarged, solidified, jointed, and otherwise peculiar underground parts; a suggestion which lay unheeded during two thousand years of botanical history, and has only recently led to the open recognition of the category of subterranean stems.

5. He recognized, by differences of size, solidity, and other particulars of structure, three classes of stems: the trunk, stalk, and culm.

6. By never speaking of calyx and corolla as peculiar and separate organs, but always referring to their parts as leaves merely, it is evident he regarded the flower but as a metamorphosed leafy branch; to which forgotten Theophrastan philosophy of the flower ${ }^{1}$ neither Goethe nor Linnæus had but returned, when each supposed himself the discoverer of a new anthogeny.

7. He divided the plant world into the two subkingdoms of the flowering and the flowerless.

8. The subkingdom of the flowering he again saw to be made up of plants leafy-flowered and capillary-flowered; really the distinction between the petaliferous and the apetalous; one the deep import of which was first realized and taken advantage of by the systematists of some two centuries ago.

9. He indicated the still more important difierences of the hypogynous, perigynous, and epigynous insertion of corolla and andrœcium.

ıo. He distinguished between the centripetal and centrifugal in inflorescences.

II. He was first to use the term fruit in the technical sense, as applying to every form and phase of seed encasement, seed included; and gave to carpology the term pericarp.

I2. He. classified all seed plants as (a) angiospermous and (b) gymnospermous.

I3. Respecting the texture and duration of their parts he classified all plants as tree, shrub, half-shrub, and herb; also noted that herbs were of perennial, biennial, or annual duration.

I4. He indicated with clearness several of those differences in the structure of stems, leaves, and seeds by which the botany of later times separates plants monocotyledonous and dicotyledonous.

I5. He described the differences between the excrescent and deliquescent in tree development.

1 Reaffirmed and somewhat improved by Cesalpino in the year ${ }_{15} 83$. 
I6. He knew how the annual rings in the stems or trunks of certain woody growths were formed.

I7. Theophrastus, with natural vision unaided by so much as the simplest lens, and without having seen a vegetable cell, yet distinguished clearly between parenchymatous and prosenchymatous tissues; even correctly relating the distribution of each to the fabrics of pith, bark, wood, leaves, flowers, and fruits.

This list of facts botanical which Theophrastus saw, and in the main discovered, is not complete, but it embraces well-nigh all the first rudiments of what even to-day is universal scientific botany. It illustrates superabundantly the fact that Theophrastus, and no man of any later time, is the father of the science as we now have and hold it. And in the light of the above partial recapitulation of his discoveries, what possible remark could be more inane than this? "If Theophrastus possessed more experimental knowledge [than Aristotle], he still saw facts in the light of his master's philosophical doctrines." When a man has firmly laid the foundations of a science, and then has added the suggestions of almost the whole superstructure, what faintest shade of pertinency can there be in asking what his philosophic doctrines were? As reasonably might one leave any scientific work, alive with new facts. quite unexamined because its author's philosophy was that of a school unpopular, or his creed unorthodox.

The most generous interpretation of the words quoted would seem to be, that their author, having no knowledge of Theophrastus, thought to absolve himself from the task of acquiring it by trusting that the Greek would never again be found worth studying.

To me it seems not improbable that historians of the future, learning to know this great founder's mind better than it is yet known, may agree in some judgment not unlike this: that all that has been added'to the understanding of plant life and form-to morphology, anatomy, physiology, perhaps even to taxonomywithin the last three centuries has been due to the inventions of the opticians, and to the increased number of students and investigators, rather than to the appearing on the botanical horizon, within the modern period, of any one mind in powers of observation, penetration, and sagacity superior to Theophrastus of Eresus.

Plumier (1703) sought to commemorate Theophrastus in a newly discovered genus of West Indian shrubs, yet was so inconsiderate as to name the genus Eresia. This Linnæus ( 1740 ) changed to THEOPHRASTA. 


\section{CHAPTER III}

\section{GREEKS AND ROMANS AFTER THEOPHRASTUS}

LEAVING Theophrastus, and going forth in search of the next landmark in the progress of our science, we seem at once to enter an almost boundless pathless waste. Or, as the outlook has been described by another: "If history be a connected succession of events, botany from Theophrastus forward to the sixteenth century has no history. Only isolated pieces of information, like bits of wreck half buried up and down stretches of seaside sand are left. These are connected with certain names; but, beyond that, are hardly of historic import. Of written monuments of real botany in the Greek language after Theophrastus there remains not one. For the small volume of Nicolaus Damascenus, known to us only by a translation into barbarous Latin, perhaps might, and possibly might not, have been reckoned such a monument." 1

What is here understood is, that a great multitude of scattered fragments, together with several completed pieces of writing about plants that, out of the literature of antiquity, have been preserved do not afford material for the history of botany for so much as one only of the ten centuries that next succeeded the times of Aristotle and Theophrastus; and that this is true partly for the reason that the pieces and the fragments that have reached us are from men who were not botanists after the order of Theophrastus, but writers on medical, agricultural, and horticultural botany.

That the whole number of Greeks who wrote of plants in one way or another was very great there is evidence enough. As many as three hundred and fifty years ago the learned botanist, zoologist, and bibliographer, Conrad Gesner, gave out a printed list of more than one hundred names of Greeks who, in his day, were known to have written more or less botany. ${ }^{2}$ Of ancient Latin authors of botanical works similar to those of the Greeks in kind, the same

1 Meyer, Geschichte der Botanik, i, 202.

2 This in one of the several valuable papers that are prefatory to Hieronymus Tragus' De Stirpium Historia, 1552. 
distinguished bibliographer enumerates ten or twelve; but does not seem to have quite finished that catalogue. As considerable a number of Arabian medical botanists of a less ancient period is also given.

The best of those botanical fragments, gathered in as it were from the wreck of ages, were what really inspired the first beginnings of modern botany in the sixteenth century. From the time of the establishment of universities and better schools of medicine in the middle ages, the best text-books of pharmacy were those of the ancients, Hippocrates, Nicander, Dioscorides, Pliny, Galen, and as many more less celebrated than they. The remedies in use were almost wholly vegetable, as were also the poisons and their antidotes; and the old authors' books were the topics lectured on in every school, and their plant descriptions were trusted to for the correct identification of plants alimentary, medicinal, and poisonous. And so, not even from the simplest outline of botanical history may all mention of the old Greek, Roman, and Arabian agricultural, horticultural, and medical botanists be omitted. We are not indeed able to construct out of their literary remains'a botanical history of their period; but we know that they became at last, and incidentally, the inspirers of a new epoch which dawned upon botany a thousand years or so after the last of their line was dead. Sketches of the life and work of a few of them, and only such as came after Theophrastus, will here find place.

Nicander of Colophon. - This Greek grammarian and poet flourished in the second century before the Christian era; was native of a small village, Claros, close by Colophon in Ionia, and was anciently known as the Colophonian Nicander by way of distinction from others of the name of Nicander. He was of great renown as a poet, and his topics were mostly such as invite to the consideration of the living things of field, forest, and wilderness. Evidently Nicander was a naturalist, also learned in pharmacy and toxicology, and chose to express himself in poetic measure. That which may have been his most elaborate work has been lost, that is, the Georgica, a versified treatise of agriculture praised by Cicero, ${ }^{1}$ and extensively quoted by Athenæus, ${ }^{2}$ whose quotations are all that remain of the poem. Among these remnants, there is a long passage on flowers and other ornamental plants, an account of the Egyptian nelumbo, a dissertation on poisonous fungi-the earliest on record-and even another on the cultivation of edible

1 Cicero, De Oratore, Book i.

2 Athenæus flourished some three centuries after Nicander. 
mushrooms, besides many things relating to various other food plants. ${ }^{1}$

The only works of Nicander that have reached our time are two poems, under the somewhat lugubrious titles Alexipharmica, a treatise on poisons in general and their antidotes, and Theriaca, on poisonous animals. The first of these, according to Meyer, ${ }^{2}$ who appears to have read both of them carefully, is of 630 verses, and has under discussion 2 I different poisons, of which 2 are mineral, 8 animal, and I I vegetable products; and the remedies for them are with hardly an exception vegetable. The account of the symptoms of different poisonings is said to be both true to modern experience and vividly drawn, but the plants themselves, whether poisonous or antidotal, are hardly more than named, never described, and the book as a whole is devoid of matter properly botanical.

In the Theriaca, a more extensive work of $95^{8}$ verses, botany, as well as zoology, fares somewhat better. After a preliminary statement of means of frightening away poisonous animals or keeping them aloof, together with certain precautions to be observed by such as sleep out of doors at night, there follow some descriptions of certain more common and dangerous kinds which are often drawn with remarkable exactitude and faithfulness to nature. And here again, the bites and stings of these have always their remedies in certain plants, of which also in most cases only the names are given, though sometimes a few hints are given as to how the plant may be identified. The three particular plants, centaurea, aristolochia, and trifolium, are together efficacious against every poisonous animal's bite or sting. The identity of Nicander's centaurion is uncertain. It may have been Hypericum olympicum, but that of Theophrastus, whom Nicander often quotes, is Ferula opopanax more probably. The aristolochia is that of modern botany, the species either $A$. rotunda or $A$. longa or both. The only trifolium known to the Greeks was our Psoralea bituminosa. In the two poems thus adverted to Meyer counted the names of 125 different plants. ${ }^{3}$

Sprengel gives a list of some thirty species of Nicandrian plants which, though not in all cases identifiable with certainty, seem to have been first mentioned by this writer. ${ }^{4}$

Adanson in $I_{7} 6_{3}$, resolving to dedicate a genus of plants to

1 Haller, Bibliotheca Botanica, vol. i, p. 54.

${ }_{2}$ Meyer, Geschichte der Botanik, vol. i, p. 247.

'Ibid., 248.

- Sprengel, Hist., vol. i, p. I 29. 
Nicander, doubly distinguished himself in so doing; for NICANDRA not only commemorates a worthy name in old Greek plant lore, but the type that was to bear the name was with an exquisite sense of fitness chosen from out the family of the nightshades.

Marcus Porcius Cato (B. C. 235-150). - An illustrious Roman of vigorous mind and great originality, serving the public in the most exalted and responsible offices with great acceptance, affluent as to means, he lead a life of great simplicity, temperance, and frugality, delighting in nothing else so much as the training of his children in virtue, and cultivating flowers and fruits. Practically a philosopher indeed himself, Cato held in abhorrence the philosophies of the Greeks, was strongly averse to the introduction of Greek art and Greek customs into Rome, apprehending the destruction thereby of Roman valor and simplicity, and recalling his son from the study of Greek. Later in life Cato must have fallen captive to the charms of Greek erudition; for he himself mastered the language, and on a visit to Athens addressed a concourse of the people in their own tongue; and it is observed that his own writings have quotations from Greek authors.

The literary monument that immortalizes Cato the Censor is his De Re Rustica, a treatise on farming, gardening, fruit growing, etc. It is the oldest book of its kind in Latin literature, and therefore is of botanical interest. We learn from its pages that almost every method of propagating choice varieties in use with twentieth-century pomologists and vineyardists was practised by Cato long before the beginning of our era, even to the different modes of grafting; and there is no intimation that any of those methods were other than ancient at that time. The number of named varieties of things which they had and were careful.to perpetuate is also sufficiently interesting to merit such exemplification as I here subjoin, culled from Cato's book:

Brassica crispa

Brassica erratica

Brassica lenis

Brassica lævis

Olea albiceris

Olea Colminiana

Olea conditiva

Olea Liciniana

Olea Salentina

Olea Sergiana
Myrtus alba.

Myrtus nigra

Myrtus conjugalis.

Ficus marisca.

Ficus Africana.

Ficus Herculana.

Ficus hiberna.

Ficus Saguntina.

Ficus Telana atra.

Vitis aminea majuscula. 
Pirus Aniciana

Pirus cucurbitina

Pirus mustea

Pirus sementiva

Pirus Tarentina

Pirus volena
Vitis aminea minuscula.

Vitis Apiciana.

Vitis gemina.

Vitis helvola.

Vitis helvola minuscula.

Vitis Lucana.

Vitis Murgentina.

All this would pass readily for good twentieth-century botanical nomenclature; but these names are easily two-and-twenty centuries old.

No fewer than five genera dedicated to Cato have been proposed, by as many different botanical authors, each apparently unaware of the attempts of the others. The Catonia of Patrick Browne (I 756) has priority.

Marcus Terentius Varro (B. C. II 7-27). - In so far as the mastery of human learning gives distinction, Rome had in Varro the most distinguished personage of all whose names adorn the pages of her ancient history. One Symmachus, who lived four centuries later, and whose letters are extant, wrote to a friend: "You know the writings of Terentius, not the comedian, but the Reatine, the father of Roman learning." 1 This Terentius was sometimes called the Reatine in allusion to his birthplace, which was the small village of Reate-now Rieti-some ten miles north of Rome. The family was plebeian, but there had been gifted scions of it before this one, and there were others after him. A century before him there had been a consul Caius Terentius Varro, chosen by the tribunes of the people for the reason that he was of the common people. ${ }^{2}$

Concerning the childhood, youth, and even the early manhood of Varro, and under what conditions the passion for learning was developed, nothing seems to have been recorded; and we seem to obtain our first certain view of him as in the public service under Pompey in the war against Mithridates; but he is then fifty years of age. Also at seventy he is still a naval commander. Being a man of great wealth, owning extensive landed possessions in several provinces, and having acquired so costly a thing as a great library was at that time, the fact of his having devoted his energies to the military service of the Pompeys and Cæsars for so long a period has not seemed easy to account for. In these chances of war certain of his richest estates were confiscated, and his library

1 Quoted by Meyer, Geschichte der Botanik, vol. i, p. 356.

2 Livy, vol. xxii, chs. 34,35 . 
was plundered, this event entailing the loss of not a few of his own writings. And all the while his own tastes and preferences were for the life of quiet study, with rural avocations for his pastime.

Varro was more than seventy years of age when Julius Cæsar, returning to Rome as the great victor, recognized him as the most learned man of his time, and charged him with the work of collecting and arranging a great library; a noble scheme which Cæsar's assassination a year or two later brought to naught. After that, under the triumvirate of Antony, Augustus, and Lepidus, Varro's name was placed on the list of the proscribed; but by help of his friend Calinus, who concealed him in his own villa, his life was saved until this storm was past. The remainder of his life was given undisturbedly to literary work. His industry as an author has made Varro a wonder to succeeding generations. He wrote long treatises on Antiquities, a History of Literature, another of Philosophy, another of primitive Rome, a History of Religion, a volume on Education, a Latin Grammar, a book on Navigation, and unnumbered other treatises, all, or nearly all, long since lost, though referred to by many contemporaries. His treatise on Agriculture, in three books, almost alone of all his writings, has survived. He tells us in the first chapter of the work that he begins the writing of it in his eightieth year. It is replete with learning of all kinds, and is still a practical treatise; yet also evincing the author's familiarity with those Greek authors who, like Aristotle and Theophrastus, wrote on the theories of plant life and form.

As compared with Cato, the list of Varro's cultivated plants is not as long, and he does not enumerate as many varieties of Brassica, Pirus, Myrtus, and other genera. The choice varieties of cultivated cherries, long known in Pontus, Varro adds to the list of Roman fruits.

He is first among Roman authors to take note of certain phenomena of plant life, such as the growth and development of leaves and flowers, and also certain movements. The leaves of the olive, white poplar, and willow, whitened underneath, are apt to become inverted so as to show the lower face, and this at about midsummer, which phenomenon they take for a sign of the arrival of the solstice. The flowers of heliotrope follow the course of the sun from morning until nightfall; and there are other kindred observations, with even a hint that there is a physiology of such things that it might be interesting to know something of. In a passage on cattle raising one of Varro's interlocutors is represented as saying: "The thing is so, but why it is so, that is your affair, you 
who read Aristotle." 1 By such tokens is Varro more a botanist than Cato. True, he has derived every one of these ideas from the Greeks, not one of the observations being original with himself; but it was something to have been first to call the attention of Romans to them.

Patrick Browne (I756) sought to establish a genus VARRonia. It seems that the name is untenable; the same genus having been named Cordia more than a half century earlier.

Publius Virgilius Maro (B. C. 7I-I9). - Virgil, who has often been designated the prince of Latin poets, was born at Andes, a small village near Mantua, some seventy years before the beginning of the Christian era. His early years were passed at Cremona, where his father had valuable landed possessions. These were among the lands which, after the battle of Philippi, Augustus Cæsar confiscated, distributing them to his veteran soldiery. On this occasion the future poet was near losing his life through attempting to dispute with the soldiers, the possession of his fields. He escaped by swimming across a river, and then Virgil with his father repaired to Rome. It was the beginning of his greatness. His presence, manners, and accomplishments recommended the young man to the great Mæcenas, the power behind the throne of Augustus, and the latter soon restored to Virgil his lands; and the emperor's reward for this kindness was the ten pastoral poems (Bucolica) composed in the course of the next three years, and dedicated to the imperial benefactor.

After these followed the Georgica, accounted the most perfect and finished of all Latin compositions.

The simple narrative of the poet's career at Rome, and elsewhere until his rather early death, is one of the most fascinating and beautiful chapters in all history, but for several reasons must not here be presented anew.

The Georgics, by which Virgil is even more favorably if less universally known than by his unfinished epic, the Eneid, treat of agriculture and gardening; but also again one must refrain from anything like a botanical analysis of the poems. It may suffice to indicate how prolific a field for botanical research the poems of Virgil long have been. The following list of works on the Virgilian botany is doubtless incomplete.

(I) Virgilii Georgicormm Libri IV. The Georgics of Virgil. With an English translation and notes by J. Martyn. London, I74I, 4to.

' Varro, De Re Rustica, Book ii, ch. 5 . 
(2) Virgilii Bucolicorum Ecloge $X$. The Bucolics of Virgil. With an English translation and notes, by J. Martyn. London, I 749, 4to.

John Martyn was a physician, and Professor of Botany at Cambridge, the friend of Sherard, Sloane, and Dillenius, and was the first to establish the fact of this poet's profound knowledge of plants. Both the works named were in so great demand among men of erudition as to have been several times reissued, and in octavo form. A German translation of Martyn's edition of the Georgica was published at Hamburg in $1759 .{ }^{1}$

(3) Flora Virgiliana. Eller forsök at utreta de wäxter som utföras i P. Virgilii Maronis Eclogæ, Georgica och Aeneides. Jämte Bihang om Romanes Matwäxter, by Anders Johan Retzius. Lund, I $8 \circ 9,8$ vo.

(4) Flore de Virgile. Composú pour la collection des Classiques Latins, by A. L. Fée. I822; also again in 1837 .

(5) Osservationi sulla Flora Virgiliana, by M. Tenore. Napoli, I 826 .

Although Virgil was by profession a man of letters and a poet, he nevertheless exceeds the other agricultural writers of Roman antiquity in the number of different plants which he knows, and of which he makes mention; for Cato (B. C. 235-I49) knew I 25 kinds, Varro (B.C. II 7-27) mentions Io7, Virgil (B.C. 70-I9) I64. Yet the sum total of the plants of these Romans, 245, is only about half the number that had been known by Theophrastus some 300 years earlier.

The celebrated Lamarck (I793) dedicated to Virgil a new genus. of African trees under the name Virgilia.

Lucius Junius Moderatus Columella.-This very celebrated Latin writer on agriculture and horticulture flourished in the next generation after Virgil, during the reign of Tiberius Cæsar, and may have been in the midst of his years at the opening of the Christian era. He was a native of Cadiz in Spain, and was educated by his father, whom he characterizes as having been a man of erudition and also an experienced practical farmer. ${ }^{2}$ The son declares himself to have been what one would now call an omnivorous reader, and before settling in Rome had travelled somewhat widely in Greece and Syria.

Columella is the most voluminous of all the classic Roman authors on rural topics. There are thirteen books, and these

' Haller, Bibl. Bot., vol. i, p. 68.

2 Columella, De Re Rustica, Book ii, ch. I6. 
aggregate some two hundred and sixty chapters, mostly long ones, and if none of the chapters are very strictly botanical, the whole work is a treasury of information about ancient husbandry, and the treatment of cultivated plants and trees. From him we have the earliest account of the device called a hot-bed, heated from beneath by a mass of fermenting manure, and protected from the rigors of winter weather by panes of glass. He reports that by these means Tiberius Cæsar raised cucumbers all the year around. ${ }^{1}$

To Columella we are again indebted for a complete account of the methods of grafting as practised by the ancients. ${ }^{2}$

Sprengel has given a considerable list of plants and trees that are first brought to notice by this author. ${ }^{3}$

Near the end of the eighteenth century two distinguished botanists almost simultaneously bethought themselves of the propriety of consecrating a genus to Columella. The Columellia of Ruiz and Pavon (I794) appears to have the priority.

Pedanios Dioscorides (about A. D. 64). - If to have written the most practically serviceable book of botany that the world of learning knew of during sixteen centuries were the best title to botanical greatness, to Dioscorides would readily be conceded the absolute supremacy over all other botanists, not only of antiquity but of all time. Concerning the duration and the absoluteness of his supremacy Sprengel has the following: "During more than sixteen centuries he was looked up to as the sole authority, so that everything botanical began with him. Every one who undertook the study of botany, or the identification of medicines swore by his words. Even as late as the beginning of the seventeenth century both the academic and the private study of botany may almost be said to have begun and ended with the text of Dioscorides." 4

Almost volumes have been written in controversy as to the time when Dioscorides lived; though the extremes of opinion do not assign him an earlier date than B. C. 30 , or a later than A. D. $99^{5}$; and the most probable seems to be that which locates him in about the middle of the first century of our era. That he lived in the time of Nero is inferred almost to a certainty from remarks of Tacitus and of Galen. ${ }^{6}$

1 De Re Rustica, Book xi, ch. 3.

3 Ibid., iii, ch. I I.

${ }^{3}$ Hist. Rei Herb., i, I 49-1 $5^{\text {I. }}$

- Ibid., p. I 5 I.

5 Meyer, Geschichte der Botanik, ii, 96-100.

- Sprengel, Hist. Rei Herb., i, I 52. 
Though in relation to this author biographic dates fail us, the land of his nativity does not. It is well established that he was a Cilician Greek, his native city being Anazarbos; for in order to distinguish between him and others named Dioscorides, eminent writers referred to him as Dioscorides Anazarbæus, the Anazarbean Dioscorides. It is clear also from his own writings that he was a learned physician and practised medicine; also that he had travelled widely to study plants, and obtain knowledge of other than vegetal remedial agents. In these travels he came to know many plants before unknown to Greek and Roman physicians, and was at the pains of describing many such; that is, of indicating not only their qualities and remedial effects, but also something of their aspects and morphology as living plants; describing their roots, stems, foliage, and even sometimes their flowers; and the number of plants and plant products of which he gives account is about 600 . Such a list of merely medicinal and alimentary plants is by more than 100 greater than the sum of all plants known to Theophrastus three centuries before Dioscorides. And it was because he had described so many, and often so well, that in after ages he came to be regarded as the supreme botanist. The usefulness of his medical botany, from the phytographic point of view, was not only fully realized, but also enthusiastically somewhat overestimated. The scientific botanist among the Greeks was Theophrastus; and there is no comparison between him and Dioscorides, whose theme was medical botany; but, quite as usual, the man of "applied science" was the one to meet with general appreciation and approval.

So highly esteemed was Dioscorides during the middle ages, that early after the invention of printing, his work, though in Greek, obtained an editor and a publisher at Venice as early as the year I499. ${ }^{1}$ This edition must have obtained a ready sale, for in ${ }_{5}{ }^{1} 8$ it was repeated. A third Greek edition appeared at Basle in $1529 .{ }^{2}$

Latin being the universal language of the schools, Latin versions of Dioscorides were in demand, and early became rather numerous. The very first of these, a book rare and obscure, purports to bear the date $1478,,^{3}$ thus antedating the first Greek prints. But from the year $1_{5} \mathrm{I} 6$, when the first excellent translation by Ruellius appeared, Latin versions became numerous; and for a whole century thereafter the most voluminous and most useful books of botany were in the

1 See Pritzel, Thesaurus, $2 \mathrm{~d}$ ed., p. 84.

2 Ibid.

3 Said to bear the name of Petrus Paduanensis; see Pritzel, 2d ed., p. 85. 
form of commentaries on Dioscorides. Such in large part are the works of Anguillara, Matthiolus, Maranta, Dodonæus, Cesalpinus, Fabius Columna, and the Bauhins. In several of these the annotations and comments quite exceed in bulk the Dioscoridean text, and are replete with new botany; that is, they contain the names and descriptions of many plants which the commentators are convinced Dioscorides did not know, and which they therefore judge to be new. One may fairly say that the greater part of all the new botanical matter published during the whole of the sixteenth century, and a part of the seventeenth, came out in the form of annotations upon the text of Dioscorides. Thus it appears that the Greek, who only meant to provide medical students with a full compend of remedies, and of the marks by which to know them; became incidentally the first master of phytography; the one every line of whose plant descriptions has been more attentively studied word by word, and that by a greater number of erudite men than any other book about plants that has yet been written; unless one should possibly be obliged to make an exception of Bauhin's Pinax. But even that is, first of all, a compend of Theophrastan and Dioscoridean phytography, together with such augmentations and improvements as in the year 1623 were found necessary.

Latin editions of Dioscorides are too numerous to be given a reckoning; and almost the same may be said as to early translations of him into modern tongues; for between the years 1555 and $175^{2}$ there were at least twelve Spanish editions, as great a number in

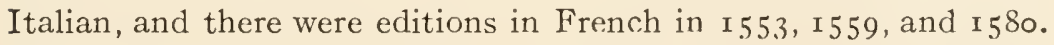
There was one translation into German as early as 1546 , another in 1610 , and this last appears to have been issued again in $16{ }^{4}{ }^{1}$

Little in the way of botanical taxonomy will be looked for in a work on pharmacy that is nearly nineteen centuries old. The most comprehensive of his groups are formed according to properties; thus his Book I is devoted to the consideration of plants that are of merely aromatic rather than medicinal qualities; growths that furnish oily, gummy, or resinous products, such as enter into the composition of salves and ointments; and after these follow the trees that yield fleshy fruits of grateful though not specifically aromatic flavors. Book II, beginning with animals, and animal products that are of dietetic and medicinal use, ends with the cereals, the leguminous, malvaceous, cruciferous, and other garden herbs. Then Books III and IV deal with a vast number of plants more distinctively medicinal.

1 Pritzel, Thesaurus, 2d ed., pp. 86, 87. 
It is to be observed that he does not treat first of herbs consecutively, then of shrubs, then of trees. That would have been the formal adopting of a piece of regular taxonomy even in his day, as we have seen, already long established. There are merely spicy things that are trees, others that are shrubs, and some that are herbaceous; and the same is true of things alimentary and of things medicinal. This qualitative classifying is better suited to his purpose. But that even the more strictly botanical taxonomy may now and then gain a point by ignoring herb, shrub, and tree as fundamental divisions, comes out interestingly in Dioscorides' chapter on Sambucus. ${ }^{1}$ He has two species, one of which is only an herb, the other woody and almost a tree. We shall see later that, after the revival of botany, at a comparatively modern period, such a hold had been gained by the old distinction between the herbaceous and woody that in deference to it systematists almost with one accord divided Dioscorides' Sambucus into two genera and separated them widely, Sambucus being located among the trees, and Ebulus among the herbs; and that hardly after Bauhin as late as $1623^{2}$ had followed Dioscorides in writing them as one genus was the botanical world of that time ready to accede to a proposition so subversive of what was deemed fundamental in taxonomy, i.e., that a tree and an herb could not be congeneric.

Subordinately to the more general and qualitatively outlined divisions of the work, Dioscorides recognizes all the more familiar natural families of plants; that is to say, within each Book there is a line of labiate genera, another of the leguminous, another of the umbelliferous, and the succession of cognates is not often interrupted by the intrusion of a genus not of such natural alliance. Even among the composites Anthemis, Parthenium, and Cotula are in close conjunction on his pages, as are Anchusa, Lycopsis, and Echium; and the succession of the representatives of five or six genera of solanaceous plants is only broken by the intrusion of Cardiospermum. Examples of this need not be multiplied. It is propagating fable in place of history to affirm that natural families were first recognized and indicated by any Linnæus, or Adanson, or Jussieu of the eighteenth century.

The whole subject of Dioscorides as a taxonomist merits a fuller development. A thorough study of his text might show that classification had progressed somewhat during those three centuries that had then elapsed since Theophrastus.

1 Diosc., Book iv, ch. 155 .

2. Bauhin, Pinax, pp. $455,456$. 
The services of this next to the last of great Greek physicians to botany are well commemorated in that fine generic type Dioscorea dedicated by Plumier in the year 1703 .

Carus Plinius Secundus (A.D. 23-79). - Two venerable cities of Italy contend for the honor of having been his birthplace, namely Como and Verona. But wherever he was born, the elder Pliny lived in Rome and called himself a Roman. $\mathrm{He}$ is known as Pliny the elder, to distinguish him from a nephew of his who bore the same name, and is also an author of some note. But the elder Pliny is one of the remarkable men, and among the most voluminous authors, of ancient times. His character, his manner of life, and his rather early martyrdom to knowledge, were written of after his death, by his nephew and namesake in a letter to a friend:

"I rejoice exceedingly that thou readest so eagerly my uncle's books, that thou wishest to obtain a complete set of them, and makest inquiry concerning all of them. I will serve you in the capacity of an Index, and shall even indicate to you the order in which they were written; for to know that is a matter of interest to the learned. Spearcasts of the Cavalry. One Book. He wrote this while in command of a company of cavalry, where his leadership was marked equally by courage and prudence. The Life of Pomponius. Two Books; a tribute to the memory of his best friend. Twenty Books of the German Wars, embracing a full account of all our wars with the Germans. He undertook this work while in military service in Germany, and it was suggested to him in a dream. Three Books of The Student, so comprehensive as to fill six volumes, wherein the aspirant to oratory is advised and directed from the cradle forward. Eight Books on Hesitancies in Public Address. These were written under Nero, when anything like bold or unrestrained writing was unsafe. Thirty-one Books supplementing the (historic) Work of Aufidius Bassus. Thirtyseven Books of Natural History; a work as comprehensive, learned, and many-sided as nature itself. Thou wilt wonder how a man of so many business affairs could bring to completion so many volumes, and on such difficult subjects. You will be still more surprised to learn that for a long time he was a busy lawyer, that he died in his fifty-sixth year, that he had been much occupied with the duties of the most responsible public offices, and that his time had also been heavily taxed by the exactions of the friendship of princes. The explanation is, that he was of the keenest intelligence, and his economy of time something almost beyond belief, 
even to the reducing of his hours of sleep to the shortest limit. In the winter, he was accustomed to work until between one or two o'clock in the morning, or at the shortest until midnight. He could fall asleep at once, no matter at what hour; sometimes even at work he would fall asleep for a few moments and awake again. Before the break of day he would go to the Emperor Vespasian - for he too used to work at night-to receive his orders or to fu'fil some commission. Returning home he would study until breakfast time. After a light breakfast, if it was summer, and he had a little leisure, he would lie down in the sun and have a book read to him, taking notes and extracts; for he read nothing without making some excerpts, being accustomed to say that no book was so bad as not to contain something useful. After sunset he would usually take a bath, then recreate and sleep a little. After that, as if another day had dawned, he studied again until dinner time. Even at this principal meal a book was read, and comments written, and this without interrupting the reading. I remember that once upon a time one of his friends present checked the reader, who had given a wrong inflection, and had him read the line over again. 'But you understood the meaning at the first reading, did you not?' my uncle interposed; to which the other nodded assent. "Why, then, did you call for the repetition? We have lost the time it would have taken to read ten lines, by this interruption.' So avaricious was he of time. He arose from the dinner table, whether while it was yet daylight in summer, or when in winter it was after dark, always with the same promptitude, as if compelled by law. This was his manner of life amid the business and turmoil of the city. In the country the only respite he allowed himself was that of the daily bath; and when I say that I mean the actual time of the bath; for while the drying and dressing was going on he was either listening or dictating. On his journeyings, as if putting out of mind all business cares, he did nothing else but that; keeping always close beside him a rapid penman, a book, and a writing tablet. . . . For the same purpose even in Rome he had himself carried from place to place in a sedan. I remember well how once in meeting me when I was walking he said: 'You ought not to lose these hours'; for he reckoned all time lost that was not given to study. It was by such exertions as these that he brought all those volumes to completion." 1

We have from another letter by this same kinsman annalist-a letter to the historian Tacitus - an account of the circumstances of

1 Pliny the younger, Book iii, Epistle 5. 
Pliny's untimely death. ${ }^{1}$ The facts must here be presented in brief.

In the summer of A.D. 79 Pliny had command of the Roman fleet, then in the Tyrrhene Sea, at anchor behind what is now known as the Punta di Miseno. On the $22 \mathrm{~d}$ of August of that year, at about noonday a terrific earthquake and rain of ashes accompanied that frightful eruption of Vesuvius which buried the cities of Herculaneum and Pompeii. A cloud in the shape of a huge Italian pine, with straight trunk and horizontal branches, seemed to arise from the crater of the volcano. Immediately, on a small and light sailing vessel Pliny set forth in the direction of the mountain to gain a nearer view of the phenomenon. Soon discovering that by the dread progress of the eruption the lives of the whole population along the mountain's base were imperilled, and that they had no way of escape but by sea, he ordered the larger ships to sail to the rescue, and went with them. At one time, when a shower of stones and ashes was falling on his ship, and the sailors were trembling in mortal terror, the commander was seen to be quietly dictating his own observations to the amanuensis. They made land at a point where some friend of Pliny had a country seat. The villagers were found already provided with the means of escape by sea, only a strong contrary wind prevented embarkation; meanwhile the dangers of remaining on land increased with every hour. Pliny, when nightfall came, as if to inspire courage in others, took his bath as usual, then dined, and composed himself as for a night's rest; but the inhabitants of the place remained awake. Towards morning the fall of stones and ashes so increased, and the earthquake shocks became so much more frequent, that the people awakened Pliny, fearing the closing up of the porch on which he had made his bed. The demolition of buildings appeared imminent, while out of doors the stones fell still more thickly. People bound cushions and pillows about their heads and rushed down to the beach; but winds and waves are still high and there is no boarding the ships. It is now daytime, but the blackness of night is still over land and sea, interrupted only by flashes of lightning or flames bursting forth now and then from the fissures of the earth. The people rush to and fro in the frenzy of despair. The fumes of sulphur threaten to suffocate them. Pliny, helped by two slaves, arises from his couch, and falls dead.

The Historia Naturalis is Pliny's monument; no other work of his having survived. The following outline of the contents of the work may be useful here. Book II, Cosmology and Meteorology;

2 Pliny the younger, Book vi, Epistle 16. 
Books III to VI, Geography; Book VIJ, Anthropology; Books VIII to XI, Zoology; Books XII to XXVII, Botany, in the main agricultural, horticultural, and medical; XXVIII to XXXII, Zoology again, but in relation to medicine; as also in connection with aquatic animals some paragraphs on the remedial efficacy of certain waters; Books XXXIII to XXXVII, Mineralogy, more especially as applied to medicine, painting, plastic art. Book I of the work is prefatory and introductory to the work as a whole.

At first thought it may seem extraordinary that so vast a work, filling so many volumes, should have escaped the fate of many hundreds of less voluminous things, and should have reached modern times in its completeness. The probable explanation has been suggested by the historian Meyer, who thinks that its very voluminousness was its safeguard. The copying of the complete Natural History by hand was a large enterprise, and the manuscript when done was very costly. Men take care of that which is worth much money. ${ }^{1}$ In the middle of the nineteenth century, an excellent authority reported the existence of more than sixty manuscripts of Pliny of greater or less antiquity. ${ }^{2}$ Since the invention of printing more than eighty different editions have been printed of which number as many as eighteen appeared in the fifteenth century, and more than forty in the sixteenth.

The high prestige held by Pliny throughout mediæval times was due to the fact of his having written in Latin. All the other authors of greatest importance as to natural history had written in Greek; and Latin was the language of the middle ages. The work was also extensively, if not mainly, a compilation, and was made up in large part of translations into Latin from the greater Greeks, Aristotle, Theophrastus, Nicander, and Dioscorides, and so had much the character of a compend of all natural history.

As a Roman among Romans, Pliny was of the utilitarian bent of mind; even a subscriber to the dogma, then antiquated, that all things that are upon earth are here for the sake of man; not that he so holds it as piously to praise nature for universal benignity or generosity; for in one of his earlier volumes he says: "If nature appears to have produced everything for the sake of man, still man is often obliged to pay rather dearly for her gifts; so that it is not so easy to decide whether she has more the character of a benign mother than of an unkind stepmother." 3

1 Meyer, Geschichte der Botanik, vol. ii, p. I25.

${ }^{2}$ Julius Sillig, quoted by Meyer, Ibid.

"Pliny, Hist. Nat., Book vii, ch. I. 
Whatever nature may or may not be to man, it is impossible to establish any natural order and sequence of things on those utilitarian principles; and he who looks into Pliny's botanical volumes for anything like what we understand by taxonomy will be disappointed. Here is what a distinguished botanical systematist of the eighteenth century said of the Roman's plant classifying: "Pliny, the indefatigable compiler, published in fifteen books all that Theophrastus, Dioscorides, and their predecessors had said about plants. But he treats this matter in a manner so strictly historical, although in such flowery language, that one may well say of the whole that it is in beautiful disorder." 1 True it is that Pliny begins his history of plants with the discussion of trees. The philosophic Theophrastus had done so; but it was for the reason that trees seemed to him to claim the first place as being the most highly organized type of plants. Pliny begins with trees because he judges them to be, on the whole, more useful to man than herbaceous plants. Similarly everywhere in his writings the thread of the economic rather than the philosophic is that by which one is to trace whatever of system there is in his treatment of p'ants and plant lore.

It has been claimed by some, and disputed by others, that Pliny was more than a compiler, and that some of the facts which he records were from his own observation. A renewed and thorough study of all his botanical books, with such a question foremost, is still called for; but rather unusual accomplishments are also demanded on the part of the investigator; those of the ripe classical scholar and of the master botanist combined. Adanson, who if I mistake not had for his thesis inaugural a study of Pliny, accredits him as discoverer of the distinction between growth buds and fruit buds in trees, and says that he named the former kind germen, the latter gemma. ${ }^{2}$ It was a botanical discovery of high rank, whoever first announced it; but I should suspect it of having been made anterior to Pliny.

As if to crown Caius Plinius Secundus with a wreath of myrtle, Plumier (I703) dedicated to him a genus Plinia belonging to the family of the myrtles.

Claudius Galenus (A.D. I30-20I).- In respect to natural endowments, wealth of information acquired by study at home and travels abroad, and fertility of able and learned authorship, Galen was one of the great celebrities of antiquity; as a physician

1 Michel Adanson, Familles des Plantes, Preface, p. vii.

1 Adanson, Histoire de la Botanique, p. 94. 
ranking above all others figuring in the early history of medicine except Hippocrates.

Galen was a Greek, born at Pergamos in the year I3I of our era. Ancient annalists take note of the fact that Pergamos was the seat of the most celebrated of temples to Æsculapius; therefore of good augury as the birthplace of predestined physicians. Nico, the father of Galen, was skilled in philosophy, geometry, and astronomy, and was an architect; also evidently interested in plant life from the philosophic point of view, for the son reports it that Nico, as if doubting about the transmutability of one species into another, made some experiments with grain sowing, the result being the removal of all doubt concerning the changeability of certain grains into chess, or darnel.

The career of the son seems to indicate that the architect Nico was a man of wealth; for the child received most careful education under the best masters at Pergamos. At the age of seventeen years, having chosen the profession of medicine, he was sent upon his travels, and continued them until the age of twenty-eight. $\mathrm{He}$ spent several years in Ægypt, with headquarters at Alexandria, passing thence into Bithynia, Palestine, Thrace, Macedonia, Italy, and the islands of Crete, Cyprus, and Lemnos, these all noted in that early time for the wealth of drugs, and the good quality of them, that were imported from them into all the cities of the then known world. The high distinction to which he afterwards attained attests the improvement made of those rare opportunities that wealth had afforded him. One object of these prolonged journeyings had been that of profiting intellectually by converse with learned men, and the most noted physicians of every land. He was reputed also to have mastered all the dialects of Greek, as well as the Latin, Persian, and Ethiopian tongues. Also everywhere he sought the most perfect knowledge of every plant anywhere in use remedially. It was not enough that a given remedy might be purchased from any druggist. The physician ought to know all about the plant, even as living and in its native soil, and thus become qualified to distinguish pharmacologically between the false and the genuine, and to detect adulterants.

Galen's years of travel were concluded by a considerable sojourn in Egypt, at Alexandria, then the world's greatest center of art and erudition; and thence he returned to his native Pergamos, where for some years the surgical and medical care of the gladiators was committed to him. In the year 164 , when he was about thirty-three years of age, a revolutionary disturbance in his native 
city was the occasion of his be aking himself to Rome. Here he now practised medicine with distinguished success, and gave lectures on anatomy; all this, however, to the arousing of a storm of jealousy on the part of the native Roman physicians, to whose unrelenting sallies, or else to a malignant outbreak of the plague, or to both forces combined, he yielded at the end of three years and once again returned to Pergamos. The stay there was this time short, for the Roman Emperor Marcus Aurelius, with his imperial brother Lucius Verus, going to war with the Quadi, Parthians, and Marcomanni, desired his services as their physician on that expedition. The plague broke out in the country of the attempted conquest, the expedition became a failure, and the imperial majesties with their Greek plyysician began a retreat to Rome. Lucius Verus, stricken with apoplexy, died on the way, and the imperial philosopher and Galen reached Rome in safety. Here the latter now engaged actively and industriously in medical authorship during a number of years, and when in the year 172 Marcus Aurelius set forth on a second attempt to go and conquer the Marcomanni, desiring Galen to accompany him as his physician, the latter interposed, piously, that the god of his native city, the revered Asculapius, to whom he was under solemn vows, had decreed otherwise. The excuse availed, and gave no offence to the pious Aurelius; so that Galen continued in Rome, as physician to Commodus, son of Marcus Aurelius and heir to the empire, then very young. Later, and at a date unknown, Galen returned to his native city, where he ended his long, laborious, and most distinguished career, at the age of 70 years, or, as some authorities say, at 90 .

Some idea of Galen's industry as an author may be conveyed by a note or two on editions of his works issued since the invention of printing. One published at Basle in the year $\mathrm{x} 538$, and containing the Greek text only, fills five folio volumes. ${ }^{1}$ An edition given forth at Leipzig between I $82 \mathrm{r}$ and 1833 , embracing both the Greek text and a Latin translation, is in twenty octavo volumes. ${ }^{2}$ And such editions do not include certain of his works the Greek originals of which have been lost, and only the Latin versions of them have been handed down from ear'y times; much less others which have been lost altogether. Even in Galen's lifetime certain books of his, kept in the Temple of Peace at Rome, were destroyed in a conflagration of that building and were never reproduced.

1 Edited by Cossæus, Fuchsius, and Gemusæus.

2 Claudii Galeni, Opera Omnia. Editionem curavit C. G. Kuhn, Lipsiæ, Tom. i-xx. I $\delta_{21-1} \delta_{33}$. 
A man of as profound erudition, and of such high attainments in' botany as the celebrated Albert Haller, conceding the supremacy of Galen as a man of genius, and a great master of everything relating to the healing art, seems to deny that he was anything of a botanist, affirming that almost all his botany is borrowed from his predecessors, and chiefly from Dioscorides. ${ }^{1}$ This criticism, in as far as it is adverse, touches the writings of the man as a possible contributor to botanical knowledge. It does not-or if it does it ought not to-stand as an impeachment of his knowledge of plants. It is incautious to pass judgment against any man's attainments in a subject until he has at least in some way expressed himself on that subject. To know many plants familiarly and well is to be something very like a botanist, whether one ever write a paragraph of botany or not. A familiar knowledge of many plants Galen not only urged upon the whole medical profession; he claimed that he himself possessed such knowledge. "In as far as possible the physician ought to know all plants, and if not all, the greater proportion, and those most useful. . . He who knows the different kinds in all their states from young and small to fully grown, and can so distinguish between them, will in many places find certain useful plants, as I have done in various parts of Italy, where he who knows them only in the dead and dry, would never recognize them whether in the young state or the mature. There is no quacksalver who does not readily identify the herbs that are imported from Crete by their fruits; but that some of these selfsame things might be gathered on the outskirts of Rome they do not know, because the season of their herborizings does not correspond to that of the maturity of these plants. But that time is well known to me, and I go in quest of Chamæpitys, Chamædrys, Centaurium, Hypericum, Polium, and others of that kind, at just the right time, and gather them in their perfect maturity, neither waiting until they are past that, and are sunburnt, nor going too early, that is, before the fruit is well formed." It has well been observed by one of the historians of botany, that "The man who wrote thus must have been either a consummate charlatan, or else a man of deep and thorough knowledge, and a charlatan Galen was not." 2

When one reads in Galen over and again such commendations of an intimate knowledge of many living plants, and when it is remembered that he made long journeys by sea and land in the

- Haller, Bibliotheca Botanica, vol. i, p. I I I.

${ }^{2}$ Meyer, Geschichte der Botanik, vol. ii, p. I 9 I. 
endeavor to familiarize himself with the medicinal plants of different climes, and when one has marked the keenness of his powers of observation everywhere, it is impossible to agree with the learned Haller that in botany Galen was inexpert; nor can it reasonably be questioned that had he betaken himself to phytography, he would have laid all botanical posterity under deep obligations to himself. Now, that he did not describe plants, but was accustomed to give their names only, or but little more, one might have been disposed to charge to the fact of his having flourished in the very next century after Dioscorides whose 600 . species, embracing the whole vegetable materia medica, may have been for the most part well identified at Galen's period, so that the mention of a name only would sufficiently recall a species. But such apology for Galen would be superfluous. The truth seems to be that he had next to no faith in phytography at all. He takes openly the ground that "The identification of plants is better accomplished by the actual observation of them under the help and guidance of a teacher, than by that method which may be likened to the attempting to learn to navigate the seas by studying books on navigation." 1 This, then, is the main reason why Galen almost abjured plant description.

The passage is luminous with historic information about the study of botany in the Rome of eighteen centuries ago. We know already that at this period the occupation of a well trained physician is lucrative. There are many of them; therefore the candidates for the profession are not few. The remedies in use are almost all botanical, and they all study botany; quite otherwise, by the way, than botany is studied in twentieth-century schools of medicine, and less perfunctorily. Unless in their practice of medicine they are to be at the mercy of the unscrupulous among herb gatherers and drug vendors, they must know the marks of the genuine thing. Therefore important among their regular exercises is that of identifying plants, the book open before them, the specimen it may be a withered and shrunken root or rootstock, not improbably supplemented by a fresh one newly brought in from its native soil, or from some drug garden. The standard botanical work, descriptive and pharmaceutical, is Dioscorides-its author hardly a century dead-and there are others. The descriptions are mostly brief and often inadequate, so that mere guesses at the identity of things frequently pass instead of certainty, and about the identity of some that are of remedial importance the whole fraternity - Galen himself perhaps excepted-is wrong. At all events none

1 Galen, ed. Kühn, vol. xi, p. 96. 
but he is so discouragingly aware of the multitude of errors that have originated through placing dependence on descriptive botany. He thought there was a better way; but this proposal of his seems to imply on his part an overweening confidence in the perpetuity of things. He did not foresee a time when the race of capable phytognosts would fail, and when in default of such teachers for the identifying of plants there would be no other dependence at all but the old and often imperfect descriptions.

Men follow great leaders when the leaders are in the wrong, about as faithfully as when in the right; and if, during several centuries after Galen, lesser lights continued to mention plants hardly more than by their names and remedial qualities, it was after the example of his authority as supreme. In such manner may the most expert man of science chance to antagonize the best interests of that science, and heavily impede its progress along one line while advancing it in a different direction.

His indifference to phytography notwithstanding, Galen has been credited with having made some few additions to the list of known plants by new name, and by some sort of description.

Michel Adanson attributed the discovery and the naming of two new genera to Galen. They are Lycopersicon ${ }^{1}$ and Arctostaphylos. ${ }^{2}$ Both names are now in use for genera, but it is impossible to identify either one with the type which Galen had in hand; but from such description as the Greek gave out, his Arctostaphylos would be Vaccinium Arctostaphylos rather than Arctostaphylos uva ursi.

In the year 1737 Linnæus dedicated a genus GaLEnIA to the memory of Galen.

1 Adanson, Familles des Plantes, vol. ii, p. 572.

2 Ibid., p. 165 . 


\section{CHAPTER IV}

\section{INTRODUCTORY TO THE SIXTEENTH-CENTURY GERMAN FATHERS}

THAT long course of ages intervening between the last decline of the Roman empire and the revival of learning in the fifteenth century is chiefly distinguished botanically by what we do not know about it. Even the historians of botany, with hardly more than a single exception, ${ }^{1}$ instead of making intelligent and unimpassioned use of the scattered fragments of botanical record for the period, have done what they could to perpetuate their own hereditary prejudices against the whole period. ${ }^{2}$

However, he who is in quest of landmarks chiefly will be absolved from the task, interesting though that would be, of following the vicissitudes of botany through the middle ages. The period has not apparent landmarks of botanical history.

The tenor of the German writing of its history is, that the science of botany was born again, as it were, in the year 1530 and in Germany, by the publication of Otho Brunfelsius' folio entitled Herbarum Vive Icones-Living Pictures of Herbs. The Germans have always been and are the chief historians of botany. I pay full tribute of acknowledgment to their supremacy in this field of high endeavor when for the heading of this chapter I adopt what is become their own favorite caption. All of them use it: Kurt

1 Meyer alone (Geschichte der Botanik, vols. iii and iv) has treated the subject of botany in the middle ages with impartiality.

2 Emphatic examples of this kind of writing in the name of history are in Sprengel's Historia Rei Herbarice, vol. i; particularly his chapter on "Monastic Botany," pp. 222-228, and on the "Latinobarbarous Age," pp. 274-299; wherein even concerning the botanical volume of Albertus Magnus he says, "Let him read it who has time to throw away"; though Meyer, only a half-century after Sprengel, and as much an antimonachist as he, devotes seventy serious pages of his history to the merits of this same Albertus of the middle ages. 
Sprengel, ${ }^{1}$ Ernst Meyer, ${ }^{2}$ Emil Winckler, ${ }^{3}$ Julius von Sachs. ${ }^{4}$ All of them name Brunfels, Fuchs, and Tragus (Bock) as the fathers of the new botany of modern times.

It has been indicated in a preceding chapter of these Landmarks that the real father of botany as a science was Theophrastus of Eresus. If he is the father of the science he is the father of even modern botany, though not of those developments of it that have been the peculiar achievement of modern botanists. Science is truth. The foundations of a science are its fundamental truths, and so the foundations of a science once laid are laid forever. These things are self evident.

We shall not be able to realize in how far the "German Fathers" contributed to the superstructure of modern botany until we have examined with great care and diligence their best works; and this is something which, I shall make bold to say, not even the German historians have been at the pains of doing; though Sprengel, first of their lineage, did much and well in this direction, while also leaving very much for others to accomplish. Julius von Sachs, the latest in the line, copied Sprengel's caption "The German Fathers," etc., but knew next to nothing of their works, even rating as unimportant Valerius Cordus, ${ }^{5}$ who was immeasurably the greatest of them all.

The four now named represent two rather distinct kinds or grades of botanical work. Brunfels and Fuchs busied themselves almost wholly with medical botany. It is a rare thing with either of them to mention a plant of unknown or even uncertain medicinal or alimentary qualities; and their plant descriptions are almost as uniformly either compiled or literally copied from authors of centuries and even almost thousands of years before them. The books of Tragus and of Cordus abound in new and original descriptions. These demonstrate that these two men examined plants with their own eyes, and for the love of them as plants, and that they saw many things about the structure and the behavior of them to which the other two men, and even all botanists before them, had been blind.

There is another contrast. Brunfels and Fuchs, realizing the defects of many of the ancient descriptions, sought to render the

1 Historia Rei Herbarice, 2 vols., 8vo, I $807-1808$.

${ }_{2}$ Geschichte der Botanik, 4 vols., 8vo, $1854-1857$.

${ }^{3}$ Geschichte der Botanik, I vol., 8vo, I 854.

- Geschichte der Botanik vom I 6 Jahrhundert bis I860, I vol., 8vo, 1875 .

'Geschichte der Botanik, p. 3 I. 
identification of remedies more easy and certain by supplying engravings of the plants. This idea was very far from being new; indeed, it was almost as old as botany. Pliny knew as many as three Greek authors who, before the Christian era, had illustrated their manuscripts by paintings of the plants. ${ }^{1}$ The traditions of still others have been brought to light. In the middle ages early and late rare manuscripts of old botanical authors illustrated by drawings or paintings of plants were known and referred to. The most noted of such ancient manuscripts, now some thirteen centuries old, has been reproduced photographically, and in this way actually published since the beginning of the twentieth century. ${ }^{2}$ Even forty or fifty years before these fathers of plant iconography, there were printed copies of the Hortus Sanitatis, ${ }^{3}$ and of its German version, Gart der Gesundheit, illustrated by some five hundred wood engravings of plants. Doubtless the wretched character of those first printed plant pictures, along with the fact of the great popularity of the books containing them, were what moved Brunfels to undertake the production of the Herbarum 'ivce Icones; and the success of his enterprise stimulated Fuchs to inaugurate a larger one. These two might worthily have been styled Fathers of Plant Iconography, but to name them the German Fathers of Botany is superlative; for it will have to be admitted that the mere publishing of plates of plants, with names of said plants and their uses, is not in itself the setting forth of any scientific principles beyond the few taxonomic ideas which the mere grouping of the plates may chance to indicate. What are plant picture-books for? In the case of the authors of them, they may be the refuge of those who can not describe, or, with such as can describe, they are a condescension to such as can not read; also to others who are

1. Plin., Hist. Nat., Book xxv, ch. 2; see also Meyer, Geschichte, vol. i, 250. The names of the ancient painters were Cratevas, Dionysius, and Metrodorus.

2 A celebrated Greek manuscript of the Materia Medica of Dioscorides, known as the Codex Anicie Julianc, in which each plant is represented by a painting of natural size. The manuscript dates from the sixth century and was done at Constantinople. It has long been in the Imperial Library at Vienna. The whole has lately been reproduced photographically. The title page of the published work has the following:

"Dioscurides. Codex Aniciæ Julianæ picturis illustratus, nunc Vindobonensis Med. Gr. I. photographice editus. Moderante J. Karabacek. Prefati sunt A. de Premerstein, C. Wessely, J. Mantuani. Lugduni Batavorum, A. W. Sijthoff, I906."

3 For some account of these earliest specimens of printed books of popular medicine chiefly botanical, the reader is referred to Pritzel's Thesaurus, 2d ed., pp. 364-368; also Meyer, Geschichte der Botanik, vol. iv, p. I89. 
incapable of mentally imaging a thing from the verbal description of it. By the large picture-books of Brunfels and of Fuchs all sorts and conditions of men, lettered and illiterate, could identify some hundreds of useful plants; a thing which never had happened in the world before that day. For this they deserve only praise. Nevertheless, had no books of botany been issued in the sixteenth century essentially different from those of the two authors named, it is difficult to see how botany could have progressed a single stage within that century.

In the works of Tragus and of Valerius Cordus we have books in character essentially different from those of the two aforenamed. Both these were deeply interested in plants of all kinds; were given to examining their organs minutely and marking the behavior of certain growths at different stages, and all this before ever having thought of writing books thereon. Also when they betook themselves to writing it was without any purpose of calling upon artists to make pictures remedying the defects of their descriptions. They were under the inspiration of a new idea in botany, namely, that plants might be so described as to be identifiable by description. Galen's dream about a kind of apostolic succession of living teachers, one generation of whom should forever teach the next to know the medicinal plants by their right names ${ }^{1}$-all that had proven a very idle dream. Thirteen changeful, turbulent centuries had now passed since Galen. The succession had been obsolete a thousand years, and the world botanical was far at sea as to the true identity of many important plants. There must be descriptions; and they must be better than those handed down from ancient times. I should not venture to credit the erratic and garrulous Tragus with having known the history of botany so well, or having planned the opening of a new era in descriptive botany. We shall probably see, by the perusal of his book, that what he achieved here, and it was not a little, was but the spontaneous outcome of his admiring curiosity about plant structures. On Cordus' part, it is unmistakable, there is the deliberate plan of creating a new phytography. Therefore, and by a study of the men and their books, I think we shall perceive that in the Germany of the first half of the sixteenth century, there were two fathers of plant iconography and two fathers of descriptive botany.

1 See page 165 preceding. 


\section{CHAPTER V}

\section{OTHO BRUNFELSIUS, $1464^{-1534}$}

First in point of time among the German botanical reformers of the sixteenth century, Brunfels is also easily first in rank respecting those educational and literary qualifications which go to the making of what one calls a scholarly book. In this particular his one botanical treatise, the Herbarum Vivce Icones, is peerless among the several books of botany that appeared in middle Europe within the first half of the sixteenth century. Others produced more and better botany; but there are marks of a dignified and conservative erudition that are characteristically Brunfels' own.

Life. His career was a long one, at least for a consumptive, ${ }^{1}$ and was singularly varied. One need not here analyze the motive of that countryman of Brunfels who pretended that the man's professional life might be summed up in one sent nnce like the following: "At first a schoolmaster at Strassburg, then a physician at Berne." 2 This would be good language in which to epitomize the professional life of one who had been at the early outset a schoolmaster, after that a university graduate in medicine, and then a practitioner. Such would be the natural interpretation of a sentence like that quoted; and the trouble with this pretended epitome is, that it leaves completely out of view Brunfels' occupations during the first fifty years of his life, revealing only the last twenty; for certain it seems to be, that when in default of other means of a livelihood he opened at Strassburg a school for boys, he was well past fifty years of age; also that when at the University of Basle he won the degree of Doctor of Medicine, he was sixty-five.

In the history of botany Brunfels will hold in the future, as he has done in the past, a somewhat distinguished place among the notabilities belonging to his century; and we must review, as well

1 Brunfels died of consumption at Berne, Switzerland, probably at the age of about seventy years.

a Sprengel, Hist. Rei Herb., vol. i, p. 3 I I. 
as at the distance of four hundred years we may, the incidents that had to do with the moulding of the youth, and helped to establish the character of the man.

The birthplace of Otto Brunfels was Mayence, or Mainz. The family had taken its name from Castle Brunsfels ${ }^{1}$ not far from Mainz where the earlier ancestry of the botanist had lived. At Mainz, John Brunsfels, the father, was in the business of a cooper; appears to have been in comfortable if not affluent circumstances; was well known and much respected as a man of character and high integrity; also, as we learn by his opposition to young Otto's plans, a man with a will and purposes of his own; qualities inherited by the son, as we shall see. Otto was the only son, and entertained the thought of devoting himself to the service of the Church. At that time Martin Luther was yet unborn and all Germany was Catholic. ${ }^{2}$ A Catholic father of that period, if rich or well to do, would have been a marvel of pious unworldliness, if he had been willing that his only son should become a clergyman; for that would mean the immediate extinction of his own branch of an ancestral line. This father of young Otto Brunfels was resolute and persistent in his opposition to the son's wish; and naturally so; and this must have continued until the son was of legal age; for at last, hopeless of otherwise attaining to the priesthood, he left home and became a novice in the Carthusian monastery that was in his native town. This he would not have been permitted to do had he been a mere youth, unless the father had given consent.

Meyer's inference that Brunfels remained but three or four years an inmate of the monastery ${ }^{3}$ proceeded from several misunderstandings, one of which was that the man had not been born until a little before the year 1500 . But there is now good authority for our accepting 1464 as the year of the botanist's nativity; so that in I 500 he was already thirty-six years old. Then, since to assume a part in the new Lutheran movement was the object of his secret flight from the house of the Carthusians, and that movement was hardly well under way before I $^{1} 7$, it becomes highly probable that the man was fifty-three years of age when, renouncing monasticism and giving his learning and talents to the support of Luther's cause, he took up the sojourn at Strassburg. He betook himself

1 Brunsfels, rather than Brunfels, was the family name. In some of our author's earlier works he wrote it Brunsfelsius; but later he appears to have changed it to Brunfelsius.

2 Otto Brunfels was born in 1464 , Martin Luther in 1483 .

3 Geschichte der Botanik, vol. iv, p. 296. 
to school teaching only after his voice had failed him, so that he could no longer preach. Here again the historian Meyer draws an inference. It is this, that his school must have been a financial success, because at the end of nine years at teaching he had saved money enough to pay the expenses of his degree at the University of Basle. Without doubting the financial success of Brunfels' school it is next to certain that he realized a much more considerable income from the sale of his rather voluminous Protestant theological writings; for these included, besides learned commentaries on certain books of Scripture, pamphlets for popular reading, and a catechism for children. There is a long list of them in Conrad Gesner's Bibliotheca Universalis. Altogether his two vocations of teacher and theological author must have yielded him a very fair income during these first nine years at Strassburg; for he was able to give employment to the best engraver of Strassburg, Hans Weydiz (Latinized Guiditius), who did the engraving of the Icones, and is a man of distinction in the history of wood engraving.

It must have been after having taken his degree in medicine, and within two or three years from the time of his death, that Brunfels made a journey from Strassburg to Hornbach for the purpose of personally urging Jerome Bock (Tragus) to write a book of botany for German readers. For the record of this visit history is indebted to Tragus himself. In the thirteenth chapter of his preface to the Stirpium Historia he says: "When information about the labors and the journeyings which I had undergone in behalf of plants had in some way been conveyed to the most learned Otto Brunfels of pious memory, he himself came journeying all the way from Strassburg to Hornbach, that he might see my gardens and collections. These things pleased him so much that from that day forward he ceased not to exhort, as did also others by letter, that I would reduce all this matter to order, and give it to the German public."

Not one of even the compatriot German historians of botany, in so far as I am aware, has set before us this evidence that it was to Brunfels' personal influence over Tragus that the writing and publishing of Tragus' work was due. How much botany owes to Tragus' unusual powers of observation and description we shall learn later; for the half of that story has never yet been told.

It is well worth noting that this visit to Tragus, with its fruitful consequences, was the last service which Brunfels rendered to botany. The visit must have been made as late as the year I532; for not until that year was Tragus settled at Hornbach; and in the 
next year Brunfels, now newly-appointed physician to the city of Berne, removed thither; where also after only a year and a half of service he died in 534 .

After having ceased from theological authorship, and subsequently to his having taken a degree in medicine, Brunfels published several medical works; but both theology and medicine appear to have forgotten his name. In the history of botany only is he immortal; and this because he was intensely a lover of nature and of plants. His book gives proof of this, although the figures are the best part of it. It was because his love of plants could not tolerate the absurd pictures then common, that he resolved to produce something in that line true to nature, despite the cost; for the employing of the best artist of his time can not have been less than very expensive to him, and there may have been no clear prospect of any return, even of that which the plates cost him. Indeed no one can assert that there ever was any. But here was devotion to an ideal; a love of plants that was bent upon procuring faithful representations of them in books. And so a well marked epoch in the study of the plant world dates from Brunfels and the year 1530 .

To the botanical memory of this ex-Carthusian, the Franciscan monk Charles Plumier dedicated the genus BRUNFELSIA in the year I 703 .

Phytography. If by a man's phytography is meant his manner of describing plants, that is his word-picturing of them, it cannot be said of Brunfels that he has any; and Julius von Sachs was never farther from writing history than when he set this man forth as among those who "went straight to nature, and described the wild plants growing around them."1 Brunfels publicly disclaims all purpose of writing verbal descriptions of any plants whatever, and in the following terms:

"In this whole work I have no other end in view than that of giving a prop to fallen botany; to bring back to life a science almost extinct. And because this has seemed to me to be in no other way possible than by thrusting aside all the old herbals, and publishing new and really life-like engravings, and along with them accurate descriptions extracted from ancient and trustworthy authors, I have attempted both; using the greatest care and pains that both should be faithfully done." 2

His meaning as to phytography is plain. He will describe

1 Sachs, Geschichte der Botanik, p. 4.

2 Epistle Dedicatory, to the Senate of Strassburg, second page. 
nothing anew. He will ignore the contents of wretched mediæval herbals like the Hortus Sanitatis. He will reproduce the standard descriptions of classic Greek and Roman authors. For an example, take his presentation of the two water lilies, the white-flowered kind and the yellow. He figures them admirably, and, not having a word of his own to add to that knowledge of them which has been the common property of botanists for a thousand years and more, he supplements the two plates by three folio pages of quotations about them, taken from a list of eleven of the most approved botanical authors, ancient, mediæval, and contemporary. Here is the list:

$\begin{array}{ll}\text { Theophrastus } & \text { Serapion } \\ \text { Dioscorides } & \text { Simon Januensis } \\ \text { Plinius } & \text { Rases } \\ \text { Apuleius } & \text { Joannes Vigonius } \\ \text { Georgius Valla } & \text { Hieronymus Herbarius } \\ \text { Avicenna } & \end{array}$

And what is true as to his presentation of the water lilies holds good in the case of almost every other genus that he takes up. Rarely does he append to such a succession of quoted paragraphs a few remarks of his own; and these always indicated as his by the special caption, "Sententia nostra," or "Sententia Othonis;" nor are such original paragraphs really of the nature of descriptions. They usually express some opinion as to the identity of the plant in question; have reference to the correct application of a classic plant name. As to phytography, therefore, the Brunfelsian volumes are a treasury of select quotations from a long line of books many of which are now seldom seen. But there are no new descriptions in his volumes; and it may be doubted whether upon the whole he directly advanced the art of plant description by a syllable.

It is no impeachment of his erudition to question that he had the ability to describe plants well. There is evidence that he had not the faculty of mentally imaging an unknown plant from its description; and the ability to describe, and that of making effective use of a description are twin accomp ishments, if indeed they be not almost one and the same, so that he who has the one has also the other. Certain it is that Brunfels read and studied here and there a classic plant description to little purpose. Bringing together in one chapter the classic descriptions of Aristolochia, the figures by which he illustrates the genus are Corydalis bulbosa and C. Halleri. So gross an error explains tself in this way. The aristolochias were of southern Europe and not found in Germany. Here, however, 
the roots of the fumariaceous perennials, not so unlike those of the principal aristolochia, had usurped in medicine both their place and their name. Brunfels, though professedly reforming German pharmacy by the correcting of just such blunders, did not detect this one Yet the very descriptions of aristolochia which he reprints from Dioscorides and Pliny must have shown, had he really read them, that these things could not be aristolochias. Other such errors also remained undiscovered by him, and as inexcusably; so that when his countryman and contemporary Fuchs remarked that in Brunfels the descriptions and the plates accompanying them are not in all cases at agreement, ${ }^{1}$ he was passing but a gentle criticism on his neighbor's phytographical shortcomings.

Anthology. I have met with no evidence that during the fifteen centuries intervening between Dioscorides and Brunfels there had been any progress made in the knowledge and understanding of floral structures. There were several of Brunfels' younger contemporaries who, after the year I 530 , added somewhat to anthology; but the time was yet more than two generations distant when the science of the flower was to become so far developed as to begin happily to revolutionize plant classification. There is no sign in Brunfels that such a day is near its dawning. In his attempts to range plants in groups he is no more influenced by considerations of floral structure than were the medical botanists of remote antiquity; even less so than Dioscorides, who, as we shall see, could not abide the placement of the bilabiate-flowered dead nettles in the same genus with real nettles, but segregated them, on account of their two-lipped corollas, and assigned them a new generic name of their own, and framed to express the peculiarity of their flowers. It is possible to rate the Brunfelsian anthology as more antiquated and imperfect than that of Dioscorides; for he of the sixteenth century less openly recognizes as generically distinct the Galeopsis and Lamium "nettles" and the proper Urtica"; and if he figures the thistles, the anthemideous composites, the principal borragineous plants, the bulk of the labiates, and some other such, each as a group by itself, it is done without any particular reference to floral structure, at least on Brunfels' part; for in all these instances he is but continuing groupings which the ancients themselves had indicated as being natural, and had well established.

Taxonomy. Brunfels adopts without hesitancy the ancient primary classification of growths as herbaceous and woody. When,

t Epistle Dedicatory, in Fuchsius Hist. Stirpium.

${ }_{2}$ Herbarum Vive Icones, vol. i, pp. I 5 I-I 54 . 
however, it comes to that apparently quite as ancient division of the vegetal kingdom into things cultivated and things wild, he deliberately ignores it. His first three plates represent three most common and homely wayside weeds, members of the genus Plantago; and thenceforward throughout his volumes he deals much more extensively with wild plants than with the domesticated.

Now this eliminating of the distinction referred to is not to be attributed to any following of the suggestions of Hippon, who some two thousand years before had declared plants wild and domesticated to be all of one lineage. There is no intimation that Brunfels had made tests, and proven out of the book of nature that this old-time grouping must be abandoned. The thought had come to him solely as a deduction from theological premises. The polytheistic ancients had held that the different alliances of cultivated plants and trees were each the creation of some beneficent particular divinity; and that the less useful or the altogether useless had hardly been created at all. The theology which Brunfels accepted, and, as a profession, taught, was monotheistic. One Divinity had made all the plants that are-the wayside weeds, the homely remedial herbs, as well as the beautiful things of the field, the garden, and the orchard. Such doctrine of the equality of all plants as to one divine origin finds expression in the last one of Brunfels' severa1 prefaces, which contains a prayer, after which one reads his apology for giving to those common, lowly, and weedy things, the plantains, the foremost place in his system of botany. "They are the very commonest of plants," he says, "and are known to everybody; and being both lowly and also singularly useful, they are most apt to recall to mind the thought of God, whose way it is to work wonders through means that are usually accounted insignificant, passing by such as make more display, and which men therefore hold in more esteem." 1 This is even showing a preference for wild growths before those that have undergone domestication; a kind of preference that has been felt by the great majority of philosophic botanists from Brunfels' time to ours; and by virtue of his being the first propagandist of this new idea he sets up another landmark in the history of botany.

This idea of the equal genetic dignity of all plants seems to have come to Brunfels as a deduction from a theologic principle, rather than inductively from the study of nature; but whence he derived it signifies nothing to the disparagement of the idea itself; especially now, after all the world has come to concede its truthfulness. But

' Herbarum Vive Icones, vol. i, p. 22. 
it was not at once approved in Brunfels' time. There were learned men among his contemporaries who were at first startled by, and then made light of his having brought forward some of the most plebeian and beggarly roadside pests, and introduced them as upon an equality into the company of the nobler growths of the fields and meadows, and of the vegetable and drug gardens. Among the more serious faults that his contemporary Fuchsius found with Brunfels' work, one was "That he sometimes takes for subjects the most common weeds." 1

By at least one other item of his method, over and above this of ignoring the old distinction between things as domesticated and wild, does Brunfels commend himself as a believer in some kind of a natural classification. He declines to adopt anything like an alphabetic sequence of genera; a kind of arrangement which was adhered to by several of his noted botanical contemporaries, as we shall see. He prefers freedom to express, if but tacitly, some ideas of a more rational grouping, such as the alphabetic succession of names almost wholly precludes; and, with the medical botanist, that arrangement may be most convenient, if not even in a sense natural, in which plants, whether alike or unlike as to morphology, are held in juxtaposition by agreement as to what are taken to be their medicinal virtues.

For an example of this kind of classifying carried to an extreme, take his two genera of liverworts, Hepatica and Jecoraria. The former is that anemoneous herb that has retained in later times the name Hepatica; the other is the common Marchantia polymorpha, a cryptogam. The two are figured and described on opposite pages, and their medicinal uses are said to be the same. ${ }^{2}$ It may be noted that each bears alike, even in our"time, the common name of liverwort. Before Brunfels Hepatica usually meant the plant Marchantia, which was also called Jecoraria, and the restriction of the name Hepatica to the genus of anemone allies, and of Jecoraria to the lichenoid hepatic, seems to date from Brunfels, and was a distinctly taxonomic movement on his part; as if his judgment had been that types so very unlike morphologically ought not to be treated of under one and the same generic name.

Because of their having been employed interchangeably in medicine, under the common designation of Verbena, our medical botanist figures and discusses, one next after the other, Verbena officinalis and Senecio vulgaris. ${ }^{3}$ The botanist of a later time will

1 Fuchsius, Hist. Stirp. in Epistola Nuncupatoria.

2 Herb. Viv. Icon., vol. i, pp. 190, I9r.

${ }^{3}$ Ibid., pp. I 19-1 23 . 
see no likeness or other sign of true affinity between these; and it is very probable that Brunfels himself realized how very distinct they are when considered from the morphological rather than the remedial point of view; for when he formally designated one of them Verbena mas and the other Verbena famina it is beyond question that he was purposely indicating the morphological distinctions between them; quite as he had done in assigning to those two morphologically dissimilar liverworts each a generic name of its own. And according to the usage of Brunfels' time, as well as for two centuries later, binary generic names like Verbena mascula and Verbena fomina were thought as suitable, and were as freely made and admitted, as those of one word only.

Of such attempted improvements in classification by appeal to considerations of morphology, one may come to a fuller appreciation by looking into Brunfels' way of presenting those many herbs which, in his time, had long been reputed to be good vulneraries, and had therefore passed under the medico-generic name of Consolida, with which Symphytum, Sanicula, Vulneraria, and Solidago were synonymous, each such name indicative of the property which these plants all had, or were believed to have, of promoting the closing-up and healing of cuts and wounds. Here is a partial list of these plants under their mediæval names, with their equivalents in modern nomenclature:

Mediæval

Consolida major

Consolida media

Consolida minor

Consolida petræa

Consolida regalis

Consolida rubea
Modern

Symphytum officinale

Ajuga reptans

Sanicula Europæa

Coris Monspeliensis

Delphinium consolida

Tormentilla erecta

One thus gains an idea of how great a diversity of plants passed with mediæval pharmacists and physicians under the generic name Consolida. And the list must now be given again, that the Brunfelsian taxonomic betterment of it may as readily be seen:

Mediæval

Consolida major

Consolida media

Consolida minor

Consolida petræa

Consolida regalis

Consolida rubea
Brunfelsian

Consolida major

Consolida media

Diapensia

Symphyton petræum

Consolida regalis

Tormentilla 
One observes that out of the six Consolida names, three have been eliminated, and others brought forward to take their places. I say brought forward; for neither Diapensia, nor Symphyton petrcum nor Tormentilla is coined and proposed as new by Brunfels. He picked them up every one out of the ancient and mediæval synonymy of the vulnerary herbs; from which also it will appear that other men who lived and wrote botany in times long forgotten - but the history of which times must none the less some day be written-thought as Brunfels did, that plants totally unlike in appearance, i.e., morphologically very different, ought to be invested with names more than partially different, even when as to qualities and uses they were very similar. And these group names established upon the merely remedial virtues of things visibly most dissimilar must have been misleading and confusing in the extreme. It seems as if Brunfels realized this, and intended to suggest improvement when he set aside three out of the six Consolida genus names and wrote others in place of them. It is as if he had thought it out, that since the different kinds of plants can only be well distinguished and scientifically grouped through attending to their morphology, it is not well that they should bear names that point to their qualities rather than to their forms. Therefore, in the interests of a more sure identification of important plants, as well as at the same time encouraging the appeal to morphologic marks in classifying, it would be a good thing to at least place a check upon this multitudinous repetition of pharmaco-generic names, the first half of which is the same for a half-dozen very dissimilar genera.

If it be asked why he did not, while he was about it, proceed to the suppression of as many as five out of the six Consolida genus names-leaving perhaps one of the genera to bear the simple name Consolida-the right answer will seem to be that Brunfels was not of the temperament of the taxonomic revolutionist but only a reformer, and disposed to be somewhat conservative even as a reformer; between which character and that of the bold iconoclastic revolutionist there are differences.

Entirely consistent with his aversion for genera made up of plants qualitatively alike but morphologically unlike, is Brunfels' approval and adoption of some in which the species are qualitatively unlike, and at agreement morphologically. Such a genus as this is that which he fully illustrates under the classic name of Urtica, ${ }^{1}$ which in the botany of to-day comprises only the true

1 Herb. Viv. Icon., vol. i, pp. I $^{1-1} 57$. 
nettles. The specific constituents of his Urtica seem to be

Urtica dioica,

Lamium maculatum, ${ }^{1}$

Galeopsis Tetrahit,

Urtica urens,

and this, too, is the order in which they succeed one another in the book; first a real nettle, then two so-called dead nettles, the line closing with a second true nettle; a genus composed of two nettles, and two or three members of the very different family of the Labiatæ. And this, as intimated above, is a genus not qualitatively but morphologically constituted; a fact easily demonstrable when it is remembered that Brunfels had no anthology; that the flowers of plants not only were not at all understood by him, but were the least and the last parts of them to receive any consideration. So long as two or three herbs were alike as to roots, stems, and leaves, they might easily be designated by the same common, i.e., generic, name. Forgetting, then, all anthologic differences between nettle and dead nettle, note how remarkably they are at agreement. The roots in all are small, fibrous, and not deep-seated. The stems of all are upright, almost or quite without a branch, conspicuously quadrangular, and the leaves they bear are opposite. 'The leaves in all are short-stalked, their blades of the same ovate or oval outline, serrate as to their margins, and are of much the same texture as well as form. The seeds in all-for though anciently flowers were neglected, seeds never were-the seedș were black, and were always clustered together in the axils of the leaves all up and down the stem. All these quite marked characteristics of all their vegetative organs Urtica and Lamium and Galeopsis have in common.

Since the thought is one far from being familiar to the botanical mind of the present, it must here again be insisted on, that the grouping together of several plants upon vegetative characters only, but under a generic name, is as exactly of the nature of a generic concept as that group which is rested on characters of flower and fruit only. By either method a genus may be circumscribed which shall be unnatural; and the idea is equally the idea of a genus in either case.

I do not see what chapters of any history of botanical science should be more profoundly significant, or of a more general interest, than those touching upon the development of men's ideas of a plant genus; for the idea of the genus seems to be first and last the type-

But this one not figured, though by implication included, as quoted from Hermolaus Barbarus by Brunfels, on page ${ }_{54}$. 
idea, if one may intelligibly so speak, of taxonomy. It was because this seemed to be true, that in our Introductory on the Philosophy of Botanical History, the earliest available expressions of such idea by even the primitive and the unlettered were dwelt upon somewhat at length; and for the same reason, one desires to examine with the utmost care leading expressions of the idea of a generic group as they occur in this almost the earliest propagandist of what has slowly developed into the thing known as modern botany. Brunfels was of thoroughly well educated mind, even a profound scholar, also naturally endowed with a keen insight into the beauties and the harmonies of plant life and form. On all these accounts it would be exceedingly interesting, if it were possible, to know just what his own opinion really was as to the philosophic tenability of such a genus as this which we have been inspecting; a genus Urtica, by name, but made up of species some of them urtical, but as many others labiate. If he has any taxonomic opinion different from that which, in as far as we have proceeded, he seems to have expressed, we shall be likely to find. the evidence of it, if there be any, by reading as it were between the lines; for even a botanical genius, if writing as Brunfels professes to write, in the interests of medical botany only, inditing a work the readers and students of which are to be the physicians and the pharmacists, must not yield to every impulse he may feel to improve taxonomy; for such improvement commonly involves changes in nomenclature, and there is nothing of which the druggist, or other plant industrialist, is more intolerant than changes in names of his commodities.

The opinion, if Brunfels held it, that nettles proper and labiateflowered nettles are generically distinct, was not original with him. We observe that Dioscorides as long ago as the first century of our era segregated the dead nettle as a genus, and under a name which pointed to the character of its flower, the name Galeopsis; and this proposition had evidently been acceded to by some of the mediæval Latin botanists, who, instead of the Greek $\gamma \alpha \lambda i o \psi 15$, had employed such Latin equivalents as Urtica mortua, Urtica iners and Urtica labeo, the last a most significant appellation, "nettle with a lip," evidently taking cognizance of the floral character, while the other two refer merely to the lack of stinging hairs. Now this mediæval synonymy of the plants is perfectly familiar to Brunfels. He formally quotes every item of it; and his approval of Galeopsis $^{1}$ as a proper genus comes out plainly enough,

1 In modern botany the genus is written Galeopsis. Dioscorides (Book x, ch. 80) wrote it Galiopsis, as did also Brunfels. 
at least to the careful reader, and on this wise. In reproducing what Dioscorides had said about the labiate nettles he does it under the following caption: "De GaLiopsi simili Urticis herba, Dioscorides." 1 Of such a caption the English version is, "Concerning GaLiopsis of Dioscorides, an herb resembling the nettles."

Of course, that which resembles another thing is not that other thing which it resembles; and nothing that was ever printed in a book is plainer than that this author did not regard Galiopsis as congeneric with Urtica. When in his Icones he sandwiches the dead nettle in between two real nettles, and when as a heading to his Chapter XXIII., in which both kinds are discussed, he places that simple "DE URTICIs," he is purposely adapting himself to the understanding of the half-taught root and herb dealers, and the untaught old women, who call them all nettles indiscriminately. In a word, Brunfels is a man of some learning and insight in matters botanical, and also a man of discreet conservatism; holding it unwise to lay too openly before the general public every advanced taxonomic view that is his own.

In his indubitable though dissembled accepting of Galiopsis as distinct from the nettles he cannot but have been impressed by the fact that Dioscorides in making the segregation had done so in deference to its flowers, which he described as being "slender and purple"; and it may or may not have been in deference to similarity in floral structure that closely appended to the UrticaGaliopsis series comes an unbroken line of three other galeateflowered labiate types. If, however, this be an example of guidance by anthology to the recognition of affinity, still it is a guide which Brunfels is as far as possible from following steadily. The flowers of orchidaceons plants have as much agreement in character as have those of labiates; but when he comes to the grouping of what are known to us as the orchid genera we find that all those which have two or three large tuberiform roots are gathered into one place by themselves, ${ }^{2}$ while their merely fibrous-rooted kindred form a group quite apart from these, ${ }^{3}$ various wholly unrelated types intervening between the two orchid groups. This is all.quite after the method of antiquity; the method of those who, heedless of flowers, to the knowledge of which they had not advanced, concluded things to be allied because they were alike as to roots, and, it may be, as to stem and foliage also.

1 Herb. Viv. Icon., vol. i, p. I 55.

2 Ibid, pp. 1о3-1 го.

${ }^{3}$ Ibid., pp. 18 I, 182 . 
Let us give a moment's attention here to another set of plants which he places in juxtaposition for the reason that they all exhibit a kind of tuberiform organs as developed among their roots. The group is

Brunfels

Scrophularia major

Scrophularia media

Ficaria
Modern

Scrophularia nodosa

Sedum Telephium

Ficaria ranunculoides

The point that is of special interest here is, that for the third member of the group Brunfels rejects that which was one of its common mediæval names, that is, Scrophularia minor; though more anciently, even with Dioscorides, it was called Chelidonium minus. What he did with this third plant of the list seems to attest that there was in him, botanically, as there was ecclesiastically, something of the spirit of the revolutionist, or reformer. If there had not been, he would have been almost sure to have called this ranunculeous herb by one or other of its ancient and mediæval names rather than startle the herbalists and pharmacists of his time by that new name, Ficaria, for a type so long known under very different appellations. We shall also, I think, miss a part of what was in his mind, if we do not read here the expression of an objection on his part against the old way of naming and grouping of plants conformably to their medical qualities rather than according to their morphology. All three of the plants had been called kinds of Scrophularia, because they were believed to be efficacious against :crofula; and there is with me no doubt that Brunfels in displacing one of the old Scrophularia names by the new generic name Ficaria is to be understood as mildly protesting against qualitative criteria of plant affinities, and affirming the need of appealing to the morphologic.

We were observing above how Brunfels might be said to have limited his group of the orchids to such genera of them as have a certain kind of underground organ; that he excluded from the group such as have only fibrous roots, himself all the while oblivious -as all the world before him always had been-of the flowers by the structure of which all stand at agreement. Let us now observe him locating as far away from each other two groups of genera known to us as borragineous plants. In this instance he does. not separate on ground of differences as to roots, or form of leaves. but of pubescence only, that is, over and above certain qualities common to all. Upon such principles are Echium, Cynoglossum, 
and Borrago made to form a group of genera. ${ }^{1}$ We of to-day, after four centuries of taxonomic progress, concede that Brunfels was correct in apprehending a very intimate consanguinity between the three. But we hold them in juxtaposition on quite other grounds than those which had weight in the early sixteenth century. We judge them near allies because the plan of their flowers, and the common characteristics of their fruits are the same. With Brunfels the flower was so a'most wholly unknown that no such thing as the plan of a flower had been thought of. And, viewed superficiallythe only view that had yet been taken of flowers at all,- - they were very notably dissimilar. The corollas of the genera are of remarkably distinct types, that of Echium being narrowly tubiform below, with an irregular almost bilabiate limb; that of $C y$ noglossum is shortsalverform, perfectly regular; that of Borrago broadly and flatly star-shaped. Few families of plants present three genera so unlike. as to the cut of their respective corollas as these three. We therefore seem to infer to a certainty that in collocating these three generic types, he had had the utmost regard to their likeness as to roots, stems, foliage, and especially to that armature of harsh somewhat stinging bristles wherewith all three alike defend themselves; and that in the process of his reasoning the corolla, i.e., the "flower," was not at all considered. And, as if to place this beyond dispute, two other borragineous types are relegated to another part of the book. One is a Cynoglossum, the other a Myosotis. ${ }^{2}$ Both differ from the other group in that they show no trace of the stinging-bristly or any other rough indument. They are almost silkily soft-hairy. Had he not held such differences to be most significant, taxonomically, it is impossible to see why he separated so widely these two groups of what we of to-day understand to be near allies.

If one is to follow the progress of plant taxonomy from the year 530 forward, it will be needful to bear in mind such things as Brunfels' failure to apprehend the consanguinity of all the borragineous genera that he knew; as well as to note, if perchance one may discover the reason, why he failed. Then afterwards it must be observed how those who came after him, one after another and little by little, brought the other genera of such a family into a continuous sequence; also all the while attending to-even carefully noting-the development of new principles, whatever they may have been, in accordance with which the better taxonomy of more

1 Herb. Viv. Icon., vo'. i, pp. III-II3.

Ibid., I75-177. 
recent centuries has been attained to. Thus may we learn, and thus only, the lesson of the modern development of the very old idea of plant families.

Nomenclature. All plant names are names of groups; and to group things together under a common name is to classify. Nomenclature and classification are therefore so intimately connected that neither topic can be fully discussed apart from some consideration of the other. They can not be completely divorced; and so it was inevitable that something in relation to Brunfels as nomenclator should be brought out under the heading of taxonomy. It will be useful, however, to epitomize his work as nomenclator, and particularly since he now and then evinces a disposition to amend and improve upon ancient and mediæval names and name-making methods; or, it might perhaps better be said, a disposition to return from mediæval to ancient methods; for what I have in mind is something like a distinction which, in a general way, holds between what may be termed the ancient and the mediæval plant naming. It is, however, not much more than a difference between the genius of the Greek language and that of the Latin as to manner of framing distinctive names for things.

In Greek the noun and adjective readily combine to form a single word, such word beginning with the adjective part and ending with the noun; whereas in Latin noun and adjective are kept as distinct words, even with the noun rather than the adjective standing first. To make this as plain as possible let us use a few examples :

\begin{tabular}{ll}
\multicolumn{1}{c}{ Greek } & \multicolumn{1}{c}{ Latin } \\
Leucoion & Viola alba \\
Melanion & Viola nigra \\
Chrysion & Viola aurea \\
Herpetion & Viola repens \\
Chelidonion & Viola hirundinaria
\end{tabular}

By many scores of such one-worded Greek plant names which by translation into Latin become binaries, there is revealed one of the misfortunes under which mediæval and early renaissance botany labored everywhere-for mediæval botany was Latin botany -that of having in its employment hundreds of binary names, some of which were of specific import, while as many more were but the names of monotypic genera.

The continual perplexities involved in this phase of nomenclature seem to have exercised the mind of Brunfels to a degree, so that 
he made bold to displace here and there some binary generic name, substituting one of a single word. A few examples of such action on his part were brought forward under the heading of his taxonomy. A more considerable exemplification of this practice is given below, in a selection made from the first volume of the Vivce Icones:

\begin{tabular}{|c|c|c|}
\hline Carly binary generic names & & felsian substitutes \\
\hline $\begin{array}{l}\text { Fumus terræ } \\
\text { Fumaria herba }\end{array}$ & $=$ & Capnos \\
\hline $\begin{array}{l}\text { Ferraria major } \\
\text { Consolida minor }\end{array}$ & $=$ & Sanicula \\
\hline $\begin{array}{l}\text { Testiculus canis } \\
\text { Testiculus vulpis }\end{array}$ & $=$ & Satirion \\
\hline Lingua bubula & $=$ & Borrago \\
\hline $\begin{array}{l}\text { Sacra herba } \\
\text { Verbenaca supina } \\
\text { Cincinnalis herba } \\
\text { Lacryma Junonis } \\
\text { Herba sanguinalis } \\
\text { Sanguis Mercurii } \\
\text { Mustelæ sanguis } \\
\text { Crista gallinacea }\end{array}$ & $=$ & Verbena \\
\hline $\begin{array}{l}\text { Trixago minor } \\
\text { Quercula minor }\end{array}$ & $=$ & Chamædrys \\
\hline $\begin{array}{l}\text { Scrophularia minor } \\
\text { Chelidonium minus }\end{array}$ & $=$ & Ficaria \\
\hline $\begin{array}{l}\text { Herba Apollinaris } \\
\text { Faba suilla }\end{array}$ & $=$ & Hyoscyamus \\
\hline
\end{tabular}

The credit of having reformed the nomenclature of genera by the exclusion of names made up of two distinct words has been given to Linnæus, who, in the year $175 \mathrm{I}$, is thought first to have laid down such a principle. ${ }^{1}$ But the actual reform had been quietly inaugurated by Brunfels two hundred and twenty years before Linnæus came forward with his Philosophia Botanica.

Sprengel, the one nineteenth century author of a Genera Plantarum who has observed the law of priority in the crediting of generic names, ascribes to Brunfels the authorship of the following:

$\begin{array}{lll}\text { Ammi } & \text { Fragaria } & \text { Pyrola } \\ \text { Calendula } & \text { Linaria } & \text { Sanicula }\end{array}$

' Nomina generica ex duobus vocabulis integris, ac distinctis facta, e Republica Botanica releganda sunt." Linn., Philosophia Botanica, Art. 242. 


$\begin{array}{lll}\text { Carthamus } & \text { Melissa } & \text { Spinacia } \\ \text { Castanea } & \text { Parietaria } & \text { Scrophularia } \\ \text { Euphrasia } & \text { Potentilla } & \text { Valeriana }\end{array}$

To this list of fifteen, credited to this author by Sprengel, I find two more to be added, namely Hepatica and Ficaria. Sprengel's reason for not taking them into the reckoning was simply this, that he did not admit the types as worthy of generic rank, but held with Linnæus that the former was but an Anemone and the latter a Ranunculus.

Now when Sprengel and other advocates of priority credit such genera to Brunfels, it is not to be understood as their meaning that in his book these types are for the first time named and defined. The truth is, that all of them had been known before Brunfels, and some of them had been much written about, under different names. For a heading to each chapter in which a genus is discussed, Brunfels selects, out of the several names current for that genus, the one that pleases him best; and, by virtue of the great prestige which his book obtained, the plant names in it were continued in use by other authors. Therefore they who credit Sanicula, Potentilla, Fragaria or Hepatica to Brunfels affirm no more than this, that each such name, as the fixed appellation of a certain generic type, is traceable back to Brunfels.

In his researches upon native German plants he came to know here and there a type which, after the most diligent comparison with all the classical plant descriptions, he felt certain had not been known to the ancients, neither been described by any one. They were new generic types; and to such he never assigns any name at all, other than that by which it is known to German peasants. There is beautifully figured in one place a flowering plant of Cardamine pratensis. ${ }^{1}$ Above the figure the German name Gauchbluem is inscribed; beneath it the statement in Latin that the plant was unknown to the ancients, though common enough in Germany, and native. One page is occupied by a most accurate and life-like representation of Anemone nemorosa, with the legend: "A wildwood herb, the name of which is unknown." 2 Nor is there any other mention of the plant; not so much as a record of its being known by a vernacular name. This is doubtless the earliest publication of the Wood Anemone.

Out of such namelessly figured types there might here be gathered surprising items of plant history. For one instance: any one

'Herb. Viv. Icon., vol. i, p. 2 I 8.

2 Ibid, vol. ii, p. 80. 
informed as to how familiarly hundreds of useful plants were known two thousand years before Brunfels would expect to find so common and important a plant as Trifolium repens among that number. Nevertheless, it is one of the things which Brunfels presents as new to botanists. ${ }^{1}$ He says it is well dispersed throughout Germany, chiefly in meadows, and is known to the common people by the name of Weiss Fleischbluem; also that his engraver brought him the plant under that name. That Old German name of the plant, and Brunfels' brief remark upon it, both printed on the plate page, seem to constitute the earliest publication of Trifolium repens. ${ }^{2}$ Both the botanist and the artist seem to have agreed in the opinion-a purely philosophic one-that no little weed was beneath botanical notice, and between them they have given us the beginning of the history of Draba verna. The plant is elegantly figured under the vernacular designation of Gensbluem; but not another word is said about it. ${ }^{3}$ It is, however, the first record, and a perfectly definite record, of an interesting though diminutive type; one that within the last century has been much discussed by very able botanists who have investigated it morphologically, taxonomically, and even as to its rightful name; and that Old German popular name Gensbluem-in later German Gansblum-has proven a somewhat fateful appellation. More than two centuries after Brunfels had printed it, Michel Adanson proposed its adoption as being by right of priority the lawful generic name. ${ }^{4}$ For two reasons, not calling for mention here, Adanson's movement failed of any public approval. Yet once again, in the end of the nineteenth century, Otto Kuntze renewed he Adansonian proposition; ${ }^{5}$ but the attempt to reinstate Gansblum was again fruitless, at least as to gaining public approval. It was not a Latin-made name. Probably it did not occur to Brunfels' mind that a little weed, of no use in medicine or any art, needed to be dignified by any other name at all than that by which the country people of Germany knew it.

To the nomenclature of species it is evident Brunfels gave no thought; nor was there any reason why he should have given it any attention. Most of the genera, with him as with the botanists of antiquity, were monotypic, and the generic name was all that was

1. Herb. Viv. Icon., vol. ii, p. 55 .

2 The botanists of remote antiquity knew but one plant which they called Trifolium. It figures in modern nomenclature as Psoralea bituminosa.

${ }^{3}$ Herb. Viv. Icon., vol. ii, p. 34 .

- Adanson, Familles des Plantes, vol. ii, p. 420 ( 1763 ).

5 Kuntze, Revisio Generum, vol. i, p. 29 (I $89 \mathrm{I}$ ). 
needed. There was not the shadow of a reason for appending a second name; and he, no more than hundreds of botanical writers before his day, ever thought of such a thing. Sometimes when there are one or more notable modifications of a type-varieties or species of it - the original goes by the generic name only, while the others have each its own cognomen. Of this sort is his nomenclature of three buttercups which he figures and gives account of. ${ }^{1}$ In the nomenclature of to-day they are (I) Ranunculus acris, (2) its doubleflowered garden variety, and (3) Ranunculus bulbosus. The generic name which Brunfels adopts is Pes corvinus, i.e., Crowfoot, turned into Latin. With him the first species is simply Crowfoot, its variety of the gardens is Full-flowered Crowfoot, the third plant is Lesser Crowfoot.

This early practice of leaving the one original representative of a genus without any cognomen, even after said genus has ceased to be monotypic, is a practice doubly suggestive in relation to the philosophy of nomenclature; for, in the first place it plainly reveals the antiquity of the idea of generic types, and emphasizes it. In the second place, the failing to assign a cognomen to the type species entails a difficulty; becomes a possible source of ambiguity and perplexity; for, Pes corvinus being mentioned, the question may chance to be asked: Which one of the three? That question is virtually a demand, and a most reasonable one, that the type species have also its particular cognomen. That botanists of fifteen centuries anterior to Brunfels had seen this to be desirable, one may infer from the nomenclature of Plantago. Two species of this genus were known to Pliny; and he had a specific cognomen for the type species as well as for the other. They were Plantago major and Plantago minor; and Brunfels follows Pliny in this. His type species is not simply Plantago; it is $P$. major, which name, as well as $P$. minor, the German father duly credits to the Latin author of the olden time. He uses, then, a specific name for the original representative of a genus when there is classic authority for so doing; but I have not observed him taking the initiative in this course by actually himself assigning to the type species of any genus a cognomen.

These paragraphs on Brunfels as nomenclator ought not to be concluded without our having taken a briefly comprehensive survey of his principles. These principles, such as he was more or less ruled by, will be all the more suggestive to us from the very fact that he did not professedly have any; for doubtless he had never

'Herb. Viv. Icon., vol. i, pp. I43-1 50. 
so much as heard, or even thought the phrase "botanical nomenclature." The laws governing the naming of plants were not different from those observed in the naming of other things. All that we may gather by observing his procedure along these lines may be the course which a cultivated and philosophic mind, unhampered by prejudices, will naturally take. But such a study will be well worth while; because one does not often meet with an author who so nearly antedates all our stereotyped conventionalities, and takes his own course so little influenced by traditions and prejudices. Without having enunciated one of them, he seems to have been more or less under the guidance of principles like the following:

I. That for the science of botany there is an initial bock; that is the Historia Plantarum of Theophrastus of Eresus. He quotes that work constantly, but never, I think, any earlier book or author. Others of Brunfels' time and a little later we shall find citing Moses, Solomon, and other Hebrew writers as if these had been botanists; but not so Brunfels, who, notwithstanding his training in theology, and the distinction he had won as a Biblical scholar and commentator, does not intimate that he has found botany in Holy Scripture, and never cites an author who antedates Theophrastus. It will not, however, follow that he must adopt Thephrastan generic names in such wise as to make that author's monumental work the point of departure for nomenclature. The existence of an historically first book of botanical science is one thing. The having a starting point for an universal nomenclature of botany is quite another; and the two are both logically separable and historically separate. Brunfels was well informed about the historic beginnings of botany; but the idea of an universal system of nomenclature for groups of plants had not in his day been conceived.

2. Brunfels writes in Latin. The text of his book is for those who know Latin, and, knowing it, know things by their Latin names. The writer is under the necessity of using the Latin names of plants rather than those by which the same plants are known in Greek or Hebrew, Arabic or Persian. If a man pretending to write in Latin about animals should write hippos instead of equus, or alopex in place of vulpes, he would stultify himself; would be writing unintelligibly, absurdly, and ridiculously. It is not imaginable that Brunfels, in a Latin book of botany, should have done so insanely as to write drys instead of quercus, or kittos in place of hedera, ion rather than viola, or arnoglossa rather than plantago. 
Nevertheless he might have done so and most reasonably; indeed he must have done so, had the ideas of universality and priority in nomenclature been conceived and approved by him; because botany is of Greek rather than Latin origin, and so the Greek names of plants happen to be older than the Latin names. It was needful here to take a survey of the whole situation; for from Brunfels forward we must be looking for adumbrations of any of those principles which in our time have come to rule-or misrule-biologic nomenclature.

3. Even as a Latin writer, and using none but Latin generic names as headings for his chapters, Brunfels does not pay respect to priority. He readily adopts, out of several Latin names, ancient and mediæval, not the oldest, but the one that best suits his own purpose or fancy. From before the Christian era until six or seven centuries after it the water lilies had been known as the genus Nymphca. Then from the eighth century forward to the thirteenth and later the Arabic name Nenuphar had usurped its place in Latin botany generally. Brunfels adopts Nenuphar and writes Nymphea down among the synonyms; this manifestly for the reason that most of the botanists and druggists of his own time knew the plants as Nemuphar and would be disturbed if he should restore the classic name. Here, then, we have

4. The principle that the name by which a genus is known to most of one's contemporaries is the one to be taken up, there being no other objection against the name.

5. That a later name consisting of one word only is commonly permitted by Brunfels to supplant a very ancient one made up of two words has been already quite clearly demonstrated.

6. A species name, or cognomen, is not assigned the type which alone represents its genus.

7. While plainly favoring the selection of the best of several names as the one to be perpetuated, Brunfels, as if realizing the inconvenience of having many synonyms, is moved to use the greatest care and caution against creating them; that is, against creating Latin synonyms. This is well shown by his great aversion to assigning Latin names to types which to him appear undescribed. He publishes freely the engravings of such, but is careful to label them with no other than the German vernacular names. I have not found him once deviating from this very conservative practice. And, under his beautiful plate of Pulsatilla, in a long paragraph he explains why he holds to such a course. In none of the authors whom he has been able carefully to study has he found any descrip- 
tion of this sort of plant. It may have been named and described somewhere nevertheless. He is resolved to print the figure, and leave it to others who have more leisure than he, to study it in the light of all descriptions to them accessible. ${ }^{1}$ Meanwhile the thing may be known by one or other of those German names by which the common people know it.

8. The student of botanical nomenclature should here note well the distinction which Brunfels tacitly makes between the Latin names used by Latin botanical writers, and those invented in their mother tongue by the common people. It is plain that with him they have not the same status. The vernacular name cannot figure among the Latin synonyms. It is upon no equality with them. His action and his words together bring it out clearly that, in his mind, there is a botanical nomenclature, and synchronously with it a kind of plant naming that is not valid scientifically. The botanists of antiquity had not, and hardly could have had this thought. Is the expression of it new with Brunfels? He who is to answer this question must first learn pre-Brunfelsian and mediæval botany. The prevalence of that opinion is long since become universal, despite its having been ably disputed two centuries after Brunfels. It will be important to the history of nomenclature that one trace its progress from Brunfels forward.

9. In respect to the nomenclature of species it should be observed that what is often spoken of now as the phrase name, or more unadvisedly the "polynomial," and commonly attributed to all botanists preceding Linnæus, is a thing unknown to Brunfels. In genera of several species I have not found him using in a single instance any name that is more than binary. Where there are three words to a name the first two are the generic name.

1 Herb. Viv. Icon., vol. i, p. 217. 


\section{CHAPTER VI}

\section{LEONHARDUS FUCHSIUS, I $501-1566$}

AN early and a clear vindication to Brunfelsius of the honor of having made an epoch in the history of botanical iconography is the fact that his Herbarum Vive Icones inspired a younger countryman of his to embark at once in a still larger enterprise of the same kind; this with the manifest purpose of outdoing the originator of the movement. Brunfelsius and Fuchsius were alike in that they were college bred Germans and university graduates; their early and also their later academic and professional training having been acquired in Catholic schools, and mostly while they themselves were yet Catholics; and they were witnesses of the beginnings of the Lutheran movement, and both became partisans of the Augustinian; Brunfels with voice and pen actively and zealously furthering the movement, and Fuchs so expressly in sympathy with it as to have forfeited thereby the professorial chair with which his alma mater had early honored him. Both were regularly graduated medical practitioners, and both eminently successful, even famous, as physicians; though this good fortune came to the elder of the two only very late in life, and after he had abandoned theology and polemics.

Life. Fuchsius was a native of Memmingen, Bavaria. The father died when the child was in his fifth or sixth year. The small boy must have been precociously intelligent. The care and cost which the widowed mother bestowed on his education, and the academic honors conferred on him in boyhood, youth, and very early manhood attest this. At the age of ten he was sent away to a noted school at Heilbronn, at eleven to Erfurth where, after a year and a half of very special and zealous devotion to what were already his favorite studies, the ancient languages, the university conferred on him the degree of Bachelor of Philosophy; this before he had completed the thirteenth year of his age. During a year and a half, and that while he was somewhere between the ages of 
fourteen and eighteen years, he was master of a private school in his native town; to the success of which undertaking on the part of one who was a mere boy in years, a precociously large stature, quiet seriousness of mind, and a manly dignity of bearing are said to have contributed. ${ }^{1}$ At the age of eighteen he again left home, and this time to enter the university at Ingolstadt. where at first he applied himself to advanced classical studies, and two years later obtained the degree of Master of Philosophy. Entering at once upon the study of medicine at the same institution he won the doctorate in the year 1524 , at the age of twenty-three. He undertook to establish himself in the practice of medicine at Munich; but after a residence there of some two years, within which time he had married, he was called to the Professorship of Medicine at Ingolstadt. Here another and more honorable place was soon tendered him, and he became physician to the Margrave George of Brandenburg. During an outbreak, at Anspach, the residence of this prince, of that very fatal epidemic which one reads of as the plague, Fuchsius acquired reputation by the success that attended his treatment of the disease. He remained physician to George of Brandenburg some five years, and it was during this period that his career as an author began. He published a Compend of Medicine, then a translation from the Greek of one of the books of Hippocrates. He was now called a second time to the Chair of Medicine at Ingolstadt. The call was accepted: but again the stay was short. This university still remained one of the strongholds of the old faith. Doctor Fuchsius let fall expressions of sympathy with Luther's movenient. Within less than a year he withdrew, returned to Anspach, where the Margrave George gave him welcome, and reappointed him body physician. The next year witnessed another outbreak of the plague, and this time Doctor Fuchsius with his wife and children fled the place.

In the year 535 he received a call to the Chair of Medicine in the then newly established Protestant university of Tübingen. Here he remained to the end of his life, that is, for thirty-one years; and they appear to have been years of the most arduous and unremitting activity. His lectures on medicine were extraordinarily popular, and the intervals between lectures were occupied by the duties of the practitioner. He declined one offer of a professorship in the celebrated University of Pisa, and another to the office of Physician to the King of Denmark. ${ }^{2}$

- Melchior Adam, Vite Germanorum Medicorum.

2 Meyer, Geschichte der Botanik, vol. iv, p. 3 I I. 
As to when, and amid what surroundings Fuchsius became interested in botany, I have met with no record. It may, however, safely be assumed that no passion for nature study, or for plants in particular, was congenital with him. There is internal evidence in his book that as a botanist he was not born but made. The curricula of the schools of medicine at that period offered the possibilities, at least, of the making of botanists. The medicines in use were still chiefly plant products, either native or imported from Asia. The names of them were plant names. Each was the subject of a chapter in the standard books of the materia medica. Thosc books were all ancient, and had been written by the Greeks, Hippocrates, Theophrastus, Dioscorides, Galenos. Their chapters were the texts on which university professors of medicine lectured to their students; and the identification of the plants more or less succinctly described in those classic chapters was a part of the regular work. It was the examination of plants in the light of what purported to be the original and authentic descriptions of them. Critical work of this kind may be done by a student as a piece of drudgery, or it may become an inspiration. To those not too sluggish it must have been stimulating to be able to demonstrate by Greek texts ten or fifteen centuries old that the vendors of drugs were selling important medicines under wrong names; that what they sold under the Greek name aristolochia, for example, was not in the least like what the great Greek physicians had used under that name either morphologically or qualitatively. And if such questions took them to the drug gardens, or led them afield into wild places in search of medicinal plants in their fresh and growing condition, all this would tend to the fuller devclopment and the decpening of a sincere interest in botany.

There is every reason for believing that Fuchsius' interest in botany was thus awakened. His earliest botanical publication fully substantiates this view. It was issued by Brunfels as an appendix to the second volume of his Icones in $\mathrm{I} 5.3 \mathrm{I}$, that is, ten or eleven years earlier than the appearing of his principal botanical work. Its title translated is Leonard Fuchs' Notes on certain Herbs and Simples not yet rightly understood by the Physicians. ${ }^{1}$ It consists of thirty-fotr long chapters upon more than as many plants and plant products then in use; dealing mainly with the right application of ancient names; often quoting the language of authors whom he

1.. Leonardi Fuchsii Annotationes aliquot Herbarum et Simplicium, a Medicis hactenus non recte intellectorum." In Brunf. Icon., vol. ii, app., pp. I29-I 55 . 
charges with having brought in this confusion under which the pharmacy of his time is laboring, and denouncing the errors of such authors with scathing sarcasms. The aim of the essay is the elimination of gross errors from the pharmacopeia, and all the subjects are plants that have been in use for ages. Nothing new is added; neither is there any trace of the philosophic investigation of the plant world as such; or the revelation of any interest in plant life and form in themselves considered. But this is Fuchsius' juvenile botanical production. Will there be awakened within him later an interest in plants as plants rather than as drugs?

There is no evidence that such an awakening ever came; or that any considerable part of his work with plants had other than utilitarian ends primarily in view. In the last chapter of this earliest piece of his botanical writing he expresses the design of going through the whole of Greek and Latin botany, correcting errors and giving the right identification of everything, after the method exemplified in the treatise he is now concluding: even adding that he has been urged to do this by those fully convinced of the great need of such a work. But this promise remained unfulfilled. The twofold duties incident to a professor's chair and an extensive medical practice claimed his energies, and the twofold emoluments enabled him to undertake a line of botanical workbotanical recreation, rather-which it is improbable he ever would have thought of but for the great success which had promptly attended the publication of Brunfels' Icones. He employed two painters, and also the best engraver in Strassburg, ${ }^{1}$ and set them to work figuring plants. Thus within seven or eight years after the appearing of Brunfels' work Fuchsius had ready for the press his great volume of the Historia Stirpium; though it was not issued from the press until some four years later, that is, in ${ }_{542}$. Its success seems to have been speedily assured, and was really wonderful. To a generation that had been accustomed to such books as the Hortus Sanitatis, filled with the most wretched caricatures of plants in place of true representations of them, this great book by Fuchsius must have appeared as nothing less than luxurious; and the epoch which, ten years earlier, Brunfels had introduced by his 35 good illustrations of as many plants, was strongly accentuated by the appearing of this new volume with upwards of 500 large plates more than equaling, on the average, those of Brunfels.

1 The portraits of these artists, with their names, Heinrich Füllmaurer, Albert Meyer, and Veit Rudolf Speckle, are appended to the first edition of the Historia Stirpium. 
Within a year, or a little more, there was issued an edition in German, this augmented by six more plates. Then in 1545 there came out, as if in condescension to the class of the unlettered, an inexpensive edition of the plates only, and this was so successful that a second issue was made in that same year; both these were in octavo. After that there were not a few small-sized and cheap editions brought out, with Latin text, but with figures so greatly reduced in size as to be of little use. With these, however, Fuchsius had nothing to do.

During the long tenure of the professorship at Tübingen, which covered nearly half his lifetime, there was no return to that critical work upon the history of medicinal plants with which he had inaugurated his career as botanical author; nor were there any more than casual questionings of nature even as to the affinities of plants. But the botanical artists were kept at work. To have more plants figured, and to formulate a page of text to accompany each plate, gave him pleasant respite from professional work, and promised greater fame and fortune. Before his death he had ready for the press the plates and descriptive texts of fifteen hundred plants; a work which, if it had been printed, would have made three folio volumes as large as the Historia Stirpium. But when all was done, no publisher could be found who would undertake the issuing of so vast a work without the advance of a considerable sum of money. This the author would not-perhaps could notaccede to, and the manuscript remained unpublished. ${ }^{1}$

In the original Latin edition of 1542 , the Introductory Epistle, addressed to the Margrave of Brandenburg, is a document deserving fuller notice than can here be given it. It is a rather lengthy discourse, but withal instructive as to the condition of botany at the time, and exceedingly well written; amounting to something like an abstract of the history of medical botany from the earliest times down to his own date. As a piece of writing it reveals in its author general abilities altogether superior to what I can not but consider the mediocrity of his gifts as a botanist. It is in these introductory pages that he earns for himself the praise of being a fair and equitable judge and critic of the work of others, of whatever race, religion, or nationality. ${ }^{2}$ At a time when it was usual in Germany to depreciate, if not to denounce, all French and Italian efforts to restore botany, Fuchsius proclaims it that they are all inexpressibly indebted to such great scholars as Hermolaus

1 Meyer, Geschichte der Botanik, vol. iv, p. 3 I3.

2 "Aquissimus majorum suorum judex." Sprengel, Hist., vol. i, p. 324 . 
Barbarus, Marcellus Virgilius, Ruellius, and others who, through corrected texts and Latin versions of the Greek fathers, first placed them at the service of the botanists of every country. $\mathrm{He}$ takes pains to defend them one and all against aspersions that have been cast upon their works by men incompetent to criticise them, and recommends the study of them to all.

When, in their turn, his own countrymen and contemporaries, Brunfelsius, Cordus, Tragus, come up for mention, it is always most respectful and even honorable mention; and this despite the fact that among them there is a rival or two whom he fears, and has good reason to fear, still is he solicitous to be just to each, and to speak out the favorable things concerning their work which may be said.

A representation which he makes in this preface, of the low estate into which the pharmacy of his time had fallen, I must in substance reproduce. "The times once were when not only great philosophers and poets but kings and princes both investigated plants, and favored others so occupied. But in our day even the physicians are so much averse to that kind of study that you will hardly findone among a hundred of them who has correct knowledge of even a very few kinds. They appear to think that this kind of information does not belong to their profession, and to judge that it would be condescending froin their proper dignity to entertain doubts about the accuracy and trustworthiness of those who buy and sell such things. And so it comes to pass that the druggists - God knows that they themselves are for the most part an illiterate set-leave all this to the foolish and superstitious old women who gather herbs and roots. Error is therefore heaped on error, and will be so long as the identification of vegetable medicines is left to rustic and vulgar ignorance."

The superb South American genus FUCHsia was dedicated to this, the second father of plant iconography, by Plumier in the year I 703 .

Vegetative Organography. Fuchsius has a very instructive and useful introductory chapter which he styles "An Explanation of Difficult Terms." From the historian's point of view this will be regarded as most valuable. It is the earliest vocabulary of botanic terms that I have met with thus far; and no historian that I know of has made mention of it. One gathers from this vocabulary good information of progress gained-and also of retrogressions madein descriptive and organologic botany in the seventeen centuries and more between Theophrastus and Fuchsius. True to his title, our author omits all easy and familiar terms; does not define anew 
the root, the stem, the leaf, the flower. By this we know that he has nothing to add to the ancient and classic diagnoses of these organs. He does, however, define a bulb. "Bulbs are roots that are round and tunicated; such are those of the hyacinth, asphodel and colchicum." There is here a retrogression from Theophrastus, who doubted that the tunicated mass ought to be considered a root, and who also mentioned that the tuft of fibres descending into the ground from underneath are undoubted roots. Neither of these considerations affects the mind of stolid Fuchsius. Bulbs are roots that are rounded and tunicated. I do not recall having met with an earlier use of the word tunicated as describing certain bulbs. It is very apt, and has now long been everywhere in use as definitive of one kind of bulbs. With him, however, the employment of it is unfortunate; for it makes the tunicated structure to be characteristic of all bulbs, which is a bad mistake, as excluding the scaly kind, like that of lilies, from the category of bulbs; for not the crudest morphologist could call a scale a tunic. And Fuchsius proves his definition fallacious by stating, when he comes to the figuring and describing of the true lilies, that they have bulbs. ${ }^{1}$ His referring to the asphodel as an example of a bulbous plant will be misunderstood. He has not at all in mind that plant which in later times has been identified as the famed asphodel of antiquity, the underground parts of which have nothing that is in the nature of a bulb of any kind. That which Fuchsius believes to be the asphodel, and figures for it, is a lily, and its scaly bulb is well shown. ${ }^{2}$ If his third familiar example, colchicum, illustrates to us what we distinguish now as a corm, it is at least fibrous-coated on the outside, and would therefore answer at least to the letter of his diagnosis of a bulb.

There is one term in use in the sixteenth century in connection with certain bulbous plants which has not survived; that is, the neck (cervix). Fuchsius defines the cervix as "an elongated and cylindric body intervening between the summit of a bulb and the tuft of leaves, and has the appearance of a neck." From its position, and its external appearance as cylindric and supporting leaves in onions, leeks, dafiodils, and their kindred, one might have expected to find it designated as a stem. That it was not, is a circumstance that must convince us of two things: first, that Theophrastus' immortal definition of a stem as made up of bark, wood, and pith, was a part of the very alphabet of botany in Fuch-

1 Hist. Stirp., p. 366.

2 Ibid., p. II 5 . 
sius' time as it is in ours; and second, that the stem-like cylinder surmounting onion, leek, and dafiodil bulbs must have been examined in cross section and found completely destitute of every characteristic of stems in general; discovered to be made up of nothing else but the compacted bases of the leaves themselves. It looked much like a stem. Investigation proved it wanting every claim to that title; and they named it cervix, the "neck" of a growing bulb. The word was not destined to a permanent place in the vocabulary of the science. When at length it came to be seen that the bulb itself, as well as the cervix, was also but a mass of leaf-bases, and therefore no root at all, the term lost its particular significancy and disappeared. And this very fact of the invention of a new word that seemed to be called for, and its later passing into desuetude, is an interesting kind of episode in the history of morphology, and well merits notice in a place like this. We shall meet with other instances.

Respecting that more marked phase of underground stem, the rhizome, or rootstock, Fuchsius appears quite securely to rest in a position which Theophrastus had held with wavering. Fuchsius denominates them all radices geniculate. The Greek had realized that they have rather too much in common with stems.

In his treatment of stems in general, one observes in Fuchsius some divergencies from, even here and there some little advance ment beyond, the status of these things in the minds of the ancient authors. The word culmus, modified from the Greek calamos, is his term for the stems of grass-like plants. The first and largest divisions of tree trunks are denominated brachia, arms, though not unless such diverge from one another rather strongly, suggesting, as he says, arms of the human body when extended. Others had always noted what they called the knots, or nodes, of stems. Fuchsius uses, and even defines, the good term internodium, internode; though I much doubt his having invented it. He also observes in trees and shrubs the occasional development of long and vigorous shoots from trunks and main stems; points at which branching is unusual if not abnormal. He names such shoots adnates. Botany still recognizes this class, and knows them as adventitious shoots, from adventitiously formed buds

One reads in this author and in others of his time of such things as the ale of stems. The usual meaning of alæ is wings, as of a bird; but in ancient Latin the term also meant the armpits; and quite like this is the sixteenth-century use of it in botany. Fuchsius defines the alæ of stems as being a kind of sinuses from which new 
growth proceeds; they are the axils of modern terminology. It is also here that I meet with scape as a botanic term; and the application is just that now in use, designating an elongated peduncle arising from under the ground; though neither Fuchsius nor his contemporaries so understood it. They regarded it as a true stem without nodes. But Fuchsius' "scapus" was not at once adopted; until long after his time it was usually denominated a stylus.

Two of the several modes of leaf arrangement are named and defined in this vocabulary, the decussate and the verticillate; but there is yet no one word in use by which to distinguish leaves as opposite. A phrase is required to express that. Any leaf margin that is evenly indented is described as crenate, or as serrate, quite indiscriminately, the terms being treated as synonymous; but if serratures be quite deep and close, as in the nettles, the leaf is fimbriate. Pediculus and petiolus, i.e., peduncle and petiole, are employed as indiscriminately, either one applying to leaf-stalk or to flower-stalk. The word stipula also makes its appearance in Fuchsius' vocabulary, but with nothing like its meaning in more recent botany. His definition proves it to have been in his mind merely a special name for the peculiar leaf of grass-like plants, not a part of such leaf, but the whole of it. ${ }^{1}$ It is a definite proposal that, since the stems of grains and grasses have the special namc of culm, the leaves of the same class of plants ought not to be called leaves, but should have their own special designation-should be called stipules; and this is perfectly logical and consistent; for the leaves that grow on culms are quite as unlike all other leaves as culms are unlike other sorts of stems. It will be recalled that Theophrastus had named this entire group the Calamophylli in allusion to the remarkable characteristics of the foliage. But Fuchsius does not seem to have met with success in this endeavor to have grain leaves and grass leaves become known by the name of stipules; and, more than two centuries later, Linnæus picked up the old term stipula and applied it anew, and with perfect success.

Fuchsius tried also to invest the compound leaf with a name of its own, as a thing too different from the simple leaf. The distinction itsclf, as we know, was perfectly and for all time made by Theophrastus, who discovered things and left them nameless. The German father would have the compound leaf called a frons, i.e., frond, thus restricting the other Latin word folium to the simple leaf and the individual leaflet of the compound. But this also fell short 1 "Stipulæ sunt folia culmum ambientia." Fuchs. 
of general adoption; and long after Fuchsius, frond came into use as designating the peculiar foliage of ferns. It must be said of Fuchsius' application of frond that it was the more correct; for frons with the old Latins meant the leaves of trees, or even leafy twigs of trees, such as, anterior to Theophrastus, and by thousands in later times, the compound leaf was believed to be.

Inflorescence. The term inflorescence of course did not appear in botany until long after Fuchsius; but the thing had been of necessity both observed and discussed. The using of words definitive of the various clusterings of fruits and flowers must be older than history. Perhaps few if any of those defined by the German father were newly coined, or even otherwise applied than they had been in far earlier times. But here in the Historia Stirpium we have a goodly number of them brought together, along with not indefinite statements of what that author understood to be their meanings. And what must vouch for the importance of this paragraph of history is the fact that not one of Fuchsius' terms relating to inflorescence bears with him the meaning which the same term has in the botany of our own time.

Take the word thyrsus, which at its first origin in Greek and Latin was but a synonym of caulis, any stalk or stem; though later, and still in ancient times, it acquired a special significance; while with botanists of our time it means a particular kind of inflorescence. There is with Fuchsius no kind of a flower clustering that is called a thyrse; yet he essays to define the term as if in the botanical terminology of his time it had gained some new shade of meaning. From his definition itself nothing of the kind is apparent; but at definition Fuchsius is no adept; and when he says a thyrsus is a straight wand-like or arrowy stalk he has hardly departed from the earliest of ancient definitions. But when we make search for his practical use of the term we find that it has with him a meaning which he had not indicated or intimated in his definition. In the description of the hyssop he uses the expression: "Flowers purplish-blue, investing the thyrses like a spike."1 Here it is plain that the thyrsus is the axis of a spicate inflorescence; that which in much later botany is become the rachis. But it is only now and then that he notes the arrangement of flowers; though the clustering of fruits is much more frequently taken into account.

The term racemus occurs not infrequently; but I think only as specifying the arrangement of some berry-like kinds of fruits. The type of the raceme is the grape-cluster; but in his definition 1 Hist. Stirp., p. 840. 
of racemus he says it is the fruit cluster not of the grape only, but also of the ivy and of any kind of herbs or shrubs that have bunches of berries. In practice we shall find him writing of the compactly spicate berries of the arum as forming a racemus.

As with the ancients, so with Fuchsius the spike is rather more a taxonomic than morphologic term. His definition of it is the most concise of all. "A spike is that which a culm bears at its summit. . . I It consists of three parts, grain, glume, and beard. A muticous spike is one that is beardless." Plainly, then, the spike with him is the peculiar inflorescence of grains and their natural allies. The typical form of a spike, that in which as in wheat and barley there is a simple rachis-thyrsus, he would have called it-up and down which the several parts are sessile, is not alone a spike. The one prerequisite of a spike is, that it shall crown the summit of, or at least be connected with, a culm. And so we find him naming as spikes the inflorescences of broom corn, ${ }^{1}$ and also of maize. ${ }^{2}$ In modern botany they are panicles. Only thus far, however, does he abide by his own diagnosis of the spike as the fruiting cluster of grass allies; beyond this point, and nere and there, we find him overstepping the bounds which he himself has set to the application of that term. Lavandula stoechas, an aromatic shrub common in European gardens of that time, is of the family of the labiates, the flowers of which are congested within a somewhat elongated and cylindric involucre of chaffy and overlapping scales. This involucre vividly recalls the head or ear of some short-spiked kind of wheat; and Fuchsius transgresses his definition boldly enough by calling the involucre of this inflorescence a spike. ${ }^{3}$ In justice to the botanist it must, however, be admitted that he was following popular precedent. The inflorescences of not only this but a number of other lahiates had long been called spikes. There is then traceable in Fuchsius a tendency toward a point that was not actually gained until more than two centuries later, of defining terms by murphologic rather than any other characteristics; of naming a raceme from its structure rather than from the fact of its bearing berries and not capsules; and a spike not as the fructiferous terminal of a culm, but as an axis, bearing up and down its length sessile flowers or fruits, this irrespective of the family of plants in which it may occur.

The panicula is almost unique among Fuchsian inflorescences in

1 Hist. Stirp., p. 772

2 lbid., p. 824.

Ibid., p. 777 . 
that it is not made the mark of any particular taxonomic group, and is defined in quite strictly morphologic terms. As far as possible from the panicle of modern vocabularies, it consists of almost any very compact cluster that is somewhat elongated and, at the ends, well rounded. The first example given is that of the cones of spruces, which are not conical, and therefore would not have been called cones by botanists of antiquity, nor by their disciples of the sixteenth century. But it is said by our author that the Latins applied panicle mostly to such as, being of the requisite form and density, were also appendaged by some sort of coma; and so, among the Fuchsian panicles, one finds the bristly hairy spikes of millet, and the elongated furry heads of the mouse-ear clover, otherwise called lagopus, i.e., Trifolium arvense. Also individual spikes of scirpus, eleocharis, and others of their tribe-the individual spikes, I say, and not the whole inflorescences-are panicles.

The umbel, though defined morphologically as a flower and fruitcluster constructed upon the plan of an umbrella, would never be applied to an unbel of berries. The umbels with Fuchsius are the inflorescences of the family of umbellifers, or at least of dryfruited plants, exclusively. The flat-topped clusters of certain anthemideous composites like millefolium he speaks of as umbels; though they are not really umbels, but corymbs; a distinction that had not then been made.

Anthology. In the vocabulary of Fuchsius there is vouchsafed a perfectly intelligible definition of what he calls the calyx. It is a kind of "bag within which at first the flower, and after that the seeds are enclosed." Note first of all, that such a calyx as this can be no part of a flower. It can not be determined to be a calyx until it has shown itself permanent; until the seeds have ripened. A deciduous calyx would be a contradiction in terms. A circle of green sepals behind a flower, even though at first enclosing the "flower" does not constitute a calyx; at least if it fail to persist and to enfold the seeds after the other parts have fallen. Under this definition all mintworts and sages, the borrageworts and other synsepalous things have a calyx, while the poppies and the buttercups and their allies have none. The pomegranate and all pomaceous fruits are furnished with that organ; the olive and all drupe bearing trees are destitute of it. This appears to be the earlier idea of a calyx; the first movement toward the bringing in of that green-leafy circle close behind what was called the "flower," to where it should be recognized as a part of the flower. But his having technically defined the calyx does not preclude his occasional 
employment of the term in an untechnical sense, that is, as designating some other organ that happens to be shaped like a cup; thus we find him calling the lily flower a calyx, ${ }^{1}$ i.e., a chalice-shaped flower.

His doctrine of the flower in general is that of Theophrastus hardly improved upon. There are two kinds, the leafy and the capillary; but both are united in, for exampie, the rose. The term petal is still wanting in botany. Its introduction into the vocabulary will not. be proposed until two generations after Fuchsius. The foliar parts of a flower are still leaves only. Yet what is curiously interesting is, that already as the green leaf is seen to have usually that which they have called its petiolus, or pediculus, so the flower leaf is credited with having its unguis, or claw; the more or less narrowed basal part by which it is attached to its receptacle. Fuchsius defines well enough this unguis, even remarking that in the flower of a red rose this claw is white. And so the distinguishing of the two parts, blade and claw, in this organ historically antedates the naming of the whole organ as petal; and Fuchsius, so far from affirming this to be a new distinction of his own making freely attributes it to "the ancients."

In this Fuchsian vocabulary occurs what is perhaps the earliest botanical definition of stamens. There is so much of history in it that one must reproduce it as literally as may be. "Stamens are those apexes that come forth from the middle of a flower-cup; and are so called because they rise up like filaments out of the inmost bosom of the flower." 2 As a definition this is illogical and bungling; for both the anthers and the filaments are separately called the stamens; not by any means the two parts that go to the making up of stamens; either one alone is stamen according to his absurd statement. In the first clause the anthers, apices, are the stamens; in the second, the filaments are the stamens. That what he denominates apices are the anthers is clear as day from his description of the flower of the common white lily, where he remarks that in this the apices are yellow; for no other parts of the lily blossom are yellow but the anthers. ${ }^{3}$ The term filamenta by its very meaning applies to no other organs but the filaments and styles. Let us note here that there is yet no description of a stamen. The author neither thinks nor speaks of the thing but in the plural. What he

1 Hist. Stirp., p. 363 .

2 "Stamina sunt qui in medio calycis erumpunt apices; sic dicta, quod veluti filamenta ab intimo floris sinu prosiliant." Fuchs, in the vocabulary.

${ }^{3}$ Hist. Stirp., p. 363. 
has seen, and what all the botanical authors before him had seen, is a tuft of delicate things standing up from the midst of the circle of colored flower leaves. The ancients had written of them as flocci, or as capillamenta, still only in the plural. No one had ever looked into the individuality of one of those flocci or capillamenta. To have done that would have been to lead the way to the discovery that the members of the filamentose tuft are not all alike; that at least the one central member-if not the whole central membership of the tuft-is different from those that stand between them and the circumference of the flower. There would soon have been two kinds of stamens to describe if one stamen had been defined, because of those-the styles and their stigmas-which would not have answered to the definition.

Now Fuchsius in practice writes of these tufted things in the middle of a flower as the apices. This is a distinct departure from the terminology of antiquity, and is withal a departure in the right direction; for the ancients had seen and written of flocci, capillamenta, and the German had seen-perhaps by some unknown mediæval botanist had been taught to see-the little knots that surmount the outer set of the flocci, and from these little apical knots the whole stamen-tuft had been named anew, "apices." This term, whensoever it made its appearance, came in like a kind of prophecy that the terminal knots were one day to be received as the only essential parts of the tuft. One would willingly concede to Fuchsius the invention of this term which shows that anthers are being noticed; but he was in no sense a botanical discoverer, and he availed himself of many an old book and manuscript of which we have no knowledge.

For the staminate tassels of hazel, walnut, and oak trees he has also now a name; whereas the ancients seem to have had none. But he has no more idea what these tassels are for than the ancients had; though he ventures the guess that they are instead of flowers; thereby proving that he had never seen the pistillate or rea! flowers of any of them. He calls the pendents mucamenta, nut-tassels, and describes them in language borrowed from Theophrastus who, as we have been learning, had a much better knowledge of nut-tree flowers then Fuchsius ever attained to.

Fruit and Seed. The Greek !philosopher's comprehensive and classic definition of a fruit is either unknown to Fuchsius, or else he purposely condescends to the popular notion; for he says that a fruit is something made up of flesh and seeds. This is quite in keeping with his definition of a raceme as being a cluster of fruits. 
i.e., fleshy fruits, rather than a particular mode of ciustering in both flowers and fruits. Seed coverings other than fleshy are disposed of by him under two or three distinctive terms. There is the silique, the vasculum and the caput as well as its diminutive, the capitulum. The legumes he says are siliques, and yet many other herbaceous plants and even shrubs bear siliques; and we infer his silique to be any kind of an elongated and two valved pod. He ventures upon no definition of what he calls vascula, beyond this, that they are the coverings of seeds. His account of head and capitulum is, that they apply to any well rounded and solidified part of a plant, whether basal or terminal. An onion-bulb, resting wholly above ground and therefore not a root, is a head, a caput; and so is the head of a cabbage, and also the round indurated capsule of a poppy. If he knew anything of Theophrastus' technical definition of a fruit as composed of pericarp and seed, he dnes not appear to me to have made use of it, or of the term pericarp.

The seed is not defined in our author's vocabulary, or even mentioned there otherwise than incidentally.

Phytography. There has already been cited this opinion of phytography from Brunfelsius, ${ }^{1}$ that the best way to reform and improve upon mediæval plant description would be to restore word for word the descriptions of the ancients. At a later time it was thought-and the thought was carried into action-that the only possibility of improvement in phytography lay in wholly disregarding the classic texts, and writing all plant diagnoses anew. Such a proposal as this last would have filled either Brunfelsius or Fuchsius with amazement; and also not unreasonably, for neither of them had in view the reformation of botany in general. Both were aiming at the correction and improvement of that which we of today would speak of as the botanical part of the pharmacopeia. They were interested in phytography, because it is one of the necessities of medical botany. The most trying part of their work was that of the identification of ancient remedies; and their only clues to the identity of any of them were in the ancient descriptions. We have followed Brunfelsius in his giving, for some plant newly figured, page after page of difierent descriptions literally quoted from those whom he regards as standard authors, not willing to divert the attention of the student by a single line of his own; willing that they who study his book shall judge for themselves whether what he has figured under a given Theophrastan, or Dioscoridean, or Plinian name has been rightly identified.

1 See page ${ }_{1} 72$ preceding. 
The ideal of Brunfelsius is high. His book is for scholars; but Fuchsius plans to be more popular. He will publish twice as many plates as the former had done, and for the sake of economy must reduce the number of pages of printed matter. The average is not much more than a half-page to a plate; yet the descriptive part of Fuchsius' volume is not in all respects insignificant when compared with that of Brunfelsius. There is a falling off in the bulk of interesting and useful matter; but some good phytographic distinctions are made which do not appear in Brunfelsius.

Every chapter of Fuchsius is divided into separate and separately named paragraphs, of which always the first, headed Nomina, is devoted to the name and synonymy of the genus, and con'ains nothing else. In the case of every monotypic genus the second paragraph is headed Forma. In this we read always the morphologic marks of this type; at least such of them as Fuchsius can copy out of standard authors. When, however, a generic type is known to be made up of two or more species or varieties, then this morphologic paragraph is not second in order but third; the second being now given to the naming and defining of the species or varieties; and this occasional second paragraph is always under the caption Genera. In an earlier chapter an explanation has been given of the primitive use of the term genus, and its plural genera, as meaning nothing more nor less than the kind or kinds of a thing. ${ }^{1}$ It is plain that Fuchsius' "genera" are the species and varieties, while under Forma he gives the morphology of the genus as a whole. The placing of the descriptions of species and varieties first, and that of the genus next below is illogical in the extreme; but there are still other intimations that a logical mind was not among the learned Fuchsius' natural endowments. But this segregating of the morphology, the ecology, and the properties of a plant, and the relegating of each to its own paragraph is definitely an improvement in phytography, and is perhaps an invention of his own.

Taxonomy. We are learning that there was in Fuchsius nothing of the plant anatomist or physiologist, something of the organologist, but that he was in no wise given to philosophizings about plant life and form in general; that he was a medical botanist, dealing with plants from the utilitarian point of view. He would not have appeared as a taxonomist had not taxonomy been inevitable wherever more than one individual plant is treated of. Concerning the larger and more comprehensive groups, the

1 See pages $x 15$, I 6 preceding. 
genera majora of the botanists of a somewhat later period, the orders or families of to-day, there is little to be read in Fuchsius; for his sequence of genera is alphabetic, a kind of arrangement which precludes the grouping of genera into families. It does not, however, in any way influence the definiteness of the genera themselves, or of the species composing them. The work is divided into 343 chapters, and each chapter is devoted to one genus and no more; so that the number of genera treated of is the same as the number of the chapters. Many of the genera are represented by only a single species, many by two or three, several by four or five, and one has seven species, all described and figured. But one must not pass to the study of his genera without noting certain lapses from the alphabetic arrangement which are made in deference to what are held to be the affinities of a genus. These are not numerous, but they are enough to show Fuchsius as susceptible of being influenced by the idea, even in his time an old one, that some genera are interrelated. Here it must also be observed that the alphabetic order he follows is that of the Greek rather than Latin names of genera. For medical botany, all through the ages and down to Fuchsius' time, Greek rather than Latin was the preferred language of nomenclature, at least with those best educated; because all three of the most venerated authorities upon that part of botany, Hippocrates, Dioscorides, and Galenos had been Greeks and had written their treatises in Greek. Now while in his Latin text Fuchsius uses the Latin names of things, quite as he ought, the generic names heading the chapters are the Greek generic names; and the sequence is that of Greek letters of Greek names; so that the chapter on the genus of the elder trees or bushes is headed not Sambucus but Acte, and that of the plantains not Plantago but Arnoglosson.

Now for a sequence of genera in a book of sixteenth-century botany, the choice of the Greek alphabetic order left its author certain liberties. All Latin names are naturally exempt from such a rule; and there were now in Fuchsius' time not a few plants holding places in the pharmacopeia which had not been known to the Greeks of old, and which therefore had only their Latin and their vernacular appellations. Since the Latin names of these may not consistently head chapters where the headings are professedly Greek, Fuchsius is apt to use these as occasions for giving expressions of opinion about natural affinity by placing them in the line of what he conceives to be their real kindred. For one instance, take his placing of Datura Metel, a plant then newly 
introduced into Europe, where it was known only by the Italian name of Stramonia. Since it has no Greek name he locates it where he will; and we who have been taught that there was no natural classifying of plants until well toward the end of the eighteenth century may well be surprised that Fuchsius places this at the end of a line which begins with Solanum nigrum, such perfectly solanaceous types Solanum melongena, Physalis somnifera, and Atropa Belladonna intervening.

That very early in the sixteenth century there was already in exercise the taxonomic skill to put together as under one comprehensive natural genus such diverse-looking consanguinities as the five plants here named is something that merits more than passing notice. It is another of those forceful intimations that much of the botanical history we once learned must be unlearned. Let us remember that we are now at a point more than one hundred and fifty years anterior to those great lights, Morison, Ray, and Tournefort, and some two hundred anterior to Haller, Jussieu, and Adanson, to which latter trio is usually accorded all the glory of having first outlined such natural groups as this. But Fuchsius himself intimates that from very ancient times there had been a somewhat familiar knowledge of four out of these five plants, and says that both Dioscorides and Galenos had held them to be kinds of $\sigma \tau \rho^{\prime} \chi^{v o v}$, i.e., Solanum. ${ }^{1}$ But the referring of so marked a new type of plant as Datura to the anciently recognized group of the Solanum allies by men of the sixteenth century will hardly fail to suggest to some that there must have been, after all, some appeal to anthology. Certainly the conventional nineteenth-century botanist finds no stronger links uniting these two plants to one family than the symmetrical pentamery of the flower, coinciding with a plicate præfloration and superior ovary. It is none the less well beyond question that not a single point anthological had influence in determining the affinities of Datura. The corolla has not yet, at this period obtained its name. It is still the "flower" simply. Neither stamen nor style had been taken note of as an individual organ; much less had the two been distinguished, or the members of either set been counted. Floral symmetry was yet unnoticed; and, marked as is the xstivation, or præfloration of solanum and all its allies, the very topic of præfloration was not yet heard of in Fuchsius' time, nor did it begin to figure in taxonomy until some two centuries after his demise. According to Fuchsius, 
his best reason for locating this type in the line of the nightshades is the fact that its herbage exhales the narcotic odor characteristic of all other nightshade allies. Plant classification, then, in Fuchsius' time has not yet emerged from the period of antiquity; and botanists are still considering agreement among plants as to their vegetative and qualitative characteristics, giving little heed to those of flowers or fruit. And a fair measure of success not rarely attended taxonomic effort guided by these criteria. But the success, however marked in the case now in mind, was not quite complete. Capsicum is undoubtedly a solanaceous type, but this fact Fuchsius failed to apprehend; yet the failure is not unaccountable, notwithstanding that, viewed morphologically, capsicum is much more plainly akin to nightshade than is Datura. The plant was a new one in German gardens of the sixteenth century as was also Datura. It had been as unknown to the ancient Greeks, and had no Greek name; therefore Fuchsius could have placed it next Solanum. The fact is, no one had yet seen its relationship. The plant lacks the narcotic odor. Every part from leaf to seed is of a peppery orlor; and this quality, amounting to a burning pungency of taste, joined to the peculiar medicinal qualities, blinded every one to that affinity for Solanum which every one now sees in Capsicum.

It must not, however, be inferred that this principle of qualitative agrcement is held an inviolable rule in this early taxonomy. With botanists of that time, quite as with those of every later generation, the endeavors to form groups are duminated sometimes by one principle, sometimes by another. It is easy to bring forth out of Fuchsius instances of putting things together as of the same genus regardless of odors and flavors and of almost all other marks save those of roots and leaves and general mode of growth. Under the genus Verbena he figures two species. There is the most deceptive likeness between the two as to roots, stems, leaves, and a slenderly spicate inflorescence of small flowers; but one of these verbenas is Verbena supina, the other is Sisymbrium Laselii; a true verbena and a crucifer made congeneric; in the Fuchsian binary nomenclature Verbena recta and Verbena supina. ${ }^{1}$ It will not be easy for the systematist of to-day to imagine so natural an alliance as that of the crucifers remaining unrecognized by those who had already recognized the solanaceæ; yet as to roots, foliage, and habital characteristics the crucifcrs differ among themselves a hundred-fold more widely than do the solanaceæ.

1 Hist. Stirp., pp. 591-593. 
Despite what we of later times perceive to be the naturalness of the cruciferous group, its recognition had to await the development of anthology; and I have met with no evidence that up to the time when the career of Fuchsius was ended there had yet lived a botanist who had known the floral structure of a crucifer. Even the Theophrastan elements of anthology seem to have been sunken in oblivion ages before the birth of Sprengel's and Meyer's and Sachs' "German Fathers of Botany," one or two of whom were to renew the investigation of floral structures; though Fuchsius was hardly one of these.

The contemplation of these quaint herbalistic genera based on vegetative characters and ignoring flowers and fruits is both entertaining and instructive. It is as if one had discovered in these antiquated tomes a fossilized and now extinct system of plant classifying; and the reader will not fail to be interested in glancing at the outlines of other such genera. Fuchsius has one little genus for which he brings forward into print, from out an unpublished manuscript, the name Pilosella. Here is the composition of the genus: ${ }^{1}$

Fuchsian

Pilosella major

Pilosella minor
Recent

Hieracium Pilosella.

Antennaria dioica.

He has tried to make one of the plants answer to the Myosotis of Dioscorides. It does not well agree, and he is confident that neither of the two was known to the ancients. Both are well known in Germany, and of repute as vulneraries, on which account he must not omit them. The German herbalists of his time know one of them by the name Pilosella. That will suffice for a formally generic name, and with it he has already headed his Chap. ccxxx. "Two kinds of it are found, differing in nothing but the flowers. One of them has leaves that are larger, and do not lie flat upon the ground. Its flowers are yellow, and it is named Pilosella major. The other has smaller leaves that lie flat upon the ground, and purple flowers which disappear with a pappus. The Germans have for this the names Little Mousear and Rabbitsfoot. In a manuscript herbal I find these plants disposed of as Pilosella major and minor." I thus present a literal version of what our author had to relate respecting the components of this his genus Pilosella, even to the interesting admission that the whole chapter had been borrowed 
from an old herbal in manuscript-illustrated by drawings, no doubt - which had been available to him. Even the specific names $P$. major and $P$. minor were from said manuscript. Contemplating these two plates, whether the proposed genus consisting of a hieracium and an antennaria seem rational or absurd will depend entirely upon whether one view the types with the eye of the modern botanist, or with that of him of Fuchsius' time. The modern, taught by the traditions of not more than five or six generations of his more recent botanical ancestry, looks at the flowers only, and in consequence realizes only that the two must be regarded as of widely separate genera; for one has the flower head of a hawkweed, the other a congested bunch of cudweed heads; and as to the structure of their individual flowers they represent something like two extremes. But it will be both illogical and unfair to test the consistency of the earlier classification by presuming to hold it amenable to modern taxonomic principles; though this seems to be about what the readers of old botany, and even the historians, have always hitherto been doing. The consistency of the Fuchsian Pilosella is readily seen if, blinding ourselves as he and his forbears were blind to small floral structures, we look at and compare those parts of the two plants which they looked upon as bearing marks of consanguinity. Both the antennaria and hieracium are small perennial herbs of one and the same mode of growth, and that mode rather exceptional. Each has its leaves mostly in a basal tuft, and bears its flowers at the summit of scapiform stems. A number of depressed stolons leafy with a smaller foliage radiate from the base of the stem of each, so that both in the same fashion propagate vegetatively and form colonies. Add to these and other points of morphologic agreement the consideration that both were received as possessing the same remedial virtues, and we have a rational genus according to all the leading principles of sixteenth-century taxonomy.

Thus comprehending the situation-realizing that these groups that look so strange and motley have not been formed at random, but rather under guidance of definite principles-every such group acquires a new and even a lively interest. Let us open the book at its initial chapter. The name of the first genus is Absinthium. Three species are described, two of them figured well. They are:

Fuchsian

Absinthium vulgare Absinthium Seriphium

\section{Recent}

Artemisia Absinthium.

Sisymbrium Lœselii. 
Thus a cruciferous plant, common in German vineyards and hedgerows, is made congeneric with wormwood because it has similar foliage, and also is thought to answer to Seriphium in several other particulars. It is a good example of futile effort to identify with the Seriphium of Dioscorides a very different plant of central Europe which Dioscorides never saw, and which, by the way, if he had seen it, he would never have thought of as a kind of wormwood; for, as we have seen, the Greek did not quite disregard floral structures, but could distinguish genera by anthologic marks. ${ }^{1}$

But Fuchsius' disregard of flowers in these generic groupings is manifest again close by Absinthium, in his Anthemis. The name of the genus and those of all three species are taken up from Dioscorides, as he says, and the following is his identification of them, the names at the right being those now in use.

Fuchsian

Anthemis leucanthemon

Anthemis chrysanthemon

Anthemis eranthemon
Recent

Matricaria chamomilla.

Anthemis tinctoria.

Delphinium Consolida.

Judged by the modern and improved standards, the locating of a larkspur as congeneric with chamomile is the worst of conceivable taxonomy; and it is impossible that in this Fuchsius interpreted Dioscorides otherwise than erroneously and even almost stupidly. The Greek had habitually looked at the flowers of things, and had shown clearly a tendency to regard the forms of flowers as taxonomically significant. Concerning Anthemis in particular he declares that the flowers in the three species differ only as to the color of the little leaves that encircle the centers of the flowers, which central part he says is yellow in them all. ${ }^{2}$ Now concerning the identity of the white-rayed and the yellow-rayed Anthemis species of Dioscorides there never had been any doubt; therefore as to these two Fuchsius was but reiterating the expression of a common opinion. The third member, however, that is, the purple-rayed anthemis, was problematic; for there is not known in those regions where the ancients botanized a purple-rayed composite having the foliage of an anthemis. But there need not be; for any ranunculusflowered or anemone-flowered branching herb, if it had the foliage of anthemis might have been relegated to that genus. It is only to the trained eye of the modern botanist that the rayed head of a 
composite and a ten-petalled flower of an anemone or a buttercup seem very unlike. By the ancients, and by everybody down to Fuchsius' time and much later they were not regarded as being different. The superficial likeness between the two is great. In either type there is a yellow center made up of little things compacted together, and this is encircled by rather many narrow leaves apt to be different in coloring from those of central tuft, or mat, or cone. The different constituency of those yellow centers in anthemis and anemone no one had yet perceived, even in Fuchsius' time. With him, as with all botanical antiquity, the yellow middle part was made up of the "stamina," the "capillamenta," the "flocci," in anthemis as in anemone: and that the circle of colored leaves is a circle of ray-flowers in anthemis, and of petals or sepals in anemone and buttercup-that is a refinement anthological of which neither Dioscorides in his day, nor Fuchsius fifteen centuries later, had ever dreamed. But in the grain fields of Greece and Italy there grew in abundance one anemoneous herb with perfectly anthemideous habit and foliage, and flower leaves dark-red-easily within the wide range of the purples of the ancients. Must not this have been the Anthemis eranthemon of Dioscorides? Its modern name is Adonis restivalis. ${ }^{1}$ Certainly this, rather than Delphinium Consolida, is the third anthemis of the Greek physician. And the fault of Fuchsius is his utter disregard of those floral marks in respect to which the Greek had said that all three species of anthemis were at agreement; though as to mere foliage, and the annual root as well as more of growth, the larkspur-anthemis of Fuchsius answers well enough to the other kinds; and this would have been the apology for Fuchsius' erroneous determination of the plant, had he not virtually disclaimed it for himself by attributing it to some unknown earlier botanist whose anonymous manuscript has been at his disposal. In this manuscript he says, "there is an exquisite drawing of this plant, which is commonly called consolida regalis," and then he proceeds to quote, from this unknown author, the following: "Some call the herb Monachella or else Capuciaria, doubtless in allusion to the hood of the monks, which the flower recalls. Dioscorides calls it Eranthemon, and it is one of the kinds of Anthemis, having the foliage of the chamomile, though of a darker green; but the flower is rather like that of a violet." 2

Evidently the author of that unpublished commentary had been

1 See Matthiolus, Comm. (ed. of I565), pp. 904-906, with fine plate of Adonis, in between two plates of anthemids.

2 Hist. Stirp., p. 28. 
too superficial in his knowledge of the wild plants of Mediterranean fields to well interpret Dioscorides. But his identification of the third anthemis appears to have suited the fancy of Fuchsius and he approved it. His former rival, Brunfelsius, a dozen years earlier had maintained that the Consolida regalis was sui generis, and did not think it had been known to any of the botanists of antiquity. ${ }^{1}$

There seems to be evidence within the book of Fuchsius itself that the work was long in preparation, and the middle and later chapters printed so much later than the earlier as to bear intimations of his mind's having changed somewhat in the direction of an appreciation of floral structure as having some value in the determining of plant relationships. While his contemporaries Brunfelsius and Tragus hesitated to distinguish generically between the real nettles and the labiate-flowered dead nettles, Fuchsius separates them widely, and under the names of Urtica and Lamium $^{2}$; this, however, not as an original proposition, but as adopted from Dioscorides and Pliny.

In his description of the genus Pisum, the garden pea, he says that its flower is shaped like a butterfly; but I do not find him using the expression in describing other plants of that family; and while this is the earliest mention of the papilionaceous corolla form that I have met with, I still think it improbable that it was original with Fuchsius.

Among several new genera proposed by this author there is one, namely Digitalis, which he establishes almost upon the form of the corolla alone. ${ }^{3}$ This genus of two species, which he names respectively $D$. purpurea and $D$. lutea, practically concludes this volume of more than 900 pages; and so a course that began in almost total disregard of anthological considerations, ends in the admission that floral structure may upon occasion be of such high taxonomic import as to furnish the most essential character of a genus. Contrasted with the beginnings of the volume, this conclusion of it is taxonomically very significant; even prophetic. It forecasts the time a hundred and fifty years later when Tournefort, running to another extreme, would essay the systematization of all petaliferous plants, almost by the corolla alone.

Nomenclature. All the unconventionality, simplicity, and brevity of a primitive and even a classic nomenclature marks the

1 Brunfelsius, vol. i, p. 84 .

2 Urtica, Hist. Stirp. pp. 105-109, three species; Lamium, Ibid., pp. 468, 469, also three species.

Hist. Stirp., pp. 892-894 
plant-naming of Fuchsius. As already indicated he heads each chapter with the Greek name of the genus, unless perchance the plant was unknown to the Greeks and has no Greek name; then the Latin name is used. For every one the Latin and the German synonyms are given, and that in the first paragraph of the chapter, under the caption "Nomina." Still more carefully considering the convenience of pharmacists and the untutored collectors of simples, he causes to be printed on each plate the Latin name of the species at the lower left-hand corner, and at the right-hand corner the German. Quite as we expect to find it, we read on plates representing monotypic genera no name at all but the generic. Commonly such names consist of but one word. Such are Adiantum, Althea, Anethum, Asarum, Asparagus, and scores of others as familiar and as ancient. But there is also no dearth of purely generic names for monotypic genera that are of two terms. There are Acorus officinarum, Tagetes Indica, Plantago aquatica,..Aster Atticus, Barba Capri, Vitis vinifera, Vitis alba, Vitis nigra, Viola purpurea (=Viola), Viola alba $(=$ Matthiola), and very many more like these. There is no ground for questioning that every one of these names is purely generic. There is no warrant for denominating so much as one of them "a pre-Linnæan binomial," that is, a name of which the first word is, in the accepted sense, generic, the second specific. Names binary, and of just this last named quality do also abound in Fuchsius; but these now cited, and also a host of others like them, have nothing in them of the generico-specific meaning which all binaries in use to-day convey, and are understood to convey. Now that Fuchsius does not mean by Plantago aquatica any species of the genus Plantago is put beyond all doubt or cavil by the facts, first, that he takes it as the topic of a chapter apart from that in which Plantago proper is discussed ${ }^{1}$; and second, that the officinal, or more properly scientific (Greek) names heading the chapters are totally distinct, the one being Arnoglosson, the other Alisma. Concerning Vitis vinifera, now long in the status of a genericospecific binary, it is as readily demonstrable that with Fuchsius it is purely generic. Assuming that in primitive times the one word Vitis-in Greek $\alpha^{\prime \prime} \mu \pi \varepsilon \lambda{ }_{05}$-was, as it now again is become, the generic name for grape-bearing shrubs, there came in later such two-worded generic names as Vitis alba, Vitis nigra, Vitis Idca, etc., each standing for a completely and widely different genus. It is easy to see that such multiplication of generic names beginning

1 Plantago (of two species) is the topic of ch. xi, pp. 40, 4I; Plantago aquatica (monotypic) is of ch. xii, pp. 42,43 . 
with Vitis rendered it needful that the original Vitis should receive also a second and modifying term in order to avoid confusion; and thus there came into existence, and of necessity, the generic name Vitis vinifera instead of the simple and primitive Vitis. Let us see what Fuchsius' genera of which this term is a part of the name, really are:

Fuchsian

Vitis vinifera

Vitis alba

Vitis nigra
Recent

Vitis

Bryonia

Clematis

Specific names, with this German father, quite as with all his forbears that I know aught about from Theophrastus forward, are strictly binary. One simple word, almost always adjective, constitutes the specific term of such binary, and is the cognomen, as some called it. It happens, indeed, with many a such binary name that it is composed of three separate words; but that is always for the reason that the generic name is of two words. Not much less than a hundred of Linnæus' trivial names of plants are of three distinct words; but this is because he makes the specific part of such names to consist of two words, and never the generic part. This is precisely the difference between the Fuchsian and the Linnæan binary nomenclature; and there exists no other difierence. We amend Linnæus by connecting by a hyphen his two-worded specific names. This is done in order to preclude if possible any questioning of the fact that the two words which we have hyphenated are to be thought of as one. It were equally in place to hyphenate the terms of Fuchsius' two-worded generic names. This done, he who ran might read the truth that all Fuchsian plant names not those of monotypic genera are as strictly binary as those of Linnæus; with even this one difference in Fuchsius' favor, that he has no two-worded specific names.

As to general principles of botanical nomenclature, those of Fuchsius seem few, and easily ascertained. Those principles appear to be convenience, etymological suitability, brevity.

If all his names are binary, and, as being the mere names, hold places entirely apart and distinct from the descriptive paragraphs, as they always do, then there is not even the suggestion in Fuchsius of those "phrase names," so called, which became a burden upon the phytography of two centuries later; and it may be said of his work that it is quite a model of brevity in nomenclature.

Inasmuch as the Greek names of genera are older than the Latin, 
and he gives to them a kind of precedence, making them the headings of his chapters, there might arise a question whether the Greek names were preferred on account of their right of priority. But there is other evidence that the principle of priority in nomenclature obtained no recognition with him; was perhaps never once thought of. The standard works on the materia medica in use everywhere in Fuchsius' day had been written in Greek; which fact alone would give the highest prestige to Greek plant names. Their Latin names, needful to be used for the convenience of the many who knew Latin but not Greek, were in every way as valid as the Greek names. Both were used, chiefly as a matter of the greater convenience to readers and students as a body. That he never thought about rights of priority as worth contending for comes out as clearly as possible in his presenting a new genus with the new generic name Digitalis. "We make use of this name, until we ourselves or some one else shall have invented a better one."1

The above remark attests its author's opinion that there could be appropriate names and inappropriate, and that names either bad, or even not very good, might well be suppressed in favor of new ones more suitable. Even the principle of convenience, which always favors the retention of an established name whether bad or good, may be overruled for the rejection of a name that is ill constructed, and the substitution of a new and better one. There is one generic name that had held good for some fifteen centuries, a Greek name too, which he declines to adopt as the heading of its chapter, evidently because etymologically distasteful to him. The name in Greek is Ocimoides, formed by the addition of oides to the generic name Ocimum. Instead of the ancient and established Ocimoides he writes for a heading to the chapter the new name Ocimastrum $^{2}$; an initiative in the reform of generic nomenclature which Linnæus two centuries later was to carry forward with universal approval.

He who thinks that nomenclature, like the science itself, should be subject to advancement and improvement, must be believed to have his reasons; though Fuchsius does not appear to have declared his. One thing, however, we observe, and that is that all the names he uses have their meanings. A genus is named in allusion to some morphologic or qualitative characteristic; or else in honor of some personage who had to do with botany; or rarely,

1 Hist. Stirp., p. 892 .

Ibid., p. 895 . 
from some foreign country whence the plant or tree had been introduced into Europe. But there is nothing of the meaningless and cabalistic in any of the 343 generic names that head as many Fuchsian chapters. The meaning is not in every instance plainiy to be read in the name itself. That which it once had when newly coined, has now and then become obscure, if not quite lost, through the lapse of ages. But there are not yet in botany anagrammatic names, nor any that had been framed by the putting together of two or three meaningless though perhaps euphonious syllables. The beginnings of such an epoch in nomenclature we shall not look for until after the time of Linnaus.

In specific nomenclature, however, we note in Fuchsius a free use of cabalistic names. In genera of two species one is very apt to be named mas, the other frmina, and since at that time nothing was known about sexuality in plants, such names had little meaning. But quite as frequently the first species is called prima, the other altera; and in the case of his fine plates of six species of Geranium they are named $G$. primum, $G$. alterum, $G$. tertium, $G$. quartum, G. quintum and $G$. sextum. ${ }^{1}$ Though without a trace of diagnostic significancy, and purely cabalistic, we shall find that this kind of specific adjective came into use very extensively in the works of botanists of a generation later than Fuchsius.

1 Hist. Stirp, pp. 204-2 I0. 


\section{CHAPTER VII}

\section{HIERONYMUS TRAGUS I498-1554}

AN original and even eccentric character, singularly gifted as a botanist, was Hieronymus Bock, whose names in literature are several; for his earliest publications were made in Latin, under the name Hieronymus Herbarius. Brunfels in his first volume publishes a number of paragraphs the manuscript of which had been furnished by his friend Bock, and these are all credited to him as Hieronymus Herbarius-Jerome Botanist, or Jerome Herbalist, as you like. So again, in the Appendix to Brunfels' second volume, there is a document of some length, entitled Apodixis Germanica. ${ }^{1}$ This is in German, and is by Tragus, but still under the name Hieronymus Herbarius. In the numerous German issues of his principal work he figures as an author whose name is Hieronymus Bock. When the great botanical merit of this work had been intimated abroad. and a Latin edition of it was thereby called for, in this he appeared under the Græco-Latin name Hieronymus Tragus. By this name therefore is he known in the botanical world in general. The genus that was dedicated to him by Father Plumier therefore necessarily took the form of TRAGIA.

Life. No adequate biography of this interesting character seems to be known. We trust that we have to a certainty the year of his birth; we have the date of his marriage, the maiden name of the bride, the names of her parents, and even the number of guests that were in attendance; and all this out of Tragus' own diary. ${ }^{2}$ Neither is there any disputing the date of his death, the place of his burial, or the name of the preacher who delivered the funeral panegyric. But all these are matters which, in the biography of a reputed scholar, a practicing physician, and the beneficiary of a lucrative parochial endowment, are of subordinate interest. What one most wishes to know are the names of the colleges and universities at which the man studied, the schools whence he had his

1 Brunfels, Viv. Icon. vol. ii, pp. $183^{-199}$ (in my copy).

2 Melchior Adam, Vite Germanorum Medicorum, p. 68. 
degrees in medicine and in theology. In other cases there is ordinarily no doubt of the date of the conferring of a degree, or of the admission to sacred orders. Upon these several points, each of prime importance to even the briefest sketch of the career of a noted scholar, physician and clergyman, Tragus' biographers from Melchior Adam away back in the year 1620 , down to Ernst Meyer in 1857 , are silent. Not one of them names a school of any grade, or of any profession, which the man was known to have attended; and if any should suspect Tragus of having been a medical practitioner without a diploma, and of having enjoyed as a Protestant layman the income of a large Catholic parochial endowment, there is not a line in the most authentic biographies, as I have read them, by which to allay either suspicion.

Tragus was born at Heidesbach, not very far from Heidelberg, in the year 1498 . Concerning the estate of his parents as poor, or as in easy circumstances, nothing is known. As a youth he was found uncommonly well educated; whence Meyer inferred that the parents were well to do. That inference may as easily be wrong as right. ${ }^{1}$ At the monasteries of the period there was free education for boys of intelligence and promise, if their parents were poor. Meyer, writing in the middle of the nineteenth century, should have bethought himself of this, that in the Germany of Jerome Bock's boyhood Luther and the reformation had not yet appeared, and monasteries were everywhere. The biographers all affirm the disappointment of the parents at the young man's final and very fixed determination not to become a monk; and the disappointment seems to imply that he had been placed under monastic influence, and on their part hopefully.

The considerable views which we obtain of Tragus' life here and there do not show him always happily circumstanced, but rather more commonly as acquainted with adversity. Physically he was a consumptive. Even out of the ten children born to him eight died young; and he survived also the mother of them. It is in the year $5_{523}$, when he is twenty-five years old, that we find him settled in $Z$ weibrücken, under the appointment of the Palgrave Ludewig, as a school teacher, and also as in charge of gardens of this prince, which he is said to have enriched with many plants. ${ }^{2}$ This favorable incumbency Tragus seems to have held for some nine years, and came to an end in $\mathrm{I}_{32}$ by the death of the Palgrave Ludewig. Quite before this date we should have found Martin Luther a central

1 Geschichte der Botanik, vol. iv, p. $3 \circ 3$.

2 Meyer, Ibid. 
figure before the German public, the ecclesiastical revolution in progress, and Jerome Bock a zealous and outspoken Protestant. Prince Ludewig's successor, Friedrich II., was either still firmly a Catholic, or else unwilling to declare himself a partisan of Luther; and Jerome Bock, botanist, lost his position and became penniless with a young family on his hands.

A plan inaugurated by some sympathizing friend for his relief is one that ought to have been regarded as somewhat hazardous, and indeed may have seemed so to them; but it was attempted. A beautiful country place called Hornbach was the site of a Catholic church dedicated to Saint Fabian and, long before Tragus' time, richly endowed by private munificence. The parish was vacant. Luther's influence had been felt there and the membership was divided between allegiance to Rome and sympathy with Luther. It was hoped, so says Melchior Adam-himself strongly a Lutheran partizan-that the "old superstition" had been banished to such a degree that the new incumbent would be able to complete the "reformation " of St. Fabian's. The event proved otherwise, and the incumbent was obliged to retire; not, however, very promptly, nor until after he had done much botanizing in the wild rich regions roundabout; such journeyings being made, as he informs us, disguised as a peasant.

On his enforced retirement from this anomalous and only quasiofficial incumbency he was again in the straits of poverty extreme; until relief came in the form of a bidding to make his home in the castle of Count Philip of Nassau, who remembered our botanist as having once brought him safely through a dangerous illness. His sojourn with this friend seems to have continued through several years, though for precisely how long can not be ascertained. During this interval, however, the affairs of St. Fabian's Church at Hornbach had undergone a change, probably that of the elimination of the Catholic element; for a way was now open for Tragus' return to the enjoyment of that benefice. He is said to have received a hearty welcome back by those remaining, and that he ended his days there not very long after his return is certain. He died of consumption early in the year 1554 , at the age of about 56 years. A half-century or so later when Melchior Adam was engaged upon his biographies of German worthies, a search appears to have been made for Tragus' tomb at Hornbach. On the site of St. Fabian's Church nothing remained but a mass of ruins; but forth from under the fallen rocks they were able to bring a memorial tablet bearing this inscription: ${ }^{1}$

\footnotetext{
1 Melchior Adam, Vitce Germanorum Medicorum, p. 70.
} 
"Anno Dom. I554, 2 I Febr. Hieronymus Tragos, animæ corporisque medicus, et canonicus huius ædis, in Domino Jesu obdormivit; cuius anima in consortio beatorum quiescit. Amen."

Phytography. The third in order of time among the more noted German botanists of his century, Tragus is the first in their line to actually describe plants. Brunfels had caused pictures to be made, and then by way of comment on each picture had gathered together all that creditable authors in times past had written about the plant, repeating their language to the letter, and citing religiously the volumes and the pages. Fuchs had also pictured every plant, and then to lessen the cost of printing, had presented short descriptions, compiled from other authors, and for the most part given forth as his own.

Two circumstances, both beneficent, united their influences to make 'Tragus' work peculiarly and distinctively a book of plant description. First of all, the man was by nature an ardent lover of plants. He began to pursue botany for the mere love of it, without thought of thereby acquiring either fame or profit. $\mathrm{He}$ who loves things will see much in them to which the indifferent calm and cool observer is blind. If the born botanist-not the machine made one-write of plants he will find language wherewith to enable his readers to see what he has seen in a plant; and this is phytography. The second favorable circumstance was that of poverty. Tragus at first had no money with which to employ draftsmen and engravers. When he yielded to the entreaties of friends of botany that he would prepare a book, he wrote it in the German language, and with the intent that unfamiliar plants at least : hould be recognizable with German readers by his verbal descriptions of them alone. In passing at once from the descriptions in Fuchsius to those of the Latin edition of Tragus, one is impressed by the originality and the vastly superior excellency of the latter, it should be recalled that the high quality of them is largely due to their having been first written and published in German, ${ }^{1}$ and without thought of their ever being accompanied by pictorial aids to the identification of the plants; and that it was their great success as descriptions that called for the republication of the book in a Latin version, so that the whole might be available to scholars everywhere outside of Germany.

While easily to be ranked among the fathers of phytography,

1 Both the New Kreutterbuch (1539) and the Kreutterbuch (1546) are in German; the former without illustrations. 
and even as the first of them in point of time after Theophrastus, Tragus does not systematically describe all the plants which he finds occasion to present for discussion. The most familiar things of field and garden, such as every one has known from time immemorial he neglects, as to their organography, assuming, as did the ancient authors, that the names will recall the images of the plants to the mind of almost any reader. It is the wild things, the native growths of Germany, together with the more recent introductions into German gardens, which engage his powers of verbal delineation.

To the vocabulary of descriptive terminology Tragus does not make any considerable additions. He very commonly employs the old established system of comparisons; conveying an impression of the root, the stem and mode of growth, the leaf-outline, the inflorescence of a less known plant, by comparing them with the like organs in very familiar types. Sometimes he does, what every one besides had always done, that is, he repeats old comparisons that had been in steady use unaltered for a thousand years and more, and occasionally he makes bold to suggest a new one which he thinks better. Dioscorides had described in the following terms the foliage of a certain plant: "Cyclamen has the leaves of the mature ivy bush, but colored purple, and variegated with whitish markings." Of course Tragus had pondered well this classic line, but thought it might be improved. Here is his own description of the leaves of what he takes to be the same plant. "The leaves of cyclamen are spread over the ground in a circle, are very similar to those of the ivy, 01, as I think, of the asarum rather, of a dark green, underneath somewhat reddened, above more brownish, and marked with whitish spots." 2 This is liable to be promptly adjudged a better description than the other, at least for cyclamen leaves as most people are used to seeing them; and the cyclamen which Tragus knew in Germany has foliage assuredly more like that of asarum than like that of old ivy. But what renders the attempted amendment of the Greek author's diagnosis infelicitous is this, that Dioscorides never saw the cyclamen species that Tragus knew, and that at least some of the several Mediterranean cyclamens have leaves of more nearly ovate outline, and therefore better likened to bush-ivy leaves than to those of asarum. The audaciousness of Tragus is not diminished by the consideration that Dioscorides had not only also known asarum, but in describing its

1 Diosc. Book ii, ch. $5^{8} 8$.

2 Stirp. Comm., p. 905 . 
foliage had definitely indicated wherein it differs from that of ivy ${ }^{1}$; so that if the cyclamens of Greece and Italy as he had known them had shown asarum leaf outlines he would have been likely to have said so. Tragus was deceived by his own gratuitous supposition that the cyclamen of Germany was the one only cyclamen existing.

The common mullein had been used in medicine from the time of Hippocrates; but in the books not much more than one line of description, and that of the leaves only, had been accorded it. Nothing even remotely approaching the following by Tragus had been written about it:

"A very notable thing in this plant is the long straight thick root, of a woody hardness. Its leaves, especially the earlier, lie close to the ground, are rather broad and long, of a whitish aspect and woolly, more so than those of helenium (that is, elecampane, Inula Helenium). Not until the second year does it send up its stem, full of a white pith within, like the elder, and sometimes attaining a man's height, clothed with leaves which gradually become smaller and narrower as they approach the summit. The flowers, yellow, woolly, and most sweet smelling are of five distinct leaves, and completely cover the stem from where they begin up to the very apex of it; which falling away are succeeded each by a woolly globe crowded full of seeds not unlike those of a poppy. When the plant is in flower it well resembles a beautiful torch, whence the name King's Torch has been given it."

It is the earliest botanical account given of the mullein. The writer of it is manifestly a botanist; for he has busied himself with the investigation of this plant as a plant, not as a thing either useful or useless. The subject of this piece of research is but a weed, but he has followed it through its life history, examining its root, dissecting its stem, noting the norm of its foliage, and also the deviations from it, has counted the segments of the corolla, discovered that from within there is exhaled a pleasant odor, has incpected with care the seed vessel and its contents, likening the seeds within it to other seeds that every one is familiar with. There is even added an item of the folklore of the plant. The like of this comes very near to being something new in the history of botany; and the book abounds in plant descriptions of this new and original type.

For an example of his diagnosis of a plant never before described by any one, take that of the Lily of the Valley:

- Diosc. Book i, ch. 9.

2 Stirp. Comm., pp. 2 I6, 2 I 7 . 
"From a fibre bearing an extensively creeping root somewhat like that of lolium there arise in the month of April green sprouts not so unlike those of asparagus, which turn out to be nothing else than a pair of green leaves closely wrapped together, and supported on a common footstalk. Now when these two begin to separate from each other they assume the appearance of a pair of leaves of the white lily; at the same time there is seen to arise as from between them a triangular peduncle ornamented by five or six little globes placed one after another, of about the size of a chick pea, which in the latter part of April expand to little cymbal-shaped flowers of a snowy whiteness, round, hollow, serrated around the lower part (i.e., that part looking toward the ground), in the middle within marked with a purple spot. the whole flower most fragrant, but of a bitter taste. After the falling away of these they are succeeded, at the end of June, by a coral-red fruit not unlike that of the asparagus." 1

The production of this fine word picture had been prompted by something more than mere admiration for a beautiful plant which, although unknown to descriptive botany, has risen to high repute in medicine, at least in Germany. A spirit of friendly rivalry seems to have added zest to those morphologic investigations from which the description followed. Brunfels, who had been first to figure the plant, had found no description of it anywhere, and left it without any. Concerning the medical authorities of the time, whose chapters he had ransacked in search of some account of it, he says he has found them "as silent as fishes." 2 We learn from Tragus that Brunfels afterwards changed his mind in so far as to doubt whether this might not be the Hemerocallis of Dioscori$\operatorname{des}^{3}$; and Tragus the more carefully studies lily of the valley from earliest spring to the end of the season, and describes it every part from root to fruit, that he may successfully controvert the view of that "man of pious memory, Otto Brunfels." The argument, given at full length, occupies a separate paragraph appended to the description.

On his frequent excursions to the woods and other wild lands, Tragus nad discovered many growths hitherto unknown; and while never until late in life having thought of availing himself of the engraver's art, he published a long list of such by verbal delineation only; and so well that plates, when at last in a new edition he

1 Stirp. Comm., p. 572 .

2 Brunfels; Herb. Viv. Icon., vo!, i, p. 212.

3 Stirp. Comm., p. 573. 
made use of them, were wellnigh superfluous, at least to all who were competent to read the descriptions. No greate praise can be given any man of that epoch, than will be rightfully accorded to Tragus in adjudging him to be, for the whole era of modern botany, the first father of phytography after Theophrastus.

Anthology. It was now quite time that some one should resume the investigation of floral structures; a part of botany in respect to which no advancement had been made for fifteen centuries. Neither Brunfels nor Fuchs had even so much knowledge of them as had been attained to by Theophrastus eighteen centuries before. The Greek had said concerning nut trees and oak trees that, over and above those vermiform tassels whose use and nature he could not explain, they have real flowers, things out of the very heart of which nut and acorn were developed. Fuchsius, the famous professor of medicine: physician to the titled and the affluent, and moneyed employer of draftsmen and engravers to figure plants, had boldly ventured the unwarranted opinioncontradictory to that of the great Theophrastus - that the tassels of oak and hazel take the place of flowers, and that such trees have no other kind at all. ${ }^{1}$

Tragus, the poor schoolmaster, the apparently unlicensed country doctor, the unordained preacher of the new evangel, welcomes this kind of an opportunity to assail the errors of the dogmatists who sit in exalted station; for, whatever else Tragus may or may not be, he is a botanist well worthy of the name. The combined botanical knowledge of all the Brunfelses and Fuchses of Germany is but a small fraction of what he has seen and taken note of in the book of nature. He has studied the hazel bushes both wild and cultivated in their several species, from the time of the lengthening of their aments in February, all through the spring, and the summer, and the autumn. Theophrastus had averred that, whatever the tassels might not be, the bush has flowers, demonstrably such by the fact that the fruits develop from them. Of the form and coloring of such flowers, and the time of their appearing, he had given no hint; and since at the period with which we are dealing, quite as during two thousand years before, the first idea of a flower was exactly our idea of a corolla, and none had ever seen such things on hazel bushes at any time of year, it was not so wholly inexcusable to deny that there were hazel flowers. And yet, the most cursory reader of Theophrastus' chapters on flowers must have seen that he recognized flowers as either petaliferous or apetalous,

1 Fuchs, Hist. Stirp., p. 397. 
even though he did not use those terms; and thus, if corylus failed ever to deck itself with corollas, the next thing in order would be to scrutinize the shrubs in quest of the Theophrastan "capillary" flowers. In such a quest as this Tragus was successful; and since he is the first to actually describe the fertile flowers of Corylus Avellana, his words have such historic value that we must quote them: "All kinds of corylus have diminutive red flowers, resembling the very short stamens of a crocus, which they display just before the unfolding of thei-leaves. It is in the month of February that those aments which some erroneously suppose to be the flowers, acquire their yellow coloring. Theophrastus in the sixth chapter of his third book of the History of Plants makes mention of the proper flowers of corylus; nevertheless Leonard Fuchs and John Ruelle. besides some others, persistently deny that corylus has ever any flowers; a thing which beyond doubt they would not have done, had they ever once looked into the book of nature on the subject." 1

After so signal a contribution to the anthology of the hazel, and especially after such public castigation of Fuchsius and Ruellius, it was fateful that Tragus should err, and that ridiculously, in his philosophy of alder blossoms. Here, having denied that hazel aments are flowers, he is confident as can be that alder aments are true flowers; and he proves it in this wise: "The alder, at least when full grown, adorns itself in spring with brownish flowers, almost like those of the birch and the beech; but they do not fall off, as we have observed that they do in the beech, but are permanent, and come to be drawn together so that they at length acquire something like the configuration of an olive. And this is the fruit of the alder, which matures at the end of summer, and then falling sows itself, so that by this means new alder trees are produced." 2 Afterwards in giving account of the flowering and fruiting of birches he betrays the same nnocence of the real origin and history of the small seed-bearing cones ${ }^{3}$; inferring that they had been produced by a final contracting and thickening of the pendulous staminate tassels. A less erratic and more logical mind would not have been content with affirming that the loose pendulous aments of birch and alder are real flowers, and at the same time denying that the very similar ones of hazel have anything at all of the nature of flowers. Yet when it comes to the oaks, Tragus must again be given a credit mark as having detected, next after Theophrastus, their very

1 Tragus, Stirp. Comm., p. 1095.

${ }^{2}$ Ibid., p. 1085.

s Ibid., p. III4. 
obscure fertile flowers. "The leaves of all kinds of oaks when young are very small and delicate, and there appar with them at this stage long yellow aments.... After the aments there come forth very small red flowers which subsequently transform themselves into acorns." 1

Sexuality in plants never yet having been apprehended, Tragus had no conception of the fact of diocism. He studied the catkins of willows, but without discovering that those of some individuals are promptly deciduous, and that only those of certain other individuals remain longer. He therefore wrongly attributes to willow catkins indiscriminately the quality of remaining on the tree until they have developed a kind of wool which sails away on the passing breeze. In just this connection, however, he makes a remark which reveals him for once in the character of a truly inductive philosopher, unwilling to venture a broad general conclusion from an isolated fact. "Whether this wool of willows be their seed or not I do not know, except as regards the fourth species, in the case of which it at least takes the place of seed; for in this I have caught the floating wool, have sown it, and have seen willows of this same species spring up from the sowing." 2

As to certain particulars in the structure of petaliferous flowers the chapters of Tragus seem still more clearly to herald the coming of a new era in anthology. Not that he has any new doctrine of the flower. So far from it, he follows the universal and time-honored practice of calling, in the case of petaliferous flowers, that and that alone the flower, which only long after his day came to be known as the corolla. But he observes and takes note of things outside of this "flower," and of other things inside it, the tendency of which notes and observations is to raise a question as to whether there are not other things which, taken together with the circle of colored leaves, should all collectively be thought to constitute the flower. He does not formally propound any such question. Even that suggestion of it which his language carries, it is more than likely he himself did not perceive. Let us attend to a few instances of anthological comment that seem to be new and original with Tragus.

As subjects of brief description and of various comment the poppies are very ancient, and were so in Tragus' time; and he is the first man in all history to describe the plants as with the pen of a botanist; the pen of a man who had looked at them with his own

1 Stirp. Comm., p. I IоI.

2 Ibid., p. 1073 . 
eyes, and had seen points of morphology never mentioned before him. One of these points relates to the "flower" before its unfolding; or as we should now say, to the flower buds. No such expression as flower bud, however, was yet in use; and Tragus names the thing a capitulum, a little head. Poppy plants have what have been called from time immemorial their heads, that is to say their capsules, or seed vessels; and Tragus now attributes to them a second kind of head, one never before mentioned; and this is his language: "The head from which the flower is to break forth is covered with a pair of skins (cuticuli), green as to color, and also hairy. When the flower itself is ready to make its exit the two integuments separate and promptly fall away."1

He has several genera, and in all some eight species and varieties of poppy allies, and to the group as a whole he attributes this pair of caducous integuments. It is a significant item in the history of anthology. He has recorded the discovery of an organ, and has given at least the hint of its possible availability in taxonomy; but, as is usual with discoverers, he is in advance of the time in which his work will be appreciated. It will be yet two hundred and forty years before this pair of integuments to the poppy bud will acquire their name as sepals, and about as long before their caducous nature will be recognized as a good character for the family of the Papaveracece.

In respect to the forms of flowers, i.e., corollas, there are evident traces of attempts-perhaps half-unconscious efforts-to generalize. As if the wild rose might have been looked upon as the most perfect flower-form, or at least as a most representative type, he is given to speaking of other broad petalled and subrotate flowers as being rose-like, or even as being roses. In describing Paonia, which he figures in a single-flowered state, he twice refers to its "roses," hardly using the word flower at all. "In all our Germany you will hardly find a more elegant rose than that of pæonia"; and again he says that "toward the end of April a round head at the summit of each stem all at once breaks into a broad red rose."2 In like manner he speaks of the flowers of hollyhocks only as roses, and is wont to denominate any large flower of five petals widely spreading as rose, or at least as rose-like. Smaller ones, with petals equally spreading, and especially if they be acutish petals, are his "stellate" flowers. But if the five spreading petals be unequal in some degree, and especially if one of them be at_all_prolonged_at

1 Stirp. Comm., p. II $9:$

2 Ibid., p. $5^{82}$. 
base into a hollow protuberance or spur, such a corolla is not with him a flower but a "violet." The proper violets, that is the acaulescent kinds, and the pansies or tricolor kinds, are regarded by Tragus as by all others before him, as of two genera with different generic names; yet flowers of both are spoken of not as flowers but as "violets"; and the same term is applied to the flowers of larkspurs. ${ }^{1}$

But there is a second and very different corolla-type which is also called by Tragus a violet-flower, namely, the cruciform. This came about by reason of the familiarly known fact that in the nomenclature of that period there was a genus Viola purpureasometimes called Viola Martia (=Viola), and also a genus Viola alba (=Matthiola), besides even a Viola lutea (=Cheiranthus). It is with this cruciferous viola type in mind that he describes the flower corymbs of Viburnum Opulus as adorned with "an outer circle of large white violets consisting of four leaves." 2 But among the crucifers particularly, the flowers of all that have rather large and showy petals he habitually speaks of as violets; for example those of the mustard, ${ }^{3}$ the cabbage, ${ }^{4}$ and the turnip, ${ }^{5}$ with also that of celandine. ${ }^{6}$ That it was not the merely cruciform arrangement of spreading petals that caused a flower to be called a violet of this type becomes apparent when one has observed that Tragus never applies it to the blossom of any small-flowered crucifer. In the case of the lepidiums, and Bursa Pastoris, and all others having diminutive petals, it is his custom to say only that the flowers are small and of such or such a color; never speaking of them as even small violets. For the crucifer-violet to be called a violet there must be some approximation to the size and showiness of the wallflower and gilliflower.

But now, the learned philologist may interpose that, after all, both rose and violet, in the speech of primitive peoples are terms indicative of not particular kinds of flowers; that each, in its origin, is but the synonym of that other and later word flower. Nor may this be successfully controverted. The very nomenclature of scores: of familiar flowers to-day attests the truth of it. There is Christmas Rose (=Helleborus), China Rose (=Hibiscus Rosa Sinensis),

1 Stirp. Comm., p. 568, 903 .

2 Ibid., p. 1002, under the name Sambucus aquatica.

3 Ibid., p. 100.

- Ibid., p. 7 I 8.

I Ibid., p. 728.

- Ibid., p. 106. 
Guelder Rose (=Viburnum Opulus), Rock Rose (=Cistus) Rose of Sharon (=Hibiscus Trionum); also there is Dame's Violet (=Hesperis matronalis) Dogtooth Violet (=Erythronium), and a great number of other such, for plants that have no affinity to either the rose genus or violet genus. Doubtless with some of the peasantry of several countries to-day the showy flowers they know may be found classified in their languages more or less definitely as roses, lilies, and violets. And something like this was most certainly true four hundred years ago in rural Germany where Tragus was born, and where he did all his botanizing. And although I find him twice using the term violet for small flowers that do not readily fall into either of his two definable categories of violets, I do not think that either one instances a lapse into that primitive usage under which the term is synonymous with smallish petaliferous flowers in general. If he calls the flower of the catsfoot, or ground ivy ${ }^{1}$ a violet, the color of the flower, and the irregularity of its corolla-limb may have suggested it; and the corolla of a bryony ${ }^{2}$ is not unlike that of the sterile outer row of those in viburnum ${ }^{3}$ corymbs. That he in truth goes far on the way toward a convenient morphological classification of corollas is evinced by his giving diagnostic names to still other forms. Among the polypetalous he even distinguishes the rotate from the rosaceous. The flower of nigella he says is "round like a wheel," 4 that is, the petals spread away in a flatly horizontal direction from their axis, a thing which can not be said of either rose or pæony petals. It is an excellent distinction, not noted even by Tournefort the great corollistic systematist of a hundred and fifty years later; for he describes the nigella flower as rosaceous. ${ }^{5}$ The campanulate, or campaniform, was also named by Tragus. In his description of the plant hyoscyamus he says that it has little bells for flowers. ${ }^{6}$ The corollas of campanula, ${ }^{7}$ of digitalis, ${ }^{8}$ and of vaccinium ${ }^{9}$ are said to be campaniform. The funnelform is also alluded to, though under the term cymbaliform. He attributes that configuration to lily and morning-

1 Stirp. Comm., p. 798.

2 Ibid., p. 8 I 9.

3 Ibid., p. I002.

4 Ibid., p. I 7 .

s Tourn., Elemens., vol. i, 225.

6 Stirp. Comm., p. I32.

1 Ibid., pp. 724, 926.

s Ibid., p. 888.

9 Ibid., p. 974. 
glory flowers. In a word, he is so definitely the first forerunner of Tournefort in the matter of observing and carefully noting a number of marked corolla forms, that it seems due him that a list of them should here be given synoptically.

I. Rotate, typified in Nigella.

2. Roseform, typified in Rosa, Pæonia.

3. Violetform (proper), typified in Viola, Delphinium.

4. Violetform (cruciferous), typified in Cheiranthus, Matthiola.

5. Stellate, typified in Sedum, Solanum.

6. Campaniform, typified in Campanula, Digitalis.

7. Cymbaliform, typified in Convolvulus, Oxalis.

Gifted with keen perceptibilities in the matter of floral structures, it is rather remarkable that Tragus did not assign names to such very strong corolla-types as the bilabiate and the papilionaceous; for I find in him no trace of any term by which he would designate either one. Even the later Latins seem to have denominated certain very nettled-leaved labiates as "nettles with a lip"; and this most lynx-eyed and original inspector of flowers seldom names anything more than the mere color of labiate flowers, once onlythe case of glechoma above referred to-giving perhaps a hint of the form. In respect to the flower of leguminous plants he does not so much as second the suggestion of Gesner that the pea blcssom has the form of a butterfly, but attributes, for example, to the pea vine the flower of genista, and to genista in its turn the flower of the pea, and so on to the end of the series. There was nevertheless in Tragus' time a German school boy who had already coined the term papilionaceous for these flowers, though only in manuscripts that were not published until after Tragus' demise.

Among those scattered anthological notes which, to his contemporaries and to himself, may have seemed of least moment were his various observations upon stamens. Their function had not yet been guessed at, or even by Tragus himself so much as thought about. The organ had not been even morphologically contemplated, in its individuality, up to the time when Tragus began to examine it in different flowers comparatively. From time almost immemorial they had been mentioned only collectively, in Latin writing, as the capillamenta, the flocci, the stamina, the apices; mostly a tuft of thready things, with or without knotted tips. It is altogether a new thing in botany for a man to write as follows concerning the white-lily flower: "From out the bottom of it 
there stand forth six apices, and these yellow; then prominently from the midst of them a kind of thickish stamen that is green and has a triangular head, the whole being shaped something like a walking stick." 1

In a flower of the size of a lily such diagnosis of less obvious parts is easy, insomuch that one need not have been surprised if many a writer before Tragus had indicated them as well; but for similar inspection and diagnosis a gooseberry blossom was small and difficult for a botanist whose researches antedated the invention of hand lenses. The following is our botanist's account of it; and it is the oldest one extant:" "In March the bush puts forth its flowers, small, concave, purple, which if you examine them one by one you find to contain within five diminutive apices each supported on a hair, the whole resembling a little bell."3 Another Hower which he is first to describe is that of the hawthorn. This is not much larger than the gooseberry blossom, and of less simplicity in its structure; but he brings out its characteristics quite as clearly. "The individual flower is made up of five small white leaves, from out the middle of which there stand many white things like hairs supporting rose-colored apices, such as one observes in all pomaceous flowers." 4 Among his "pomes" Tragus includes also the drupe-bearing trees, and his account of their floral structure is given once for all under the caption of the Wild Plum. "The individual flowers of the wild plum consist of five bright-white leaves; and in the midst are seen about eighteen as clear white capillamenta or stamina each supporting its small yellow apex. Just about this is the structure of the flowers of nearly all the pomes, cherries, plums, pears, and apples, except that some of them exhibit a greater number of capillamenta and apices than do those of this wild plum." 5 From this point forward throughout the line of the pomaceous and drupaceous trees, he has little to say of the flowers beyond this, that "they are those of all the pomes," sometimes remarking that the "apices" are red, or that they are yellow.

In thus taking a census of individual stamens, recording the number of them as being constant in each different kind of flower, even distinguishing by name each of their two parts, it is evident

1 Stirp. Comm., p. 794 .

2 Fuchsius had said of gooseberry flowers only that they "are of a purplish green."

3 Stirp. Comm., p. 978 .

- Ibid., p. 934.

s Ibid., p. ror6. 
that Tragus on his own part was but entertaining himself and some of his readers with mere curiosities; that he had no notion whatever of the real importance, to the future of botany, of that which he was doing. Let us, then, take a still more careful survey of the things which he accomplished in this particular direction which were for the advancement of anthology, albeit he himself was all unconscious of their import. To begin enumerating the stamens of particular flowers, and to record in each instance the count, was to make a decided innovation upon the immemorially established anthology of Tragus' time, which had always treated of them in the aggregate only, as tufts of hairs or threads. If he announces that in every gooseberry blossom there are just five such hairs or knotted threads, that is announcing that he has made two different comparisons of them: first, a comparison of the five one with another, and then of these with two other hairs quite different from them which occupy the very center within their circle. He does not mention these, the styles, or style-branches, yet can not have failed to perceive them. But he now proceeds virtually to define a stamen. It is the little apex, and the hair on whose summit the apex is sustained. Elsewhere he repeats the definition more explicitly, and, avoiding the use of any new terms, he calls that the "capillamentum" which we now know as the filament, and "apex" is his application of an old term to what has become the anther of modern anthology.

Tragus is, then, the discoverer of the stamen as a definable organ made up of two separate and different parts, each part with its own name. The same is very near being true of him as regards also the pistil. We have just seen how accurately he could describe the style and stigma of a lily as things quite apart from the stamens; and as to the flowers of common fruit trees, we must eel assured that he saw the one style of each plum and cherry blossom that he inspected, and the five of them that are conspicuous in the flowers of pear and apple trees. He did not mention them; but then, they are as plainly visible there as the stamens themselves, and both his enumeration and his definition of these prove that he did not confuse the styles with them. Curiously enough, after having located and well outlined the large lily style and its stigma, the very next account he gives of such central thing is in connection with a flower even smaller than that of a gooseberry, namely, of the little ericaceous undershrub then called Myrtillus. ${ }^{1}$ Here the stamens seem to have escaped his notice, as they easily 
may have done, being both minute and hidden away within the partly closed hollow of the corolla at its base, falling away with it; but the style is very obvious, and in describing this hollow bell of a corolla he says: "It has in the middle a red-brown something like the clapper of a bell, which, after the falling of the flower grows into a round reddish berry." 1 The Latin term used for this thing in the middle of the flower bell is pistillum. It is the first instance of the employment of that term to designate what has long since become universally known by that name.

On the whole, then, as by suggesting the classifying of corollas this author is the first herald of Tournefort; much more conspicuously as the first investigator, even fairly the discoverer, of stamen and pistil, is he the first forerunner of Linnæus. It was anthology which created the new botany of the eighteenth century and the nineteenth; and the beginnings of the modern anthology are with Tragus.

Fruit and Seed. Well in advance of classic antiquity in the knowledge of floral structure, Tragus not only added nothing to carpology, but had never learned either from Theophrastus or by research of his own anything like all that Theophrastus had attained to along this line. One may doubt if any other book was ever printed, or even written in any age, in which there find expression so many whimsical and superstitious fancies about seeds. In a general way they seem to fall short of having that value in the economy of plant life and plant distribution, in Tragus' opinion, which even a remote antiquity accorded to them. The transmutation of the seeds of cereals into germs of chess and darnel he accepts without the expression of a doubt. Abiogenesis, the doctrine of the origin of living things from lifeless matter, he accepts unwaveringly, and with a plenitude of faith probably surpassing that of the Greeks who aforetime invented the theory. He even defends it by theologic arguments ${ }^{2}$; and by it he explains the coming into existence not only of low and simple flowerless things, but also of some of the highest types, even of trees. The time seems to have been when he had thought that all willows had at first come forth spontaneously from the mud of river banks; for he knew them to be propagated by cuttings always, and no one had ever seen or heard of a willow seed. Even when with such truly scientific inquisitiveness he had planted some of the "white down" that he had gathered as it was about to float off from a willow, and had afterwards the satisfac-

1 Stirp. Comm., p. 974.

2 Ibid., pp. I 125, I 26. 
tion of seeing willows spring up as from that down, this neither convinced him that all the other kinds of willow might be raised in that way, nor even that any willow had ever borne a real seed. He says that one out of the four species of willows which he describes can be propagated in this way; but he vouches for none of the others; does not infer that the other three may be found producible from "willow down." Nor did he have any idea that he had planted willow seeds. "The down takes the place of seed."1 There are certain kinds of poplar, and even of maple, which he thinks never bear seed at all, and which he therefore thinks came into existence abiogenetically. These were diœcious trees, none of them indigenous to Germany, and perhaps then existing there in only the male sex. He has seen the tassels of Populus alba, and knows them to be always deciduous; also no one knows of any seed as consequent to the flowering of Acer pseudo platanus. They are seedless, and therefore, to the faith of Tragus, abiogenetic in their origin. It even seems to be his opinion that certain plants plentifully seed-bearing may upon occasion spring up and mature in places where no seed of them had fallen. It is upon just this theory that he accounts for the occurrence of individual plants of many kinds on high walls of solid masonry and upon the roofs of buildings. No orchids, in his understanding of them, produce seeds at all. He is familiar with the fact that in autumn, as the plants are withering away, a very fine dust falls from where the flowers were, but he affirms that this perishes together with the season's growth of stem and leaves. ${ }^{2} \mathrm{He}$ presents to his readers a strange fancy about the primal origin and the perpetuation of this class of plants. He is the first author to mention, and may or may not have been first to observe in the flowers of orchids, resemblances to birds and other flying things; but he writes much as if he had been the inventor of the theory that this kind of seedless plants originates from certain excretions of birds. It is in the chapter that is devoted to the birds' nest orchis that he explains this belief. Such plants, he remarks, abound chiefly in and about thickets where small birds mate and nest.

The belief in all kinds of spontaneous generation, of even seed plants as well as the seedless, did not preclude all research on Tragus' part along these lines. There is a picturesque account of nightly vigils in search of the problematic seeds of Osmunda regalis. ${ }^{3}$

1 Stirp. Comm., p. 1073.

2 Ibid., p. 784.

3 Ibid., p. 544. 
While it was generally held that all fern-like plants are seedless, this one seems to have been popularly credited with shedding seeds regularly on one particular night of the year. Thus runs Tragus' own story:

"Inasmuch as all writers about herbs have said that ferns produce neither flowers nor seeds, I have thought it worth while to place on record, for the information of botanists, an account of my own experiences, which prove the contrary. For four years in succession I kept vigil all the night preceding the Feast of St. John Baptist. ${ }^{1}$ and always found in the very early morning, before the break of day, very minute black seeds, not so very unlike poppy seeds lying on the pieces of cloth, and the mullein leaves which, in order that I might not miss the seeds, I had placed under the plants beforehand. Some of the ferns had shed no seeds at all; others had deposited them by the hundred. Moreover, in these experiments, I employed no cabalistics, no conjurings, no incantations, no superstitious observances of any kind, nor did any one of the three companions of my vigils; but having made a fire we watched and waited, sometimes finding none, at other times a few here, and many there. Why there should be such a diversity in the yield of seed, and what the purpose of nature may be in all this matter, I do not understand." 2

This account incidentally reveals it that in middle Europe in the sixteenth century there still flourished the ancient profession of the root and herb gatherer, in the practice of its old time superstitions; that men believed that under the sacred spell of the summer-solstitial midnight such flowerless and seedless herbs as ferns, by help of solemn incantation could be made to scatter seeds; these presumed to be efficacious in medicine or magic. Tragus, the inquirer and reformer, half believing and half disbelieving, investigated the matter, proving to his own satisfaction that ferns bear seeds; that they produce them naturally, without the promptings of conjuration; yet it seems not to have occurred even to our reformer botanist to look for fern seeds in the day time, or at night except on that immediately preceding St. John's Day!

The distinction, indicated so long ago by Theophrastus, between plants with one seed leaf and those with two, though never again brought forward prominently until long after Tragus, had not been ignored by him. It had been the cereals and their kindred to which the Greek had ascribed the one seed leaf as a universal

${ }^{1}$ The 24 th of June; otherwise called, at least in Old England, Midsummer Day.

2 Ibid., p. 544 . 
characteristic. There was now common in Germany one breadstuff plant which the ancients had not known, namely, buckwheat. Tragus describes and figures it among the proper cereals, but with the remark that it differs from all the rest of them in that it comes up from the seed with a pair of leaves instead of with one alone, in this respect more like a turnip or cabbage. ${ }^{1}$ And although he was a student of wild plants rather than of cultivated, there are many instances of his concluding a description with the statement that the seedlings of such a plant come up with two leaves. Now and then he mentions the outline of such seed leaves in some particular plant as contrasted with those of some other; showing that he not only observed but compared them in different plants. But this does not seem to have had any purpose beyond that of gratifying his own curiosity and stimulating the like in his readers. There is no indication of his having apprehended the taxonomic significance of these distinctions between monocotyledonous and dicotyledonous seeds. The time for the birth of this great thought lay distant from Tragus a hundred years and more.

Taxonomy. In his Preface Tragus abjures the alphabetic arrangement of genera as unscientific, bringing in confusion where natural order ought to be. He is clear in expressing the determination to adopt a natural sequence. "In describing things, I come as nearly as I can to keeping by themselves such plants as nature seems to have linked together by similarity of form." 2 This was no new proposition. Ever since plants had first been observed philosophically, and written about, various groups, varying severally as to their extent and inclusiveness, had gained recognition as natural groups through resemblances in morphology. Tragus knew this well, and was only indicating his choice of natural method, in preference to the purely artificial alphabetic arrangement of genera, such as Fuchs and Gesner saved themselves labor by adhering to. Neither does he contemplate considerable innovations upon the long established method of grouping and arranging things. By his own frequent peerings into the curiosities of floral structures and recording what he saw, he has vividly suggested a new anthology. He has even begun it; and in the course of its future development it is going to revolutionize taxonomy completely and that twice over; yet nothing of this is even dreamed of by Tragus; and his superior knowledge of floral morphology has little real and almost no appreciable effect upon his own classifyings.

1 Stirp. Comm., p. 648.

2 Ibid., Præfatio, ch. xiv. 
Tragus' taxonomy, like that of all his forebears, is established upon characters of the vegetative organs, with no strong appeal to flower or fruit; and the primary grouping of things as trees, shrubs, and herbs is in his estimation natural and valid. Nevertheless a few exceptions are taken by him against this rule. An underlying principle of such a rule, or at least a logical deduction from it, is that no one genus embraces both trees and herbaceous plants. And really there was but a solitary genus known in early botany that was troublesome to those who regarded the distinction between woody plants and the herbaceous as being taxonomically fundamental. There was the tree Sambucus and the herb Ebulus. These are their classic Latin names, and the import of this nomenclature is, that they are of two genera. Ebulus is not even in the least degree woody or shrubby in any part. In texture and duration it is as perfectly a perennial herb as the common asparagus or rhubarb. Dioscorides, the great Greek physician and medical botanist, having regard to pharmaceutical principles as well as taxonomic, received Ebulus as a kind of Sambucus. They are alike, he says, in foliage, flower, fruit, and medical properties. ${ }^{1}$ Tragus, consistently adhering to the fundamentals of classification there accepted, describes and figures Ebulus among the genera of herbs; for even his readers, every one, would look for it among the herbs and not among the trees; and Sambucus is treated of far away, in the third book, under the general topic of trees. ${ }^{2}$ In both places, however, he ventures the opinion that the two are naturally of one genus. Under Ebulus he says, "If you consider its foliage, flower, and the heavy somewhat sickening odor of the herbage, you must regard it as nothing else but a smaller and herbaceous kind of Sambucus." Under the latter he says again, "As to its leaf, Hower, fruit, and odor this is so exactly like Ebulus that the ancients were wont to receive them as of one and the same genus."

From a period too remote for precise limitation, only Sambucus and Ebulus seem to have militated against the taxonomic validity of that old distinction between herb and tree; and we shall be interested in following the subsequent history of this taxonomic puzzle to its final solution.

That old philosophy of the three grand divisions of Tree, Shrub, and Herb unquestionably carried with it the opinion, certainly not altogether unreasonable, that trees are of highest rank, and herbaceous plants of the lowest. Under this system it will be seen

1 Diosc., Book iv, ch. I 68.

Stirp. Comm., pp. 796 and 996. 
that some authors began with the highest and proceeded to the lowest, and that other authors, beginning with the herbaceous genera, ended with the ligneous, the largest and most enduring trees coming last of all. This last is the order followed by Tragus; not, however, as one philosophically viewing the plant world from lowest type to highest as a genetically connected whole. It is, on the contrary, quite certain that that Aristotelian idea, only now very lately reinstated, never entered Tragus' thought at all. If he takes up herbaceous plants first in order, it may well be because they are both the most numerous as to the genera and species, and of the highest importance to man. Nevertheless we shall find him very much given to running like things together and thus forming groups within groups, lesser ones within the more comprehensive, whether he be dealing with herbs or with shrubs or with trees. This is taxonomic work; and this is the way in which he fulfils the promise made in his Preface about natural arrangement. We must follow him now for some distance, and very carefully, if we are to arrive at an understanding as to what botanical system really was, in Germany, in this first half of the sixteenth century.

In no author as early as Tragus is there given any introductory synopsis or tabulation of the system. Such convenient and helpful skeletonization is a later invention; and here one gathers information about the system, even to the principles that underlie it, only through following the author chapter by chapter from the beginning of the volume to its end.

For a work like this, of 1200 pages, the selection of roo for such analytic study must suffice. They might be taken at random from any one of the three divisions of the treatise; but we shall select the first 100 . Within these there are embraced figures and descriptions of some 74 species, distributed to about 3 I generd. Now this proportion of something like two and a half species to a genus was something new in botany and is therefore one of the very significant features of the book; so much so that we must give it a moment's consideration before passing to a study of the sequence of the genera. In order to realize the meaning of my statement that, for the time at which he wrote, the ratio of two and a half species is so great as to amount to an innovation in taxonomy, a brief comparison must be instituted. The 500 or 600 plants that the ancients had dealt with represented, in the great majority of cases, what we of to-day are accustomed to speak of as monotypic genera. Not any very considerable number of their genera are defined as consisting of two or more species; so that they had but one and a small 
fraction species to each genus. Fortunately for our comparisons the volume of Tragus deals with not very far from the same number of species as that of Dioscorides, and seems to have rather more than twice as many species to each genus; or, to express it differently an equal number of species is distributed to only half as many genera by Tragus as by Dioscorides; and this must be regarded as having been somewhat revolutionary, especially in view of the fact that Brunfels and Fuchs had much less perceptibly, if at all, departed from time-honored usage in such matters.

There may be reason to doubt that such a movement originated in the mind of Tragus himself. There are intimations elsewhere that as a new departure it may have been suggested if not advised by a mind more philosophic than his own. But this is a matter the investigation of which may be deferred. What should here be remarked is, that almost every generation of active and leading systematists during now nearly four hundred years has been divided upon the question of whether plants are more philosophically disposed in few genera of many species, or in many genera of correspondingly few species; and in Tragus' book we are at a kind of starting point in this perhaps endless controversy about the delimitation of genera. As perceptibly inclining to reduce the number of them he is again the forerunner of Linnæus.

Surveying now somewhat closely 62 consecutive pages of the first Ioo, we enumerate 45 species all in one line, and with a solitary exception, all at agreement as to certain very obvious characteristics. All of them exhibit fibrous roots, quadrangular stems, and opposite leaves. In $4 \mathrm{I}$ out of the 44 the leaves are simple and in no wise divided or even cleft. Here is proof that things had been selected and brought together under the guidance of definite morphologic principle. Also much time and toil must have been bestowed upon the getting together of so considerable a number of square-stemmed opposite-leaved herbs all at agreement in a general characteristic of leaf-outline. Some of them are much branched herbs in which no trace of quadrangularity is seen on the maturer branches, but only on the growing twigs; and it was the judgment of something like a botanical expert that brought such into line among the square-stemmed. It is also worth noticing that 4 I of the 45 are plants more or less aromatic.

The number of the genera among which the 45 plants are distributed is twenty. First in order stands Urtica with three species; then seventeen genera of the family of the Labiate; then the genus Valeriana with three species. As to the nettles proper and the 
labiate dead nettles, Tragus has order where in Brunfelsius there was confusion ${ }^{1}$; for the figures of the two nettles have Urtica printed over them, while the two dead nettles are respectively indicated as Galeopsis and Lamium. To these succeeds Marrubium with an array of four species. Only one of them is of that genus; two belong to a genus that had not at the time been proposed, that is, Stachys; the fourth is a plant that was destined to stand as prototype of the genus Lycopus. The figure well represents Lycopus Europaus; and this appears to be the first publication of the species, though he writes as if it were already familiarly known in the pharmacy of the time under the name Marrubium palustre. ${ }^{2}$ It is in the course of his definition of this too amplified Marrubium that he describes the fruiting calyx with its four naked nutlets; one of the most important characteristics of the whole family of the labiates; though as we have said before he is far enough from realizing the taxonomic value of what he has thus been the first to discover and describe. ${ }^{3}$ The presence of this pouch, as he calls it, with its four naked seeds occurring as it does in some herbs with dissected foliage, does not induce him to place any such in the same line with the nettleleaved labiates. His mind upon these matters is the mind of all antiquity, and of his contemporaries, dominated by the idea that likeness as to foliage and stem and root, together with agreement in sensible qualities, more surely indicate consanguinity than do similarity in respect to seed vessels and seeds. We shall meet with plenty of proofs of this.

Next after Marrubium the first considerable genus is Mentha. Tragus is aware that it is difficult, and says that quite a number of plants which some have regarded as mints others have referred to other genera. He seems to have a new view of his own, namely, that no plant is properly a Mentha that has not an upright mode of growth, with flowers separate from the leafy part, and borne in naked pedunculate spikes at summit of the stem. It is a group of mints that is sufficiently natural, and has been recognized as such by all special students of the genus of later periods. Tragus, as his four plates show, limits the genus to this group, disposing somewhat variously of the equally numerous species that have all their flowers in the axils of the leaves. As good a species of Mentha as that called Pulegium is excluded, and held as a monotypic genus, doubtless partly on account of its peculiar odor and its

: Page I 79 preceding.

2 Stirp. Comm., p. ro.

Ibid., p. 8. 
efficacy as an insectifuge, and partly because its stems are almost or quite prostrate; for in this antique classification by vegetative characters the very posture of stems was regarded as a weighty consideration, as we shall see later.

In the treatment of these plants now long known as the family of the Labiatce, Tragus, quite as if he had recognized the family and wished to keep the members of it in as close juxtaposition as possible, again does violence to one of the very fundamentals of the old system to which he has professed fealty. Rosemary and lavender are genera of labiates, square-stemmed, opposite-leaved, aromatic, and have the flowers and fruits of labiates, but they are shrubs; at least rosemary is, and the lavenders are strongly suffrutescent; therefore the proper place for them is away in Tragus' Third Book, among the woody growths, where also we find plenty of growths that are both smaller and less woody than either of rosemary or lavender; but he has both these here in the First Book, at the end of the line of the labiates, all the rest of which are herbs.

With this ending of the series of the labiates we are brought to about the sixtieth of our one hundred sample pages. The number of genera embraced within the fifty-nine pages is eighteen. All are genera of Labiate except the first, and that is Urtica. We have already seen how nettles and dead nettles were primitively regarded as of one and the same genus. The conceding that the two were generically distinct did not necessitate any wide sundering of them. The close resemblance between them as to vegetative organs, and the clustering of the flowers in the leaf-axils, betokened still a close consanguinity. To Tragus and his contemporaries the transition from Urtica to Lamium, so far from seeming to be abrupt, was a perfectly easy and natural one

That close against the aromatic labiates of herb and drug gardens Valeriana should be located is not so difficult to explain, now that we have Tragus' point of view; for the valerians, at least as to their basal and underground parts, are notably odoriferous; they are not indistinctly square-stemmed, their leaves are opposite, their inflorescence is of the verticillastrate type, and their flowers are bilabiate.

At this juncture the series of the square-stemmed and oppositeleaved is briefly interrupted. The intercalated genera are Asarum, Geum, and Ruta. But in the primitive classifyings aromatic properties were much deferred to, and inasmuch as this whole series, all the way from Lamium to Ruta, is a line of aromatic plants, the three above named do not interrupt it save only as to stem and leaf 
morphology, which, at least for the moment, is held subordinate to the qualitative.

After Ruta there is at once a return to the line of the quadrangular stem and opposite leaf. The genus is now Hypericum, and five species of it are described and figured. These harmonize with the main series as to an undivided foliage set oppositely and at regular intervals up and down square stems; and also as being notably odoriferous even if not distinctly aromatic like labiates. At the same time they have manifest points of contact with rue, that genus which they immediately follow; for their leaves are dotted, and small flatly opening yellow flowers crown the stems and branches. Next after hypericum stands the undershrub, Santolina, an anthemideous composite; and, viewed in the light of twentiethcentury taxonomy certainly rue and hypericum and santolina placed in line together make a motley order; but, what we are here in quest of is, the set of principles on which sixteenth-century taxonomy was grounded. We are certain that Tragus had his taxonomic reasons for locating santolina where he did, for he states them. Every one who knows the plant is aware of its being notably odoriferous; and he gives as one reason why it may well stand next hypericum the fact that its aroma is that of hypericum intensified. Now on the other side we shall find santolina flanked by two labiate plants; and in respect to its mode of growth, and its aspect as clothed thickly with small grayish foliage, Tragus says that in these things it well resembles lavender and hyssop and thyme. So then, judged by the criteria employed at that period, this was not a motley arranging of things.

From santolina there is a return to labiates. Two species are figured and three described. We wish to know why he thus separated them from the rest of their line. It would be interesting if we could learn his reasons for intruding almost into the midst of the line of the mintworts Asarmm, Ruta, the whole series of the Hypericum species and Santolina. There is one thing which gives to these last members of the line of labiates an aspect very unlike that of the others; for their leaves are much dissected, while in the line of more than thirty that precede rue and hypericum there is not one that displays any other than simple leaves. This short concluding series consists of compound-leaved species of the genus Teucrium. Did Tragus, blinded by foliage so exceedingly different, fail to see that these are true allies of that simple-leaved series that has been interrupted by rue and hypericum? We have the most positive proof that he did perceive the relation; for he says 
that the stems are quadrangular, that the flowers are verticillastrate around the stems, and that each comes forth from what he calls the seed-pouch, in which particular he likens them to those of hyssop and satureja. ${ }^{1}$ But in other instances besides this he is seen to pay such deference to the distinction of compound and simple foliage as to make use of it taxonomically. Of even this genus Teucrium one simple-leaved species is not only held generically distinct from those with dissected foliage, but is located I 24 pages away from them, where, by the way, on account of its veronica-like habit and foliage it is associated with several veronicas to constitute a genus Chamadrys. In his Third Book, in taking up the natural series of the pomaceous and drupaceous trees, the compound-leaved genus Sorbus in three species heads the series, quite as if by virtue of its compound foliage it had been regarded as the highest or most advanced type of its alliance. ${ }^{2}$ Again, the bulk of the umbellifers, all having pinnated or more dissected foliage, Tragus adopts as a natural alliance, following of course the botanists of remote antiquity; but Bupleurum, vested as it seemed to him in a perfectly simple and even entire foliage, he on that account excludes from the family. The genus Achillea, of the anthemideous composites, quite imitative of the umbellifers as to foliage and inflorescence, intervenes between Bupleurum and its compound-leaved affinities. ${ }^{3}$ Other proofs need not be adduced; for we must return to that group of dissected-leaved labiates that close the line of their cognates. They have brought us to number eighty of our one hundred pages.

With page eighty-one, and thenceforward, one notes an abrupt change, at least respecting the morphology of things; for within the next one hundred it will be rare to meet with a plant square-stemmed and opposite-leaved. The stems are now terete, and the leaves alternate; and in place of aromatic odors there is now everywhere a peculiar pungency of flavor to the herbage. The genera and species are, for a time, those of the family of the crucifers. There occurs at first an unbroken line of seven of these. The student to whom the book is not available will be helped by a list of the names. of the species:

Stirp. Comm., p. 79.

2 Ibid., pp. 1008-101 I.

3 Ibid., pp. $474-48_{3}$. 
Tragus

I. Nasturtium hortense

2. Nasturtium aquaticum

3. Nasturtium pratense

4. Thlaspidium

5. Alliaria

6. Thlaspi

7. Lepidium
Modern

Lepidium sativum

Nasturtium officinale

Cardamine pratensis

Lepidium ruderale

Alliaria officinalis

Thlaspi arvense

Lepidium latifolium

It will be seen at a glance that no taxonomic account is made of the pods in drawing up the line of those crucifers. Siliculose and siliquose genera are completely intermixed. It is just what Sachs, from his mistaken point of view, calls a "motley order." Yet there is a system in the arrangement of these seven crucifers, and it is plainly apparent. Draw a line between the numbers 4 and 5 and all above the line are compound-leaved, all below it simple-leaved. It is a natural arrangement, according to Tragus' notions-certainly very crude, sometimes-about the tests of affinity. From this point, however, the succession of members of this family is broken by the intrusion of eight species belonging to three other natural groups. The intruders are, two persicarias, five buttercups, and a rather peculiar plantain. Only at the end of such a line as this does he again take up the crucifers.

If in this procedure the German father seem chargeable with having abandoned the principle laid down in his Preface, I see no clear defense for hirn. If he had been intent upon collocating things by the criterion of "form," as he calls it, he must needs have kept the line of the crucifers uninterrupted by plants polygonaceous and ranunculaceous. He was botanist enough easily to have seen the marked contrasts of form between these plants and those crucifers that flank them in considerable file on either hand. Being such, these intrusions were not made by chance or whim. Apparently it is a case of the subordinating of taxonomic principle to the convenience of a multitude of those to whom morphologic marks would go for naught, and with whom a grouping according to useful qualities would be welcome. Let us understand how, with such a purpose before him, Tragus would not unnaturally break the succession of crucifers and interpose a line of buttercups.

Where the succession of square-stemmed opposite-leaved aromatic herbs ends in a fragrant teucrium, and the terete-stemmed alternate-leaved series begins with the garden peppergrass, I have characterized the transition as abrupt; but this was done with a 
mental reservation. Morphologically it is abrupt, extremely so. Qualitatively considered, however, the entire series, from the first labiate to the last crucifer has a common character; and Tragus realized this character and allowed it to influence his classifying. The whole line, or group, is one made up of herbs either aromatic or pungent, or both. Let us accentuate this fact by denominating the mint-lavender division of the series the spicy plants, and the peppergrass-buttercup end of it the peppery plants. Now if one should catalogue and enumerate all the aromatic-scented and all the pungent-tasting herbs that are, the aggregate of them all would be but a fraction of the whole number of herbaceous plants. Such constitute, I suppose, not much more than a tenth of all the herbs known to Tragus. But his thought is that such a qualitative thread as this, pervading many species, may be used to line them up by, even so as to include within the line here and there a few which in the particulars of their morphology are not at agreement with the others.

Now this first series of seven crucifers is made up of species the tender stems and leaves of which were eaten raw as salads, or else the crushed seeds were used as condiments. They are particularly pungent, or peppery crucifers. Even the name nasturtium, which half the species bore, the etymologists derive from that irritation of the nasal passages experienced during mastication of these things. It must here be stated that, after the interpolation of the buttercups, the resumption of the line of crucifers is made at the genus of the mustards, plants the ground seeds of which had been employed in medicine as counter-irritants from time immemorial. And there will be readers to whom the information will be new that the seeds of the buttercups are as pungent as the seeds of mustard and were long used for the same purpose of raising blisters on the skin. Yet this acridly pungent quality of them is expressed in the very names by which the commonest species are known in botany, that is to say Ranunculus sceleratus and Ranunculus acris. And Tragus was so familiar with all this, as to have been constrained to locate the Ranunculus species in the midst of the counter-irritants; for his whole volume was indited to a great extent in the interest of those who practiced, even rudely and primitively, the healing art. These would expect to find remedial equivalents treated of in contiguous chapters, and he was willing to meet their expectations.

The resumption of the line of the crucifers has brought us to the limit of the one hundred sample pages which we were to examine somewhat thoroughly in quest of the man's mind and method. And now, perhaps in no way may one more easily arrive at a still fuller 
comprehension of his method than by following him in his further treatment of the cruciferous plants. The list of seven species which, set in line, precede the buttercups, together with the line of five species that succeed the buttercups, amount to about half the number of this family which he figures and describes. The other twelve or fifteen are discussed in two groups, each widely removed from the present series and also from one another. This is because the author must conform to the ancient usage of treating ornamental plants all by themselves in one place, and the edible plants of the kitchen garden also apart from all others. Under these divisions, however, we find the crucifers in each well kept together. The ornamental kinds, to give them by later names, are Cheiranthus, two species of Matthiola, and Hesperis matronalis. ${ }^{1}$. The last is a little separated from the line; two other plants, both remote from the crucifers, but popularly called violets, being intruded. I entertain no doubt about Tragus' having perceived the real consanguinity subsisting between these wallflower-gilliflower ornamental plants-all known as violets-and the other crucifers; for in describing the wallflower he remarks that it belongs to the four-leaved-that is, the four-petalled-group of the violets, rather than to the five-leaved sort. Then again under Hesperis he describes the seeds of it as being enclosed in elongated and terete siliques like those of the cabbage.

For a glance at his final series of crucifers we must pass to the Second Book, where the topic is that of culinary herbs and roots in general. The series begins with cabbage, which is at once followed by the kales, plants the herbage of which and not the roots is the useful part. At the opposite end of the line occur in order the turnips, the radish, and lastly horseradish ${ }^{2}$; all these being so called root crops, the sum of the members of the family assembled at this point being seven; the line being divided according to nature of the roots as fibrous or fleshy. More than that, the cruciferous series is here again slightly interrupted; for just after the cabbage-kale series, and before that of the real turnip-radish series, two campanulaceous plants are intruded; both of them with fleshy roots so turnip-like in form, and in such frequent use in cookery as substitutes for turnips, that people call them wild turnips, or little turnips, so that this vernacular name became turned into Latin as Rapunculus, ${ }^{3}$ the earliest Latin name for the genus now long

1 Stirp. Comm., pp. 560-567.

2 Ibid., pp. 7 $6-735$.

3 The Latin for turnip being Rapum. 
known as Campanula. There are three crucifers described and figured, each of which stands isolated from all the others. One is Bursa pastoris. ${ }^{1}$ Its having been located so far from its allies of the peppergrass kind was but accidental. At the time of the printing of those, the shepherd's purse does not appear to have been well known to the author, and his first expression concerning it is that its rightful place is next to what he has called Thlaspidium, ${ }^{2}$ i.e. Lepidium ruderale.

Another of the isolated members is Camelina. ${ }^{3}$ In certain districts it is common, he says, in fields, especially among flax, to which he likens the plant, except as to its having small yellowish flowers. He reports that its seeds ground with grain impart a certain sweetness to bread; also that the oil expressed from this seed is, in his opinion, of a flavor superior to that of olive oil. From many a passage in Tragus it is evident he was accustomed to identify plants as of the cress and mustard alliance by a pungent flavor of the seeds. Possibly in Camelina they lack this quality. Possibly also our author, variously misled, never tested them in this regard, or thought of such an experiment; for he nowhere intimates that the plant is of that alliance.

The genus Isatis 4 is a second member of the crucifers whose relationship Tragus shows no sign of having recognized. Possibly he did not know the plant but by hearsay. His draftsman copied Fuchsius' plate of it, and in so doing made the mistake of representing most of the flowers as either five-petalled or six-petalled. It is also to be noted that the fruits of Isatis at first sight are sadly bewildering; pendulous like the samaras of the ash tree, which they also much resemble. In the next generation after Tragus, and by one of the most illustrious of all botanical systematists, Isatis was indeed referred to the crucifers; though even a century after that its right to a place there was disputed. Tragus will, then, be excused for not having guessed this thing to be a cressmustard ally; nevertheless in describing the fruit he proved that a German father of the sixteenth century in his going "straight to nature," might well have taken with him the old Greek father Dioscorides more often than he did; for Tragus, having described the pendulous pouches or bags that succeed the flowers avers, that "this pouch is the seed of the plant." Dioscorides in describing the

1 Stirp. Comm., p. 214.

2 Ibid., p. 82.

Ibid., p. 655 .

- Ibid., p. 255. 
fruit of Isatis had said that "within the pouch there is a seed"; and here Tragus' powerful rival, Fuchsius, by plagiarizing Dioscorides' whole account of Isatis had been right about its fruit and its one seed. ${ }^{2}$ It seems not improbable that a man as keen of botanical vision as Tragus, had been relying on other people's statements when he wrote that pouch and seed are here one and the same.

With the exception of these two, Camelina and Isatis, Tragus' comprehension of the group of crucifers appears to have been complete; and this will become still more manifest by an item of his taxonomic procedure still to be adduced. Fuchsius, as was related in the preceding chapter, guided by superficial resemblances in purely vegetative characters, and wholly inattentive to their small flowers and fruits, had received a hedge mustard and a small flowered vervain as members of one genus which he called Verbena. To Tragus this misplaced plant is so plainly of the mustard alliance that he becomes impatient of his rival's blunder. "This thing is about as much like a verbena as a nettle is like a rosemary bush. I could wish that none should be displeased with me for saying this; but I am aware there are some who will take it much to heart that I have transferred their Verbena famina to the category of the mustards, and judge me rashly for having done so. But it was reason that compelled me to this course, when I perceived the plant by its whole substance and flavor to be at accord with Sinapis." 3 Though he names the texture and flavor of the herbage as the reason, that is because it is the one which will appeal to most people, those into whose minds anthological considerations do not enter. It is none the less presumable that the diminutively mustard-like flowers, along with the pods and seeds so concordant therewith, first led Tragus to investigate the qualities of the plant.

Some twenty-six species of crucifers all told are described by Tragus. That is probably three times as many as may be found in any author earlier than he, except Fuchsius, who allows them to be scattered about according to the alphabetic order of their Greek names, and nowhere gives expression to a thought about their affinities. And Tragus, inasmuch as he plainly discloses his recognition of their consanguinity, except in the case of two species both of them anomalous, ought to be accredited as the first discoverer, so to speak, of this important and taxonomically interesting

1 Diosc., Book ii, ch. 180 .

2 Fuchs, Hist. Stirp., p. 330.

Stirp. Comm., p. I04. 
family. He did not, indeed, name the family. He was not, like the philosophic Theophrastus of old, given to using significant names for such groups of genera. But let us not here perpetrate a fallacy too common with historians, of attributing the discovery of a thing to the man who did but name it, after it had been discovered by another.

There are to be noted in Tragus not a few other instances of decided movement in the direction of a better grouping of genera; but only two or three more may here be allowed even a passing mention.

In our study of Fuchsius we had observed that, despite the alphabetic artificiality of his arrangement, by dint of stretching to the uttermost the application of the Greek generic name Strychnos (=Solanum), he had brought almost all solanaceous plants into one line ${ }^{1}$; but that while a thing as anomalous as Datura had thus gained admission to the company of its cognates, Capsicum had not been at all apprehended by him as a member of that group. He does not appear to have seen in it any likeness thereto. Tragus, while also doubtless like Fuchsius finding the peppery properties of all parts of the plant too foreign to those of other solanaceous genera, nevertheless observes that as to the form of its leaves, and especially of its flowers, it recalls Solanum. ${ }^{2}$ This was giving that serviceable hint by which later taxonomists were to be led to place Capsicum within the lines of the Solanacea.

The borrages are a group all the then known members of which are first brought together in unbroken line by Tragus ${ }^{3}$; and he has seven genera of them, embracing something like twice that number of species. All much alike in habit and inflorescence, but differing one genus from another very notably as to nature of the pubescence, and still more so as to form of the "flower," they again come to almost one and the same thing as to the calyx and its ... three or four naked seed-like nutlets; and all these peculiarities of the flowers, together with the aspect and character of the fructifcation, Tragus is the first botanist to describe; and he describes them for each genus. In all except the naming of it he is the founder of the family of the Borraginacea.

While there is evidence enough that this man's perceptions of plant affinity were keener than those with which any earlier author had been endowed, yet there was never with him any such thought

1 Page 209 preceding.

2 Stirp. Comm., p. 928.

Ibid., pp. 229-24r. 
as that natural groups of genera are very numerous; still farther from his mind was such an idea as that all genera may be reduced to a line of natural families. The time was not ripe for the engendering of that thought; nor was it to find expression until three generations later. The list of genera which Tragus can not systematize, as he had done those of the labiates, the crucifers, and the borrages, is a long one. But he must needs bring them all into some kind of grouping, or succession; and the principles upon which he collocates monotypic genera are various. We must take note of several of them.

There is one quite extended series made up of the following: Convolvulus, two species, Nummularia, Cuscuta, Humulus, Smilax, Dulcamara, Clematis, Bryonia and Lonicera. ${ }^{1}$ There is one character, at least a negative one, by whch all these are connectible. Not one of them has an upright stem. All are in some manner climbing; and twining and prehensile plants are much more exceptional, at least in cool-temperate latitudes where Tragus botanized, than one would suppose. Outside of this series now in hand not many were known to him; for the series does not end with Lonicera. To that there immediately succeed all the genera of cucurbits that are rough-leaved and are grown in gardens. ${ }^{2}$ The smoothleaved and unvigorous or delicate genera Bryonia and Momordica had not yet gained recognition as members of the Cucurbitacea. And if neither the twining leguminous plants nor the tendril-bearing are placed in this succession, it is for the reason that in their case, and ages befor Tagus, the principle of stem-posture had been subordinated to the higher one of their agreement with the upright and bushy kinds in a peculiar and distinctive morphology of flower and fruit. Tragus was perfectly aware of all this; and can not have had so much as a thought of including in this present line the weak-stemmed and prehensile peas and beans.

Sometimes one finds him placing two generic types in juxtaposition for no botanical reason, but only for what may be called a literary motive. The vine, the fig tree, the palm, the olive, and the bay are types not genetically interrelated ${ }^{3}$; neither to Tragus' knowledge was any one of the five related to any other tree. But in ancient history and poetry all had often been associated. They form a group, and that most historic and distinguished, but on the basis not of botany but of literature. And yet, as regards the after

1 Stirp. Comm., pp. 804-823.

2 Ibid., pp. 824-835.

3 Ibid., pp. 1049-1056. 
part of this line, comprising palm, olive, and bay, one would not dare either affirm or deny that these three had been botanically connected in the author's mind by their drupaceous fruits.

Repeatedly does he bring together two types in every way dissimilar for the sole reason that their names are practically the same; this of course in condescension to those who, in looking for a given plant under a certain name may find that and its homonyms all in one place. Thus at the end of the buttercups does he locate the herb called Coronopus (= Plantago Coronopus). It would be irrational to require of Tragus that he should have referred this to the genus Plantago. The floral structure which connects them could never have been seen until after the invention of hand lenses at least. The leaves of this Coronopus are cut into narrow and remote pinnated segments and beset with bristly hairs; on the whole as far from plantain leaves in form as imaginable. The form of these leaves had procured for the plant the name coronopus, Greek for crowfoot, and that very anciently. Ranunculus had also for a second Latin name Pescorvi, the exact equivalent of the Greek coronopus and English crowfoot. Because they had the same name our author placed side by side these different plants. He did the like with the labiate that was usually called Hedera terrestris, that is, ground ivy, locating it next the true ivy, Hedera Helix, as well aware as any one ever was that there is no consanguinity between them; but this disposal of it would suit the convenience of those untaught in better classification.

Nomenclature. No special attention is given to nomenclature by this author. He follows the usages of antiquity and of his own period, yet in ways of his own by which it comes to pass that he illustrates those usages uncommonly well. We have already observed that such family names as Umbelliferæ, Cichoriaceæ, Carduaceæ, Legumina for the leguminous plants, and Malvæ, for the malvaceous had been in familiar use time out of mind. Tragus essays the addition of a few new terms of that kind to comprehend other groups of genera; but these have not been successful; and the cause of their failure will readily be seen. He proposed the name Serpentariæ ${ }^{1}$ for that group of trailing, twining, and climbing herbs referred to above as embracing Convolvulus, Humulus, Clematis, and others; both the outlining and the naming of it being made, curiously enough, just at a time when taxonomists - even Tragus himself foremost among them-began to depend less upon the texture 
and posture of stems, and more upon characteristics of flowers and fruits. And his small group of the Lappæ ${ }^{1}$ was equally futile; for while this series might at first view seem to be connected upon a thread of fruit characters, a more attentive inspection brings it out that nothing more significant than the hooked character of the prickles investing the fruits holds the genera together; for they are Lappa, Xanthium, Trapa, Caucalis, and Agrimonia. Thus Tragus' two new family names, Serpentarice and Lappe, were both destined to suppression, because the grouping in either case was little better than fanciful; being based on agreement as to certain peculiarities that are of no general taxonomic value.

Upon the then settled principles of generic nomenclatureprinciples approved by all antiquity-Tragus attempts no inroads. It does not enter his thought to question the perfection of the established methods in naming things. A generic name of two words, noun and adjective, suits him as well as one of a sing'e term and that substantive; perhaps even better, as signifying somewhat more; for there is more of meaning conveyed by a noun qualified by an adjective than there is in a noun standing alone; and the time is yet distant when meaningless and cabalistic names will be tolerated. So when he becomes the discoverer of a new and nameless generic type that is an ally of Cyanus, the common cornflower, or bluebottle, though not of its genus exactly, he assigns the new genus the compound name Cyanus silvestris ${ }^{2}$; and we, well aware that half the generic names in sixteenth-century botany are thus made, must read his whole account of the plant in order to assure ourselves that he does not, after all, mean simply a new species of the genus Cyanus.

Fuchsius, convinced that the genus Plantago aquatica is identifiable as the Alisma of the Greeks, had taken up the latter name ${ }^{3}$; but Tragus shows a preference for the two-worded appellation and restores it; taking pains also to inform the untaught that, although the plant's name is Plantago aquatica, it does not belong to the genus Plantago.4

Even for Fuchsius' new genus aptly named Digitalis 5 Tragus thinks that such a two-worded name as Campanula silvestris would be better; and he formally proposes this as a substitute, writing

Stirp. Comm., pp. 836-844.

2 Ibid., pp. 2 I8, 2 I 9.

3 Fuchs, Hist. Stirp., p. 43.

- Stirp. Comm., p. 227.

- Fuchs, Hist. Stirp., p. 892. 
Digitalis down as a synonym. His remarks at this point illustrate well the idea then prevailing, that the nomenclature of newly proposed genera should be freely open to amendment and improvement. "Let any one name this plant what he will. We, in consideration of the form of the flower, shall name it Campanula silvestris, at least for the time being, and until a still more appropriate name shall arise. There are those who call it Digitalis."1

While Tragus, like others both before him and long after, leaves the representatives of monotypic genera without specific names, yet up and down the margins of a great majority of his I Ioo pages are the binary names of species. If many of these seem to consist of three terms, it is usually because two of them constitute the generic name. Occasionally the third word indicates that what is in hand is a mere variety of the species preceding; and now and then it will be seen that a fourth word is introduced to indicate the variety. In case the generic name itself is binary, the fourth term becomes needful for the indicating of a named variety. Still there is no trace in this author of those phrase names that became a burden upon the botany of the seventeenth and eighteenth centuries. The marginal placing of these binary names is as universal with Tragus as one finds it in Linnæus; but these same names are often repeated as headings to the chapters, and again over the plates. The author employs less freely the numeral adjectives for specific names, and has not many that are geographic. The personal names for species are less rare; though most of these are of earlier mediæval origin, commemorating saints of the Roman calendar; and he is perhaps the first of botanists to have dedicated a new species to himself. ${ }^{2}$

Ecology, Phenology. Tragus is far from emulating in any general way the endeavors of Theophrastus to indicate groups of plants ecologically considered; but there is one piece of such work that ought not to be allowed to pass unnoticed. The Third Book of his volume is to be devoted to the trees and to other lesser but strictly woody growths. Accordingly in the first chapter at its beginning there is introduced the figure of a large tree, a spruce tree, as we are able to determine from a branch or two of small dimensions which are all that remain alive; for the tree is moribund. All up and down its trunk there are fungi and lichens of several kinds; then upon the ground beneath are as many more. The text of the whole chapter, and it is a long one, covering seven pages, relates

- Stirp. Comm., p. 88 g.

2 Quinquefolium Tragi, Tragus, Stirp. Comm., p. 587 . 
exclusively to these plants, and a considerable number of them of various genera, embracing an aggregate of some thirty species. The next chapter treats of mosses; the third, of mistletoe. Thus the whole assemblage of German saprophytes and tree parasites is made one ecologic group, as of things growing together, many of them upon trees, most of the others upon the ground beneath trees.

Ecology, however, forms an item and a very distinct one in the account of almost every wild plant which he describes; a fact that will be best impressed by a few citations.

"Asarum affects shady places where the soil is rather moist, and is usually found under thickets of hazel, but sometimes also in deep damp woods." 1

"Alliaria is an elegant plant which in the month of April is found in certain waste places, under walls, along the bases of hills, by hedges and in cavernous places which are the abode of lizards and other vermin." 2 The chickweed is located thus: "This most common of herbs is found throughout the whole year in gardens and vineyards; and the richer the soil, the more large and tender the herbage." 3

Ranunculus sceleratus "grows in low swamps, especially if the soil be sandy, and preferably where there are frogs; but occasionally in very rainy years it will be found in wet lands that are more elevated." 4

"Fumaria grows in gardens, fields of rye, and also among flax, onions, and cabbages, where it flowers in May, and again in autumn it reappears in turnip fields. "5

The almost omnipresent knotgrass, Polygonum aviculare, he thus descants upon: "Polygonum among common plants is the very commonest of all, at the same time a useful one also. What part of the country is there where one does not meet with it? What roadside is there where it does not abound? What fields (for in cultivated fields it particularly delights): what hedgerows, and what by paths are not covered with it?"6

"Aquilegia, mostly a garden plant with us, also grows wild in elevated woodlands, on rocky hills, and sometimes in the crevices of precipitous rocks." "

'Stirp. Comm., p. 65.

3 Ibid., p. 85.

3 lbid., p. 384 .

4 Ibid., p. 93, under the name Apium aquaticum.

s Ibid., p. II I.

- Ibid., p. $39^{\circ}$.

'Ibid., p. 136 . 
In phrases like these does Tragus almost always particularize about the habitat, the soil, the expozure of the wild plants of Germany which he describes; and it would not be difficult to gather out of these antiquated and yet living pages definite outlines of the plant associations of every part of the country with which he was familiar.

The fungi, lichens, and mosses, already alluded to under this heading, are not the only plants in connection with which he permits ecological considerations to influence his taxonomy. $\mathrm{He}$ collocates in an unbroken series, as plants nearly allied, broadleaved houseleeks, and sedum species the leaves of which are small and terete. Such a series is of course a faultless one in the judgment of modern botany, because the structure of flower and fruit is the same in all; but the case was otherwise four hundred years ago, when anthology was hardly yet in embryo, and even leaves were more generally received as furnishing the criteria of affinity. Tragus had to defend the position he had taken when placing certain small plants regarded as leafless in the same line with live-forever and houseleek as their next of kin. He himself could not claim that Sedum acre and its cognates had leaves at all. They exhibited, he said, in what seemed to be the places for leaves, grainlike things which he preferred to call acini; and an acinus may be a seed, a grain, a germ, or even a berry. He has but one argument to offer in defense of this line of broad-leaved things and things green though leafless, as being a natural series, and that argument is purely ecological. All of them inhabit peculiarly the roofs of buildings, and thrive there much better than elsewhere. Even such of the species as now and then establish themselves on the ground are never seen but in the most open exposures. All of them everywhere avoid all protection from extremes of temperature, retaining their fresh verdure unimpaired under the rigors of the severest winter. ${ }^{1}$ Such ecologic groupings are of course traditional, having come down from earlier times; and under such defense as Tragus makes of this one, his contemporaries would perhaps admit its validity despite the great diversity among the members of it as to foliage.

Another instance of this kind of procedure to which I wish to call attention is the reverse of the above as to the result attained. German species of the rather ample genus Veronica are placed in widely sundered groups on principles as purely ecologic. In one 
place, under the generic name Sium non odoratum, he describes wisat is now Veronica Beccabunga, appending to his excellent diagnosis the following. "It grows around springs which never freeze, or in such ditches as are equally immune from frost during the whole winter." 1 Then the habitat of a second species of the genus- Veronica Anagallis aquatica is its Linnæan name-is given in similar terms: "Throughout the whole winter season this keeps its verdure quite untouched by frost, growing as it does in the water of warm springs." Now six chapters away from this which treats of the two aquatic veronicas, and with more than as many plants not allied to Veronica intervening, he describes the dry land members of this same genus, but under the generic names Chamedrys and Teucrium. ${ }^{2}$ These have retained in more recent botany those generic names as specific under Veronica.

Thus do we find that our familiar genus Veronica was all unrecognized as a whole by Tragus, its members being ranged in two rather widely separated groups, bearing different generic names; and all this in deference to mere ecology, as it were; for, if those of the aquatic group have a tender subsucculent and glabrous herbage holding its freshness all winter, whereas those of the dry land are thin-leaved, soft-hairy, and die down to the ground in autumn, and if these differences may have helped to keep the groups apart, yet are they anatomical differences rather than morphological. And the case can not fail to convince us of the weight which ecological considerations carried in sixteenth-century classifyings. Neither Tragus, however, nor any of his contemporaries had invented these ecologic distinctions. They were already an old, old story. Contemplate the mere name for those aquatic speedwells, Sium non odoratum. It is a generic name, because there are two very clearly distinct species of it. There is somewhat of early botanical history concentrated in that very name. It implies beyond mistake the existence of a genus named Sium odoratum. Still further it suggests as almost certain that the name Sium odoratum is less ancient than the other. Searching old records now, we shall find that things happened exactly after the manner which the name Sium non odoratum seemed to indicate. Sium odoratum, the original of all siums, was at first Sium, simply, that is, a monotypic genus. More than a thousand years before Tragus, and maybe two thousand or three, the Greeks had known, and had used medicinally, an aquatic of springs and spring runs

Stirp. Comm., p. I87.

2 Ibid., pp. 203-209. 
that never freeze. It had the foliage and the pleasantly odorous quality of certain umbellifers, as Dioscorides had intimated ${ }^{1}$; and this was Sium²; and centuries later when up in middle Europe men versed in the materia medica looked in wild springy places for the Sium of Dioscorides, and more often found there those different things, unknown to the ancients, which though green in midwinter were odorless, and therefore not the real thing, and named them Sium non odoratum, they were proceeding upon the principle that both, and all such plants, being generated as most of them believed, by spring water and the earth at the bottom, were naturally allied, and might all be named so many kinds of Sium. Furthermore, the establishment of such a name as Sium non odoratum rendered it needful that original Sium should be invested with a cognomen in order to avoid misunderstanding and confusion. Hence its later generic name Sium odoratum.

That this sium, constant inhabitant of springs and warm drainage ditches, is classed not ecologically but morphologically by Tragus argues no inconsistency. It would be one thing for a sixteenthcentury botanist to fail to recognize by morphologic marks the membership of the Scrophulariacece, and quite another thing to miss the family characters of any umbellifer. Sium at first glance, as well as by its properties, is unmistakably an umbellifer; and the time is not to be found in the annals of botany when this family had not obtained general recognition, marked as it is both morphologically and qualitatively. The family, so-called, to which the veronicas belong is not so. The Scrophulariacea have never yet been circumscribed otherwise than most arbitrarily and unsatisfactorily. Tragus understood well the superiority of morphologic over ecologic criteria, and that the latter are to cede to the former when the former are manifest. The anthologic harmony between hardy undying water veronicas and the tender perishable kinds of dry meadows and uplands it was not given him to see; nor, indeed, to any one until long after Tragus' day. And yet, an umbellifer to him was an umbellifer whether hydrophilous or xerophilous. But in the arranging of his umbelliferous genera it will be observed that the two aquatic genera Sium and Apium are placed side by side. ${ }^{3}$

To the botanist of the fields, the plains, the marshes and the

1 Diosc., Book ii, ch. 120.

2 The plant is Sium angustifolium Linn., type of the genus, though now called Berula angustifolia.

3 Stirp. Comm., pp. 464,465 . 
mountains it is easy to recall the special habitat of almost any plant, but not so the average time of its flowering year by year. To be able to say that this shrub will be found in bloom about the middle of May, that tree in the early part of May, this flower appears late in March, the other in the last days of April, is not likely to be a matter of unaided memory. To know the average time of flowering for everything that grows involves the keeping of written notes through years. Tragus tells this time of the annual flowering of things in almost every chapter of his book; and he is the first of botanical authors to have done this.

Transmutation. Though much given to diversifying his botanical pages by bits of invective against superstitions that are of theologic type, Tragus has never doubted the easy transmutability of wheat and rye into chess. In a long chapter he demonstrates to his readers how this may and does come to pass, under various conditions. And here some experimentations of his own are recorded: "That it is possible for seeds of one species to degenerate and become so changed as to come up as another species is something which I have learned by experience; for from very old cabbage seed sown by my own hands I have raised a crop of turnips."1 At another place he has the following upon the same subject: "There are those who think that a sowing of turnip seed upon very dry and sandy ground, especially if the seed be very old, will come up as wild mustard; or at least in that which is as much of the nature of mustard as of that of turnip. In the same fashion cabbage seed very commonly changes into that of a poor and stunted kind of turnip, as I myself have often proven by experiment."2

Again in his dissertation upon wheat he reports a certain darkgrained kind as apt to appear intermixed with the other in the low moist parts of the fields; so dark-blackish is his word-as to render flour and bread from such admixture dark-colored. He in perfect confidence accepts this admixture of dark-grained as another instance of transmutation; has never a suspicion that it is another variety of wheat, the seed of which was mixed by chance, in the sowing, with the other.

The case is one entirely apart from that of the melampyrum, or black wheat, of a totally different plant alliance, the seed of which, accidentally harvested with the grain and ground with it also 
caused a darkening of the bread; for on this weed he has a chapter apart, ${ }^{1}$ as well as another upon smut ${ }^{2}$ in grains.

From our view point of four centuries later it may not be easy to understand how such childish fancies could hold their places firmly in gifted minds which, after all, were seriously bent on cold scientific enquiry into all nature's mysteries and were often successful; but of the fact itself there is abundant proof.

1Stirp. Comm., p. 662.

${ }^{2}$ Ibid., p. 666. 


\section{CHAPTER VIII}

\section{EURICIUS CORDUS, I486-I535}

ONE of the most gifted and scholarly men among all who figured in German botany in the early sixteenth century is Euicius rCordus who, though a cultivator of plants, and also a zealous field botanist, wrote no great book, and is chiefly interesting here as having been the father and the educator of that most brilliant of early German botanists, Valerius Cordus.

Life. Henricus-the name was altered by himself in his school days to Euricius-was the thirteenth child of a pair of honest and worthy Hessian peasants, and was born at Siemershausen in the year I 486 . His parents died when he was a child, and in some way he became for a time the inmate of a collegiate school at Frankenberg. Here he formed a strong and lasting attachment to a youth, his junior by two years, who afterwards under the adopted name of Helius Eobanus Hessus became celebrated as a philologist and as one of the most elegant Latin writers of the period. On account of a treatise upon dietetics favoring vegetable foods, ${ }^{1}$ which in its day was well received and passed through several editions, Haller has enrolled the name of this Eobanus Hessus in his list of botanical authors. What influence he had upon botany was more indirect. It was evidently by virtue of this strong attachment between Hessus and Cordus that the latter was brought finally to devote himself to intellectual pursuits.

After those first school days at Frankenberg, and while Cordus was very young, he married and was settled at his native Siemershausen; in what occupation no records tell; but when in the year I 5 I 5 a son was born to him, the event appears to have stimulated him to renewed endeavors to attain distinction in scholarship; for before the son was two years old Euricius Cordus had won the Master's degree at the university of Erfurth; his special studies

1 "Præcepta bonæ valetudinis conservandæ" is the title of this treatise according to Haller, Bibliotheca Botanica, vol. i, p. 260. 
having been the ancient languages and philology, the same which his particular friend Eob nus Hessus had been all the while pursuing. The year following, i.e. I $5 \mathrm{I} 7$, we find him a student at Leipzig, where also he gives lectures on pastoral poems in Latin of which he is himself the author. Here also he makes a lasting friendship with the young Joachim Camerarius-father of the botanist of that same name-a much younger man than Cordus, and at the time a student at Leipzig, and who subsequently became distinguished in philology. Camerarius soon removed to Erfurth, and Cordus returned thither with him. Eobanus Hessus was still there, and the three determined to open there a select school of their own. That Cordus' lectures and poems had already earned for him a reputation is evinced by this, that his opening a seminary of learning brought him a letter of congratulation and good counsel from so great a celebrity as Desiderius Erasmus.

The time at which this new school enterprise was undertaken proved inopportune; a time when, in Germany, even the oldest and most renowned seats of learning were realizing the influences of that ecclesiastical and civil upheaval commonly called the Reformation; and Cordus and his companions closed their school in the year I52I. And now, as if in hope of thereby gaining a better, or at least a surer, living for himself and his family, he entered the medical profession. Without the means of journeying to Italy and maintaining a year's residence at the most celebrated school of medicine in Europe, that of Ferrara, a physician at Erfurth, one Doctor Sturtius, ${ }^{1}$ offered him financial aid; and at Ferrara, in 1522, Cordus received the Doctorate in Medicine at the hands of the venerable Leonicenus then 94 years of age and still active in the discharge of his professorial duties.

Returning now to Erfurth, Cordus practiced medicine during four or five years, and then in 1527 accepted an appointment to the chair of medicine in the newly founded Protestant university at Marburg; from which movement the historians infer, and not unreasonably, that Cordus had abandoned the Catholic faith and become a Lutheran. In this new position he found leisure for study and authorship, for he translated into Latin verse both the Alexipharmaca and the Theriaca of Nicander. both published by Egenolph of Frankfort, in I 532. Here also his own Latin pastoral poems were published, but without date, or name of publisher. Here also he wrote and gave to the public his one botanical work, the

- Winckler, Geschichte der Botanik, p. 76. 
Botanologicon, which closed his career as an author. This was published at Cologne in 1534 . In this he complains of oppositions and persecutions which he has had to endure at Marburg, such as had compelled him to accept a proffered appointment as City Physician at B1emen, to the Senate and Citizens of which city the book is dedicated. He died at Bremen in I535, at the age of 49 years.

The Botanologicon. ${ }^{1}$ The book is in the form of a colloquy between Cordus and a few friends of his, most of them away back in their younger years fellow students at Erfurth, all now men of middle age, physicians, pharmacists, or men otherwise interested in plants, at least the medicinal. As having been university students of medicine every one of them is assumed to be somewhat familiar with all the ancient line of Greek and Roman authors who had written on the materia medica, and whose books were still the standards of study and reference.

Euricius Cordus, even while young, and as yet aiming at nothing else but distinction in languages and philology, had been a great lover and cultivator of plants, training his child Valerius from infancy to know and love them. Then when through mad religious partizanship the universities of Germany began to suffer disruption and depletion, ${ }^{2}$ and Cordus with a family on his hands was obliged to prepare for a remunerative calling, he was trebly prepared to make a mark in botany. He was a genius. He was intensely a lover of plants. He was uncommonly well skilled in those ancient languages in which the old standards of the materia medica had been written.

The useful purposes which the Botanologicon has in view are several, and are essentially reformatory. Prominent among them is that of demonstrating that, through sheer ignorance, a considerable proportion of the jars and drawers and packets in the drug shops are falsely labelled. They are marked with the names of Diocoridean and Galenian roots and herbs, while commonly filled with things which can not be the same as those which the ancients knew and made much of under those names. If this was really the case it would follow that the lives of those in illness calling for a certain powerful remedy, were apt to be endangered by the administration, either of some drug wholly inert, or else with pro-

- Euricii Cordi Simesusii Medici Botanologicon. Coloniæ, apud Joannem Gymnicum, Anno I 534 .

2 The Botanologicon abounds in expressions deploring the adverse influence of the religious dissensions of the time upon the universities of Germany. 
perties aggravating rather than remedial to that ailment. It was a strong arraignment of the whole united company of the doctors and pharmacists of the time; and Euricius Cordus complains bitterly of the oppositions and persecutions that had followed him and driven him from place to place, while lecturing and writing in endeavors to correct this ignorance. He was not philosopher enough to comprehend that just this abuse and this feigned contempt are the very highest encomiums: the only attestations of his learning and genius which the envious horde of the criticized and the offended know how to pay.

In this colloquy, the Botanologicon, there are given many particular instances of errors on the part of the physicians and druggists as to plants. We have already noted, in our study of Brunfelsius, how that author mistook German species of Corydalis for the classic Aristolochia, thus, at once agreeing with, and confirming in their ignorance, the whole array of the German doctors and druggists of his time. ${ }^{1}$ Euricius Cordus takes up this case as one which easily. establishes that for which he contends. One member of his party reads from Dioscorides that Aristolochia has leaves like the bush ivy, i.e. well rounded and entire. ${ }^{2}$ This which the Germans call by that name has leaves dissected like those of rue. The leaves and even the flowers of ancient aristolochia were described as having an odor somewhat sharply aromatic; a quality of which there is no trace in these fumariaceous herbs. The root of these, it is confessed by all the party, are rounded and turnip-like, as Dioscorides and all the others of olden time had described those of Aristolochia rotunda; but that was the only point at which the Corydalis answered to the Aristolochia description. The fact was plain that people in comparing the plant with the ancient diagnosis of aristolochia, finding that the root agreed, became at once blind to all the points of disagreement. Among the many instances of this kind of error the author presents that of the druggists having mistaken the common wild plum of German woodland borders for the acacia of the ancients. ${ }^{1}$ The acacia had been described as a thorny tree, yielding a mild gum. In these two points the wild plum was at agreement with the old acacia description. They gathered this native German gum and made the accustomed uses of it, believing all the while that in this thorny tree they had the real gum-bearing acacia. Cordus invites

1 See page 173 preceding.

2 Botanologicon, p. 96.

3 Ibid., pp. 77, 78 . 
their attention to an important part of that classic diagnosis to which they all the while have been blind; that which says that acacia produces its seeds in a pod, after the manner of the lupine; and Cordus asks his party how this gum-bearing thorny tree that yields plums instead of legumes can possibly be believed to be the acacia? It would be easy to mutiply by twenty the examples of this kind which find mention and full demonstration in the Botanologicon; but the above must suffice. They are representative.

A'most every one who has written a few chapters of botanical history has made record of the fact that at first the botanists of middle Europe wrongly expected to find, and as wrongly believed themselves to have found there most of the plants that had been described by ancient Greek and Arabian authors. The discovery of the error and the correction of it have usually been credited to botanists of later centuries. But Euricius Cordus is the man who at the very outset, and himself a German, saw the magnitude of this mistake, and so clearly exposed it, that despite the rage of an incensed multitude of doctors and apothecaries, the reform began at once. If Fuchsius in his great folio of pictures had in many an instance corrected Brunfelsian errors as to the identity of plants, it was largely if not altogether due to his having studied and been guided by the Botanologicon. He pays full tribute to the importance of this work in his Preface, which was not written until after the demise of Euricius Cordus. In this Fuchsius says: "In this work of restoring botany Brunfelsius was succeeded by Euricius Cordus, a man of high integrity, great industry, distinguished as a poet, and a man of varied learning. What he accomplished for the elevation and advancement of botany so abundantly appears in his Botanologicon as to need no further commendation from us. But this I wish to say; that one so singularly qualified seemed worthy of a longer life, in which to have contributed to medical botany much more matter of the same high import."

At the time when the Botanologicon appeared, the illustrated folios of Brunfelsius were quite new, and the work is often referred to. On one of the earlier pages of this botanical colloquy there is such a record of contemporary opinion about the merits of Brunfelsius' book as can not fail to be interesting, and for the sake of which I shall attempt a reproduction of the whole passage.

Megobacchus. Since Gallus desires it, may we not all go out and botanize a while?

Ralla. Please grant us this favor. 
CoRDus. I am willing, and the more so as hoping to learn something from all of you.

Niger. You learn from $u s$ ?

Cordus. Why not? I have sometimes learned botany from illiterate women and peasants. I am not ashamed of gaining information from a child even, much less from you, men of learning. So whenever it pleases you let us go forth. I will not keep you back; nevertheless I, just as if none of you were here, shall follow my usual practice of taking along a little book or two. I take the greatest delight in these sallyings into the country, where I can have before me fresh and growing those herbs which I have read about at home, and may compare them with the pictures of others which I carry in memory; also taking such note of their names and reputed virtues, as I may gather such from old women whom I meet upon the way. By the use of all these means I am the better able to arrive at a sound conclusion, or at least a more probable opinion, about the identity of a thing.

Gallus. I wish that Brunfelsius had followed your course; for concerning a good part of his plants it will have to be said that he named them not according to their descriptions, but after the opinions of the ignorant vulgus.

Cordus. How do you know that?

Gallus. I have read his two volumes, and have compared them with Dioscorides.

Cordus. That was advisedly done; and if there are errors, we must overlook them, and stand by the things that are well and rightly said.

Gallus. What if, in the meantime, by virtue of that authority which a new and plausible work must carry with the unlearned, those old errors which ought to have been eradicated, are only made to strike root still more deeply? I do not think this a matter to keep silence about.

CoRdus. Speak out, then; and if you wish to, cry aloud.

Gallus. This should be your province rather than mine.

Cordus. Cordus himself is too unlearned to undertake that piece of criticism. Let him address himself to the task who may choose to; I shall only indicate, with all candor and open-heartedness, some things which I do know and stand by; yet all the while ready at any moment, and without a blush, to be taught by any of you who may know better than $I$.

RALLA. What are we waiting for?

Cordus. Young man, lay aside that genteel cloak, and carry this little volume of Dioscorides. 
Niger. You advise well; this author alone suffices.

Gallus. I have the two volumes of Brunfelsius.

Cordus. If it please you, we will first enter this my little garden by the house. ${ }^{1}$

The conversation carried on between the five friends while on this botanical excursion constitutes the body of this rare booklet of I 85 pages, and gives a clearer insight into the state of medical botany in middle Europe in the time of Brunfels, Fuchs, and Tragus, than could be gathered from the most exhaustive study of those author's folios themselves.

1 Botanologicon, pp. 26, 27. 


\section{CHAPTER IX}

\section{VALERIUS CORDUS, $15^{1} 5^{-1} 54$}

Hitherto Valerius Cordus remains almost unknown except by name. Not one of the four of his own countrymen who wrote botanical history within the nineteenth century ever looked into Cordus' writings - all of them published after his early deathfar enough to see whether he had been least or greatest among German botanists of the sixteenth century.

Sprengel says that "Valerius Cordus, son of Euricius, if he had lived longer, might have given to his works a certain maturity which is conspicuously wanting to them" ; ${ }^{1}$ after which anything but laudatory opinion he proceeds to give the young man full credit for having travelled widely in many parts of Germany, and for having discovered and published a goodly number of new plants.

Of a very different tenor is the language of Ernst Meyer: "A splendid and all too transitory phenomenon was Euricius Cordus' son Valerius."'2 While in my view this opinion of Valerius Cordus' merits is not extravagant, still Meyer, as it seems to me, fails to show reason for such high praise. He does much better than Sprengel; yet I am obliged to infer that he borrowed the opinions of sixteenth- and seventeenth-century authorities on Cordus, rather than as having made the young man's writings a subject of careful examination. The estimate of the best botanists of two generations after Cordus was an exalted one, as to his merits; and that outside of Germany.

Sachs in his volume of history seems to have found it easy to adopt Sprengel's tone of indifference to this youth of rare genius. "For the present," he says, "we pass by Valerius Cordus, Conrad Gesner, Matthioli, and several others of no importance," 3 etc., etc.; and this is the only reference to him which I have been able to find

1 Hist. Rei. Herb., vol. i, p. 346.

2 Geschichte der Botanik, vol. iv, p 3 I 7 .

3 Sachs, Geschichte, p. 3 I. 
save mention of the fact of his having observed the sensitivity of certain leaves. ${ }^{1}$

Such conflict of opinion on the part of nineteenth-century writers has seemed to make it incumbent on me to determine if possible, out of Cordus' writings themselves, why it was that for nearly two centuries before the nineteenth he was held in such esteem by accomplished botanists of every nationality in Europe.

Life. Valerius Cordus was born in the year I5I5 at Siemershausen, where also his father Euricius Cordus had been born. There is a beauty and a certain pathos in the story of how the destined father while a boy had made fine progress on the road to higher learning, and then by an early marriage, evidently in poverty, seemed to have extinguished all hope of a scholar's career. Yet when this son was born, the young father's zeal for learning returned; for to the child there must be given every advantage of high education; and he himself would be the educator of his Valerius. In some way he managed, as we have already seen, to go to the university of Erfurth, where he very soon obtained his first academic degree. Thenceforward he supported his family by teaching and lecturing until other degrees had been gained, and he was settled in the profession of medicine; meanwhile training his boy carefully in the ancient languages, philosophy, and the sciences, among them botany in particular. We have a biographer's testimony to this. "Valerius Cordus was imbued with an incredible zeal for learning thoroughly not only medicine, but also the right recognition of plants, to which latter his father Euricius, a physician and also an illustrious poet, urged him by both precept and example; for he had reared the child even from the cradle in the midst of herbs and flowers." 2

Cordus took his degree in medicine at the univers ty of Wittemberg, and there shortly after gave regular lectures on Dioscorides, and with such marked acceptance that to the audience of medical students certain professors joined themselves. ${ }^{3}$ It must have been earlier than this that he prepared his Dispensatorium, or manner of preparing all medicines, the only work of his that was printed in his lifetime, and which was a great success. He had not even intended it for publication, but appears to have written it as a pas, time while with his uncle, Joachim Ralla, an apothecary at Leipzig.

1 Sachs, Geschichte, p. 579.

2 Walter Riffius in Preface to first edition of Cordus Annotations on Dioscorides, Frankfurt, r 549; also to Strasburg ed. of Cordus' works, I 56 r.

3 Meyer, Geschichte, vol. iv, p. 3 r 7 . 
But the uncle thought so highly of the manuscript that he placed it before the magistracy of the city of Nuremberg, and they ordered it printed. ${ }^{1}$ It was first published in $\mathrm{I}_{535}$, was often reprinted during the next 150 years, and was even translated out of the original Latin into French. ${ }^{2}$

The Annotations on Dioscorides, being a kind of abstract of his Wittemberg lectures, were not published until five years after his death, and were never by Cordus himself prepared for the press; perhaps not even so much as once written down by him at any time; for the printer's copy, when it came to the printing, consisted of the notes of a student who had been his auditor, whose note book was found available. ${ }^{3}$

In this kind of work young Cordus is before us in but the ordinary rôle of the early sixteenth-century botanical scholar, a master of the ancient languages, delving deeply into the medico-botanical works of Greek and Roman antiquity, and laboring to correct, amend, and in some degree perhaps augment the ancient pharmacopeia. To have been able to accomplish so much in this direction, and that while yet hardly having attained to manhood, was in itself a proof of genius. To understand the exalted character of this genius it is only necessary to canvass what the youth had also attained to along other and different lines at the same time.

In field work in Germany, for botany alone-not to speak of geology and mineralogy, in both of which he was, for his time, an expert - he had wrought out more results that had his older contemporaries, Brunfelsius, Tragus, and Fuchsius combined. In his repeated journeyings to the great forests and wildest mountain districts, it is estimated that he discovered several hundred new plants. 4 Sprengel has given the Linnæan names of some twentyfive of these new discoveries of Cordus; and that is perhaps double or treble the number of novelties gathered in by the whole three above named; and they both were men of longer life and more or less extensive travel. At the time when Cordus' field studies of Ġerman botany were in progress nothing had ever been published bearing on Germany in particular as to its plants. The investigator of the botany of its forests, fields, and mountains had no other descriptive resources than the folios of Theophrastus, Dioscorides, and Pliny. Even Brunfelsius' book, which had appeared when

- Meyer, Geschichte, p. 3 I 8.

2 Haller, Bibliotheca Botanica, vol. i, p. 282.

3 Meyer, Geschichte, vol. iv, p. 3 r 8.

- Haller, Bibliotheca Botanica, vol. i, p. 28 I. 
Valerius Cordus was sixteen or seventeen years old was, as to its descriptive text, nothing but the reiteration of ancient botany. Soon after the publication of that work Euricius Cordus had publicly cautioned men against expecting to find all the trees, herbs, and flowers of Germany described in the botanies of the ancients, who had known but the plants of the very different region of the Mediterranean Sea. This was nothing like an intimation that the books of the ancient scould not be serviceable to students of German botany, and might therefore well be closed and laid aside. That would have been the proposition of an ignorant man and a charlatan; never of one of reason and erudition. The fields, the gardens, culinary and ornamental, the orchards, waysides, and hedgerows abounded in plants cultivated or naturalized which, in part purposely and in part fortuitously, had been brought into Germany from the South and from the East; and the discussion of just these formed no small part of the phytography of antiquity. All this had been clear to the elder Cordus, and was as easily comprehensible to the younger. But there must now be conveyed a better notion than we have yet gained of the rare subjective equipment wherewith young Valerius went forth to the botanical conquest of the great German forests and unexplored mountain districts. On this we have the following from a contemporary once before quoted.

"To the best possible education of an intellect naturally keen, there was united in him that happy temperament to which nothing is impossible, or even difficult of attainment. To these gifts he added a truly marvellous industry and assiduity in research; and above all a most wonderfully retentive memory for everything he either saw in nature or read in books. In this he so greatly excelled as to be able to carry in mind in their entirety descriptions of things which he had not seen but was looking to find; thus having the descriptions always available whenever occasion called for the use of them."1

Probably it is not unusual in modern botany for one who is afield to carry in mind, as gathered out of books, the essential characteristics of certain plants not yet met with, so that he is able to recognize such the instant he first sees them; but it will come as a revelation to most botanists of the present, that just this thing was being done almost four centuries ago, by a German boy in his teens, and while as yet the only plant descriptions extant for him

1 Riffius, in Preface to Cordus' Annotations on Dioscorides. 
to memorize were those of ancient Greek and Roman physicians, philosophers, poets, and historians.

In the year I540, when Cordus was twenty-five years of age, he had in manuscript among other things four books which he had entitled Historia Plantarum. The four books contain an aggregate of 446 chapters, each devoted to one species; so that in this manuscript he had described that number of species. The work embraces a part of the results of his travels at home in Germany. Finished, as to these four books, as early as 1540 , the work was not published until I $_{5} 6 \mathrm{r}$, or seventeen years after Cordus' death. We shall get an idea of the wealth of these pages in botanical matter entirely new if we but glance at the contents of Book I. The first four types described are, in modern nomenclature, Drosera, Gratiola, Sagittaria, and Bistorta. Every one of them, at the time when Cordus here described them, was new to science. Bistorta had been figured by Brunfels, though guessed by him to be one of the dracontiums of Dioscorides, and not described.

In the year 1542 Cordus went to Italy, dividing his time for nearly two years between the universities of Padua, Ferrara, and Bologna, where he made the acquaintance of Luca Ghini, reputed the most accomplished botanist of his time, but of whose greatness only the tradition remains, because he published nothing; thence he proceeded to Florence, Pisa, Lucca, and late in the summer of 1544 , to Rome. The misdirected and ungoverned zeal with which he prosecuted this summer journey in a southern climate cost the young man his life. In the company of two friends and a servant, while tending Romeward, he ranged everywhere from the cool mountains down to the heated and malarious marshes of the seaboard. Almost immediately on reaching Rome, Cordus fell ill of a fever and died there in September, I544, at the age of 29 years. His body found its resting place there in the Church of S. Maria de Anima, where there is a long Latin epitaph, ending with the lines ${ }^{1}$ :

Ingenio superest Cordus; mens ipsa recepta est Celo; quod terre est, maxima Roma tenet.

The botanical outcome of these Italian journeyings was a Book $\mathrm{V}$ of the Historia Plantarum, consisting of descriptions of 25 plants which he had studied in that country, as not having been met with by him in Germany. This work was first published at Strasburg in ${ }_{15} 6_{3}$; then again reprinted at late as $175 \mathrm{I}$, in the large folio entitled Opera Botanica Conradi Gesneri.

1 Gesneri Opera Botanica, vol. i, p. 20 (1751). 
Cordus left no dissertations on the philosophy of plants; but only his descriptions of some 500 species; and it is out of these fragments, all posthumously published, that we gather proofs of his resplendent genius.

Phytography. When some years after Cordus' death the manuscript of the Historia Plantarum had been sent to the erudite Conrad Gesner at Zurich, in hope that he would approve the work and procure its publication, this worthy, in his letter of acknowledgment-subsequently printed-says that the four books are "truly extraordinary because of the accuracy with which the plants are described."1

Almost a century and a half later Tournefort named Valerius Cordus as having been "the first of all men to excel in plant description." 2 Then coming down to the time of Linnæus we shall find the very learned botanist and historian Haller still more pointedly crediting Valerius Cordus with having been "first to teach men to cease from dependence on the poor descriptions of the ancients, and to describe plants anew from nature."'3

This, then, appears to be Cordus' title to special distinction among German botanists of the sixteenth century. He is the inventor of the art of phytography. This is saying very much, and the warrant for it must be shown. In our study of Tragus we observed that he, writing in Geıman, and for popular reading, also without thought that his writing would ever have the helpful accompaniment of pictures, used an originality and a minuteness of detail in his descriptions of many plants that were quite new in botanical writing. It is one thing to write popular plant descriptions for every class of readers, and quite another to institute a set form of describing them, and that in the common language of the world of learning, and as if for learned botanists only. Just this is what Valerius Cordus did, thereby actually creating a phytography of a new type. And this new phytography had in view the philosophic end of doing away with the need of pictured illustrations. A leading purpose of Cordus was to demonstrate that every species could be so characterized in words as to be identifiable by description alone. It is, indeed, the only reason there ever was at any time in botanical history for describing plants; and the remotest ancients, when one of them undertook to describe a plant at all did it not so badly, but often very well. The trouble they made

1 Gesner, in letter to Hieronymus Heroldus, Cordus' works (r 56 r), p. 85.

2 Tournef., Inst. Rei Herb. vol. i, p. 26.

3 Haller, Bibliotheca Botanica, vol. i, p. 282. 
was through giving but the names and medical properties in the majority of instances. Euricius Cordus had expressed himself in print as to the unreasonableness of hoping to find the names of all German plants in Dioscorides and Pliny; and the logical sequence was, that German types unknown to the ancients ought to begin to be named and described. Knowing the intense devotion of the father to the son, and recognizing the zeal and ability of the latter, it is not possible to think of Valerius Cordus' work of describing German plants as having had other than this origin. It was likewise of deliberate purpose that the help of the engraver's art was to be dispensed with, as being unnecessary where the verbal descriptions are what they ought to be, except to the untaught, to whom descriptions are useless; for whom, however, Cordus did not pretend to write.

That which I here affirm is a fact which became obscured, and was in effect contradicted, by the editor and the publisher of Cordus' posthumous works; for the folio appeared almost throughout bedizened with woodcuts of plants, to the number of some 280 figures; a condition of things which Cordus could not have dreamed of as possible, and to which, living, it is most improbable that he would have consented. It was by urgent demand of the printer and publisher that figures were inserted. He evidently considered them to be indispensable to the financial success of the undertaking; and most probably he was right in that. The proposal to publish Cordus' works came at the time when the new iconographic movement that had been inaugurated by Brunfels thirty years before was at its high tide of public favor; for Fuchsius' larger and more specious volume with doubly numerous plates had followed, and even Tragus had at last come out in an edition with 567 figures. It was not a time when the publisher would look for the success of a volume of plant descriptions in Latin unaccompanied by figures. The Strassburg printer, Rihelius, prospective publisher of Cordus' Historia, was in possession of the plates of Tragus' work and desired Gesner as editor to make use of them in as far as possible to illustrate the text. Gesner acceded to the proposition, and did as well as he could, yet not altogether very well; for there were some of Cordus' plant discoveries that were quite unknown to Gesner; moreover, the latter sometimes erred rather sadly in his interpretation of Cordus' diagnoses. Altogether, the attempt to illustrate by those old woodcuts the beautiful texts of Cordus has led to much misunderstanding and many errors in the interpretation of his chapters; the errors being in the main such as have 
arisen from incautiously concluding the identity of a given plant from the figure which Gesner by mistake associated with the description, rather than from the description itself.

This is not the place for indicating severally the errors made, as editor, by Gesner; but it may be well just here to call attention to the serious mistake made by Tournefort when, justly lauding Cordus' merit as a phytographer, he said also that he "did not disdain to make use of plates." 1 He had not read Gesner's letter prefatory to the History, with its apology for the introdution of the plates; and many another since-even Linnæus among them-has been chargeable with the same oversight, to his own humiliation.

I suppose Valerius Cordus is the first in all history to have formulated for himself a definite plan or model of botanical description. There is a plan which he follows with such uniformity as to leave not the least room for questioning that he had studied it out for himself; and he presents it by example only, without formal announcement, without explanation, defense or apology, and on its obvious merits. In this plan of his we have the first foundation, and the actual beginning of modern phytography; therefore we must analyze it carefully.

I. There must be a plant before him, a living one; for, while in his day herbarium specimens, especially of uncommon plants, were in the possession of some botanists and pharmacists for purposes of identification, Cordus would not have had the temerity to offer the diagnosis of a dead fragment, or even of a more complete dead specimen, for a plant description. That innovation on phytography was not attempted until two centuries later.

2. The subject must be mature, or at least in flower; the fruit to be waited for if it must be, and described later; for Cordus describes flowers, fruits, and seeds invariably if at all available.

3. He begins with those parts of the plant that are most obvious as it stands living before him. If the foliage is most conspicuous, and the stem insignificant, as in a dandelion or a sundew, he begins with the foliage, proceeding thence to the stem; otherwise the stem is first described, then the foliage.

4. The flower is taken up next in order, the actual diagnosis of it being proceded by a mention of the time of year when the flowering occurs. As to the floral organs, while neither calyx nor corolla has its name as a separate part, he manages to describe both, and always very accurately.

1 Tournef., Inst. Rei Herb., vol. i, p. 26. 
5. Fruits and seeds are described with great precision. In the case of capsular fruits if the cells are several he tells the number of them and notes the lines of dehiscence, often giving not only the color and the form of the seeds, but the number of rows they form within the capsule.

6. The root is always the last part of the plant which Cordus describes. This, as has been remarked in an earlier chapter, is the inconspicuous or at least the hidden organ, the one that has to be unearthed often with difficulty; and if physiologically and biologically speaking the root is the first of plant organs-and Cordus must have known this, or at least might have learned it from Theophrastus-phytographically it is perhaps well enough regarded as the last; for it is perfectly natural that a man in describing a plant should begin with those parts that are obviously before his eyes, and then proceed in a search for those that are hidden away.

7. In describing herbaceous plants Cordus never fails to state the natural duration of the species if he knows it. Everything with him is annual, or biennial, or perennial. He is far more careful about this than most botanists of the present.

8. To the morphology of things he adds faithful reports of the odors and flavors, whether of foliage, flowers, or roots; and he is so distinctively phytographic as to make the briefest possible mention of medical qualities. This all the more clearly reveals in him a purpose to separate between descriptive botany and economic botany; for as a young physician he was particularly distinguished in pharmacy.

The boldest innovation that was made by any botanist of the whole sixteenth century, in whatever part of Europe, was that of Valerius Cordus when he proceeded to describe anew, and according to his own phytographic scheme, some of the best known and even best described plants of Dioscorides. And yet the ultimate success of the innovation might have been foreseen, doubtless was foreseen, by the young author. The reader must here be given one example of Cordus' new description of a very old medicinal plant; contrasting his with that of Dioscorides.

Dioscorides, Book II., Ch. I62. "ARUM, called Lupha by the Syrians, sends up leaves like those of Dracunculus, but larger and less spotted; stem purplish, nine inches high, bearing something like a pestle, upon which the red seeds grow; rootlike that of Dracunculus white."

VAlerius Cordus, Hist. Book I., Ch. 50. "ARum in early spring sends up its leaves each rolled together like a cloak and the roll 
slenderly pointed; these gradually expand and assume the outline of an ivy leaf, though they are much larger, sometimes attaining the length of nine inches, ending in a point, but widening below, yet receding into a sinus where joined to the petiole. In certain localities the leaves are purple spotted. At the same time of the year it sends up another rolled up cloak ${ }^{1}$ which rests at the summit of a short upright stalk, and which about the middle of May opens to something like the form of a rabbit's or a donkey's ear, and shows within that which may be likened to the pestle of a mortar, is of about the length of the little finger, erect, oi a dull purple or ashy color, and rests on a kind of roughish tubercle, beneath which there is another tuberculation of the same size, but paler as to color. This last-named tuberculation, after the one above it and the pestle have withered, grows to the size of a walnut and takes on the aspect of a bunch of red berries, each berry containing a seed or two a little smaller than a lentile. This thing ripens at about the summer solstice, and the knot of shining berries and its stalk are all that remain visible of the plant at that time; and when these have fallen away everything disappears. The plant is from a bulbous perennial root of the size of the first joint of the thumb, white, delicate, which is found in a shrunken and withering state under the growing herb, yet after the withering of the herbage is found increased in size and firm. It sends out many eyes or tubercles by means of which the plant is propagated. Every part of the herbage exhales a heavy odor, and is so acrid in flavor as to afiect the tongue and palate of him who tastes it as if he had swallowed thistles or briers. The plant inhabits shady places in deep woods, or old and shaded drains and ditches, or along hedges. Some cultivate it in gardens."

Cordus' descriptions of new types discovered by himself do not differ in plan from the above. Some such are longer, others shorter, according to the requirements of the plant itself as examined by him in minute detail. One sees that in them all the same attention is given to the morphology, and also to the life history of the plant in as far as this is known to him. In his practice of describing each species both morphologically and biologically, he is a herald of our late nineteenth and early twentieth century writers who, now that we have the microscope, give life histories with minuteness of detail before impossible.

It will also be observed that Cordus' descriptions of plants

1 Cordus' Latin word here is involucrum. 
are lengthy. The writing them over again in the descriptive terminology of eighteenth- and nineteenth-century phytography would reduce the number of words by at least one half, if not by two thirds, yet would not greatly improve them as to their definitive quality. But the same thing may be said of hundreds of more than equally lengthy descriptions of species published very recently.

Vegetative Organs. One meets with a new term or two in Cordus relating to vegetative organs; and new terms, with a man of his mentality, mean new thoughts. Foremost among such new terms of his is coliculus, i.e., cauliculus, or caulicle, diminutive of caulis, a stem. This caulicle appears as the very first word in the descriptive account of an herbaceous plant newly discovered in Cordus' day, now known as Calla palustris. The only organ this plant has which Cordus could possibly have identified as any kind of stem is that part now for some time known as its rootstock, or rhizome. The account given of these caulicles is, that they are spread about over the ground, are about a foot long, of the thickness of one's little finger, are green, glabrous, and jointed; that from each joint white fibrous roots descend into the ground, and broadbladed leaves arise above them, ${ }^{1}$ etc., etc. Every other botanical writer all through the long ages had called every such thing a root. Theophrastus alone, and that seventeen centuries earlier, had gone so far as to register a doubt about the propriety of classing them with roots. Cordus is the first to publish a decision that they are primarily of the nature of stems. Note also that the name he assigns this organ is one that accentuates its stem characteristics, veiling those conditions which had led to its having been denominated a root. Such prudence in the selection of a name for the organ evidences a philosophic mind. He might have named the thing as rootstock or a rhizome; thereby, however, veiling those stem characteristics which he wished to impress, and accentuating the very things which had led to their being mistaken for roots; and so the adverse critic would have made light of the whole affair; pointing out that one says it is a stem, yet names it by a name which seems to say that after all it is a kind of root. It is very possible by the injudicious naming of a scientific discovery to retard the acceptance of the discovery itself.

Cordus must not be thought of as having regularly defined these horizontal root-like stems, or as having even recognized them in all their phases as being of the nature of stems. Their distinctly 
articulated and leaf-bearing character is in many cases far from being obvious. Such plants as iris and acorus are credited by him, as they always of old had been, with having thick fleshy horizontal roots. But he is none the less first to name as stem any form or phase of rootstock or rhizome, and all the merit of such fine organologic discovery belongs to him.

The occurrence of adventitious roots at the lower joints of large culms Cordus remarks upon admiringly. He names them fulcra, not perceiving that at their very earliest starting forth from aerial joints they are roots. He makes the subjoined comment on them as he has studied them in the Indian millet: "The plant has many obliquely descending and quite firm roots, but is not content with these; for when the culm obtains its growth and begins to be top heavy with leaves and the growing spike, it sends down from its inferior joints certain braces which, when they reach the ground put forth roots and fibres. Through Divine Providence, by means of these braces the plants more securely maintain themselves erect against the force of winds." 1 The same is stated more succinctly and briefly in his account of Indian corn. ${ }^{2}$

There are intimations that Cordus is not content with the notion that leaves may spring from roots immediately, but that leaf bearing should be the prerogative of stems, or of that which represents them. When having in view a plant the leaves of which form a rosette hardly raised above the level of the ground, he seems purposely to avoid writing them down as radical leaves, or root leaves, and is wont to describe them as radiating "around" the root. It is an evasion, certainly; but it subserves its purpose; for he thereby escapes the necessity of saying that they grow from the root. But again, in describing some garden biennials, like the carrot, the part to which the leaves are attached is visibly distinct from the fusiform root, though it is extremely short, too short to be called a stem, and he denominates it the caput, ${ }^{3}$ the head above the root. Only tardily has botany come to approve, formally, this one of the improvements in organography which it owes to Cordus. It is now taught that such apparently radical leaves grow from what is called a crown, and is understood to be but a shortened and thickened stem; but the teaching is still ineffectual to altogether prevent our occasional speaking and writing about stemless plants and root leaves.

1 Hist. Pl., p. I43.

2 Ibid., p. II 2.

3 Ibid., p. I03. 
To the fundamentals of leaf morphology I have not found this author contributing very much that is new; but his descriptions show him always carefully discriminating between the equally and the unequally pinnate in compound leaves. Not that these leaves have yet been formally designated as "compound." They have not been, nor will they be so named until after the lapse of more than a century after Cordus' time. The epoch is one of discovery, not of always naming the thing discovered.

But Cordus is the man who first reaches the conclusion that an organ need neither be green colored nor horizontally explanate in order to be a leaf. It seems to have fallen to his lot to describe but two orobanchaceous types. In the case of the first of them it is evident he had not yet seen that the colorless scales investing the base of the stem have the nature of foliage; for he says "the plant is destitute of leaves." 1 Some years after this, travelling in Italy, he becomes acquainted with another and much more scaly member of this alliance. His opinion respecting what the scales are now undergoes a change. "The dense investiture of scales upon the stems of this plant, all of them pointing vertically, are to be interpreted as being its leaves." 2

Anthology. Among botanical authors of his time Cordus alone gives some attention to inflorescence. $\mathrm{He}$ is the first after Theophrastus to have noted the distinction of the centripetal and centrifugal in anthesis; or, to state it otherwise, of the indeterminate and determinate in inflorescence; and every historian of botany appears to have overlooked this. Meyer writing on this topic little more than a half century since says that, in as far as he is aware, all the way from Theophrastus down to the times of Link and Robert Brown, no mention was made of these distinctions. ${ }^{3}$ Cordus' writings antedate those of the worthies last named by almost three centuries; and Meyer can not have taken the time to read them; for it is a very common thing with this German youth, in describing plants spicate or racemose as to their flowering, to say that the expanding of the individual flowers proceeds from base to summit of the axis, and that thus the succession of the flowering is prolonged indeterminately as it were, and may continue indefinitely, through a long season. In the case of loose inflorescences such as the corymb and the umbel he does not make note of such differences. But in the crowded, though quite spherical flower-cluster

1 Hist. Pl., p. 89.

2 Ibid., Book v, p. 5.

3 Meyer, Geschichte der Botanik, vol. i, p. 166. 
of Echinops sphaerocephalus, he observes and records it that the first flowers to open are those at the summit of the cluster and that the succession is from that point downward to where the globose head is joined to its peduncle. ${ }^{1}$

It will be taken for granted that Cordus had received from Theophrastus the suggestion of the centripetal and centrifugal in inflorescence; but there is one excellent definition of a particular kind of inflorescence which modern botany receives from this German youth of the sixteenth century; that of the word umbel. The word itself as a botanical term is as old as botany, and was in the first place suggested by the mechanism of an umbrella or sunshade, which in more than one way certain inflorescences recall. There are two things essential to an umbrella, and these not equally conspicuous. The more obvious part is the rounded and expanded externally more or less convex surface; and there is also the frame work beneath supporting it in expansion. Now while the modern botanist is taught to look not at the expanded surface, but at the structure of the framework beneath for the evidence that a flattish topped inflorescence is an umbel, it was quite otherwise with the botanists of antiquity, and with all of them before Valerius Cordus. Brunfels, Fuchsius, Tragus, and this young botanist's wisest contemporaries held the broad flat clusters of the elder and the viburnum to be umbels equally with those of carrot and caraway, parsnip and fennel; no heed being given to the complexity of the supporting framework in the elder, or to the simplicity of it in caraway and fennel. Even the small heads of those composites the yarrow and the tansy were said to be arranged in umbels. It is in the midst of his own new and improved description of the common yarrow that Cordus suggests the need of distinguishing between umbel and corymb; and that nothing should be called an umbel the stalklets of which do not all arise from one and the same point. ${ }^{2}$ This is done with the utmost modesty, the revolutionizing proposition being enclosed in a parenthesis. He sees the important distinction between umbel and corymb, names briefly the characteristic of the original and true umbel, and quietly passes on, leaving it to be inferred that other flattish-topped inflorescences not answering to this clear definition of the umbel may be called the corymb; and his practice proves this to have been his purpose. We shall be interested in observing later how long after Cordus botanists in general saw the need of distinguishing between umbel and corymb.

1 Hist. Pl., p. 87.

2 Ibid., p. 139. 
Just here, however, it may be observed that when the vast family of the composites first gained clear recognition, Corymbiferce became at once the family name, and remained steadily in use for a century and more; and Cordus made the first beginning of calling the inflorescences of many commonest composites corymbs.

Those modified leaves now known as bracts, and collectively as an involucre subtending inflorescences and flowers, first obtained mention and description by Cordus. In Daucus they so conspicuously embrace the umbel, and are so very unlike the proper foliage that he is careful to bring out in writing all their peculiarities ${ }^{1}$; the first step in the direction of giving taxonomic significance to the involucre in the family of umbellifers. Recalling that that comparatively modern and well advanced anthologist Tournefort wrote down the involucre of every araceous plant as its "petal," 2 it is interesting to note that this German youth more than a hundred and fifty years before Tournefort denominated it an "involucrum," as do we of to-day; for the spathe is but one type of involucre.

The calyx under Cordus makes noteworthy though by no means great progress toward gaining recognition as a part of the flower. Quite in conformity to the definition which we found in Fuchsius' vocabulary Cordus calls that a "calyculus" which is synsepalous and either becomes a part of the fruit, or at least a protection to the growing and mature seeds. All labiates and borrageworts will readily be accredited as having calyxes. But how will it fare in this regard with the solanaceæ. In the some half-dozen genera of this family then known in German gardens there was not one, Hyoscyamus excepted, which could exhibit an organ answering to the then accepted definition of a calyx; and, curiously enough Tragus, and even Fuchsius, when they name the "calyx" of Hyoscymus, mean nothing but the operculate, and therefore literally chalice-shaped, capsule. ${ }^{4}$ The real calyx goes with Tragus for a "vasculum," while Fuchsius makes no reference to it whatever. One can not but regret that Cordus did not describe Hyoscyamus; it would have been so interesting to have seen what he with his perfect originality of view would have made of the anthology and carpology of a type so marked. But the youth was much engaged in bringing from German meadows, river banks, and woods representatives of genera unknown to the ancients, and describing these.

' Hist. Pl., p. go.

2 Tournef. Inst., p. 158.

s Cordus, Hist. Pl., p. ros.

${ }_{4}$ Tragus, Stirp. Comm., p. 132; Fuchs, Hist.Stirp., p. 832. 
The presentation of his views about calyxes in solanaceous plants will be helped by a list of the genera which at that period, over and above Hyoscyamus, were in German gardens. They were Solanum, Atropa, Mandragora, Melongena, Physalis, Capsicum and Stramonium, or Datura. The last had been credited with a calyx by Tragus, though not technically, or as being an organ regularly so named, but only as a cup-shaped green thing forth from which "the flower proceeds." 1 The corresponding part of the plant Physalis Fuchsius had described collectively as "rounded pouches resembling bladders," 2 and Tragus calls them simply "bladders." 3 These I think are all the references made by Fuchs and Bock to anything like a calyx in their eight or nine solanaceous genera. Of course the small, flat, hardly more than disk-like calyxes of proper solanum, mandragora, capsicum and their like, would not be noticed by them in any way. They were no part of the flower, nor had any significancy. With Valerius Cordus every one of them - the tubiform cup of Datura, the globiform-inflated and closed bladder of Physalis, the prickly saucer-shaped thing holding the mere base of a melongena fruit, and the almost flat green disk visible at the basal end of a pepper pod-is a "calix" or "caliculus." This was a most significant innovation; the employment of an old term in such wise as to make of it a strictly scientific term. Hitherto "calyx" had been used in botany from the remotest times as signifying any organ that happened to be cup-shaped, the ovary of a pear or quince or pomegranate in their early stages, a cup-shaped corolla, the cupshaped corona within the perianth of a jonquil or daffodil, or even an operculate dry seed-vessel. Any one of these was a "calyx" in pre-Cordian terminology. Now, according to this use of the term, which makes its first appearance in Cordus' descriptions of solanaceous plants, calyx is not calyx by reason of its shape, but because it holds always one and the same place-relation to "flower" and to the fruit that succeeds the flower This principle of the location of an organ, the place which it visibly occupies as next some other organ, rather than its form or coloring or texture, is one which, long after Cordus' day came to be received a s absolutely fundamental in anthology. Morphologically considered the whole doctrine of the flower, as almost every reader will know, rests on this basis, and most securely. Therefore Cordus' mere application of this principle to the identifying of calyx in all its extremes of form

1 Tragus, p. 896 .

2 Fuchs, p.881.

Tragus, p. 304 . 
throughout the one family of the nightshades must rank among the most important contributions ever made to anthology; for it was the first hint ever given of a truly scientific classification of floral organs.

The truthfulness of this last statement will remain unimpeached notwithstanding that Cordus did not name the calyx as forming a part of the flower. It was too early for the expression of anything so iconoclastic as that. From the earliest dawn of botany down through uncounted ages, a circle of green-colored leaves, no matter what their size or form, or where placed, had been a circle of leaves, and a whorl of leaf-like organs colored otherwise than green had been a flower. Even in the mind of young Cordus this appears to have been a prejudice too deeplyseated to fade away even before the light of his own brilliant discoveries. He never admitted the calyx to the rank of a floral organ; though he seems upon the verge of doing so. In describing the "flower" of the white water lily he actually sets apart, as too different from the others, those four outer members which are green externally and which also, as he says, completely enfold all the others, and he gives to them collectively a name by which they must be distinguished from the many and narrower white "flower leaves"; the name is not calyx but "tunica." He does not, however, look on them as partaking so much of the nature of a calyx as of ordinary flower leaves. $\mathrm{He}$ observes that they are not altogether of that green color which at first glance they seem to be, but that at summit and marginally they are of the same texture and whiteness as the others. They impress him as being modified flower leaves, whereas the green things at the back of buttercups and others like them are but reduced and modified ordinary leaves. The terms calyx and caliculus I have failed to find Cordus making use of at all except for such as are synsepalous. If such a circle is quite chorisepalous, or even approximately so, he calls it a circle of leaves simply. He does not overlook the fact that such chorisepalous circle has a particular function, and that in immediate relation to the flower; and here again he seems as on the verge of extending the use of the term flower so as to make it include the calyx; but he never quite does that. His manner of expressing himself in such cases is exemplified in his description of what he calls Hepatica alba, which is his name for a new genus of his discovery, its equivalent in modern nomenclature being Parnassia; the type, $P$. palustris. Here is his

1 Hist. Pl., p. 99. 
account of what is now called the calyx in that species. "Beneath the flower itself there are five very small leaves within which the flower before it opens is enclosed." a flower before its expansion can be no part of that flower. There is here a more than whispered call for a new extension of the use of the word flower; a new definition of that organ, by the terms of which the calyx shall be recognized as a part of it. All this will come, but by no means speedily.

There is one use of the term calyx frequent with Cordus which practically implies chorisepaly. I refer to his habitual writing of the involucres subtending the flower heads of all cichoriaceous plants and some of the true composites as the calyx. This was a complying with the terms of the then accepted definition of a calyx as that which enfolded at first the flower, after that the fruit. As a somewhat special application of the term this, perhaps introduced by Cordus, seems strongly to have commended itself to future generations; for, long after the "flower" of chicory and its cognates had been seen to be an inflorescence, this term calyx remained in use instead of involucre. With Tournefort in I 700 it was still a calyx. Linnæus a half century later modified the expression in so far as to write it "calyx communis"; but this needful modification was afterwards ruled out. A number of prominent botanists, even down to the middle of the nineteenth century, wrote down the involucre even of the sunflowers as a calyx, and the bracts composing it, as sepals.

To the morphology of the corolla-if one may use that term in writing about a time which far antedates the term's inventionCordus adds a few items of high import to phytography. Botany has now not many expressions which it could as hardly do without as the terms papilionaceous and bilabiate; for they at once recall, and respectively designate, two large and important families of plants. Fuchsius in one instance speaks of a certain "flower" as having the form of a butterfly. ${ }^{2}$ In as far as I have been able to discover the idea of comparing the pea blossom to a butterfly originated with Fuchsius' brilliant contemporary Conrad Gesner. ${ }^{3}$ Neither of these appears to have used the expression "flore papilionis forma" in connection with any more than the single species Pisum sativum; but this evidently suggested to Cordus the possibility of something better than the antique usage of describing a vetch blossom as

1 Hist. Pl., p. I 53.

2 Hist. Stirp., p. 628, under Pisum (1542).

3 Historia Plantarum, p. I92 (I54I). 
being like that of a lupine, and the lupine flower in turn being compared to that of a pea. And his appears to have been the botanical eye that was first to perceive in the flowers of the whole long line of beans, peas, and lupines, and of broom and cytisus, and laburnum tree, only more or less marked deviations from-mere modifications of - that pea-blossom type which Gesner had compared to the insect called a butterfly; and by and by the adjective term papilionaceous was coined by him. Such readers as may not have access to Cordus' works may be interested in following the gradual genesis of that useful adjective in the young master's mind; and this can be shown by citing his expressions in precisely the order in which they occur in the succession of his pages. I therefore give these in the footnote. ${ }^{1}$

Of equal service to all botany was his invention of a term that should at once indicate and describe the corolla of the Labiatæ. His term is "flos hians," the gaping flower, or corolla as we now say. Nor does it require but a moment's reflection to become convinced that the expression gaping, or yawning corolla is more perfectly and exactly descriptive of the most common and typical corollas of labiates than is the term bilabiate; for certainly that which one sees clearly in the form of such is, not a pair of lips, but a wide-open yawning mouth, exposing even the throat itself. Terminology certainly lost something of the accurately definitive when later authority displaced Valerius Cordus' "yawning" flower and substituted the less fitly chosen bilabiate.

It was yet far from the time when any taxonomic use would be made of the different ways in which members of floral circles are enfolded in the bud. Cordus was first to observe some such differences, and to name them in his plant descriptions. In describing Iris he notes that the parts of the flower are convolute in the bud. ${ }^{2}$

1 "Flores parvi, *** papilionum figura." (Hist. Plant., 992).

"Flores ** figura papilionibus similes." (Ibid., p. Ioo).

"Flores $* * *$ papilionum figura." (Ibid., p. IоI).

"Flores papilionibus similes." (Ibid., p. I2 $7^{2}$ ).

"Flores **** figura papilionum." (Ibid., p. I37).

"Pediculus ** parvis oblongis papilionaceis floribus circumdatus. (Ibid., p. $\left.164^{2}\right)$.

"Flores forma papilionacei et oblongi." (Ibid., p. I66²).

"Flores $* *$ producit $* *$ papilionaceos, quales in omnibus leguminibus est videre(!)." (Ibid., p. I $87^{2}$ ).

The reader must not fail to note that, when once the term papilionacea has presented itself to Cordus' mind he thenceforward employs it constantly.

2 Hist. Pl., p. 133. 
Similarly he describes the corolla of Datura as being laid in folds before expansion. ${ }^{1}$ It will not be assumed that in first writing these things down he had any thought of their important bearing upon affinities. He may have had; but whether so or no the terms he chose are so perfectly correct for the kinds of prefloration which they indicate, that no reformer of terminology has sought to displace them, and they remain in common use to-day.

The word petal was still unheard and unwritten in our science. It will be proposed by an Italian botanist two generations later. It is evident Cordus has realized to some degree the desirability of some term by which flower leaves shall be distinguished from ordinary foliage; for where flowers are choripetalous he uses the diminutive foliolum (leaflet) instead of folium; this, however, not as an inviolable rule, nor in such wise as to preclude the application of the term to ordinary green leaves that are of very small size. Also such elongated and more or less strap-shaped flower leaves as radiately encircle the middle of a flower, or head of flowers, Cordus repeatedly describes as resembling rays, "radii"; the earliest adumbration of the term now long in use for this kind of corolla.

The disk-corollas in the composites that have rays were still undiscovered. They were seen in the mass only and were always written of as the "stamina," therefore quite undistinguished from the central parts of a buttercup or anemone blossom. Cordus alone I find in one instance so writing of the "stamina" of one particular composite as to prove that he had seen the individual "stamen" as he could have called it, and had found its form peculiar. The plant is Tussilago; and having described the rays, he says that the stamina in the midst of them are "in form like minute lilies." 2 No matter what he calls the thing, it is plain that he is the discoverer of the disk-corolla in composites.

If both stamens and pistils are numerous, small, and slender in the same flower Cordus makes no distinction between them in name. In this case all are "stamina"; thus in Pulsatilla all the threads in the midst of the flower are stamina; but those occupying the very center he observes as "changing into a tuft of long hairs at the base of each of which there is a seed as in clematis." 3 If, however, in flowers at once many-stamened and many-pistilled the pistils, being without styles, have no capillary aspect in the aggregate, then the two sets are not confused and the inner ones are not

1 Hist. Pl., p. 90.

${ }^{2}$ Ibid., p. 93.

3 Ibid., p. I 2 I. 
"stamina." This is apparent in the account which he gives of thalictrum flowers. He says they are "very small, and consist of pendulous stamens only; but after the falling away of these, very small oblong black seeds remain." 1 In the case of larger flowers, where the stamens are fewer and easily counted, it becomes clear that by "stamen" Cordus means primarily the filament; this doubtless partly because in very many instances it was all he could find. There are no "apices" to the inner "stamina" of pulsatilla or clematis; none to the forked styles of the many cichoriaceæ and compositæ which he examined, and he always calls these the stamina. Even in the solanum type of floral structure, where five stamens, almost all anther, form a central column forth from whose summit one slender style-thread protrudes, Cordus, seeing them all, denominated all six indiscriminately "stamina." 2 Evidently his mind was exercised by these small things, in the morphology of which he saw enough to prevent him at least from calling them indiscriminately stamin a and apices as others of his time were doing. In the large and therefore convenient flowers of lilies he saw and took note of the transverse position of the anthers, but would not name the things by any name at all. The stalks which these rested on were what he called stamina. The term apex he seems to have wished to transfer to the style and stigma and to have it apply to that part of the flower only. ${ }^{3}$ He takes particular notice of dust-rubiginosus pulviusculus - which the lily anthers shed before collapsing. Again in describing the anthers of Paris he sees this same kind of dust, and there proceeds to assign it a name; even the name which it has always since borne; for he describes these parts as being "luteo polline conspersa." 4

Since the most ancient times what they knew as a fruit they had recognized in its germinal state resting at the bottom of the flower, or else below it; but in every stage from the tender germinal condition forward to its maturity they had called it the "fruit" simply. Cordus makes the first inroad upon this time-honored usage. That which we know as the ovary he uniformly declines to write of as the fruit; as if perceiving an absurdity in making this small and tender mere promise of fruit, identical with the future actual fruit, even in name. He does not, however, formally propose a

${ }^{1}$ Hist. Pl., p. $97^{2}$.

${ }^{2}$ Ibid., p. $90^{2}$.

${ }^{3} \mathrm{Ibid}$., p. $139^{2}$. Also in the flower of Paris, p. 152, he calls the stigmas, not the anthers, apices.

'Ibid., p. I52. 
universal name for this hitherto really nameless thing. Where, as in the water lilies and in some others, it is rather large and conspicuous within the flower, he applies to it that already much and variously used term capitulum; but in the more numerous cases of smaller flowers, where it appears as only a small protuberance in the bottom of the blossom, he writes of it as the tuberculum. The ovary, then, like the pollen, is one of Cordus' discoveries, so to speak, in anthology. Furthermore, this tuberculum, as he calls it, is openly recognized as an integral part of the flower as a whole. The proof that he so received it is found in the language he employs in describing the pæonia. Having given the characteristics of the flower leaves, he passes from these to the two large ovaries occupying the center. These he calls a pair of horns, cornicula, mentioning that they are hedged about by the yellow stamens, then proceeding to state that these two cornicula "remain after the other parts of the flower have fallen," then grow to be an inch and a half long, ${ }^{1}$ etc., etc. The idea that corolla, stamen, and pistils collectively constitute a flower could not be expressed more unmistakably; and it is the earliest record I have met with of such a proposition. Theophrastus, as we have seen, first classified flowers as leafy and capillary, so that a mere tuft of stamens only, unattended by leaves of any kind, was a flower. Then, with a wild rose blossom before him he construed the yellow stamens as being, not a circle of floral organs, but a capillary flower within a leafy one. Thus the rose had two flowers; the very central axis, globosely enlarged below, was the "fruit" even then, and no part of the flower. This Theophrastan anthology of two flowers in one, rather than one flower made up of two sets of organs, was everywhere accepted in Cordus' time. Tragus had reproduced it, though with augmentations, even to calling the petals "rose leaves," and the stamens the "rose flower." 2 Now in Cordus' procedure we have an illustration of how the making of one little distinction, and the invention of a word that accentuates that distinction, may revolutionize a science. The man had seen an inaccuracy in the practice of calling by the one name of fruit both the little tubercle lying at the bottom of a cherry blossom and the subsequent ripe cherry. That mere floral sign and promise of a fruit he determined to name a tubercle. Logically a fruit is no part of any flower; as logically this "tubercle" is a part of it. In rose and pæony there are not three flowers one within another, but one flower made up of three different kinds of parts. We shall not be

${ }^{1}$ Hist. Pl., p. 135 .

2 Tragus, Stirp. Comm., p. $9 \$ 8$. 
likely to meet with any other one botanist in the whole history of our science who so greatly advanced the morphology of the flower as Valerius Cordus. To the finishing of morphologic anthology only two things remained to be done. The calyx was to be added to the category of floral organs, and the "flower leaves" awaited a distinctive name; for the "foliolum" proposed and used by Cordus did not satisfactorily meet the demand. It was not sufficiently different from folium. The discovery of the functions of certain floral parts, though of the very highest importance, awaited not the coming of a more astute botanist, but the invention of mechanical aids to natural vision.

Among a number of Cordus' signal new discoveries in anthology, one must not omit to mention the flowers of the genus Ficus. Every botanical authority from Theophrastus forward had averred that fig trees have no flowers, and that the fruits are only fruits and nothing more from their first small appearing to their ripening. Cordus says: "When the figs are half grown they develop in their interior (what you may be surprised to know) what appear to be crowded stamens, of a pale purplish color, standing forth from the fleshy part, and all pointing toward the central hollow, to each of which there suceeds a flattened yellowish seed."1 It is most remarkable that, two hundred years after this clear description of fig flowers, Linnæus should have placed Ficus among the genera of cryptogams.

Fruit and Seed. Not Brunfels, nor Fuchs, nor Tragus shows sign of ever having read Theophrastus' scientific definition of a fruit. As far as my careful reading has gone the Greek's term pericarp. first reappears in Cordus; and he uses it frequently. Then, in his full descriptions of various plants it comes out that he has made sections, longitudinal and transverse, of many pericarps, so as to be able to record the number of the seeds when they are not too numerous, or the number of rows in which they arrange themselves when the number of the seeds is too great to be told. While the elder German authors have quite minutely and well described the curious and beautiful seeds of cardiospermum, this youth, as if belonging to a later generation and to a later century than the

1. Hist. Pl., p. 184. In my copy of Cordus, and presumably in the whole edition, a word has been omitted by the printer. As printed, the first line about fig flowers reads: "Flores, ut omnes tradiderunt, fert, sed statim parva fructuum rudimenta." This is wholly unintelligible, as a sentence, until you supply the negative non before fert, so that the reading shall be, "non fert." Cordus' manuscript was not printed until seventeen years after $h$ is death. 
sixteenth, makes note of the fact that these same seeds are attached to the central part of their pericarp ${ }^{1}$; thus suggesting long before the botanical world had apprehended its taxonomic usefulness, the several modes of placentation.

$\mathrm{He}$ is accustomed to peer into and take note of every aspect of the various dry dehiscent fruits that he meets. with in the gardens or in the wilds. In describing species with capsular fruits he tells whether its capsule is one-celled or several-celled, naming the lines of dehiscence, the commissures, the partitions, if there be any, the septa, and the compartments themselves the loculamenta. Then the seeds are reported on, not only as to the method of arrangement but as to every item of their form, the color and texture of their testa, and the color and flavor of the nucleus - so he names itwhen they are large enough to be tested by the sense of taste.

Cordus has not, like Tragus, followed up the suggestions of Theophrastus about the cotyledons; for that belongs to the garden student, who plants seeds and watches their germination and first appearing above ground; and Cordus is more zealously devoted to wild botany. To him, however, must be conceded priority in the matter of distinguishing between spores and seeds on the one hand, and between spores and pollen on the other; this also without his ever having seen either an individual spore or an individual pollen grain. For the clearer understanding of Cordus in this particular field of enquiry we must recall Tragus' having so studiously and so laboriously gathered what he and others believed to be the seeds of the fern osmunda. ${ }^{2}$ That he called them seeds implies the belief on his part that young ferns could be produced from them. But then, the superstitious Tragus seems also to have believed that trees could be reproduced both by their proper seeds, and also by that flower-dust which Cordus afterwards named pollen. ${ }^{3}$ Among

1 Hist. Pl., p. 89 .

${ }_{2}$ See page $23^{8}$ preceding.

3 Tragus at page 1073 has the following as to the reproduction of junipers: "Maio mense"tenuissimus ac luteus pulvis è juniperis in auras avolare conspicitur, quod semen illius esse animadverti. Post hunc quem diximus pulverem baccæ prorumpunt exiguæ, virides, quæ altero demum anno antumno appetente, quod illi tempor maturitatis est, cœruleo tinguntur colore, etc., etc. È nucleis lapidosis, qui in hisce baccis continentur, novæ Juniperi plantulæ fruticnmt." If in this passage semen is used botanically the meaning can be no other than that junipers may grow from pollen. If, what is improbable, he employs it in a zoological sense, as meaning that the dust which he says sails away upon the air is needful to the fertilization of the seed within the juniper berry, then he is the first to proclaim the modern doc- 
nature students of four hundred years ago I know not who else is so far from accepting things on other people's guess or hearsay as Valerius Cordus; in whom I have not yet read a line that savors of the fabulous or superstitious; and that, for the period, is much to say of any author. Concerning the propagation of scolopendrium he says: "Phyllitis has no stem, or flower, or seed; nevertheless, from the vermiform patches on the back of the leaf, when these are resolved into powder and are scattered abroad, it is propagated."1 Substantially the same proposition is repeated with emphasis at the end of his description of Aspidium filix mas: "Although it has neither stem nor flowers nor seeds, it nevertheless propagates itself by means of the yellow and hairy powder that is produced on the back of the leaf and is blown away by the wind."2 Again, of trichomanes it is said: "It grows copiously on moist shaded rocks, although it produces no stem, or flower or seed. But it reproduces itself by means of the dust that is developed on the back of the leaves, as do all kinds of ferns; and let this statement of the fact once for all suffice." 3 From this point forth he proceeds to describe a half dozen other ferns in close succession, carefully bringing out the form and arrangement of their fruit-dots or lines not omitting even the indusium, but not again mentioning their seedlessness or their means of propagation.

This positive and reiterated assertion that ferns have no seeds, yet propagate by organs so infinitesimal that he has never seen one, 4 implies that what ferns shed from the back of their fronds is understood to be of a different structure from that of seeds. It is an easy matter for one frequenting the native haunts of certain ferns to see their prothallia both with and without the first diminutive fern leaf; and it can not reasonably be doubted-indeed Cordus by his strong language compels us to think-that he had seen these things, and had assured himself that the germination of ferns is most different from that of seed plants; thence inferring to a certainty that those particles, invisible except in mass, are things different and distinct from seeds.

trine of bisexuality in plants. He who knows Tragus' belief in the reproductibility of even seed plants apart from any kind of seed or germ, will not very readily accept this latter interpretation of his language.

i His.t. Pl., p. I 3 .

2 Ibid., p. $169^{2}$.

3 Ibid., p. 170.

4 The individual spores of ferns were first seen some seventy years after Cordus' demise. 
Taxonomy. Cordus' Books I and II are devoted to herbaceous plants, Book III to woody growths great and small. He accepts, then, and without objection, these anciently established first Grand Divisions of the plant world. The primary division of the herbaceous plants is not made from the point of view of affinities, but is ordered historically rather, as one may say; for while the heading of Book I is "Concerning Divers Herbs," that of Book II reads, "Plants whose History was either inexactly transmitted by the Ancients, or else altogether omitted." Such headings do not seem to promise much of taxonomic doctrine, or of the tacit expression of it by grouping. Members of the same natural family, and species of the same genus will almost inevitably be distributed partly to Book I and partly to Book II.

Despite these seeming obstacles to ready expression, and while there has never yet been any attempt to relegate all genera to families, or even formally to characterize any of those several families that have always been recognized, still Cordus advances well beyond all his predecessors in this significant part of botanical systematizing. When, as sometimes happens, his general plan has led to the placing of some type away from its real cognates, he is apt to give the hint that such genus thus isolated in his book belongs to a certain family. An example of this occurs in connection with his new description of the old genus Lupimus. His first word is "Lupinus is a leguminous plant."' He seems to be offering this as a piece of taxonomic information that is needed. He is not presenting his readers with an empty platitude. When writing of $\mathrm{Faba}^{2}$ and Cicer, ${ }^{3}$ and Phaseolus ${ }^{4}$ he does not tell that either one is a leguminous plant. All the world knows that these are, and have been so classed immemorially. The family of leguminosæ of antiquity consisted of such papilionaceæ as yielded edible seeds and were therefore food plants. Important though they were, they could not be harvested and threshed after the manner of harvesting the frumenta, or cerealia. The individual pods had to be collected by hand; hence the very name legumina. Lupinus was not one of the leguminous plants with the ancients. Its seeds were bitter, but endowed with active medicinal qualities. It was by virtue of botanical principles quite new in Cordus' day that he dared to say Lupinus is a leguminous plant. The family was now receiving

\footnotetext{
1 Hist. Pl., p. I 37.

2 Ibid., p. 166.

3 Ibid., p. 99.

${ }_{4}^{4}$ Ibid., p. $127^{2}$.
} 
new accessions, not of plants newly discovered, but of such as had been known very anciently but not admitted to the group, but now ready to be received because new and truer criteria of relationship were being exploited, and gaining recognition. Cordus, as we have seen, had been the discoverer of the papilionaceous flowerthe expression tells but the truth - and one immediate result of the discovery was, the augmentation of the ancient group of the legumina by the referring thereto of every genus the mere form and plan of whose corolla was at agreement with that of beans and peas. Anthology, dormant if not dead for fifteen centuries, has come to life, is developing with some rapidity, and the ancient taxonomy that had been constructed largely according to vegetative characters, culinary uses, and medicinal properties, is being steadily but quietly displaced. The chief agent of this radical taxonomical reform at this period is Valerius Cordus. We must follow him in his bringing in of one other new accession to the family of the leguminous. The type had been well known to the ancient Greeks. They had given it the name which, as a genus, it has always borne from their day to ours, Glycyrrhiza, Sweetroot. No use was known for any part of the plant but its root. Anciently no one would have called it a leguminous plant; and for this very reason Cordus argues the case of its proper admissibility to membership in the family. In the place of a concluding note, supplementing a fine description of the plant in all its parts, in the course of which he has announced having found the flowers, though small and crowded, to be precisely papilionaceous, he says, "The roots have a very sweet flavor, moderately astringent, and a trifle acrid, to which there is added the mere trace of a certain bitterness that belongs to all leguminous plants; for even this plant is as certainly referable to the leguminosæ as the peas and beans themselves; in view of which decision it seems fitting that I should make mention of this one sensible quality that it has in common with all the leguminosæ; for perhaps not every one would prove to have the sense of taste sufficiently cultivated to be able to perceive it and attest its presence."1

One is obliged to pause a moment in admiration of the calm, judicious conservatism of this youthful botanical genius, as it reveals itself in the last of those lines. He has discovered, and as modestly as possible he announces the discovery, that by their floral structures alone the family relationships of hosts of plant genera may be determined, and unmistakably. The detection of a

1 Hist. Pl., p. $164^{2}$. 
principle so manifestly valid, and so surely destined to revolutionize completely all botanical system, can not but have fired with enthusiasm a man only some twenty years old - a year or two more, possibly, and quite as possibly a year or two less - but in his writing how completely does he repress all enthusiasm. Profoundly respectful toward venerated authorities of two thousand years before who had held that agreement as to properties was required in order to establish the fact of interrelationship, he investigates licorice root to find that also by qualitative criteria as well as by floral structure the plant proves itself a member of the leguminosæ. In this repression of excessive enthusiasm for the new, and continuing to respect the old principles, some later celebrities are in unfavorable contrast to Cordus; for they so greatly magnified the value of the new anthology, as to write intolerantly and even in derision of the old ideas that vegetative characters and sensible qualities have taxonomic weight. ${ }^{1}$

We must follow Cordus a few steps further in this path of the discovery of relationships; for he is making distinct and lasting landmarks in the history of plant families.

Tracing backwards the history of the Cucurbitacece, we reach no point, however ancient, at which gourds, pumpkins, squashes, melons, and cucumbers were not recognized collectively in their status of a family, or larger genus, as such a group was at first named. In their mode of growth, their coarse, rough herbage, and even as to the structure and qualities of their familiar large firmfleshy fruits, they were in a comprehensive way at one. Any cultivator of them, however untaught, would be botanist enough to see that. Meanwhile there were two or three other types, long and familiarly known, which had never been thought of by even the most skillful botanists, as cognates of gourds and cucumbers. They were the bryonias and the momordicas. According to such signs of consanguinity as availed with the ancients, these could never have been thought of as possible cucurbits. They were not large, coarse, harshly almost hispid plants, but were small, comparatively smooth and delicate in texture; and the bryonias, so far from yielding any fruit the least like gourds and melons, put forth bunches of small, soft, pulpy berries, red or black, more like those of nightshades. In the second place there were no mild qualities in these plants, no parts were edible. They were actively medicinal, and some of them powerfully narcotic-scented. It was no less

'See Tournefort's Elemens (1694), also Linnaeus' Philosophia Botanica (175I). 
than a master stroke of the new taxonomy, Cordus' bringing in of momordica and bryonia to augment the series of genera of the cucurbitaceæ. ${ }^{1}$ He had examined their small flowers, dissected the little bryony berries, and compared their plan of structure with that of their robust innocuous neighbors of the fields and gardens, and by these tokens had found them all to be of one lineage.

Singularly the little soft-leaved weed Lithospermum arvense had never been thought of as in the least degree akin to the coarse, rough, stinging borrage and bugloss and anchusa; but Cordus describing the plant in every part with a minuteness and accuracy unapproached by any earlier writer, concludes it all with the proposition that its affinities are with the anchusas and echiums. "It is of their kindred; something which the ancients did not apprehend." 2 It had been through a comparison of their inflorescences, and by a recognition of the same floral plan and fruit characters that he had become able confidently to add lithospermum to the family of the borrage-worts; and yet not by these alone; for he avers that as to properties also it is much like the others.

In his delimitation of the genus Ranunculus Cordus defers unwontedly to floral characters, and slights those of root, stem, and foliage. This is very interesting as proving that the trend of his mind has been strongly in the direction of what has come to be the established and settled first principle of classification.

Upon this point the subjoined list of his Ranunculus species will be instructive. They are given in the order in which he places them. The equivalents of them, that is to say the identification of them, in modern nomenclature is somewhat doubtful in only one or two cases.

cordus

I. Ranunculus palustris

2. Ranunculus Sardous

3. Ranunculus tertius

4. Ranunculus quartus

5. Ranunculus quintus

6. Ranunculus flammula

7. Ranunculus coronarius

8. Ranunculus octavus

9. Ranunculus nonus

Io. Ranunculus leptophyllus

II. Ranunculus undecimus

I 2. Ranunculus platyphyllus

1 Hist. Pl., pp. II $4^{2}-\mathrm{II} g$.

2 Ibid., p. 94.

\section{Modern}

Ranunculus sceleratus.

Ranunculus Sardous.

Anemone ranunculoides.

Anemone nemorosa.

Ranunculus arvensis.

?Ranunculus repens.

R. acris, double-flowered.

?R. acris, single-flowered.

Ranunculus bulbosus.

Pulsatilla vernalis.

Anemone silvestris.

Ranunculus flammula. 
A genus Ranunculus of such composition as that perfectly illustrates taxonomy in its stage of transition from where, as at the first, it was almost wholly dependent on vegetative characters, to where it relies almost as entirely upon those of flower alone; and this at a time when as yet the calyx has received but little attention and has not been admitted to the category of floral organs; and the wholly petaloid sepals of Anemone, Sylvia, and Pulsatilla form as good a "flower," i.e., corolla, as do the flower leaves of a rose or pæonia. It is also a stage at which the fruit is not yet accorded the taxonomic weight that was allowed it fifty or sixty years after Cordus by Cesalpino. In the eyes of a twentieth-century botanist the above is a curious medley to be called a genus Ranunculus; and what is more, no one anterior to Cordus had done as badly as that. The remotest Greeks seem to have admitted to Ranunculus no species not thereto referred by most botanists of the nineteenth century. Here there are added to the genus, and admirably indeed, a considerable list of true buttercups unknown to antiquity; but over and above these a trio of representatives of anemoneous genera that differ much among themselves. This kind of a genus Ranunculus, for that period, explains itself readily. It is plain that Cordus has yielded for once to enthusiasm for the newly rising anthology; that he has attempted the abandonment of the old reliance on vegetative characters, and is putting things together more with reference to the structure of the flower. Throughout this series there is always a five-leaved or six-leaved "flower," a circle of indefinitely numerous stamens within that, and in the middle a compact head of many "seeds." If the time had then arrived for the formal statement of the generic characters of such a group, we know that it would have been on this wise that Cordus' Ranunculus would have been characterized by him; to which morphologic diagnosis it would have been appended that certain acrid properties prevade the entire line of species. When I say that we know he would have done this, I have before me this proof, that the clear mention of just such common characteristics forms a part of the description of each leading species. One may take Cordus' separate diagnoses of any one line of related species and cull from them to a certainty that which to his view is the generic character. Not that this is peculiarly true of Cordus; for with equal certainty does one gather out of Brunfels' and Tragus' groups of square-stemmed oppositeleaved axillary-flowered aromatic herbs-or those otherwise vegetatively marked - the characters of their more crudely conceived genera. What distinguishes Cordus is -we must once more insist- 
this one rather steadily maintained appeal to floral organs, while for the time quite too much neglecting the vegetative; and also too little heeding very marked differences in the fruits of things; for he is perfectly aware that one of his ranunculi has "seeds" with long feathery tails, that another has them densely woolly-coated and compacted into the closest kind of a head, and that in a third they are rather few, and more like those of a Thalictrum than they are like the seeds of buttercups.

On the whole, and as thus studiously looked into, this Ranunculus of Cordus is one of the most significant chapters of taxonomic history ever written; for herein is illustrated as nowhere else the transition from an old taxonomy to a new one. By its making too little use of fruit characters it calls for the carpologically established genera of a Cesalpino ${ }^{1}$; but by the very pronounced corollism of such a chapter Cordus most clearly presages Tournefort.

We shall fall short of a fair comprehension of all that is in this chapter of taxonomy, unless we as carefully consider his disposal of two other types not referred by Cordus to Ranunculus, but so placed as immediately to succeed that genus. These are:

Cordus

Chelidonium minus Chelidonium palustre

\section{Modern}

Ficaria ranunculoides.

Caltha palustris.

These bring the number of ranunculaceous species in this unbroken line up to fourteen. That, in as far as it goes, is very good; yet there will seem quite a glaring inconsistency in the man's having excluded Ficaria from a genus to which he has already admitted, over and above many good ranunculi, three anemones and a pulsatilla. If the last four could go into Ranunculus, why not-and much more easily-Ficaria? There never is in any age any other so ponderous a dead weight upon scientific progress as so-called "authority," and the prejudices it entails. Those particular anemones and the pulsatilla were plants in Cordus' time newly discovered; northern types of which no ancient Greek or Latin authority had ever heard. They hardly yet had well established Latin names, or fixed places in the new books of botany. It was easy for Cordus to name these what he would, and to place them where he would, without risk of seeming to set himself superior to ancient and revered authority. The case of Ficaria was as different as possible. All antiquity had known this plant. From Dioscorides forward

1 Cesalpino was but four years younger than Cordus, but lived to old age. 
through the ages its name had been Chelidonium minus. Cordus, as a university lecturer on Dioscorides, by the acuteness and originality of his genius, had made himself famous at the age of twentythree years. To have given any Dioscoridean plant a new name would have been venturesome. He had been bold enough when, afterwards, in his own Historia Plantarum he had indicated the plants' intimate relationship to Ranunculus rather than to true celandine. This, to my mind, seems the explanation of the inconsistency referred to. The inconsistency is, however, more than condoned by the neat item of constructive taxonomy with which it is intimately connected.

I have never been able to comprehend the view point of the professedly natural systematist who fails to perceive a most intimate relationship as subsisting between Ficaria and the plant called Caltha palustris. With Cordus the type last named was new. The German peasantry had always known the plant, and had their several vernacular names for it; but the botanist became convinced that botanically it was unnamed and undescribed; and then, like an accomplished expert in the detection of affinities - a master in taxonomy-locates it close against Chelidonium minus, i.e., Ficaria, and to accentuate the expression of this relationship, names the new type Chelidonium palustre, ${ }^{1}$ this to be understood, I doubt not, as a binary generic name, just as Chelidonium minus was understood to be; for no one now thought of this as a mere species of the celandine.

Even as to the conception of a species Cordus is so far in advance of his own time as to appear quite abreast of Tournefort, who flourished a hundred and fifty years later. Among the botanical fables that have passed for history, none is more familiar than that Linnæus was first to clearly recognize varieties; but Cordus seems to realize the difference between species and variety as well as if he had lived in the nineteenth century. The instances of his mentioning varieties are not numerous, but they suffice to show that he discriminated them readily enough. The double-flowered buttercup which he calls Ranunculus coronarius ${ }^{2}$ he describes with the utmost brevity, remarking that it is not a proper species, but is a "factitious" thing of the gardens.

In giving full account of the Viburnum Opulus and its ornamental variety the Snowball Bush which appears so different he is careful to say that there is really no difference between the two save this,

1 Hist. Pl., p. 122.

Ibid., p. $120^{2}$. 
that the latter, instead of having both kinds of flowers, the fertile and small and the sterile and showy, has but the sterile kind. Plainly, he regards it as but a freak, a variety of the other. It is also worth noting that his is the earliest mention in history of this universal favorite, which he says grows wild along with the other, but is rare, except in gardens and pleasure grounds to which they transferred it from its native wilds. ${ }^{1}$

The question of the degree of relationship subsisting between the two kinds of Dipsacus, or teasel, has exercised the minds of successive generations of taxonomists early and late. Cordus appears to have settled it at the outset in the right way; or at least in a manner to satisfy the requirements of the modern evolutionary. He almost fills a folio page with his fine description of the original wild and useless $D$. silvestris, and then disposes of the cultivated and singularly useful $D$. sativus in five lines; even these five relating in the main to the mechanical serviceability of the hard, prickly heads; presenting as the only morphological distinction between this and the former, the harder, firmer texture and convenient curvature of the prickle-like bracts investing the head. ${ }^{2}$

A philosophic botanist, writing for the philosophic, need not more explicitly avow his belief that Dipsacus sativus is but a usefully variant offspring of Dipsacus silvestris; nor need he more clearly express his understanding that the wild thing, being the type of the species, is the thing for the botanist to describe in full.

Illustrations have been given already of Cordus' superior skill in bringing into line related genera, as if members of a natural family; but these taxonomic notes must not be concluded without allusion to one of the most striking manifestations of his ability to segregate, amend, and improve larger groups. Perhaps the best example of all is one that occurs in his early lectures on Dioscorides. The pharmacists of the time have a group of plants which they know as the Lactariæ, that is, milky-juiced herbs. Those best informed understand the species of the euphorbiaceous genus Tithymalus to be meant by this name Lactariæ, so says the lecturer; but then, he adds the suggestion that so many other herbs besides these have the faculty of shedding drops of milky juice when their stems are cut or broken, and the milks of these different herbs are so dissimilar as to their properties - some being innocuous, others poisonous - that the plants ought clearly to be distinguished in groups.

I Hist. Pl., p. I 90.

2 On the history of the Dipsacus controversy, and its nomenclature, cf. Greene, Pittonia, vol. iii, pp. I-9. 
"Let us, then, indicate three groups by their (morphologic) differences. Let the first be the Tithymali, the second the Intybaceæ. Then we shall have a third group that is of neither the Tithymali nor the Intybaceæ. We shall now proceed to demonstrate how these two may be distinguished. Tithymalus is a genus of many species every one of which has elongated leaves devoid of any kind of indentation or division. All intybaceous herbs have their leaves more or less erose or incised all around the edges. The greater proportion of the tithymali have an umbellate inflorescence and all of them, even those not umbellate have each flower and fruit subtended by a pair of opposite leaves. But the flower stalklets of the intybaceæ bear each a flower composed of small leaves compacted together, yellow as to color, Chondrilla minor and Cichorium excepted, in which they are either blue or white. The flowers of intybaceous plants resolve themselves into a kind of wool called a pappus. Never so the tithymali, for all of them have a threecelled fruit with a single seed in each cell. The seeds of intybaceæ with their pappus sail away on the breeze. The tithymali eject their seeds forcibly and with a sound. The milk of the intybaceæ is bitter at first taste. That of the tithymali is at first taste mild, even not so unlike that of cow's milk, but after that it begins to burn the mouth and throat, and if applied to the skin may blister it; which the mild juices of the intybaceæ never do. Now these herbs, which I have thus distinguished by their proper marks from the Intybaceæ, are called the Tithymali and may be known by that general [i.e. family] name. To the Intybaceæ belong all the species of Lactuca, both kinds of Chondrilla, Intybus sativus, and silvestris, commonly known as Cichorium, also Hieracium, and whatever other plants are like them [i.e. organologically], and have a milky juice.

"My third assemblage o $\mathrm{f}$ lactiferous plants can not be distributed among these two groups, neither do they of themselves constitute an alliance; for they are not united by any resemblances which they have in common. But they are not very numerous. Ficus, Erinus, Scammonia, and Cissampelus are among them; each seeming to belong to an alliance of its own." 1

Cesalpino, of the end of the sixteenth century, will be praised in future millenniums for having founded Systematic Botany. But had Valerius Cordus lived to only twice his nine-and-twenty years, it is easy to conceive that the great Italian might have missed his laurels.

1 Cordus, Annot. iñ Diosc., p. $74^{2}$, of Cordus' works, edition of $156 \mathrm{r}$. 
Nomenclature. Euricius Cordus having demonstrated that many a plant type native to Germany and well known to Germans was entirely unknown to the Greeks and Latins of antiquity, his son Valerius proceeded to name and describe such types, so that they might take their places - so that each might become the subject of a chapter - in books of botany. Valerius Cordus was the first man in history to establish many new genera of plants. I do not know that any one author between Dioscorides and Valerius Cordus proposed more than one or two new genera. This man all at once proposed so very many that his book is a great landmark in the history of genera. What we are here interested in finding out is whether in the naming of his new genera Cordus either tacitly or openly subscribes to any particular principles of generic nomenclature. From what we know of his antecedents as the carefully instructed favorite son of a celebrated Greek and Latin scholar, we shall reasonably expect to find him constructing his new names after classic models; making no inroads upon ancient usage. Let us make a selection of his new names, that the student of nomenclature may observe the manner of their construction.

\begin{tabular}{ll}
\multicolumn{1}{c}{ Cordus } & \multicolumn{1}{c}{ Modern } \\
Anblatum & Lathræa. \\
Balsamella & Impatiens. \\
Coralloides & Dentaria. \\
Drosion & Alchemilla. \\
Isophyllon & Bupleurum. \\
Limnesion & Gratiola. \\
Lycostaphylos & Opulus. \\
Millegrana & Herniaria. \\
Moschatella & Adoxa. \\
Helianthemum & Helianthemum. \\
Oxycoccus & Oxycoccus. \\
Pneumonanthe & Pneumonanthe. \\
Rorella & Drosera. \\
Sagitta & Sagittaria. \\
Thamæcnemum & Vaccaria.
\end{tabular}

It will be seen that by far the greater proportion of these fifteen generic names is regularly Greek-made; some five are as plainly Latin, while one only, and that the first of the list is very barbarous Latin; for Anblatum is said to be the old German name Ohnblatt (leafless) written over into Latin and supplied with the convenient terminal. It may be remarked that there is not one in this list 
of fifteen generic names that ought ever to have been displaced. It will hardly be possible to point out one of them which is not as good as its modern equivalent. Yet Helianthemum is the only one of the fifteen that never has bcen set aside; and the suppression of the rest is mainly to be attributed to Linnæus' recklessness in the matter of priority in nomenclature.

While most of Valerius Cordus' new generic names are of the universally acceptable one-worded type, it is clear from the following list that he did not find the binary sort objectionable.

\section{Cordus}

Chelidonium palustre

Chelidonium phragmites

Hepatica alba

Pentaphyllum palustre

Trifolium palustre
Modern

Caltha.

Corydalis.

Parnassia.

Comarum.

Menyanthes.

Here again I apprehend a difficulty on the part of many a reader to see that these two-worded names are purely generic; we are so perfectly accustomed all our life long to read every such name as being half generic, half specific; and so I affirm again that not one of those second and adjective terms is a specific name at all. Colloquially, and in our vernacular, we make use of two-worded generic names most freely without thought of impropriety. When we speak of Rose (=Rosa), Christmas Rose (=Helleborus), Rock Rose (=Cistus) and Guelder Rose (=upulus) we have no such thought as that all these are so many different kinds, or species, of Rose. No more had Valerius Cordus any such thought as that the four types which he knew as Chelidonium majus, Chelidonium minus, Chelidonium palustre, and Chelidonium phragmites were four kinds or species, of Celandine. To his mind they were as clearly four distinct genera as their respective modern equivalents Chelidonium, Ficaria, Caltha, and Corydalis are different genera to the mind of the botanist of to-day.

Nevertheless there were people in Cordus' time and before that, untaught, unbotanical botanists--to whom such binary generic names were a stumbling block; peoplc who supposed that the above four were but so many kinds of celandine, being misled by the reiteration of the substantive part of the name; and Cordus, while himself creating some such double generic appellations, suppresses several of the older ones in favor of new ones of one term; and this as if to correct in each instance a deep-seated popular error. The labiate plant known now as Glechoma had long been known in Latin 
as Hedera terrestris, a name which caused it to be thought of as really a kind of ivy. Cordus proposes that botanists shall call it by a new name Chaincelema. ${ }^{1}$ Similarly what had always been called Trifolium acetosum, or sour clover, seeing they really mistake it for a kind of clover, Cordus proposes shall be known as Oxys. ${ }^{2}$ The genus, by the way, was so known for two centuries after Cordus had proposed it, and until Linnæus without the shadow of a reason for so doing, changed it to uxalis.

In respect to the construction of new generic names Cordus represents the most rigidly classic type of nomenclator in this, that he creates no meaningless names. Every appellator of this kind that he makes is framed in allusion to some characteristic, either organologic, or ecologic, or qualitative, of the type itself, and is therefore full of meaning. The nomenclature of genera in even the remotest antiquity was not universally so; for they had in ancient times the genera Artemisia, Eupatorium, Euphorbia, Gentiana, Pconia, Valeriana, and several others which, like these, were named in honor of eminent medical botanists. Not one, however, of Cordus' many new genera is dedicated to any person whether historical or mythical. Even Theophrastus, Nicander, Dioscorides, and Pliny were not to be commemorated in generic nomenclature until after the lapse of more than a century and a half from the date of Cordus' death.

As regards the principle of priority, it is to be observed that he stands by it and contends for it only in the case of names that are of great antiquity. For instance, he finds that the name Eupatorium has been displaced from its ancient type so that the plant is everywhere in his time known under the name of Agrimonia. He will enter into no compromise with this kind of error. While as he says, "Almostall physicians an d pharmacists of to-daycall it Agrimonia,"3 he declines to head his chapter with that appellation, and writes Eupatorium instead, regardless of the convenience of the erring multitude. It is taking boldly the ground that the scientific man must be true to history in his plant naming; and that it belongs to the doctors and druggists to correct their errors according to the light of history. This is nothing less than the most tenacious adherence to the principle of priority; the restoring of an ancient name, where the whole concourse of those in a business way interested will be opposed to the restoration, and he knows it.

1 Hist. Pl., p. I6r.

2 Ibid., p. I 73 .

3 Ibid., p. I69. 
We have observed Brunfelius suppressing so ancient and classic a generic name as Chelidonium minus in favor of a new name, Ficaria ${ }^{1}$; this presumably on the ground that the latter is short, oneworded, and free from ambiguity. Cordus, as if intolerant of any change that should relegate to synonymy so old a name, continues the old binary in use, not deigning to cite Brunfelsius' Ficaria even as a synonym. ${ }^{2}$

Specific nomenclature, as far as Cordus is concerned, remains in statu quo. All specific names are binary. There is not in him the trace of a tendency to combine name and description in one phrase. No botanist of the nineteenth century was any further from that than he. But he is no more careful than his contemporaries to avoid the use of those meaningless things, the numeral adjectives, as specific names. He has an even dozen species of Ranunculus, and the names of three are $R$. octarus, nonus and undecimus. The use of these cabalistic appellations, however, perfectly demonstrates that he had no idea of any other than binary names for species in genera that were more than monotypic.

Anatomy and Physiology. Almost every page of original plant description in Cordus bears evidence of his having been accustomed to examine the interiors of organs. We shall hardly expect him to lay any foundations of a science of plant anatomy; for he knows nothing of any artificial aids to vision. The vegetable cell will not reveal itself to him, nor anything else that is too small to be seen with naked eye. But he makes sections of roots, stems, leaf-stalks, fruits of all kinds, and even of seeds, and records the anatomical aspects of them all. Neither Grew nor Malpighi, had he lived at the time of Valerius Cordus, could have done more.

One meets with these records of anatomic and physiologic observation only as distributed up and down the pages of the whole volume and forming part of the regular descriptions of genera and species; and they are so very numerous that one may here reproduce but a small selection of them.

That stemless aquatic, the common European sagittaria, is a large plant noteworthy on account of small size of the leaf-blades and the flowers, in contrast to the great dimensions of the leafstalks. The bulk of the plant as a whole consists of mere leafstalk. It is certain that by way of enquiry into this matter Cordus has dissected those leaf-stalks; for the first clause of his description of the plant is this: "Sagitta has triquetrous petioles, very thin and

1 See pages I 82, I 85 preceding.

2 Hist. Pl., p. I 22. 
spongy as to the inside, a yard high or sometimes longer, or shorter, all according to the depth of the lakes in which it grows."1 In like manner he has examined the interior of the flower stalk in its turn, ascertaining that while smaller than the petioles it is also of "spongy texture, and of remarkably light weight."

The water lilies are plants large in all their parts, so that viewed in cross section they exhibit clearly their structural characteristics, and he notes them fully. What he takes for the main root of Nymphcea alba he reports to be as thick as one's wrist lying horizontally along the mud, knotted on at the places where the leaves of former seasons were inserted, are quite black on the outside, but of a clear white within, and of a very spongy and porous substance. The fibres that descend from these into the ground he reports to be outwardly greenish-white, quite white within and also porous. The stalks that support the flowers and leaves in this species he finds to be terete, and to have open tubes extending throughout their whole length within. The yellow water lily rootstock he finds less knotted on the outside, and white both without and within; otherwise like the former, but with coarser fibrous roots and these still more spongy; the petioles, obtusely angled rather than terete, show smaller tubes in the middle. ${ }^{2}$

There was a coarse rank dry land herb, the teasel, Dipsacus silvestris, which lent itself as readily to Cordus' anatomical inspection. He says it is of but biennial duration; that its root, of a finger's thickness, during the first year of its life is fleshy; the second it is of a ligneous hardness, and in that condition dies after the plant has flowered and fruited. The tall stem of the plant he remarks is heavy enough to warrant the inference that it is solid; nevertheless he finds it hollow throughout in the very center. Even the large egg-shaped head that bears the flowers and the seeds on its surface he has cut across in each direction to find that within it is filled with what he calls a woolly pith. ${ }^{3}$ And this inspection of the interior of stems is made not only in easy and inviting cases, but everywhere. Seldom is there wanting to any of his plant descriptions the clause that tells of the internal structure of its stem, as being solid, or hollow, or as filled in the center with pith; and the color of the pith is also often given. Manifestly the cutting of stems across is as much a part of his work with herbaceous plants as it is to note the exterior of them as terete or angled, smooth or rough, even-surfaced,

${ }^{1}$ Hist. Pl., p. $86^{2}$.

2 Ibid., p. 99.

s Ibid., p. $105^{2}$. 
or striate, or fluted; and he is particular about mentioning every such characteristic. Of still deeper interest are his dissections of all manner of fruits, fleshy and capsular, and of seeds; but on account of the taxonomic significancy of their results, these have been reiated under another heading.

The intimations of what seemed like a sense of feeling in some mimosaceous foliage had been one of the wonders of plant phenomena as observed by ancient Egyptians and Greeks. Cordus had seen no mimosa, or sensitive acacia, but in two plants frequent in German gardens he observed the foliage remarkably sensitive to varying meteorological conditions. In his very full and minute description of the licorice plant the first remark about the foliage, after having stated its character as a compound leaf, is that its leaflets exude some substance by which they adhere to one's fingers when handled; then he proceeds to describe the several different degrees of enfoldment or of expansion which the leaflets exhibit according to the altitude of the sun on clear days, and how they keep themselves folded together all day long if the sky be cloudy or the weather wet or cold; concluding with the observation that all this is true of the leaflets only, and that the leaf-stalk itself does not alter its position at any time of the day, and that in all kinds of weather its attitude is the same. ${ }^{1}$ This last remark is called for by what he had said in an earlier chapter about nyctotropic movement in the common foenugreek. ${ }^{2}$ In this he says the nightly folding together of the leaflets is accompanied by a deflection of the whole leaf, petiole and all.

In every description of a twining species of herb Cordus mentions the direction of the circumnutation, whether as following the course of the sun or as taking the contrary direction. Of these phenomena he is the first of all writers to make record, I think. He was the first to describe the plant called sundew, ${ }^{3}$ and its physiology interested him. Its description occupies the first chapter of the Historia, and as a new genus he would like to call it Rorella. 4 He seems to have perfectly established it, that what seems like dew on the leaves of the plant is really an exudation; for he says that in the very driest weather the plant is still sprinkled all over

Hist. Pl., p. $164^{2}$.

2 Ibid., p. гоo.

3 Ibid., p. 86.

4 Tragus had known Drosera rotundifolia, and has it figured as a species of Polytrichum, P. minus (Stirp.Comm., p. 528). He said its habitat was "dewy rocks," and had no idea that the "dew" on its leaves was an exudation. 
with those minute drops that have the appearance of dew. $\mathrm{He}$ has done what was in his power to ascertain at least the qualities of those minute glistening drops. He has tasted, and reports the flavor to be a little bitterish, with also a hint of the acidulous, and slightly acrid.

The plant physiologist of to-day, interested in the functions of the root tubercles of leguminous plants may find in Valerius Cordus the earliest mention of these organs. I do not find him taking note of them except as occurring in the cultivated lupine of Europe. Accustomed to give a full account of every kind of root, even to its medicinal usefulness or uselessness, he says of that of the lupine that it is "slender, woody, white and without useful properties, parted into a few slender fibres upon which there sometimes grow small tubercles." 1

Ecology. We have already been learning that even from the most primitive times every botanist was an ecologist; at least to the extent of observing and recording the special environment which every kind of wild plant affects, and sometimes to the mentioning of some of its associate species. Valerius Cordus, being well skilled in both chemistry and mineralogy, goes beyond all his predecessors in that he names the petrography of a plants' habitat, or otherwise indicates the constituency of the soil in which it is to be looked for. We can in no other way so well present this, his own new aspect of matters ecological, than by the translation of a few of his passages.

The fern called hart's tongue, best known as Scolopendrium, but which Cordus knew as Phyllitis, he says, "grows on shaded and rocky declivities of mountains; loves a rich soil, though not springing from the soil directly, but from the moss that covers the rocks, especially limestone."'2

To Saxifraga Aizoon he attributes the habitat of "Limestone cliffs, especially where they are wet and overgrown with moss." 3

Describing two species of Sanguisorba, that which he calls $S$. major "inhabits low clayey pasture lands that are subject to inundation from rivers," while S. minor also "grows in clayey soil, or even gravelly, but on open sunny slopes and along roadsides." 4

He seems to take a special interest in the ecology of such plants as he has himself first discovered and described as new. The

1 Hist. Pl., p. 137 .

2 Ibid., p. $x_{3}$.

3 Ibid., p. 92.

4 Ibid., p. 144. 
cranberry is one of these. ${ }_{5}^{6} \mathrm{He}$ says he found it growing "in wild and very wet and soft mossy bogs; often with the sundew not far away."1 Then, under his description of the sundew itself-also new-we learn that he found that, though as a neighbor to the cranberry, yet in soil distinctly of another character, that is, "in very wet sandy places." 2

In the case of that new generic type which he denominates Moschatella (=Adoxa, Linn.) he mentions its most interesting associates. "It grows in shady places, under trees, in soil very rich, along with the fumariaceous kind of Celandine (=Corydalis cava) and also the ranunculaceous Celandine (=Ficaria ramunculoides $\left.{ }^{3}\right)$."

Cordus knows at least one specific type which, as he observes, has a way of establishing itself upon some diversity of soils, and adapting itself to several different kinds of locality; and the phases which it assumes according to its altered environment so much interest him that he gives a particular account of them. The subject is the shrub Spartium scoparium.4 He says: "It inhahits rough places on mountains in a hard reddish soil somewhat sandy, as in Hesse, etc.; but sometimes occurs on the lowest plains in mere sand and gravel, as about Nuremberg, etc. Nor should it be left unmentioned that while on sandy plains it is a low bush seldom exceeding a yard in height; on the mountains, where the soil is better, it approaches the dimensions of a tree, with a trunk from seven to nine feet high and so thick that one can not span around it, supporting a head of virgate branches so dense as to intercept and hold all the snow of a considerable storm, so that the traveller, passing through such a wood in winter, may walk on almost bare ground under arches of snow overhead."

There is no indication that the author would distinguish even as varieties these rather strikingly different phases of the shrub. He regards them as the natural products of different conditions as affecting a simple species. It is the well skilled botanist's view, whether of the sixteenth century or of the twentieth.

Pomology. The recognition of marked varieties in the same species of cultivated fruits - varieties originating under cultivation -is so very ancient that there is no hope of one's ever tracing it to

1 Hist. Pl., p. I 40.

2 Ibid., p. 86.

3 Ibid., p. I $72^{b}$.

- Ibid., p. I89, as Genista angulosa; where- the editor, Gesner, made the inexcusable error of inserting Tragus' wood cut of the extremely different Genista sagittalis. 
its beginnings. Also before the dawn of history men had learned that valued varieties of fig, olive, grape, and other fruits could not be depended on to come true to seed. Seedlings of these were apt to prove degenerate, as they called it; and the propagating of them by layers, and especially by grafting, had been invented as the sure means of preserving and perpetually reproducing choice varieties.

They who wrote of fruit culture two thousand years ago and more mention by name great numbers of varieties, not only of fig, olive, and grape, but also of peaches, cherries, and other fruits; sometimes favoring the reader with a few hints of the differences subsisting between two varieties; but I have met with nothing like descriptive lists of the varieties of even such common and variable fruits as figs, olives, and grapes, in the writers of antiquity; nothing that was written for the purpose of enabling the reader to identify the varieties. I can not discover that any one anterior to Valerius Cordus, engaged in this kind of an enterprise.

There are long chapters in Cordus' book which so read as to make it certain that in the course of his botanical expeditions to many parts of Germany, as well as at home, he made everywhere very special studies of the different varieties of apple and pear which were under cultivation in the orchards of the time, and that he wrote a careful description of each on the spot, and that so full that the properly qualified reader would be able to indentify the different kinds by the description alone. I say the qualified reader, meaning of course the educated; for every line of Cordus' pomologic writing, like all the rest of his botany, is in Latin; and a knowledge of the Latin terminology of descriptive botany is essential to the full understanding of hin here.

With the intention, then, of interesting the botanical fraternity in this diversity of cultivated varieties, he describes as many as fifty named varieties of pears, and thirty-one of apples, all of which he has found in one part or another of Germany. ${ }^{1}$ The original German names are always given, then the name is turned into Latin as if for the convenience of the botanists, all of whom in the time of Cordus, like the other educated people, find Latin the only adequate medium of scientific converse. The excellency of these pomologic diagnoses can more readily be seen than described, and I therefore present English translations of two or three of them; and since it is his practice to describe one variety partly by comparison with another, I shall take up three descriptions that are consecutive. 
Also inasmuch as most of the pears which one sees in the fruit marts of to-day are quite pear-shaped, I shall begin with one which Cordus knew that was globose as an apple.

"KAULBIRN, that is, Globe Pear, is almost as round as a globe, except that at base it ends in a blunt and scarcely manifest protuberance. It is hardly two inches long, seldom at all exceeding that, and the diameter is a trifle greater than the length. The color is altogether pale green; the flesh very tender, melting in the mouth, and of a mild delicious flavor, and by its abundant juiciness satisfying thirst, delightfully fragrant when pared. This matures at the beginning of autumn, and is very perishable. It is cultivated about Eisleben.

"HAUFFBIRn, that is, Hemp Pear, is similar to the Globe, but a little larger, in color green, with darker spots and dots; in flavor answering to the Globe, but the flesh not as tender and juicy; matures at the same time and soon decays. This also is grown at Eisleben.

"Glockenbirn, that is, Bell Pear, is abruptly narrowed below into a narrow neck, this again at the very base widening into a blunt head-like protuberance, the fruit as a whole having the configuration of a bell, ${ }^{1}$ whence it has its name. The color is yellow, well specked with green, the length a trifle less than three inches, the diameter not more than two inches. Rather fragrant when pared; the flavor that of the Hemp Pear; matures at the same time with that and is perishable. Grown in quantities at Eisleben.

"KüNIGSBIRN, that is, Royal Pear. Large and ventricose, sometimes four inches long, the diameter somewhat less; color blue-green, but on the side exposed to the sun faintly reddening. Flavor a trifle astringent, flesh somewhat juicy and vinous, assuaging thirst. Matures at the end of September and is not very perishable.'

It is perhaps less difficult to describe apples well, than pears; and all those familiar to Cordus are very vividly depicted. We present two or three:

"HARTlinge Weiss, that is, White Harding. Somewhat depressed-globose, the height about two inches, the diameter two and a half or somewhat more. Colored reddish-yellow on the sunward side, elsewhere greenish-white, dotted with specks that seem to lie beneath the transparent epiderm. Flesh tender though firm, juicy, of an acid-vinous and excellent flavor; the fruit fragrant

1 That is to say, a hand bell, with its handle. 
for a considerable period after having been stored. Ripens in early autumn and keeps until the end of winter.

"Grown almost throughout Germany.

"Saffranecke. Saffron Apple. In quality scarcely second to any apple, this is also nearly globose and but an inch and a half in diameter, the breadth not rarely a little exceeding the length. Color something between green, yellow, and pale saffron; in warm and dry seasons adorned with dots and narrow streakings of scarlet and orange; in moist and cloudy summers devoid of any such markings. Flesh tender, sweet, slightly acidulous, luscious, and with a kind of spicy pungency which commends it to any palate. Moreover, it is delightfully fragrant. Begins to ripen in early autumn, and keeps until the vernal equinox, and frequently even longer.

"Cultivated at Hildesheim, particularly in the orchards of the monks at the monastery in Sulta, located outside the city.

"Hartlinge Rot. Red Harding. Either much flattened at the ends and orbicular, or now and then quite globose; in size also as variable, but on the average perhaps about two inches high, and two and a half in breadth. Color rose-red, marked with long blood: red stripes. Flesh rather solid and dense, yet very tender, juicy, acidulous, and with a peculiarly luscious flavor. Rather pleasantly scented. Ripening in early autumn, and the most enduring of all apples, sometimes keeping until the middle of the next summer, and, according to the statements of some, even longer than that.

"It is found in almost all orchards of nearly every part of Germany."

I apprehend that a skillful pomologic artist should be able to draw and color these apples and pears so vividly word-pictured by this perhaps the very first of descriptive pomologists, and for the history of pomology it may be doubted that there are extant any more important chapters than these written by Valerius Cordus three hundred and seventy years ago.

Commemorating Valerius Cordus, Plumier established the genus Cordia in the year 1703 . 


\section{INDEX}

Abiogenesis, Tragus on, 236, 237

Abrotonum, genus, I Io

Absinthium, Seriphium, 2 I 2 vulgare, 2 I 2

Acacia, Arabica, I 32 metamorphic kinds of, ${ }_{1} 38$ senegal, I 32 wild plum mistaken for, 266

Acanaceæ, family, I I4

Acanthus, genus, I I 6

Acarna, name of thistle, II3

Acer pseudo platanus, 237

Achillea, genus, 246

Acines, leaves mistaken for, 258

Aconitum, genus, I I 6

Acorus Calamus, I 23

Acte, Greek for Sambucus, I I9, 208

Adam, Melchior, biographer, 220,222

Adanson, M., criticises Pliny, I 59 dedicates genus to Nicander, I45 historian of botany, I 6

on early authors, I 7

views of botany comprehensive, I 6

Adiantum, genus, 2 I 6

Adonis æstivalis once thought an Anthemis, 2 I 4

Adoxa, discovered by Cordus, 3 I I

Ægilops, genus, I 6

Aërial roots, Theophrastus on, 75

Estivation noted first by Cordus, 288,280

Affinities, of Bryonia seen first by Cordus, 298

of Capsicum not seen by Fuchs, 2 I 0 of Capsicum suggested by Tragus, 252

of Datura seen first by Fuchs, 209

of Glycyrrhiza shown first by Cordus, 296

of Mom srdica shown first by Cordus, 298

Agamemnon and famous trees, I 35

Age of trees, Theophrastus on, I34

Agricultural botany, of antiquity, I 44

treatise by Cato, 146

work by Columella, I $5 \mathrm{I}$

work by Varro, 148

poems of Virgil, I 49
Agrimonia, genus, 255

Agrostemma Flos Joris, I 23

Agrostis, genus, I 6

Aira, genus, i I 6

Alæ, early term for axils, I99

Alder tree, once believed flowarless, 88

credited with flowers by Theophrastus, 88

Theophrastan ecology of, I 27

aments of, described by Tragus, 228

Alexander the Great, scientific staff of, I 33

Alexipharmica, work of Nicander, I 45

Alexius, Greek rhizotomus, 49, 50

Algæ held to be plants by Theophrastus, 73

Alliaria, Tragus on ecology of, 257

Almond flowers studied by Theophrastus, 85

Alnus oblongata, I $2 \mathrm{I}$

Alopecurus, genus, I I 6

Alphabetic sequence, abjured by Tragus, 239

not used by Brunfels, $x 76$

precludes rational system, I 76

Althea, genus, I 6

Amaryllis, part of early Lilium, 42

Amelanchier vulgaris, 123

Aments, of alder described by Tragus, 228

of hazel described by Theophras. tus, $8_{3}$

of pine overlooked by Theophrastus, 88

of willows, Tragus on, 229

Ammi, genus, i 85

Amygdalus Persica, 34

Anagrammatic names, 219

Anatomy, Theophrastus on, 67, 97IOI

of mullein by Tragus, 225

of many plants by Cordus, 307-309

Anazarbos, birthplace of Dioscorides. I 52

Anblatum, old name of Lathræa, 304

Anchusa, genus, I I 6 
Ancient husbandry, ${ }^{50-I} 53$ phytographic method, IO2, IO3

Andes, birthplace of Virgil, I 49

Anemone nemorosa first published, 180

Anethum, genus, I I 7

Angiosperm, Theophrastan term, 94 , It I

Anguillara, L., Italian botanist, I 55

Animal and plant, Linnæus on, 73 Theophrastus on, 63

Anise, as Thcophrastan gymno sperm, 94, 95

inspach, Fuchs' life at, I 93

Antennaria dioica, 2 I 1

Anthemis of Fuchs, 2 I $_{3}$

Anthers, early names for, 233, 290 coloring of, noted by Tragus, 234 dust of, named pollen by Cordus, $290,29 \mathrm{I}$

versatile insertion noted by Cordus, 290

Anthology, little regarded by Brunfels, i 8 I

of Cordus, $282-292$

of Fuchsius, $2 \mathrm{O}_{3}-2 \mathrm{O}_{5}$

of Theophrastus, $82-90,2$ I I

of Tragus, $227^{-236}$

Antirrhinum, genus, i 7

Aparine, genus, I I 7

Apetalous flowers, Theophrastus on, $85,86,14$ I

Apices, early name of stamens, 233, 290

Apium, genus, 260

Apodixis Germanica of Tragus, 220

Apple blossoms studied by Theophrastus, 85

Apuleius quotcd by Brunfels, I 73

Aquilegia, ccology of, 257

Arabian vegetation, Theophrastus on, 133

Arboreal growths, Theophrastus on, I 26

Arbutus flower perplexes Theophrastus, 90

Archaic philosophy of plant life, 61

Arctostaphylos, gcnus, I 64

Aristolochia, Corydalis mistaken for, 173,266

Aristotle, bequests of, to Theophrastus, $5^{6}$

evolutionist, 24 I

father of biologic research, I 3 I

founder of first botanic garden, $5^{6}$, 97

friend of Theophrastus, 55,56

Armeniaca vulgaris, 34

Arnoglosson, Greek for Plantago, 208,2 I 6

Arum, genus, I I 7

early descriptions of; 278,279

Theophrastus on anatomy of, I I 2
Arundinaceæ, family, I I

Arundo, genus, 75

Donax, I I I

Asarum, ecology of, 257

Ash tree, Theophrastus on leaves of, 79

Asparagus, cladodes of, 79

Asphodel, roots of, 75

Aspidium filix mas, 294

Aster, genus, I 25

Asteracticus of Cesalpino, I 25

Aster Atticus, I 25, 2 I 6

Athenæus, early medical botanist, I 44

Athenian olive tree, I34

Athens, ancient garden at, 97

Atropa Belladonna, 209

Aurelius, Marcus, patron of Galen, I 6 I

Australian metamorphic trees, I 38

Avicenna, early Arabian botanist, I 3 I

Avicennia officinalis, 33

Balsamella, early name of Impatiens, 304

Banister's Catalogue quoted, 36 early names of Virginian oaks, 36

Banyan tree, Theophrastus on, 74

Barbarus, Hermolaus, cited, I 79 commended by Fuchsius, I $96-197$

Bark, wood, and pith, Theophrastus on, 97

Barley, germination of., Theophrastus on, 96

Batrachium, Greek for Ranunculus, I 19

Bauhin, C., on Trifolium, 3 I, 32

Beccabunga, Tragus on habitat of, 259

Beech tree flowers, first account of, 228

Bibliotheca Botanica of Haller, $26_{3}$, 272,275

Universalis of Gesner, I 7 I

Bidens, genus, I 20

Biennials and annuals, Theophrastus on, 68

Binary generic names, approved by Cordus, 305

examples of, in Brunfels, I 85

suppressed by Linnæus, I 85

prevalent in vernacular, I 24

used by Fuchsius, 2 I 0

used by Theophrastus, 123

used by Tragus, 255

Binary specific names, before Theophrastus, 59

employed by Brunfels, I9 I

examples of, in Banister, 36

universal with Cato, 146,147

used freely by Bauhin, 3 I 
Binary specific names Continued. used by Cordus, 307 used by Theophrastus, I 25

Biologic, nomenclature, I 90 sequences of Theophrastus, I0० work begun by Aristotle, I 3 I

Bipinnate leaves, first mention of, $8 \circ$ Birch flowers noted by Tragus 228

Birds, fancied parents of orchids, 237

Bistorta, genus, 274

Blastoi, Theophrastan term, 8I

Blitum, Theophrastus on, 95

Bock, Jerome, and Otto Brunfels, I 7 I

Boerhaave, H., Adanson on, I 7

Borraginaceæ, family, $183,25^{2}$

Borrago, genus, $I_{3}$

Botanic garden of Aristotle, 56, 97

Botanical, names, origin of, 27,43

nomenclature, I 89-I 9 I

principles of Cordus, 295, 297

terminology, 23, 26, 29

vocabulary of Fuchsius, 197

Botanische forschungen des Alexanderzuges, ro3

Botanists, Linnæus' classification of, $5^{2}$

Botanologicon, work of $\mathrm{E}$. Cordus, 205,209

Botany, aims of, I 3 ancient elementary, 63 antedating all books, 43 antiquity of, 37

beginnings of, $2 \mathrm{I}-24,43$

definitions of, 7,43

descriptive, two methods in, IOI distinct from plant industry, 7

divisions of, by Sprengel, 20

by Tournefort, $\mathrm{I}_{4}$

duty of historian of, 14

economic, antedating systematic, OI

German fathers of, I0, I65-168

historians of, $14^{-20}$

history of, in general, 9

initial book of, 189

medical, antedating systematic, 6 I philosophic history of, 44

philosophy of history of, I 3-5 I

physiologic, suggested by Varro, I 48

suggestions of prehistoric, 70

terminology of, $23,26,29$

Theophrastan, Bretzl on, IоI, I33

Box"tree, phytographic leaf type, Io 3

Bracts, mentioned first by Cordus, 284

Brandenburg, Margrave of, and Fuchs, 193, 196

Brassica, ancient varieties of, 146

Bretzl, H., on Theophrastan phytography, I01

Bromus secalinus, fabled origin of, I $35^{-1} 37$
Brown, R., on inflorescence, $92,2 \delta_{2}$

Browne, P., dedicates Catonia, I $\$ 7$ dedicates Varronia, I 49

Brunfelsia, genus, I 72

Brunfelsius, Otho, anthology of, I 74 authors quoted by, 172

authorship of, other than botanical, I 72

career of, Sprengel on, I 69

censured, also commended, by E

Cordus, 268

commended by Fuchs, 197

criticised by Fuchs, I 74,170

disregards priority in names, 190

genera credited to, by Sprengel, 185,186

illustrates roots with care, 45

life of, I69-192

physician at Berne, I $7 \mathrm{I}$

phytography of, I 72

plants first published by, I 86, I8 7 teacher at Strassburg, I 69-I 7 I

visits Tragus at Hornbach, I $;$ I

Brunsfels, J., father of botanist, I 70

Bryonia, affinities of, seen first by Cordus, 297

Buckwheat, Tragus on germination of, 239

Bulbaceæ, Theophrastan family, II $f$

Bulbs, as defined by Fuchs, i 95

Theophrastus on, 75

Bupleurum, genus, $2+6$

Burgess, E.S., on Aster Atticus, I 25

Bursa pastoris, 250

Butterfly-shaped flower, noted by Fuchs, 2 I 5

ignored by Tragus, 233

dwelt on by Cordus, $28 S$

Cabalistic names, 219, 307

Cadiz, birthplace of Columella, I 50

Cæsar, Julius, and Varro, $I+7, I+\delta$

Calamagrostis, genus, I I 6

Calamintha, genus, i i 6

Calamodes, Theophrastan group, I I I I 2

Calamos Euosmos, generic name, I 23

Calendula, genus, 185

Calla palustris, 280

Callias, slave of Theophrastus, $5 i$

Callio, frie. 1 d of Theophrastus, 57

Callisthenes, frien 1 of Theophrastus: 57

Caltha palustris, 280

Calyx communis of Linnæus, 287

Calyx, crude early ideas of, 93,203 , 284

of poppies, Tragus on, 230

Camelina, genus, 250

Camerarius, Joachim, 264

Campaniform, anthologic term, 233

Campanula, genus, 233,250 
Capillamenta, anthologic term, 86, 205,234

Capnos, Greek for Fumaria, I 85

Capsicum, genus, $210,252,285$

Capuciaria, early generic name, 2 I 4

Cardamine, genus, I 86 pratensis, 247

Cardiospermum, genus, I 54

Carduaceæ, family, x 8

Carthamus, genus, I 86

Carya Persica, old name for Juglans, 123

Castalia, alba, 122

Lotus, I 22

Castanea, genus, I 86 vesca, I 23

Castle Brunsfels, I 70

Catkins, error of Tragus on, 229

Cato, Marcus Porcius, I 46, I 47

Catonia, genus, 147

Caucalis, genus, 255

Celastrus, genus, I I 6

Cenchrus, genus, I I 6

Centaurea, genus, I 24

Centaurium majus, old generic name, I 24

Centaurium minus, old generic for Erythræa, I 24

Cerasus, genus, I 6

Cercis, genus, I I

Cervix, old botanic term, I 98

Cesalpinus, A., ro, 30, 32, 300

Chamæclema, genus, $3 \circ 6$

Chamædrys, genus, I62, I 85,259

Chamæpitys, genus, 162

Chamærops humilis, I 3 I

Cheiranthus, genus, $2+9$

Chelidonium majus, old generic name, I 24

Chelidonium minus, old name of Ficaria, 124,185

Chelidonium palustre, old name of Caltha, 300

Chondrilla, genus, $3 \circ 3$

Chrysion, Greek name of Cheiranthus, 184

Cincinnalis herba, old name of Verbena, I 85

Circumnutation noted by Cordus, 309

Cissampelus, 303

Cissus, old name of bush ivy, I 39

Cistus, genus, 232

Citrus, aurantium, 34

limonium, 34

medica, 34 , I 33

Classes Plantarum of Linnæus, I 7

Classification, by calyx, 17

by color of bark or wood, 29

by corolla, I 7

by ecology, I 7, I $25^{-1} 27,25^{8-260}$

by flower only, 42 , i I 8

by fruit and seed, $30,34,+\mathrm{I}$

by inflorescence, $\mathrm{I} 7$ by leaves, 26-33, I I $3,242,246$

by qualities, $17,182,209,247,248$

by roots, $42,242,249$

by stems, 32, 10 7, I II, I 79, 242, 247,253

by vegetative organs generally, 239,240

Cleidemus, rhizotomus, 49

Clematis, genus, 2 I 7,253

Clethra, Greek for Alnus, I 2 I

Coccymeles, Greek for Prunus, I 2 I

Cocos nucifera, $\mathrm{I}_{32}$

Colocasia, genus, I I 2

Colors of roots, Theophrastus on, 76

Columella, Lucius Junius, I 5o, I 5 I

Columellia, genus, by Ruiz and Pavon, I 5 I

Commissure, Cordus' term for suture, 293

Cones, Theophrastus on, 94

Consolida, early generic name, I 77

Convallaria, genus, 42

majalis first described, 225,226

Convolvulus, Theophrastus on, 89

Tragus on, 253

Coralloides, synonym of Dentaria, 304

Cordia, genus by Plumier, 3 I 4

Cordus, E., work of, 263,269

Fuchs' estimate of, 267

Cordus, Valerius, anthology of, $28_{2-}$ 292

Dispensatorium, work of, 27 I

ecology of, 3 I 0,3 I I

on fruit and seed, 292-294

Gesner's praise of, 275

Haller's estimate of, 275

Historia Plantarum, work of, 273 , 275

life of, $27 \mathrm{I}-274$

Neyers' praise of, 270

nomenclature of, 304-306

on physiology, 309, 3 ro

on plant anatomy, 307

on vegetative organs, $2 \mathrm{SO}_{2}-2 \mathrm{~S}_{2}$

phytography of, $275^{-2} 79$

pomology of, 3 I I-3It

Ralla, J., uncle and patron of, $27 \mathrm{I}$

Riffius, W., biographer of, 27x, 273

Sachs' neglect of, 270

Sprengel's view of, 270

taxonomy of, 295, 303

Corolla, term unknown anciently, 140

Coronopus, genus, I I 7, 254

Corydalis, genus, 305

bulbosa, I73

cava, 3 I I

Halleri, I 73

mistaken for Aristolochia, I 73, 266

Corylus, a vellana, 87

tubulosa, 87

Corymbiferæ, family, 284 
Cotula, genus, 154

Cotyledons, Theophrastus o12, 96 Tragus on, 238,239 used taxonomically, I 7

Cratægus, Aria, I 2 I torminalis, I 2 I

Cratevas, rhizotomus, $6_{7}$

Cresarchus, friend of Theophrastus, 57

Criteria of affinity, 17

Cucurbita, genus, I 16

Cultivated plants, origin of, $\mathrm{r}_{4}$

Cuscuta, genus, 253

Cyamus, genus, 122

Cyanus, geñus, 255

Cycadaceæ, family, 132

Cycas circinalis, I 32

Cyclamen, genus, 224

Cymo, slave of Theophrastus, 57

Cynoglossum, genus, I 83

Cyperus, genus, I I I

Damascenus, Nicolaus, author, I 43

Daphne, Greek for Laurus, 33

Datura, affinities of, first seen, 209

Cordus on calyx of, $28_{5}$

Metel, 208

præfloration of, observed, 289

Daucus, genus, $28_{4}$

Dead Nettle, r 79

De Causis Plantarum of Theophrastus, $5^{S}$

Deciduous trees, Theophrastus on, I 28

Definition of, botanic terms by Fuchs, r $97-206$

botany by Sprengel, 20

corvmb by Cordus, 283

leaf by Theophrastus, $7 \mathrm{~S}$

root by Theophrastus, 73

umbel by Cordus, $2 S_{3}$

Delimitation of, genera by Tragus, $2+2$

of Ranunculus by Cordus, $29 \mathrm{~S}$

Delphinium Consolida, I 77,2 I 3

Demotimus, philosopher, 57

Dendrologic scene, ancient, I 3 I

Dendrology of, Arcadia, ancient, r 30

Arabian deserts, 133

Egypt, I32

India, $\mathrm{r}_{32}$

middle Europe, I30

southern Europe, Iо3

Theophrastus on, I $28-r_{34}$

Dens Leonis, generic name, 124

Dentaria, genus, 304

De Re Rustica of Cato, 148

Description of, alder aments, 228

Arum by Cordus, 278

Arum by Dioscorides, 278

Cranberry vine, earliest, 3 I I

Cyclamen by Tragus, 224

Digitalis by Fuchs, 2 r 8 elder tree by Theophrastus, 104

hazel aments, earliest, 227

hazel flowers by Tragus, 228

lily of the valley, earliest, 225, 226, mullein by Tragus, 225

Parnassia, earliest, 287

stamens by Cordus, 234

stamens by Tragus, 234, 235

sundew by Cordus, 309

Descriptions, importance of, I 8 of Dioscorides overestimated, I 54

Deserts of Arabia, plants of, I32, I33

Development, influenced by environment, I 27,137

Diapensia, genus, ${ }_{7} 8$

Diary of Tragus, I 9

Dicotyledonous seeds, Theophrastus on, 96

Digitalis, early history of, I 20,2 I 5 , 2 I $8,233,256$

Diogenes Lærtius, biographer, 57

Dionysius, painter of plants, 167

Dios Anthos, old generic name, I 23

Dios Balanos, old generic name, I 23

Dioscorea, genus by Plumier, I 55

Dioscorides, Pedanius, I 5 I

Anazarbos, birthplace of, $\mathbf{I}_{52}$ authority of, in pharmacy, ${ }^{5} 5^{\mathrm{I}}$ describes vegetative organs, I 52 early editions of, $\mathrm{I}_{52}$

early translations of, I 53

Galeopsis, genus by, iso

manuscript copies of, I 67

noted commentators on, I 55, 27 I, 272

plant families of, $\mathrm{r}_{54}, \mathrm{r} 74$

plants known to, I 52

Sprengel on, I $5 \mathrm{I}$

supremacy of, in pharmacy, I 53

taxonomic suggestions of, 155

unites Ebulus to Sambucus, I 54

Dipsacus, genus, I I 3

anatomy of, by Cordus, 308

sativus, as variety, 302

silvestris, generic type, 302

Discovery, adventitious roots, $28 \mathrm{r}$

alder flowers by Tragus, 228

caducous sepals by Tragus, 230

Caltha palustris by Cordus, $30 \mathrm{I}$

dicotyle seeds by Theophrastus, 96, $\mathrm{I}+\mathrm{I}$

disk florets by Cordus, 288,289

Drosera by Tragus, 309

fern spores by Cordus, 294

fig flowers by Cordus, 292

indusium of ferns by Cordus, 294

new types, importance of, r 8, 20

Parnassia by Cordus, 286

pollen by Cordus, 290

præfloration by Cordus, $288-289$

præfoliation by Cordus, 278

snowball bush by Cordus, 301

tubercles on lupine roots, 3 ro 
Discovery-Contmmed

white clover by Guiditius, 187

wood anemone, 186

Diseases of trees, Theophrastus on, I 34

Dispensatory, medical, earliest, 270 , $27 \mathrm{I}$

Distinction between like and unlike, fundamental in science, 2 I

Distinction, earliest, of anatropous and orthotropous, 96

of angiosperm and gymnosperm, 94, I 4 I

of annual and biennial, I.tI

anther and filament, 234

apetalous and petaliferous, 85

aquatic and littoral, I 27

biologic and phytographic, 66

choripetalous and sympetalous, 89,90

compound leaf and simple, 90

corymb and umbel, $28_{3}$

dead nettle and true nettle, $2+4$

equally pinnate and unequally, 282

flower bud and leaf bud, I 59

flowering and flowerless, I 4 I

Galeopsis and Urtica, I 8 I

gemma and germen, I 59

herbaceous and suffrutescent, I09

hypogynous and perigynous, 9 I

leaf and cladode, 79

leaves sessile and petiolate, 78

modes of tree growth, I 29

monocotyle and dicotyle, 96

parenchyma and prosenchyma, 99

rhizome and root, 45

roots, subterranean and aërial, 74

spores and seeds, 293

stamen and pistil, 234

variety and species, I 46, I 47,3 I I

Distinctions, earliest, in restivation, 288,289

in anatomy of trees, 97, 100

in circumnutation, 309

of color in roots, 76

of configuration in leaves, 79

in dehiscence, 278,293

of duration in leaves, 67

of flavor in roots, 76

in floral insertion, $9 \mathrm{I}$

of herb, shrub, and tree, 67

in inflorescence, 92,282

of margin in leaves, 79

morphology in roots, 75

morphology in stem, 77

permanency in organs, 64

placentation, 292

posture in stems, 77

præfloration, 288,289

of root, stem, branch, 6 I

structure in stems, I I 2 surface in leaves, 82

texture in roots, 75

texture in stems, 67

tissue in plants, 97

venation in leaves, I I I

Dodonæus, Rembert, on Dioscorides. I 53

on genus Trifolium, 3 I

Dolichos, Greek for Plhaseolus, 12 I

Donax, Greek for Arundo, I II

name of slave of Theophrastus, 57

Dorsten, botanical author, 39

Draba verna, earliest account of, I 87

Drosera, figured as new, 304, 309

described first by Cordus, 309

named at first Forella, 309

physiology of, by Cordus, 3 I

Drosion, same as Alchemilla, 304

Ebulus and Sambucus, 2.0

Echinops, Cordus on, $28_{3}$

Echium, genus, r 54, 183

Ecologic groupings, by Theophrastus, I 27

by Tragus, $256-259$

Ecology of V. Cordus, 3 Io

Elder flowers, Theophrastus o11, 90

Elecampane, leaf type, 224

Embryology, early notes on, 95-09

Environment, Theophrastus on, 127 , I 32, I 38

Epigynous insertion first noted, 9 I

Eranthemon, old name of genus Adonis, 2 I 3

Erasmus and E. Cordus, 263,264

Eresus, birthplace of Theophrastus, 54

Erinus, Cordus on, $3 \circ 3$

Eryngium, genus, I 3

Erythræa, genus, I 24

Eucalyptus, metamorphosis of, I $_{3} S$.

Eudemus of Chios, rhizotomus, 49

Eupatorium, Cordus on, 306

Euphorbia, Cordus on, 306 antiquorum, 306

Excurrent growth of trees, I 20

Faba, genus, 295

Faba suilla, old name of henbane, I 85

Fabius Columna, writer, on Dioscorides, I 53

Fabled abiogenesis, of mural herbs, $237-238$

of maples, poplars, willows, 236-237 change of barley to wheat, I 37

change of cabbage to turnip, 26 I change of flax to darnel, i 36 change of turnip to mustard, 20 I change of wheat to chess, I 35 
Fabled-Continued

first founding of families, 106

first founding of genera, 106

first recognition of varieties, 106 , 300

origin of binary nomenclature, I I 9

origin of botany, 37

origin of orchids, 237

Fables about flowers, fruits, trees, 59

Fabric, of leaves, Theophrastus on, I00

of stems, Theophrastus on, 97

Families, Adanson's specialty, I 7 established by Cordus, 302 indicated by Tragus, 252-255 named by Theophrastus, I I 4

Family names, ancient, 27

Fancied consanguinity, Adonis and Anthemis, 2 I 4

Alopecurus and Plantago, i i 8

Antennaria and Hieracium, 2 I I

Aristolochia and Papaver, I I 8

Beccabunga and Sium, 259

Convolvulus and Humulus, 253

Drosera and Polytrichum, 309

Hellebore and Veratrum, I 8

Hypericum and Ruta, 244

Lamium and Urtica, I 79, 244

Father of, biology, I36

botany, 52

Roman learning, 147

Fathers of botany, 167,168

iconography, 167,168

phytography, 223

Fée, A. L., on botany of Virgil, I 50

Fern, seeds, Tragus on, 238 spores, Cordus on, 293

Ferula opopanax, I 45

Ferulacea, 27, I I 3

Ficaria, genus, I82, 300 ranunculoides, I 82,300

Ficus, Africana, $1_{4} 6$

Bengalensis, I 33

Herculana, I 46

hiberna, I 46

marisca, I 46

Saguntina, 146

Sycomorus, 130

Telana atra, 146

Fig tree, as flowering, 292

as flowerless, 83,292

as fruiting on trunk, I 30

Fir tree, ecology of, 126 excurrent growth of, I30

Flavors, as indicating affinities, 250 , 251,303

of milky juices, 303

of roots, 76,296

of seeds, $25 \mathrm{I}, 293$

Flax and darne1, I 36

Flocci, early name of stamens, 86

Floral structure, of composites, 289 of crucifers, 2 I I of fig, 292

of gooseberry, 234

of labiates, 288

of leguminous plants, 288

of pæonia, $29 \mathrm{r}$

of pulsatilla, 289

of rosaceous trees, 90, 234

of rose, $29 \mathrm{I}$

Floral symmetry unnoticed, 209

Flos Solis, early name of Helianthus, I 24

Flower, in ancient botany, 84 criterion of affinity, 42, I I 8 knowledge of, delayed, I 74 theory of origin of, I 40

Flowering of hazel, affirmed, 88 denied by Fuchs, 227

reaffirmed by Tragus, 227

Flowering of juniper disputed, 88,89

Flowering of oak, anciently unknown, 83

affirmed by Theophrastus, $8_{3}$

Foliage, phytographic types of, 102I0 5

Fritillaria once part of Lilium, $t^{2}$

Fruit, criterion of affinity, $30,34,4$ I first scientifically defined, 93

Fruit and seed, Cordus on, 292-294 Theophrastus on, $92-96$

Tragus on, 236-239

Fruits, locations of, on trees, 129 , I 30

Fuchsia, genus by Plumier, I97

Fuchsius, Leonhardus, anthology of, 203

artists employed by, 195

cabalistic names used by, 2 I 9

criteria of affinity used by, 2 IO

criticised by Tragus, 227

Digitalis founded by, 2 I 8

early work of, I94

fruit and seed treated of by, 205 , 206

genus dedicated to, 197

Historia Stirpium, work by, I 95

inflorescences indicated by, 20 I

life of, I 92

medical works of, I 93

Memmingen birthplace of, 192

nomenclature of, 2 I 5-2 I 9

organography of, I 97-20I

physician to Brandenburg, I 93

phytography of, 206, 207

professor at Tübingen, I93

taxonomy of, 207-2I 5

terms defined by, I 97-206

university life at Ingolstadt, I93

unpublished work of, I96

Fumaria, genus, 185

ecology of, 257

Fumariacæ, 265

Fumus terræ, early name of Fumaria, I 85 
Functions of organs, Theophrastus on, 74,75

Fungi, as doubtfully plants, 73

as undoubtedly plants, 73

early mention of poisonous, I 44

early treatise on edible, I 44

Galenia, genus, I 04

Galenus, C., Adanson on, 164

Haller on botany of, I 62

ignores phytography, I 63, I 68

native of Pergamos, I6o

physician at Rome, I6I

profoundly learned, i 60

widely travelled, I 60

Galeopsis, genus, I 79

Gansblum as generic name, I 87

Gart der Gesundheit, early work, I 67

Genera, anthologically founded, 42, I 17

based on leaf characters, $26,29,3 \mathrm{I}^{--}$ 33 , I I 3

carpologically founded, 300

ecologically founded, $25^{8}, 259$

interrelations of, debated, i I 4

major, early term for families, 208

many monotypic, 24 I

reduced number of, 242

term as used by Fuchs, 207

Generic names, primcval, 27

Theophrastan, I I 6, I I 7

of two distinct words, I 24, I 25,2 I 6

Genista angulosa, 3 I I

sagittalis, 3 I I

Genus, various meanings of, I I 5 , I I 6

Georgica, of Nicander, I 44

of Virgil, I 49

Geranium, names of species of, 2 I 9

Gesner, C., bibliographer, I 43

Bibliotheca Universalis, work of, I 7 I

editor of Cordus' works, 276,3 Io

on Greek botanists, I 43

Opera Botanica of, 274

Ghini, Luca, Iо, 273

Gleditsch, Adanson on, I 7

Glycyrrhiza, Cordus on, 296

Gooseberry flower, Tragus on, 234

Grape wood, anatomy of, 96

Greek botany before Theophrastus, 60

Guiditius, J., artist to Brunfels, I 7 I

Gymnosperm and angiosperm, I4 I

Haller, Albert, Adanson on, I 7

Bibliotheca Botanica, work of, 52, $26_{3}$

criteria of affinity relied on by, I 7 estimate of Theophrastus, 52

on Galen as botanist, $\mathrm{I} 62$

Hans Weyditz, artist to Brunfels, I 7 I

Hawthorn, early ecology of, I 26 flower of, Tragus on, 234

Hazel, anciently thought flowerless, 88

aments first described, 87

flowering first announced, 88, 227

flowering denied by Fuchs, 227

flowers described by Tragus, 227

Head, term as used by Fuchs, 206

by Theophrastus, 92

by Tragus, 230

Heart, earliest term for pith, 98

Hebrew classics as to botany, 23

Hedera Helix, metamorphosis of, I 39 phytographic leaf-type, Io 2

roots, aerial first noted, 74

Hedera Terrestris, generic name, I 24,254

changed to Chamæclema, 306

changed to Glechoma, I 24

Heidesbach, birthplace of Tragus, 22 I

Heinrich Füllmaurer, artist to Fuchs, I 95

Helenium, genus, 225

Helianthemum, genus, 305

Helianthus, genus, I 24

Heliotropism, noted by Varro, i 48

Helix, formerly held bigeneric, I 39

Hellebore, early experience with, 49 popular name of, 23 I

Hemerocallis part of Lilium, 42

Hepatica, genus, I 76,180

alba, earliest name of Parnassia, 286,305

Herb, term of many meanings, Ioo

Herba Apollinaris, old name of henbane, I 85

Herba fumaria, early name of Fumaria, I 85

Herba, Sacra, early name of Verbena, I 85

Herbaceous stems, early classification of, 78

studied anatomically by Cordus, 307

Herbarum Viva Icones of Brunfels, I 65, I 85

Hercules' Athenian olive tree, I 34

Hermolaus Barbarus, commended by Fuchs, I 96

Hesiod and Homer, 20, $5^{\mathrm{I}}$

Hesperis matronalis, 249

Hessus, Eobanus, and E. Cordus, 204

Hibiscus trionum, 232

Hieracium, Cordus on, $3 \circ 3$

Pilosella first figured by Fuchs, 2 I I

Hieronymus Herbarius, 220

Hieronymus Tragus, 220

Hilum recognized by Theophrastus, 96

Hipparchus, friend of Theophrastus, 57

Hippocrates, Greek physician, I 44

work of, translated by Fuchs, 192 
Hippon, rhizotomus of note, 58 , i I 4 , I 75

Historia Naturalis of Pliny, I 57

Historia Plantarum, of Theophrastus, 58,228

of Valerius Cordus, 274, 275

Historia Stirpium of Fuchs, I 95

Historian of botany, duty of, I 4

Historians of botany, methods of, I $4-16$

History antedated by science, 2 I

History of botany in general, 9

Hollyhock, Tragus on, 230

Holly-leaved oak, ecology of, i 26

Holly tree, ancient habitat of, I 30

Homer and Hesiod, 20, $5 \mathrm{I}$

Homo, genus characterized by Linnæus, 73

Hordeum, genus, I I

Hornbach, residence of Tragus, $17 \mathrm{I}$, 222

Hortus Sanitatis, 167, I 73,195

Hotbeds in ancient gardens, I 5 I

Hugo Bretzl on Theophrastus, I I I

Humboldt, Theophrastus compared to, 132

Humulus, genus, 253

Hydrophilous plants of Theophrastus, 126

Hyoscyamus, genus, 185,284

Hypericum, description of, 245 olympicum, I 45

Hyphene coriacea, I3 I

Hypogynous insertion first noted, 9I, I 4 I

Icones, Herbarum Vivæ, of Brunfels, I $65, \quad$ I69, I 92

artist of, I 7 I

Iconography, in use anciently, I 67

German fathers of, 167,168

Ilex, Greek name of an oak, 4I

Impatiens, genus, 304

Indusium of ferns seen first by Cordus, 294

Industrial botany, 60

Industrialist and systematist, 29, 59

Industrialists' use of word fruit, 93

Inflorescence, Cordus on, 282,283

Fuchs on, 201, 202

Meyer on history of, 282

Theophrastus on, 92, 93, I 4 I

Initial book of botany, I 89

Insertion of flower, Theophrastus on, 90, I 4 I

Intybaceæ, family, 303

Intybus sativus, 303

silvestris, 302,303

Inula Helenium, 224

Involucrum, term used first by Cordus, 279

Iris, æstivation of, first noted, 288

Isatis, affinities of, 250
Isophyllon, prior name of Bupleurum. 304

Italian efforts to restore botany, 196

Ivy, noted plant anciently, I 03

leaf of, a descriptive type, Io 3

Ixos, Greek for mistletoe, 74

Januensis, Simon, author, I 73

Jecoraria, genus, i 76

Jerome, Saint, on Theophrastus, 56

Juglans, genus, 29,40

alba, 29

nigra, 29

regia, 29

Juli of hazel, Theophrastus on, 87 Pliny on, 87

Julus, Latin for ament, $s_{7}$

Juncaceous plants, Theophrastus on, I 12

Jung, J., student of leaves, 80, 8 I

Juniper, ecology of, 88, i 26

flowering of, 89,90

Kalamos, same as Calamus, 77

Kalmia, genus, 33

King's Torch, popular plant name, 225

Kuntze, Otto, and Gansblum, I 87

Labiatæ, I 79, I 8 I, 20I, 242, 288

Lactuca, genus, 302

Laërtius, Diogenes, biographer, 57

Lamarck dedicates Virgilia, I 50

Lamium, genus, 2 I 5 maculatum, I 79

Lappa, genus, 254

Lappæ, family, 254

Latinity, as to nomenclature, 29 not necessary to system, 29

Laurus nobilis, 33 Theophrastan leaf-type, Io 2

Lavandula, genus, 202

Leaf, anatomy of, IOI, I I I

criterion of affinity, $3^{\mathrm{I}-3} 3$

faces of, 82

physiology of, 8I

transient organ, 64

Leaves, classifications of, 104, I 28 descriptive types of, IO2-I04, 224 margins of, 105

outlines of, 102, I05

Lepidium, genus, 247,250

ruderale, 247

Lesbos, ancient name of Mitylene, 54

Leucippus, tutor of Theophrastus, 55

Leucoion, Greek for Matthiola, I84, 23 I

Life, seat of, in plants, I 3 I of plants, how shortened, 92

Lily of the valley first described, 225 , 226

Limnesion, genus, 304

Linnæanism of Sprengel, 20 
Linnæus, C., amendinents of, 2 I 7 classifies botanists, $5^{2}$ compares plant and animal, 73 dedicates genus Galenia, I 64 generic names by, I 85 ignores subterranean stems, 76 judgment of, as to Theophrastus, 52

nomenclator, I i 9, 2 I 6,305 opinion of, as to Aristotle, 52 refers fig tree to cryptogams, $8_{3}$ Species Plantarum of, 23 zeal of, for Cesalpino, 30

Lithospermum, genus, 298

Lobel, M. de., Adanson on, I 7

Longevity of, Leonicenus, 264 Theophrastus, 56 trees, I34

Lonicera, genus, 253

Lotus, genus, 32

Lupha, genus, 278

Lupinus, properties of, 310

Lycopersicum, genus, I 64

Lycopus europæus, $2+3$

Lycostaphylus, prior name for Opulus, 304

Macedonia, ancient trees of, I 26

Magnus, Albertus, botanist, I 65

Malpighi, and Theophrastus, 97 ignored by Tournefort, I 5

Malus, genus, amplified, 34 communis, ancient varieties of, $3+$ communis, mediæval varieties of, $3 \mathrm{I} 3,3 \mathrm{I}+$

Nalvæ, early name of Malvaceæ, 254

Mandragora, genus, $28_{5}$

Manes, slave of Theophrastus, 57

Maranta, commentator, on Dioscorides, I 53

Marcellus Virgilius, Fuchs on, 197

Marchantia, genus, I 76

Margrave of Brandenburg and Fuchs, 193, 196

Marine, aquatics, Theophrastus on, I 28

fig tree of Theophrastus, i 28

littoral plants, I 28

oak, a cural, , $2 \mathrm{~S}$

Maro, Publius Virgilius, $1+9$

Marrow, ancient name of pith, 98

Marrubium palustre, $2+3$

Martyn, J., on botany of Virgil, I 50

Matricaria, genus, 2 I 3

Matrix, Theophrastan word for pith, 99

Matthiola, genus, 23x, $2+9$

Matthiolus, A., commentator, on Dioscorides, I 53

Medicago, genus, 31

Mediterranean region, trees of, I03 umbellifers of, I I 3
Melampyrum of ancients, 121,136 , I 37

Melanthus, father of Theophrastus, 54

Melilotus, genus, 31, 32

Melissa, genus, i 86

Melongena, genus, $28+$

Memmingen, birthplace of Fuclis, 192

Menestor, rhizotomus, $5^{8}$

Mentha, genus, $2+3$

Menyanthes, genus, 3 I

Mesophyll noted by Theoph rastus, I I I

Mespilus, Amelanchier, I 2 I

anthedon, I 2 I

cotoneaster, I 2 I

Metamorphosis in trees, 138 , I 39

Metapliysical definitions in biology, 74

Meteorology and plant life, 72

Method of Theophrastus, $60-72$

Metrodorus, Greek painter of plants, I 67

Meyer, A., artist to Fuchs, I 95

Meyer, E. H. F., on Aristotle, 55

on inflorescence, 92

on Nicander, $\mathbf{I}+7$

on Valerius Cordus, 92

Mimosa polyacantha, 8o, I 33

Mimosaceæ, metamorphoses of, I 39

Mistletoe, Tragus on, 257

Mitylene, native island of Theophrastus, 53

Modern botany and Theophrastus, I 40

Modes of flowering in trees, $9 \mathrm{I}$

Molo, slave of Theophrastus, 57

Momorica, genus, 253, 297

Monachella, old name of larkspur, $2 \mathrm{I} 4$

Monophyllous flowers, Theophrastus on, 90, 9 I

Nonotypes, early preponderant, $2+\mathrm{I}$

Theophrastan, I 6 , I 2 I

Tragus on, $2+2$

without specific names, 2 I 6

Morphologic descriptive types, I 03

Morphology, disregarded, 2 Io distrusted by Theophrastus, 76,77 of flower, Theophrastus on, $8_{3}$ of leaf, Theophrastus on, $8 \mathrm{I}_{2}, 83$

Moschatella, prior name of Adoxa, 310

Moss, sundew taken for, 309

Mosses, Tragus on, 258

Mulberry tree as flowering, 86

Mullein described by Tragus, 225

Mushrooms, Nicander on, I 45

Myosotis, genus, ${ }_{1} 8_{3}$

Myrtus, alba, I 46 conjug 9 lis, $I+6$ nigra, $1+6$

Nasturtium, aquaticum, $2+7$ 
Nasturtium-Continued

hortense, 247

officinale, 247

pratense, 247

Natural sequences of Tragus, 238

Nelumbo speciosa, I 22

Nenuphar, genus, 190

Nerium, odorum, 33 oleander, 33,133

Nicander of Colophon, I44, I45 on agriculture, I 44

on mushrooms, I 44

on poisonous plants, I44

Nicandra dedicated by Adanson, 146

Nile region, ancient dendrology of, I 3 I

Nomenclature, of Brunfels, I $84-197$ of Cordus, $30_{4}-307$

of Fuchs, 2 I 5-2I9

generic, universal, 29

of monotypes, 2 I 6

point of departure for, 189

specific, necessity of, 30

of Theophrastus, I I 8-I 25

of Tragus, $254-256$

vernacular, $27,36,4 \mathrm{I}, 42,5 \mathrm{I}$, I I 8

Nummularia, genus, 253

Nymphæa, genus, I90

alba, I 22

Lotus, 122

lutea, I 22

Nelumbo, I 22

Oaks, flowers of, first described, 227 generza of, $4 \mathrm{I}$

longevity of, I34

Pliny on, 4I

Ray on, $4 \mathrm{I}$

Ocimoides and Ocimastrum, 2 I 8

Odors, as indicating affinities, 2 ro,

$$
244^{-248}
$$

of roots, Theophrastus on, 76

Olea, genus, $125,1_{4} 6$

albiceris, 146

colminiana, 146

conditiva, 146

domestica, 125

liciniana, 146

salentina, I 46

sergiana, I 46

silvestris, I 25

Olive blossoms studied by Theophrastus, 89

Orchids, fabled origin of, 237

Organography, importance of, 25

Organs, permanent and transient, $6_{3}$ vegetative and reproductive, 63

Origanum, album, I 25

creticum, I 25

heracleoticum, 125

nigrum, I 25

Orobanche, genus, 76

Oryza, genus, III
Osmunda regalis, 237

Ostrya vulgaris, I 2 I

Ovary, as part of flower, $29 \mathrm{I}$

as no part of flower, 64,290

of junipers minute, 88

Oxalidaceous type as Trifolium, 32

Oxalis acetosella, $3 \mathrm{I}$

Oxyacantha, genus, I 2 I

Oxys, prior name of Oxalis, 3 I

Pados, Greek for Padus, I 2 I

Pæonia, Cordus on, 291

Tragus on flowers of, 230

Papaver, and Nymphæa, i 88

corniculatum, I 25

nigrum, I 25

rhœas, I 25

Papaveraceæ, Tragus on, 230

Papilionaceous, term used first by Cordus, 288

Parenchyma first distinguished, 99

Parietaria, genus, I 86

Paris, genus, Cordus on, 290

Parmeno, slave of Theophrastus, 57

Parnassia, genus, 305 palustris, 286

Pear, flowers of, Theophrastus on, 85 mediæval varieties of, $3 \mathrm{I}_{3}$

Pedantries of botany, 37,39

Pentaphyllum palustre, 305

Pergamos, birthplace of Galen, I 60

Pericarp, Theophrastan term, 93 reappears first with Cordus, 292 , 293

Pes corvinus, early name of Ranunculus, i 88

Petal, term wholly modern, I 40

Peuce, conophoros, I 2 I

Idaia, I 2 I

paralios, I 2 I

Phaseolus vulgaris, I 2 I

Phases of plant life, diversity of, 73

Phenologic notes, of Theophrastus, I 28

of Tragus, 260

Philosophia Botanica quoted, 185

Phlomis, alba, I 25 nigra, I 25

Phyllitis, spores of, 294 ecology of, 3 ro

Physalis, genus, $28_{5}$ somnifera, 209

Physiology of plants, Cordus on, 307 , 310

Sprengel on, 20

Varro's suggestions of, $\mathrm{I}_{4} 8$

Phytographic, leaf-types, $\mathrm{IO}_{2-\mathrm{IO}} 4$ sequences and biologic, 66

Phytography, ancient and modern, $\mathrm{IO}_{2}, \mathrm{IO}_{3}$

artificial and natural, 102, 103

Cordus first to excel in, 275

examples of early, 45,277 
Phy tography-Continued importance of, i 8 of Brunfels, I 72

of Cordus, $275-280$

of Fuchs, 206, 207

of Theophrastus, IOI-IO5

of Tragus, 223

Pilosella, major, 2 I I

minor, 2 I I

Pinnate leaf, named by Theophrastus, 79

new study of, by Cordus, $8 \circ$

Pinus, Halepensis, I 2 I

maritima, I 2 I

picea, I 21

pinea, 87 , I 21

Pisum sativum, 287

Pith, distinguished by Theophrastus, 100

components of, IOI

Placentation, studied by Theophrastus, 94

observed by Cordus, 293

Plan tago aquatica, generic name, 2 I 6, 255

Plantago, coronopus, 254

major, 188

minor, i 88

Plant life, many phases of, 73

Plant organs, list of, ancient, $6 \pi, 63$

Plants, as cultivated or wild, i 75

of deep fresh water, 127

interrelations of, debated, I I 4, I I 5

of lake shores, I 27

marine aquatic, I 27

marine littoral, I 27

of marshes, I 27

poisonous, Nicander on, I +5

of river banks, I 27

sleep of, known of old, I 33

Theophrastan main divisions of, I 0 7-I I I

Platanus orientalis, 10.4

Plato, Theophrastus auditor of, 54, 74

Plinia, genus, I 59

Pliny, C., Adanson on, I 59

Historia Naturalis, work of, 157

records Greek iconographers, 167

tragic death of, 157

views of nature, i 58

Plum flowers studied by Theophrastus, $8_{5}$

Plumier, C., dedicates genus to Brunfels, I 72

to Cordus, 3 I 4

to Dioscorides, I 55

to Fuchs, I 97

to Tragus, 220

Poem of Nicander on agriculture, I 44

Poems of Virgil, botany of, I 49

Pollen discovered by Cordus, 290
Polygonum aviculare, ecology of, 257

Pomology, of Cato, I46, 147

of Columella, I 5 I

of Cordus, 3 I I -3 I 4

of Varro, I 4 7-149

Pomphylus, overseer in Theophrastus' garden, 57

Pontus, choice fruit varieties from, I 48

Poplar, black, from Crete, I 29

Poppy, Tragus on calyx of, 229 water lily related to, i 8

Populus alba, tassels of, 237

Porta, J. B., Adanson on, I 7

Potentilla, genus, i 86

Præfloration, not yet noticed, 209 first noted by Cordus, 288,280

Præfoliation first noted, 278

Prince Ludewig patron of Tragus, 222

Prince of Philosophers, Linnæus on, $5^{2}$

Priority, Cordus as to, 306

Fuchs' conservatism of, 2 I 5

Linnæus reckless of, 305

Tragus' indifference to, 255

Prunus Cerasus, I 2 I

insititia, I 2 I

Padus, I 2 I

Psoralea bituminosa, 3 I

Pulicaria, genus, I 20

Pulsatilla, first figured, r 90 stamens of, 289 vernalis, 298

Punica granatum, 34

Pyrola, genus, I 85

Quercula minor, 185

Quercus, as once restricted, 4 I

alba, 36

castaneæfolia, 36

Hispanica, 36

marina, 127

rubra, 36

salicifolia, 36

Raceme, uses of term, 20I, 202

Ralla, Joachim, and Cordus, $27 \mathrm{I}$

Ranunculus acris, $188,248,298$

arvensis, 298

bulbosus, 188,298

coronarius, $30 \mathrm{I}$

flammula, 298

leptophyllus, 298

palustris, 298

platyphyllus, 298

sardous, 298

sceleratus, 248,298

Ranunculaceous types in Trifolium, $3^{2}$

Rapunculus, old name of Campanula, 249

Ray, John, on Quercus, 4I

Ray-flowers, first named, 280 
Retzius, A. J., on botany of Virgil, I 50

Rhizophora mucronata, 33

Rhizotomi, ancient, $45,5^{\circ}$ modern, 5 I

Rieti, birthplace of Varro, I +7

Riffius, Walter, and V. Cordus, $27 \mathrm{I}$

Rihelius, Strassburg, publisher, 276

Riparian ecologic group, I 27

Rivinus, A. Q., Adanson on, I 7

Root, emphasized by rhizotomi, 45 investigated by Theophrastus, 24 neglected by later systematists, 45 primitive notion of, 25

subordinated by Cordus, $27 \mathrm{~S}$

Roots, classified, $73-77$

colors of noted, 76

flavors of noted, 70

functions of stated, 73

Rorella, oldest name of Drosera, 304 physiology of, 309

Rose, Christmas, 23 I

China, 23 I

of Sharon, 232

Guelder, 232

wild, 230

Rotate, corolla-type, 232

Ruellius castigated by Tragus, 228

Ruscus Hypophyllum, 33

Ruta, genus, 245

Sagitta, old name of Sagittaria, 304

Sagittaria, anatomy of, 307

genus, 274

Salix, alba, I 25

helix, 125

nigra, 125

Sambucus, genus, 208

and Ebulus, 154,240

aquatica, $23 \mathrm{I}$

described by Theophrastus, 90 nigra, 104

Sanguis mercurii, 185

Sanguis mustelæ, i 85

Sanguisorba major, 3 Io minor, 310

Sanicula Europæa, 177

Santolina, genus, 245

Saxifraga, Aizoon, 3 Io

Scammonia, genus, 303

Science, antedates history, 2 I exacts truthfulness, 30

Scolopendrium, ecology of, 3 Io

Scrophularia, genus, i 86

major, I 82

minor, 182, I 85

nodosa, 182

Scrophulariaceæ, 260

Sedum acre, $25^{8}$ telephium, i 82

Seed of fig, Cordus on, 292

Seedlings, Theophrastus on, 58, 95 Tragus on, $238,2.39$
Seeds, Cordus o11, 292, 293

Theophrastus on, $67,95,96$

Tragus on, $236-239$

Senecio vulgaris, 176

Serapion, author quoted, 173

Seriphium, genus, 213,214

Serpentariæ, family, 255

Shepherd's Purse, 250

Sida, Greek for water lily, I 22

Siemershausen birthplace of Cordus, 27 I

Simon Januensis quoted, 173

Sinapis, genus, 25 I

Sisymbrium Læselii, 2 I0, 2 I 2

Sium odoratum, 259,260

non odoratum, 259,260

Smilax, genus, 253

Snowball bush, first account of, 30 r

Solanaceæ, 252

Solanum, genus, $25^{2}$

melongena, 209

nigrum, 209

Sorbus domestica, I 2 I

Spartium scoparium, variations of, 3 I I

Speckle, V. R., artist to Fuchs, 195

Spinacia, genus, I 86

Spodias, Greek for wild plum, I 2 I

Sprengel, C., on Cordus, 270,27 I

as historian, I 9, 20, I 65

on priority, 185

Spruce, Macedonian, ecology of, 120

Stamen described by Tragus, 235

Stamens confused with pistils, 86

Fuchs' account of, 204

Stapelius, editor of Theophrastus, $5 \mathrm{~s}$

Stellate corolla, 233

Stem, Cordus on, 280

Fuchs on, 199

Theophrastus on, 76,77

Tragus on, $243,245,253$

Stigma, Cordus on, 290

Stipula, term as used by Fuchs, 200

Stramonium, genus, 285

Suber, Latin for cork oak, 4 I

Sundew, described by Cordus, 309

figured by Tragus, 309

named Rorella, 309

physiology of, 3 io

Symphytum officinale, 177 petræum, I 77

System, universal need of, 29 of Cesalpino, 30

of Tournefort, 14,15

Tagetes, genus, 216

Tamarindus indica, I 33

Tamus communis, I 23

Taxonomic ideas of Tournefort, I 4 suggestions of Dioscorides, 154

Taxonomy of Brunfels, $174^{-1} 8_{3}$ of Cordus, $295^{-303}$

of Fuchs, $207^{-2}$ I 5 
Taxonomy-Continued

old and new, 300

of Theophrastus, I06-I I 8

of Tragus, $239^{-2} 54$

principles of 16 th century, 2 I 2

transitional stage of, 300

of the untaught, $29,37,40$

Tenore, M., on botany of Virgil, I 50

Testiculus canis, 185

vulpis, I 85

Teucrium, genus, 259

Thalictrum, genus, 290,300

Thamecnemum, genus, 304

Theophrasta, genus, $4_{4} 2$

Theophrastus, of Eresus, 52-I42

on accessory trunks, 94

on aërial roots, 74 , I $4 \mathrm{I}$

on algæ as plants 73

on anatomy of plants, $63,67,97^{-}$ 99

on animal and plant, 64

anthology of, $82-90$

Aristotle's friendship for, 56

auditor of Plato, 54, 74

binary nomenclature of, 59

botanic garden of, 56

classifies roots, $73-75$

confuses stamens and pistils, 86

contemporary of Alexander, I 33

on deciduous trees, ${ }_{2} 8$

defines fruit, 93

defines root, 73

Demetrius, patron of, 56

dendrology of, I $28-135$

on diseases of plants, 134

distinguishes cotyledons, I4 I

on domesticated plants, 69

on ecology, r25-I 27

on embryology of, 95,99

on fungi as plants, 93

on germination, 95,96

on leaves, $76-8$ I

on longevity of trees, I 34

Malpighi and, 97

on morphology, 73

on nomenclature, I I 8-I 25

on palms, I3 I

on placentation, 94

on plant-geography, I $32-133$

on plant-world and man, 6 I

on roots, $24,66,76,14 \mathrm{I}$

on sensitive foliage, 80 , I 33

on spines in place of leaves, 79

on stipules, 80

on transmutation, $135^{-1} 39$

on wood of palms, roo

Thlaspi arvense, 247

Thlaspidium, genus, 247,250

Thrasyas Mantinensis, rhizotomus, 48,49

Tithymali, family, $303^{\circ}$

Tithymalus, genus, 303

Tormentilla erecta, 78
Tournefort, J. P. de, on departments of botany, I 4

on genera of oaks, $4 \mathrm{I}$

as historian, 14,16

ignores plant anatomy, I 5

taxonomic principles of, $I_{4}, I_{5}$

Toxicodendron vulgare, +7

Tragia, genus, 220

Tragus, Hieronymus, 220-262

Anthology of, $227-235$

Ecology of, $256-260$

forerunner of Linnæus, 236

on fruit and seed, $236-238$

life of, $220-222$

nomenclature of, 254,255

phytography of, $223-226$

taxonomy of, 239-253

on transmutation, 261,262

Transmutation, Nico on, I 60

Theophrastus on, I 35-I 39

Tragus on, 261, 262

Trapa, genus, 255

Trees, popular nomenclature of, 28 , $29,35,36$

Trifolium, amplified, 3 I

acetosum, 31, 306

arvense, 203

bituminosum, $3 \mathrm{r}$

cochleatum, 3 I

corniculatum, 3 I

hepaticum, 3 I

hybridum, 27

palustre, $3 \mathbf{I}$

pratense, 27

repens, 27,187

Triphyllon, Greek for Psoralea, 3 I

Triticum, ancient kinds of, 125

Trixago minor, 185

Tussilago, genus, 289

Umbelliferæ, Theophrastus on, 77

University of, Basle and Brunfels, 169

Bologna and V. Cordus, 2 it

Erfurth and E. Cordus, 263,264

Erfurth and Fuchs, I92

Ferrara and E. Cordus, 264

Ferrara and V. Cordus, 274

Ingolstadt and Fuchs, I93

Leipzig, and E. Cordus, 264

Marburg and E. Cordus, 265

Padua and V. Cordus, $27+$

Pisa and V. Cordus, 274

Tübingen and Fuchs, I93

Wittemburg and V. Cordus, 27 I

Urtica dioica, I 79

iners, I 80

labeo, 180

mortua, r 80

Vaccinium arctostaphylos, I 64 Myrtillus, 235

Valeriana, genus, I86, 242

Valerius Cordus, $270-3$ r 4 
Valla, G., quoted by Brunfels, I 73

Variations of Spartium, 3 I I

Varieties, ancient means of propagating, 59

of apples, mediæval, 3 I 3,3 It

of cabbage, ancient, 146,148

of cherries, ancient, I 48

of fig, ancient, i 48

of grapes, ancient, I 47

of myrtle, ancient, $146, \mathrm{I}_{4} 8$

of olive, ancient, I 46

of pears, ancient, I 47,148

mediæval, 3 I 3

of wheat, ancient, I 25

Varro, Marcus Terentius, I $+7-I 49$

agriculture, treatise on, by, I 48

genus dedicated to, I 49

most learned man in Rome, ${ }_{4} 8$

naval commander at seventy, I 47 suggests plant physiology, I 48

Varronia, genus, by P. Browne, I49

Tegetative organs, Cordus on, $280-$ ${ }_{2} \mathrm{~S}_{2}$

Fuchs on, I 97-200

Theophrastus on, $72-82$

Veit Speckle, artist to Fuchs, I 95

Veratrum and Helleborus as allies, I I 8

Verbena, old synonymy of, I 85

fœmina, I 77,25 I

mascula, 177

officinalis, $7_{7} 6$

recta, 2 io

supina, I 85,2 Io

Vernacular, family names, 27

generic names, 27

specific names, 27

Veronica, Anagallis aquatica, 259

Beccabunga, 259

Chamædrys, 259

Teucrium, 259

Viburnum Opulus, 23I, 232, 30 I

Vigonius, J., quoted by Brunfels, I 73
Viola alba, I 84, 216, 23 I

aurea, I 84

hirundinaria, I 84

lutea, 23 I

martia, 23 I

nigra, I 84

purpurea, 23 I

Violet, Dame's, 232

Dogtooth, 232

Violet-form corollas, Tragus on, 233

Violets, cruciferous, 23 I

proper, 23 I

Virgil, Latin poet, I 49, I 50

Vitis aminea, 146 majuscula, I 46

minuscula, I 47

apiciana, I 47

gemina, I 47

helvola, I 47

minuscula, I 47

murgentina, I 47

vinifera, 2 I 7

Vitis alba, generic for Bryonia $2 \mathrm{I}_{\boldsymbol{}}$

$V$ tis Idxa, generic for Vitisidæa, 2 I 6

Vitis nigra, generic for Clematis, 2 I 7

Vocabularies, of botany, primitive, 59 , I6I

Vocabulary, botanical, of Fuchs, I 97-206

Vulnerary herbs, names of, $I 77, I 78$

Von Sachs, Julius, errors of, I $40, \mathrm{I}+3$, I 72

on German Fathers, I 66

on 'Theophrastus, $52,1+0, I_{4}$

Walnut, 29, 40, I 23 , I 26

Water lilies and poppies as allied, I I 8

Willow catkins, Tragus on, 229

Willows first grown from seed, $22 \mathrm{~S}$

Wood anemone, first published, I 86

Xanthium, genus, 255

Zizyphus, genus, $3+$ 




